\title{
An Integrated Modelling Approach to Estimate Urban Traffic Emissions
}

by

Aarshabh Misra

A thesis submitted in conformity with the requirements

for the degree of Master of Applied Sciences

Department of Civil Engineering

University of Toronto

(C) Copyright by Aarshabh Misra, 2012 


\title{
An Integrated Modelling Approach to Estimate Urban Traffic Emissions
}

\author{
Aarshabh Misra \\ Master of Applied Sciences \\ Department of Civil Engineering \\ University of Toronto
}

2012

\section{Abstract}

Vehicular emissions contribute significantly to poor air quality in urban areas. An integrated modelling approach is adopted to estimate microscale urban traffic emissions. The modelling framework consists of a traffic microsimulation model, a microscopic emissions model, and two dispersion models. This framework is applied to a traffic network in downtown Toronto to evaluate summer time morning peak traffic emissions during weekdays for carbon monoxide and nitrogen oxide. The model predicted results are validated against sensor observations with a reasonably good fit. Availability of local estimates of ambient concentration is useful for accurate comparisons of total predicted concentrations with observed concentrations. Both predicted and observed concentrations are significantly smaller than the National Ambient Air Quality Objectives established by Environment Canada. Sensitivity analysis is performed on a set of input parameters and horizontal wind speed is found to be the most influential factor in pollutant dispersion. 


\section{Acknowledgments}

I find it ironical how acknowledgements are featured at the very beginning of a thesis even though they are the last thing written out once all the 'real' writing is complete. Nonetheless, I feel this is probably the most well read section of any thesis!

I wish to express my sincere gratitude to thesis supervisors Professor Matthew Roorda and Professor Heather MacLean for the steady support, guidance, and useful feedback they gave me at critical junctures, during the course of my thesis. The innumerable meetings, discussions, and e-mail exchanges were really helpful in channelling my energy in the right direction.

I would like to thank Professor Greg Evans and staff at the SOCAAR laboratory for providing generous advice, along with abundant pollutant concentration and traffic data at the St. George and College Street intersection. I would like to recognise the work of Greg Hoy in developing the St. George and College Street network in PARAMICS, and organising the manual traffic count survey, both of which were used in this research; also, I am thankful to everyone who participated in the manual traffic count last year. I am grateful to Michael Brown, from the Los Alamos National Laboratory, who provided quick answers to my questions on the QUIC modelling system.

My parents and my brother have shown immense confidence in my abilities for several years now, and it has kept me steady through thick and thin. I am deeply indebted to them for their unfaltering support.

I would also like to acknowledge the contribution of my office mates, Rinaldo (who helped me with statistics), Keith (with whom I formed a semi-functional acoustic guitar cover band), and Mohamed (who played table tennis with me in times of boredom and un-productivity). Lastly, everyone in the Transportation Research Group at the ITS lab helped me on numerous occasions throughout my stint here; I will definitely miss that collective brain power I could just tap into every day at work for the last two years.

Aarshabh Misra, May $5^{\text {th }}, 2012$ 


\section{Table of Contents}

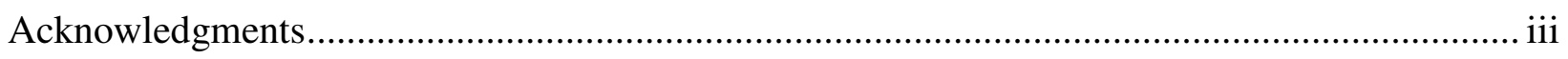

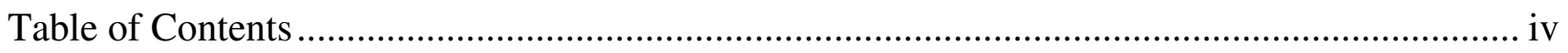

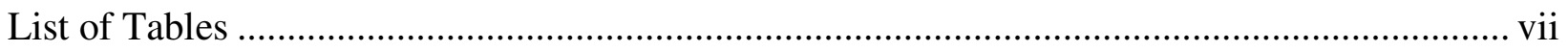

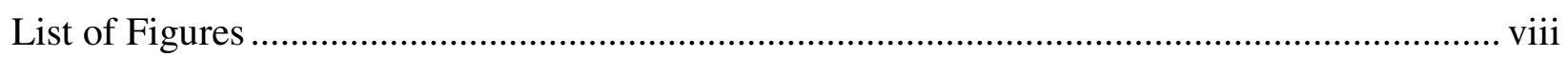

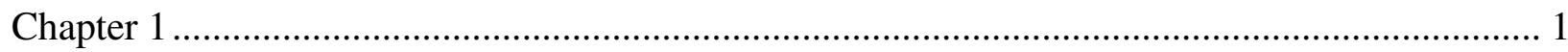

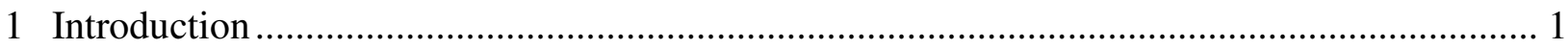

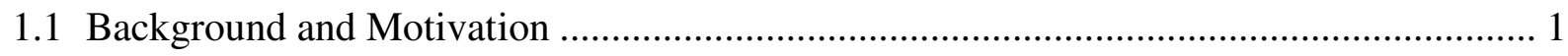

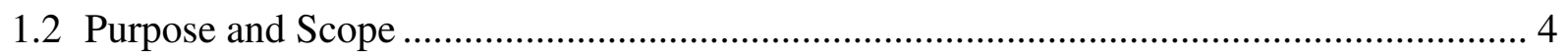

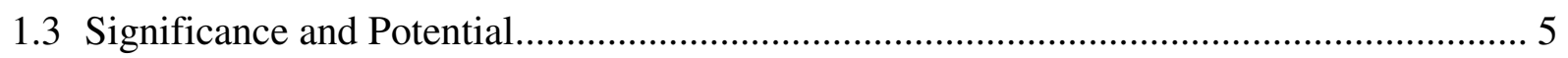

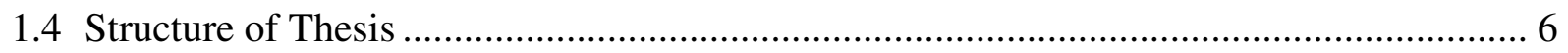

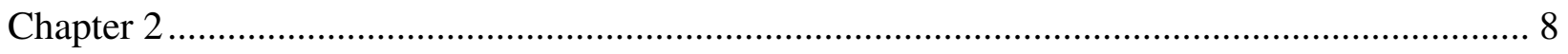

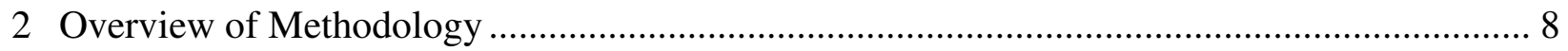

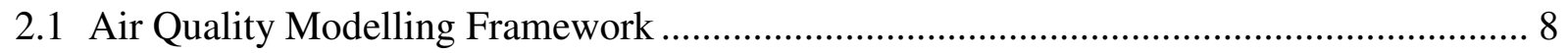

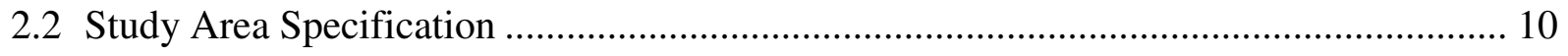

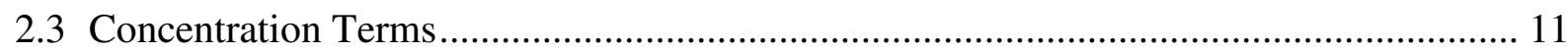

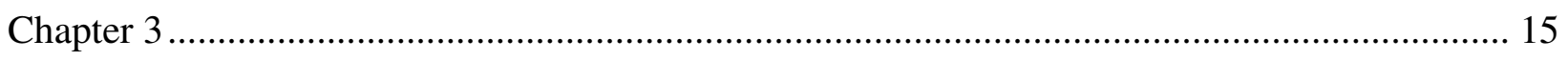

3 Traffic Microsimulation Modelling: Method ....................................................................... 15

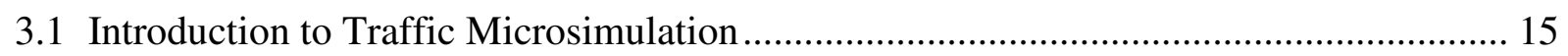

3.2 Traffic Modelling Review....................................................................................... 15

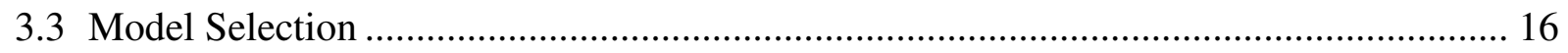

3.4 Network Development and Inputs ............................................................................. 17

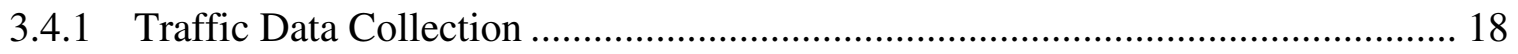

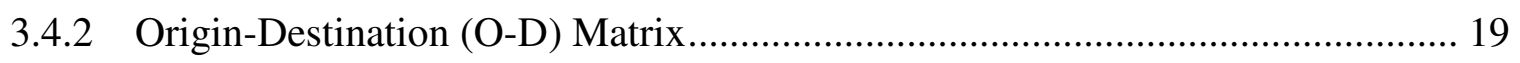

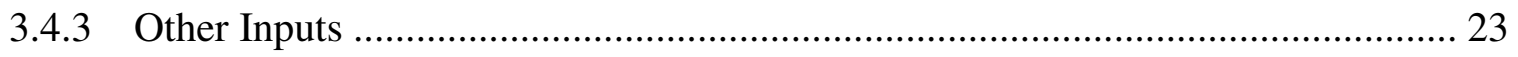




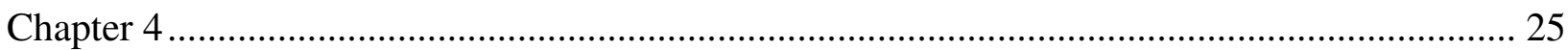

4 Emissions Modelling: Method ............................................................................................. 25

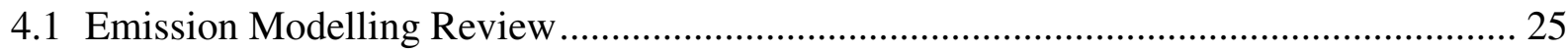

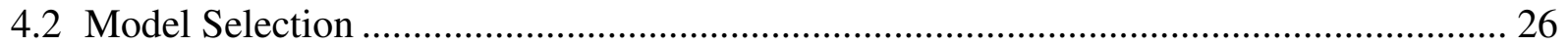

4.2.1 Comprehensive Modal Emissions Model (CMEM) ………………………....... 27

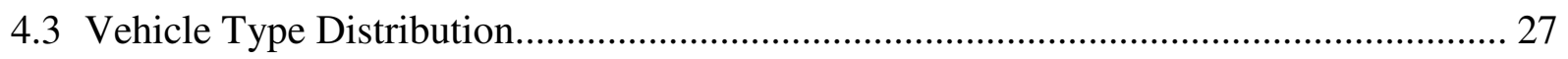

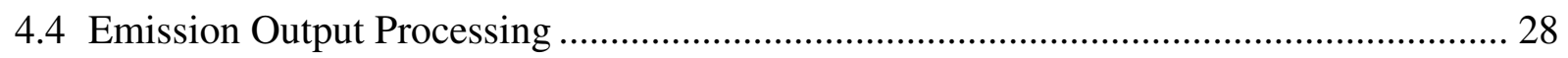

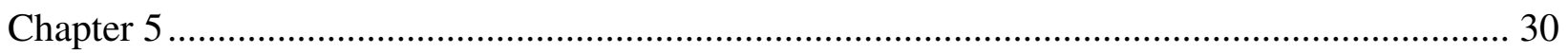

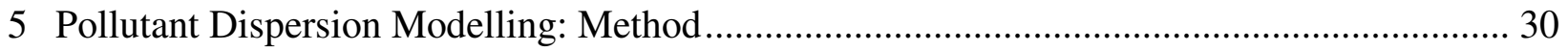

5.1 Dispersion Modelling and Meteorology ……………........................................................ 30

5.1.1 Dispersion Modelling Review and Model Selection ............................................ 33

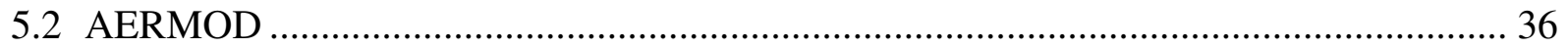

5.3 Quick Urban and Industrial Complex (QUIC) ........................................................... 38

5.4 Dispersion Modelling Inputs: Data Processing.............................................................. 40

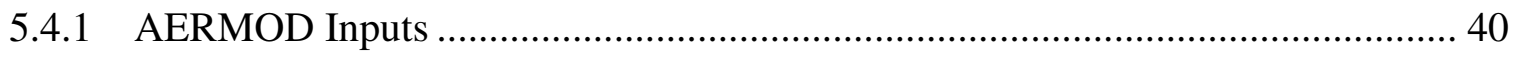

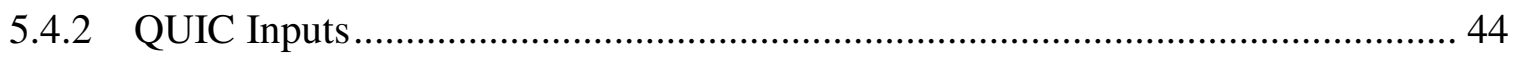

5.5 Sensitivity of Traffic Microsimulation Random Seed ..................................................... 46

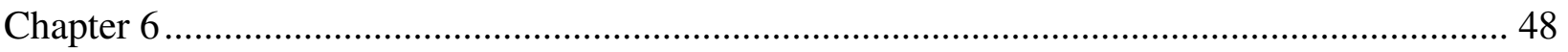

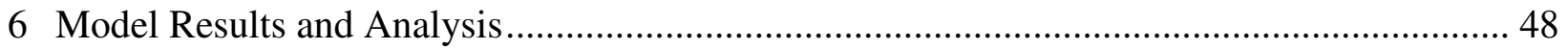

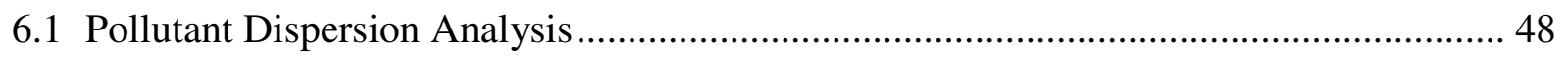

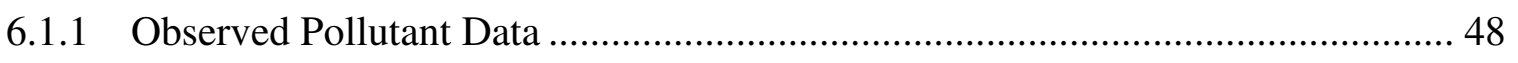

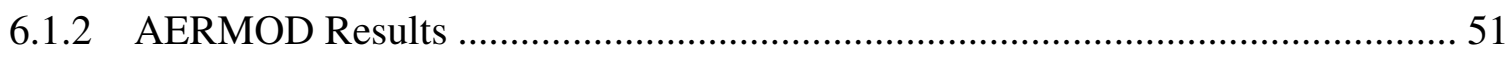

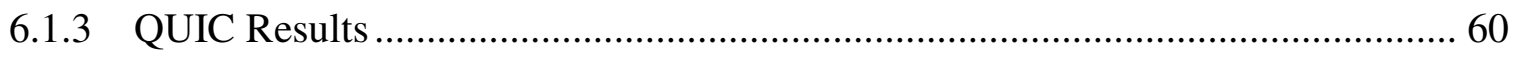

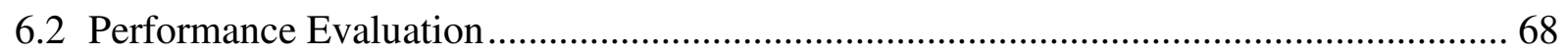

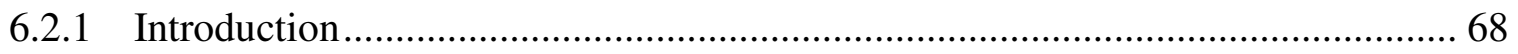

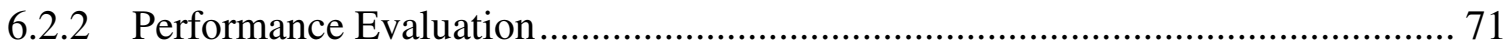




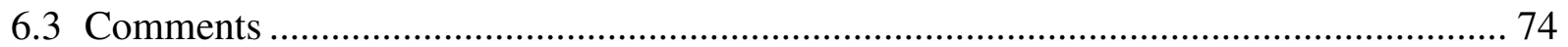

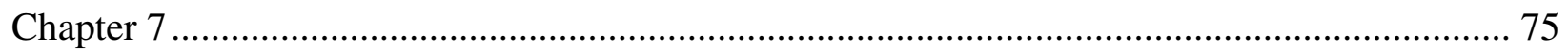

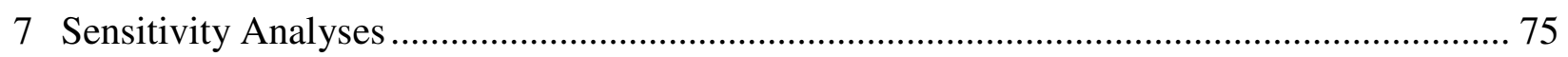

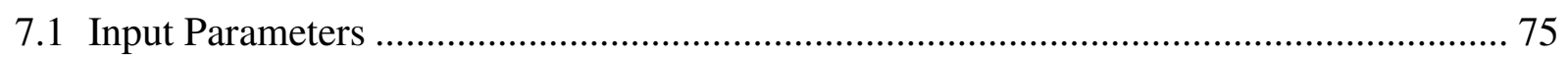

7.1.1 Mean Wind Speed and Direction ...................................................................... 76

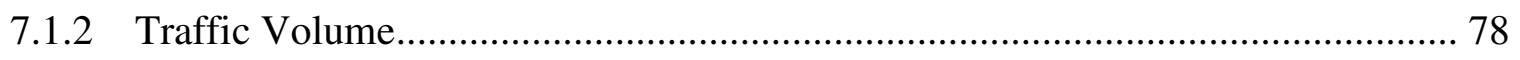

7.1.3 Vehicle Type Distribution................................................................................. 79

7.1.4 Atmospheric Stability …………………………........................................ 82

7.1.5 QUIC Simulation Time Step........................................................................ 83

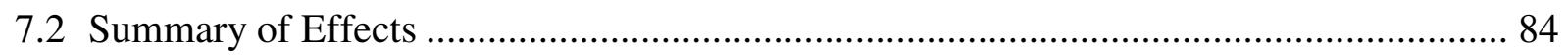

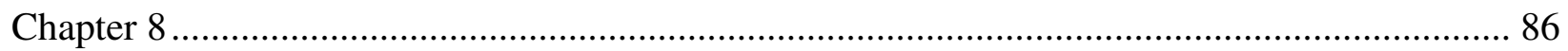

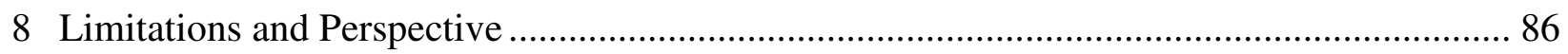

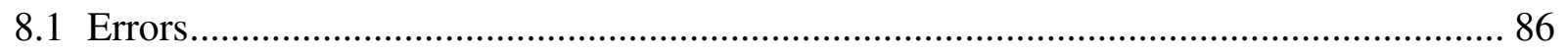

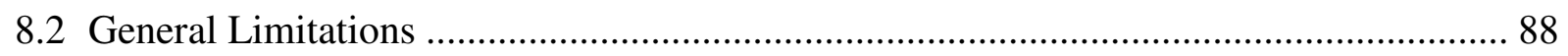

8.2.1 Comparison of Dispersion Models …………………....................................... 88

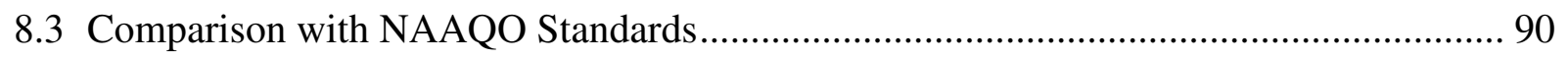

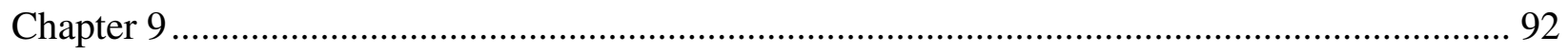

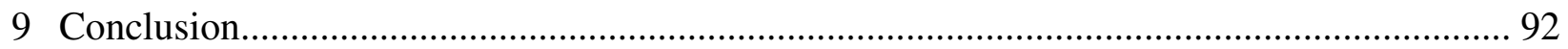

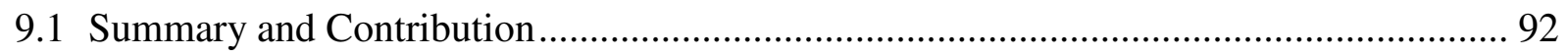

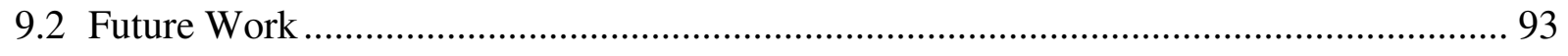

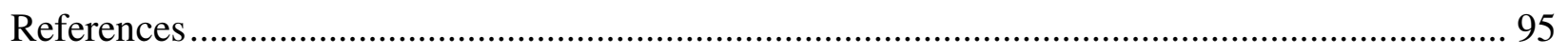

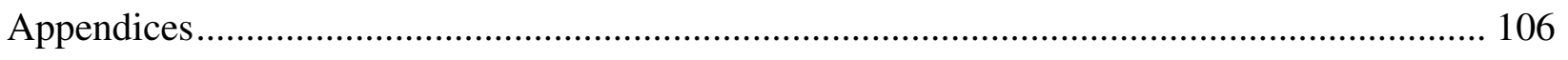

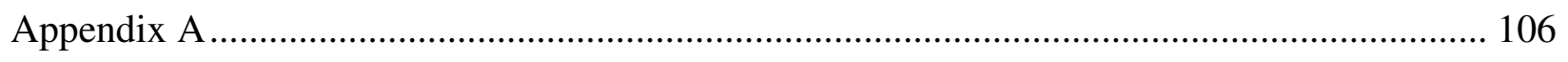

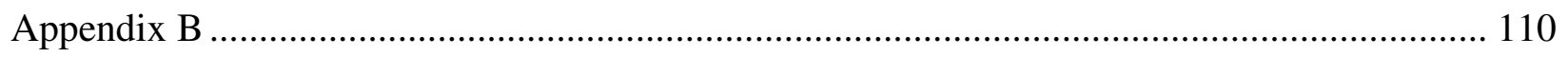




\section{List of Tables}

Table 3-1 Regression Models for Light and Heavy vehicles based on manual traffic count data 22

Table 3-2 Sample O-D matrix generated at 15 minute interval, July 7, 2011 8:15 - 8:30 AM ... 23

Table 4-1 Vehicle Type Dist. (Amirjamshidi, et al., 2012) (Data Management Group, 2004) .... 29

Table 5-1 Brief Review of Dispersion Models Evaluated ...................................................... 35

Table 6-1 Statistical Performance Evaluation of AERMOD and QUIC …............................. 74

Table 7-1 Wind Speed Sensitivity Experimental Design ..................................................... 76

Table 7-2 Vehicle Type Distribution for Sensitivity Analyses ............................................... 80

Table 7-3 Atmospheric Stability Sensitivity Analysis Inputs .............................................. 82

Table 7-4 Summary of Sensitivities and Average Coefficient of Variations ............................ 85

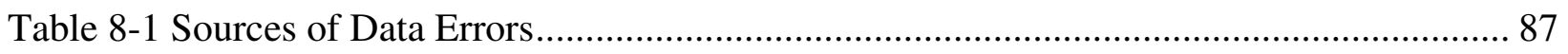




\section{List of Figures}

Figure 1-1 Canada $\mathrm{NO}_{\mathrm{x}}$ Emission Contribution (in tonnes) 1985-2010 Mobile Sources.............. 2

Figure 1-2 Canada CO Emission Contribution (in tonnes) 1985-2010 Mobile Sources ............... 3

Figure 2-1 Air Quality Modelling Framework Overview.................................................... 8

Figure 2-2 Detailed Air Quality Modelling Framework ...................................................... 9

Figure 2-3 St. George Street and College Street Intersection Area (Map and Data Library,

University of Toronto, 2011) (Lakes Environmental, 2012) ............................................... 11

Figure 2-4 Hourly Average NO Concentration, July 2011, MOE / SOCAAR Sensor................ 13

Figure 2-5 Hourly Average $\mathrm{NO}_{2}$ Concentration, July 2011, MOE / SOCAAR Sensor .............. 13

Figure 2-6 Hourly Average CO Concentration, June-July 2010, MOE / SOCAAR Sensor ........ 14

Figure 3-1 St. George Street and College Street Intersection Network in PARAMICS ............. 17

Figure 3-2 Average Hourly Sensor Observed Traffic on College Street for June and July 201119

Figure 3-3 Process Flowchart: O-D Matrix Estimation........................................................ 20

Figure 3-4 Passenger Car Model relating College St. Traffic with Southbound St. George St.

Traffic; SB: Southbound; CL: Cars / light vehicles......................................................... 21

Figure 4-1 Process flowchart: Integration of PARAMICS and CMEM ................................ 28

Figure 5-1 Process Flowchart: AERMOD Methodology ................................................... 38

Figure 5-2 Process Flowchart: QUIC Methodology ......................................................... 40

Figure 5-3 Series of point sources, AERMOD View ..................................................... 41

Figure 5-4 Wind Rose for Weekdays, 7:00-9:00 AM in June (left) and July (right), 2011 ........ 42

Figure 5-5 St. George Street and College Street Intersection, AERMOD View ....................... 43

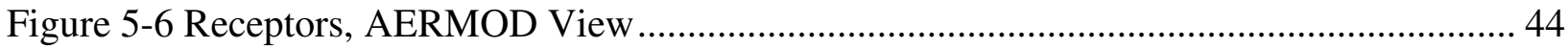

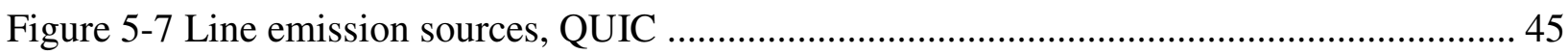

Figure 5-8 St. George Street and College Street Intersection, QUIC City Builder ................... 46

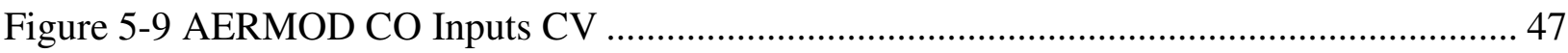

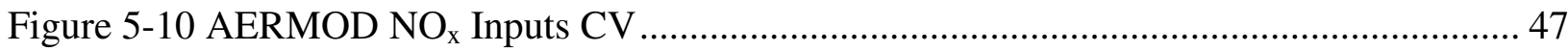

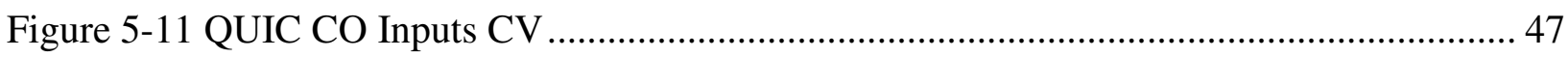

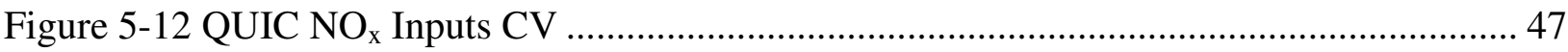

Figure 6-1 Sampling Site Location: Southern wall of Wallberg Building facing College Street. 49

Figure 6-2 Average Hourly CO Concentration, Weekdays, June 2011 ................................... 49

Figure 6-3 Average Hourly NO/NO${ }_{2}$ Concentration, Weekdays, July 2011 ........................... 49 
Figure 6-4 NO Concentration as a Percentage of Total NO $\mathrm{N}_{\mathrm{x}}$ Concentration, Weekdays, July 2011 51

Figure 6-5 Avg. CO Conc., St. George and College Street, June 3, 8:00 - 9:00 AM, 1m height 52 Figure 6-6 Avg. CO Conc., St. George and College Street, June 3, 8:00 - 9:00 AM, 3m height 53 Figure 6-7 Avg. $\mathrm{NO}_{\mathrm{x}}$ Conc., St. George and College Street, July 13, 7:00 - 8:00 AM, 1m height

Figure 6-8 Avg. $\mathrm{NO}_{\mathrm{x}}$ Conc., St. George and College Street, July 13, 7:00 - 8:00 AM, 3m height 55

Figure 6-9 Observed Vs AERMOD Predicted Hourly Average CO Concentration ................... 57

Figure 6-10 AERMOD CO: Predicted Vs Observed Concentration ........................................ 58

Figure 6-11 AERMOD Residual CO Concentration Vs Wind Speed .................................... 58

Figure 6-12 Observed Vs AERMOD Predicted Hourly Average $\mathrm{NO}_{\mathrm{x}}$ Concentration ................ 59

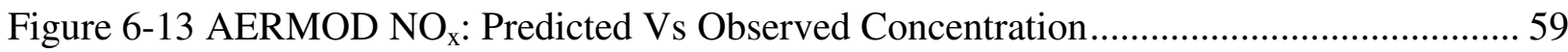

Figure 6-14 AERMOD Residual $\mathrm{NO}_{\mathrm{x}}$ Concentration Vs Wind Speed..................................... 59

Figure 6-15 Avg. CO Conc., St. George and College Street, June 3, 7:00 - 7:15 AM, 1m height60 Figure 6-16 Avg. CO Conc., St. George and College Street, June 3, 7:00 - 7:15 AM, 3m height61 Figure 6-17 Avg. $\mathrm{NO}_{\mathrm{x}}$ Conc., St. George and College Street, July 13, 8:45 - 9:00 AM, 1m height 61

Figure 6-18 Avg. $\mathrm{NO}_{\mathrm{x}}$ Conc., St. George and College Street, July 13, 8:45 - 9:00 AM, 3m height 62

Figure 6-19 Sample Normal Distribution for QUIC Modelled Concentration at the Observed Sensor location for June 3, 2011 (7:15 - 7:30 AM, CO) and July 13, 2011 (8:30 - 8:45 AM, NO $\left.{ }_{x}\right)$ 63

Figure 6-20 Observed Vs QUIC Predicted, 15 minute averaged CO Concentration .................. 65 Figure 6-21 QUIC CO: Predicted Vs Observed Concentration ................................................ 66

Figure 6-22 QUIC Residual CO Concentration Vs Wind Speed............................................ 66

Figure 6-23 Observed Vs QUIC Predicted, 15 minute averaged, $\mathrm{NO}_{\mathrm{x}}$ Concentration................ 67

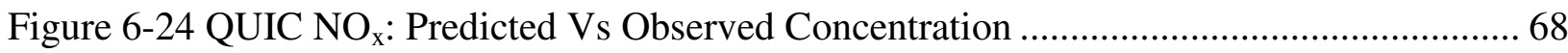

Figure 6-25 QUIC Residual $\mathrm{NO}_{\mathrm{x}}$ Concentration Vs Wind Speed .......................................... 68

Figure 6-26 Hourly Average CO Concentrations, AERMOD Vs QUIC Vs Observed............... 69

Figure 6-27 Hourly Average $\mathrm{NO}_{\mathrm{x}}$ Concentrations, AERMOD Vs QUIC Vs Observed ............. 70 
Figure 6-28 Coefficient of Variation of Hourly Concentration for QUIC Modelled and Sensor

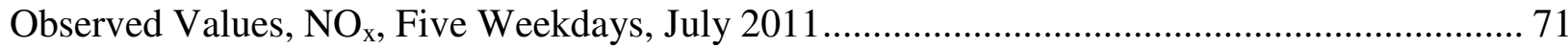

Figure 7-1 Wind Sensitivity, QUIC Modelled CO Concentrations, June 3, 2011....................... 77

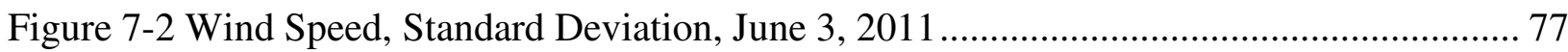

Figure 7-3 Impact of Traffic Change on CO Concentration, June 24, 2011 ................................ 78

Figure 7-4 Impact of Traffic Change on $\mathrm{NO}_{\mathrm{x}}$ Concentration, July 12, 2011; Random No. -100. 79

Figure 7-5 Impact of Traffic Change on $\mathrm{NO}_{\mathrm{x}}$ Concentration, July 12, 2011; Random No.-367.. 79

Figure 7-6 Vehicle Type Distribution Sensitivity, CO Concentration, June 10, 2011 .................. 81

Figure 7-7 Vehicle Type Distribution Sensitivity, $\mathrm{NO}_{\mathrm{x}}$ Concentration, July27, 2011 .................. 81

Figure 7-8 Atmospheric Stability Sensitivity, CO Concentration, June 22, 2011 ........................ 83

Figure 7-9 Simulation Time Step Sensitivity, CO Concentration, June 13, 2011 ........................ 83

Figure 8-1 Predicted, Observed and NAAQO Hourly MAL, CO concentration........................... 91

Figure 8-2 Predicted, Observed $\left(\mathrm{NO}_{\mathrm{x}}\right)$ and NAAQO Hourly MAL $\left(\mathrm{NO}_{2}\right)$ concentration............. 91

Figure 9-1 Street Level Exposure Micro-Modelling Framework ................................................... 94 


\section{Chapter 1}

There's so much pollution in the air now that if it weren't for our lungs there'd be no place to put it all.

- Robert Orben, Comedian

\section{Introduction}

\subsection{Background and Motivation}

Transportation is a fundamental consequence of economic activity, with urban congestion and air pollution being the unwanted but inevitable by-products. In Canada, over 19.2 million registered vehicles are driven annually for a total of 332 billion kilometres (Statistics Canada, 2009). Traffic generated emissions have been a key area of research for the past several years. Better understanding of how emissions are generated has promoted newer vehicle technologies that continue to seek better vehicle efficiencies and lower emission rates.

Motorized vehicle operation impacts environmental air quality in the form of increased Greenhouse Gas (GHG) emissions and toxic pollutant emissions. The most common air pollutants have been specified by the United States Environmental Protection Agency (US EPA) as 'criteria pollutants'. These include: ozone $\left(\mathrm{O}_{3}\right)$, particulate matter $(\mathrm{PM})$, carbon monoxide (CO), nitrogen oxide $\left(\mathrm{NO}_{\mathrm{x}}\right)$, sulphur oxide $\left(\mathrm{SO}_{\mathrm{x}}\right)$, and lead $(\mathrm{Pb})$. For a stoichiometric mix, with a perfect air-fuel ratio, complete combustion inside vehicle engine should only result in production of carbon dioxide $\left(\mathrm{CO}_{2}\right)$ and water vapour $\left(\mathrm{H}_{2} \mathrm{O}\right)$. Practically, the optimum air-fuel ratio is never achieved, resulting in incomplete combustion that causes release of pollutants. The general equation for this process is as follows:

$$
\left[\mathrm{H}_{\mathrm{x}} \mathrm{C}_{\mathrm{y}}+\mathrm{S}\right] \mathrm{FUEL}+\left[\mathrm{O}_{2}-\mathrm{N}_{2}\right] \mathrm{AIR} \rightarrow \mathrm{HEAT} \text { (energy) }+\left[\mathrm{H}_{2} \mathrm{O}+\mathrm{CO}_{2}+\mathrm{CO}+\mathrm{H}_{\mathrm{x}} \mathrm{C}_{\mathrm{y}}\left(\mathrm{VOC}^{\prime} \mathrm{s}\right)+\mathrm{NO}_{\mathrm{x}}+\mathrm{SO}_{\mathrm{x}}+\text { PM }\right] \text { EMISSIONS }
$$

Pollutants directly released from the emission source are called primary pollutants. Some primary pollutants are chemically reactive and upon suspension in the air, undergo chemical reactions to form other toxic species called secondary pollutants. Ozone and nitrogen dioxide $\left(\mathrm{NO}_{2}\right)$ are two important secondary pollutants associated with traffic emissions; their precursor primary pollutants are volatile organic compounds (VOC's) and nitrogen oxide (NO). Particulate 
matter (PM) is another important criteria pollutant that is classified into primary, secondary, and fugitive types; fugitive PM consists of emissions due to road abrasion and wear of tyre or brake lining (Cadle, 1997).

The adverse health impact of criteria pollutants is well documented in literature. CO reduces the oxygen carrying capacity of blood and could be fatal in extreme cases of exposure; $\mathrm{NO}_{\mathrm{x}}$ causes severe respiratory problems such as bronchitis; $\mathrm{SO}_{\mathrm{x}}$ aggravates lung and heart diseases while $\mathrm{PM}$ affects lung function and prolonged exposure can cause premature death. Environmental Protection Agency (2012) provides detailed information on the harmful effects of such pollutants.

Due to improved vehicle technology, use of clean fuel, strict vehicle emission standards, and implementation of environment friendly government policies such as the Clean Air Act Amendments 1990 USA, Clear Air Act 2006 in Canada, and the Canadian Environmental Protection Act 1999, total vehicular emission has generally decreased in North America in the last two decades. Figure 1-1 and 1-2 show the decreasing trend of total $\mathrm{CO}$ and $\mathrm{NO}_{\mathrm{x}}$ emissions for significantly contributing vehicle categories in Canada (Environment Canada, 2012).

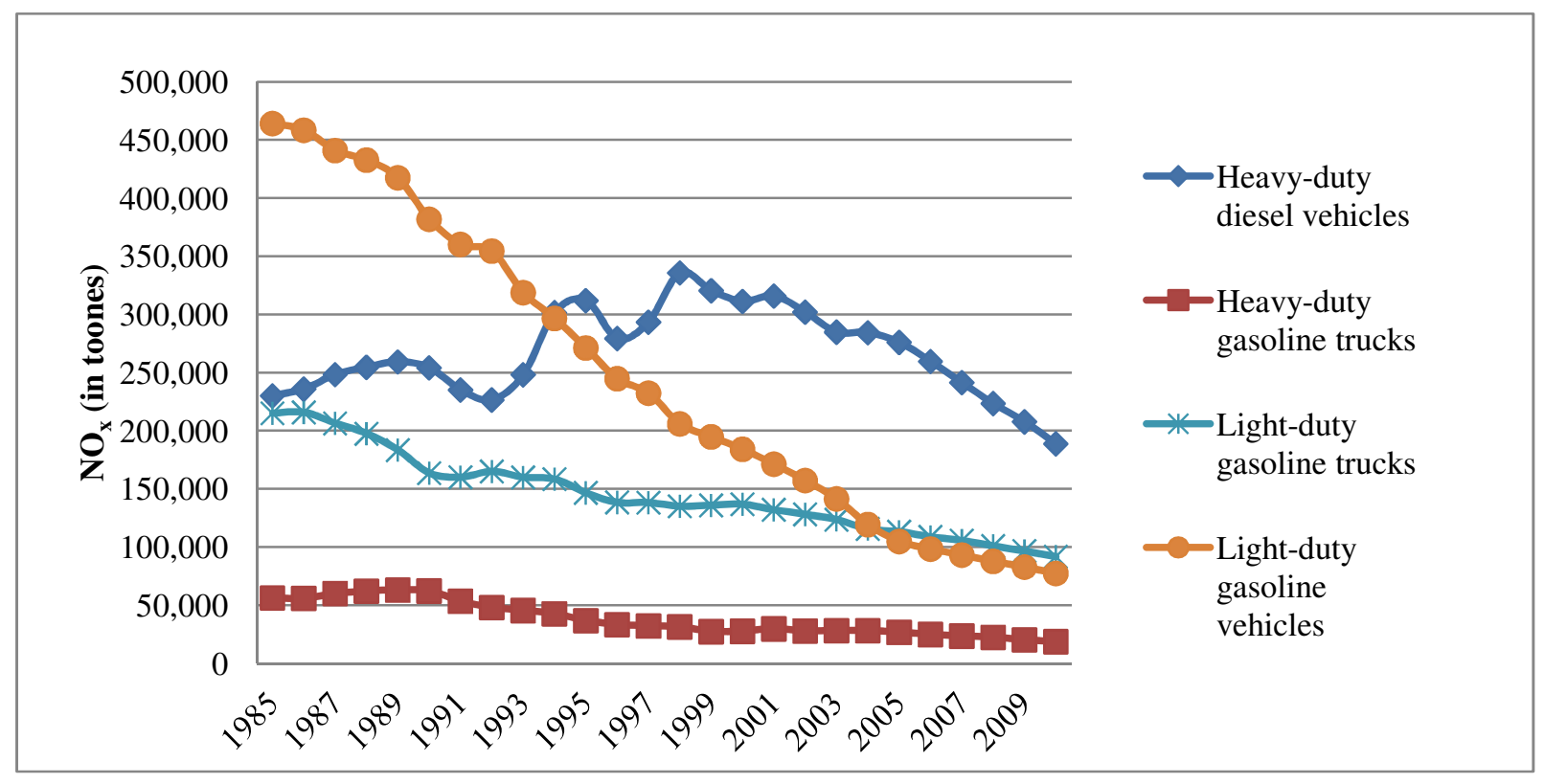

Figure 1-1 Canada $\mathrm{NO}_{\mathrm{x}}$ Emission Contribution (in tonnes) 1985-2010 Mobile Sources 


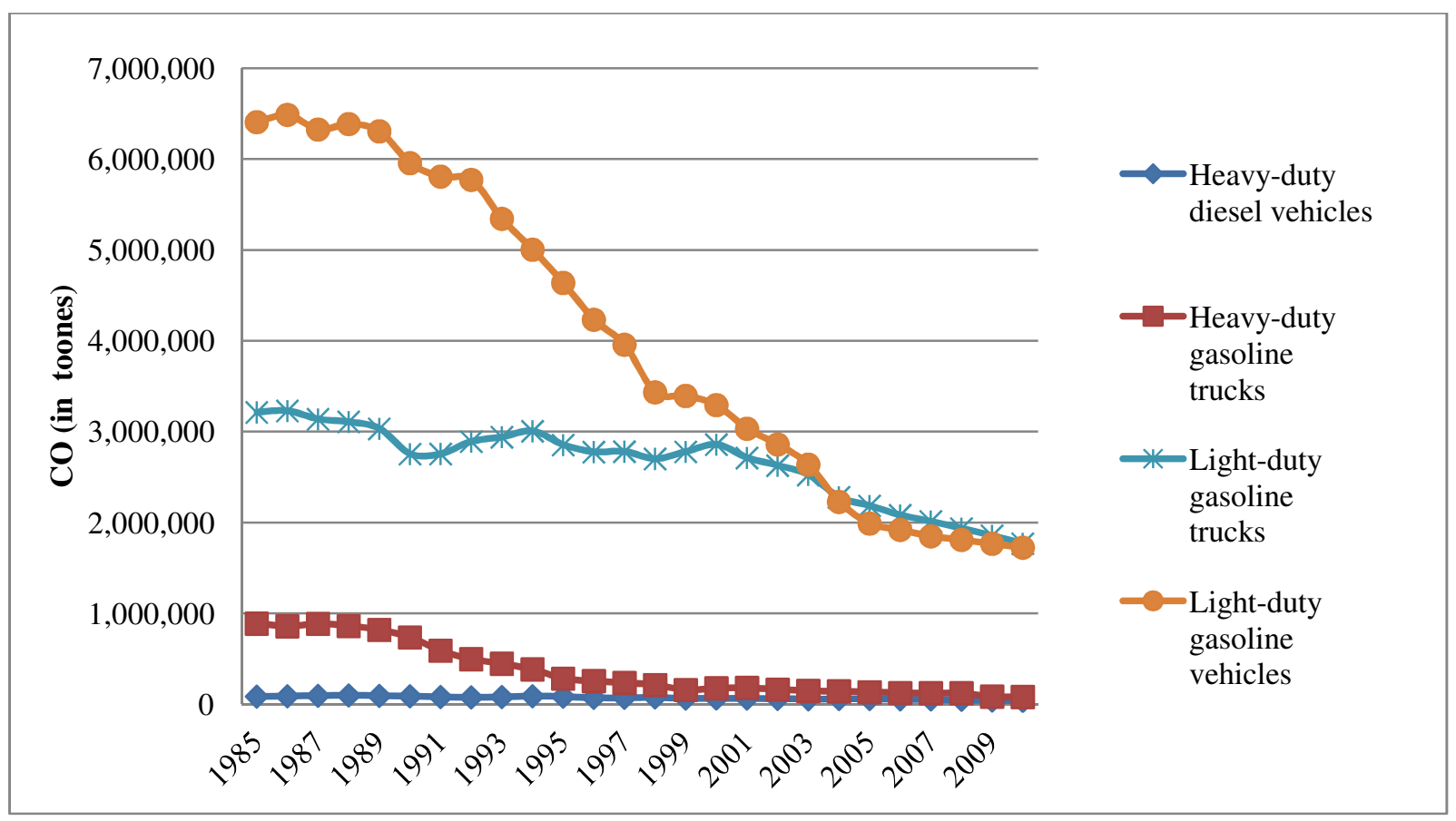

Figure 1-2 Canada CO Emission Contribution (in tonnes) 1985-2010 Mobile Sources

In spite of the decrease in total $\mathrm{CO}$ and $\mathrm{NO}_{\mathrm{x}}$ emissions in Canada due to these mobile sources, the transportation sector continues to be a major source of criteria pollutants. In 2010, all major mobile transportation sources accounted for $41 \%$ of total $\mathrm{CO}$ emissions and $19 \%$ of total $\mathrm{NO}_{\mathrm{x}}$ emissions in Canada (Environment Canada, 2012).

Geogenic and biogenic sources are large contributors to net $\mathrm{CO}$ emissions (for example, forest fires) and net $\mathrm{NO}_{\mathrm{x}}$ emissions (for example, vegetation). However, as a society, we are more concerned about traffic related emissions because of the close proximity of such emissions to a large number of people in urban areas. The recurring peaks in traffic volume correspond to higher emission concentrations in the urban areas, which in turn correspond with large pedestrian volumes on the street. Research studies have determined that high density traffic sites are a key source of higher levels of vehicular emissions (Campbell, et al., 1995) and areas close to busy roads typically have higher emission concentrations (Hoek, et al., 2002). In densely populated downtown areas, the significance of vehicular emissions is accentuated due to presence of large volume of pedestrian and biking traffic on the street level that is directly exposed. Hence, it becomes imperative to investigate street level air quality to quantify population exposure. 
Understanding the distribution of traffic pollutants in the urban environment, and evaluating regions of higher pollutant concentration is necessary to characterize the nature of risk to people walking or biking on the street. This research is an attempt to quantify such traffic generated emission concentrations for $\mathrm{CO}$ and $\mathrm{NO}_{\mathrm{x}}$ on a local road network using an integrated micromodelling framework.

\subsection{Purpose and Scope}

The objective of this research is to assess the accuracy of an integrated modelling framework that incorporates a traffic microsimulation model, a microscopic emission generation model, and a pollutant dispersion model, to predict road side pollutant concentrations. The fundamental concept is to microsimulate the movement of vehicles on a given network, estimate emission factors on roadway links using a microscopic emission model, and finally disperse the pollutants generated on roadway links, in the atmosphere within the network, to obtain predicted concentration values.

The framework is applied to a road network in downtown Toronto and predicted concentrations are compared against sensor measured values for $\mathrm{CO}$ and $\mathrm{NO}_{\mathrm{x}}$ for the morning peak period (7:00 - 9:00 AM) for five selected weekdays, each in June and July 2011. The goal of this work is to develop concentration plots at a micro-scale combining three historically different modelling methods under one common platform; these results could be used to evaluate exposure of pollutants to population at a fine resolution. Such a tool could be potentially used to inform policy decisions regarding street design, neighbourhood scale planning, vehicle technology, and vehicle type distribution. The scope of this research includes the following:

1) Application of the proposed framework to obtain predicted concentrations for $\mathrm{CO}$ and $\mathrm{NO}_{\mathrm{x}}$ for some weekdays in June and July 2011

2) Performance evaluation / comparison of two different pollutant dispersion methodologies using sensor observed pollutant concentration values

3) Comparison of predicted and observed pollutant concentrations with the National Ambient Air Quality Objectives (NAAQO), Environment Canada 
4) Sensitivity analyses of significant parameters within the framework that affect pollutant dispersion

\subsection{Significance and Potential}

Traffic generated pollution has been investigated at the local and regional scale in considerable detail using several different methodologies. Ishaque \& Noland (2008) used a traffic microsimulation model and a microscopic emissions model, to estimate emissions for a road network in London. Further, they used a line source Gaussian dispersion model (CAL3QHC) to estimate pollutant concentrations. Hatzopoulou \& Miller (2010) estimated average hourly concentration contours on the regional scale in the Greater Toronto Area by simulating pollutant dispersion using activity-based travel demand modelling, incorporating the use of EMME, an average speed based travel demand model. Similarly, Nesamani, et al. (2007) developed an intermediate model for better estimation of average link speeds and then used the MOBILE series model to estimate emissions.

Amirjamshidi, et al. (2012) investigated emissions for the downtown Toronto Waterfront network using a combination of traffic microsimulation model and emissions model; a simplified Gaussian plume dispersion model was applied to estimate roadside emissions that could not simulate the complexity of flow in urban areas. Karim \& Matsui (1998) and Karim, et al. (1998) developed and evaluated a mathematical model that predicted pollutant concentrations for $\mathrm{CO}$ and $\mathrm{NO}_{\mathrm{x}}$ in roadway micro-environments. The line source emission inputs to the dispersion model were based on vehicle speeds and total vehicular flow for eight categories of vehicles.

Ahn \& Rakha (2008) showed that macroscopic emission models that are based on average speeds on road links ignore microscopic movement of vehicles and could potentially give incorrect emission rates. Inputting incorrect emission rates into the dispersion model would further increase uncertainty in the final results obtained. Therefore, it is important to microsimulate traffic in a network in order to replicate the movement of vehicles better, and in turn, get better results from the dispersion models.

The integrated approach to combine traffic emissions and dispersion under a single framework has been explored in the past. Hatzopoulou (2008) performed a review of integrated approaches to urban air quality modelling at the local and regional scale. Some examples of integrated local 
air quality frameworks include the OSCAR system (Sokhi, et al., 2008), the integrated TREM/VADIS/VISUM system (Borrego, et al., 2003), and the DAPPLE Project (Arnold, et al., 2004). The OSCAR system combines use of traffic flow data, emissions inventory, and dispersion modelling (CAR-FMI, a line source Gaussian model) to assess urban air quality. OSCAR uses a link-based approach where emission factors are estimated using the average link speed. The TREM/VADIS/VISUM system, similar to OSCAR, estimates emissions based on average speed of the vehicles, although it uses a Lagrangian particle model (VADIS) for pollutant dispersion. DAPPLE attempts to combine neighbourhood scale pedestrian and traffic flow to assess population exposure; five minute, hourly, and daily traffic volumes are linked with vehicle type distribution attributes and emission inventories, to perform mesoscopic or microscopic traffic modelling.

The significance of this research lies in, firstly, integrating three different modelling methods, and secondly, incorporating use of traffic microsimulation and microscopic emissions model that are not based on average speed based emission inventories. Subsequently, the emission rates are input into a microscopic Lagrangian particle model and a Gaussian plume model for dispersion.

This research has potential in terms of evaluating population exposure by combining pedestrian microsimulation modelling with the proposed framework. Capturing spatial and temporal variation of street level population exposure to local traffic emissions should lead to interesting policy analysis scenarios. Re-designing urban network configurations for bikeways and pedestrian walkways based on emission exposure profiles, integrating land-use planning to develop pedestrian oriented 'walking zones', and evaluation of micro-scale air quality within mobility hubs as proposed by Metrolinx (2008), are all examples of prospective projects that could be analysed using the proposed framework.

\subsection{Structure of Thesis}

The thesis is organized into nine chapters. The first chapter gives a brief background and introduces the underlying foundation of the proposed work. Chapter 2 presents an overview of the different components of the methodology, describes the study area, and explains the concept of ambient concentrations. Chapters 3, 4 and 5 discuss each component of the modelling framework, namely, the traffic microsimulation model, microscopic emissions model, and the dispersion models. This includes literature review, model characteristics, and methodology. 
Chapter 6 describes the final results obtained and performance evaluation of the models. Chapter 7 includes the sensitivity analyses on modelled concentrations. Chapter 8 contains notes on data error, comparison between the two dispersion models used, and comparison of predicted and observed concentrations with the NAAQO standards. Chapter 9 summarizes the research effort and concludes with key remarks on future work. 


\section{Chapter 2}

\section{Overview of Methodology}

The proposed research framework consists of three components. They are as follows:

1) Traffic microsimulation model, Quadstone PARAMICS (Quadstone Paramics, 2008)

2) Microscopic emissions model, Comprehensive Modal Emissions Model (CMEM) (Barth, et al., 1999) (Barth, et al., 2001)

3) Dispersion model:

a. AERMOD, Environmental Protection Agency (EPA) regulatory model for near field dispersion (Cimorelli, et al., 2004)

b. Quick Urban and Industrial Complex (QUIC), Atmospheric Dispersion Modelling System (Los Alamos National Laboratory, 2010)

\subsection{Air Quality Modelling Framework}

Figure 2-1 shows the overview of the air quality modelling framework adopted.

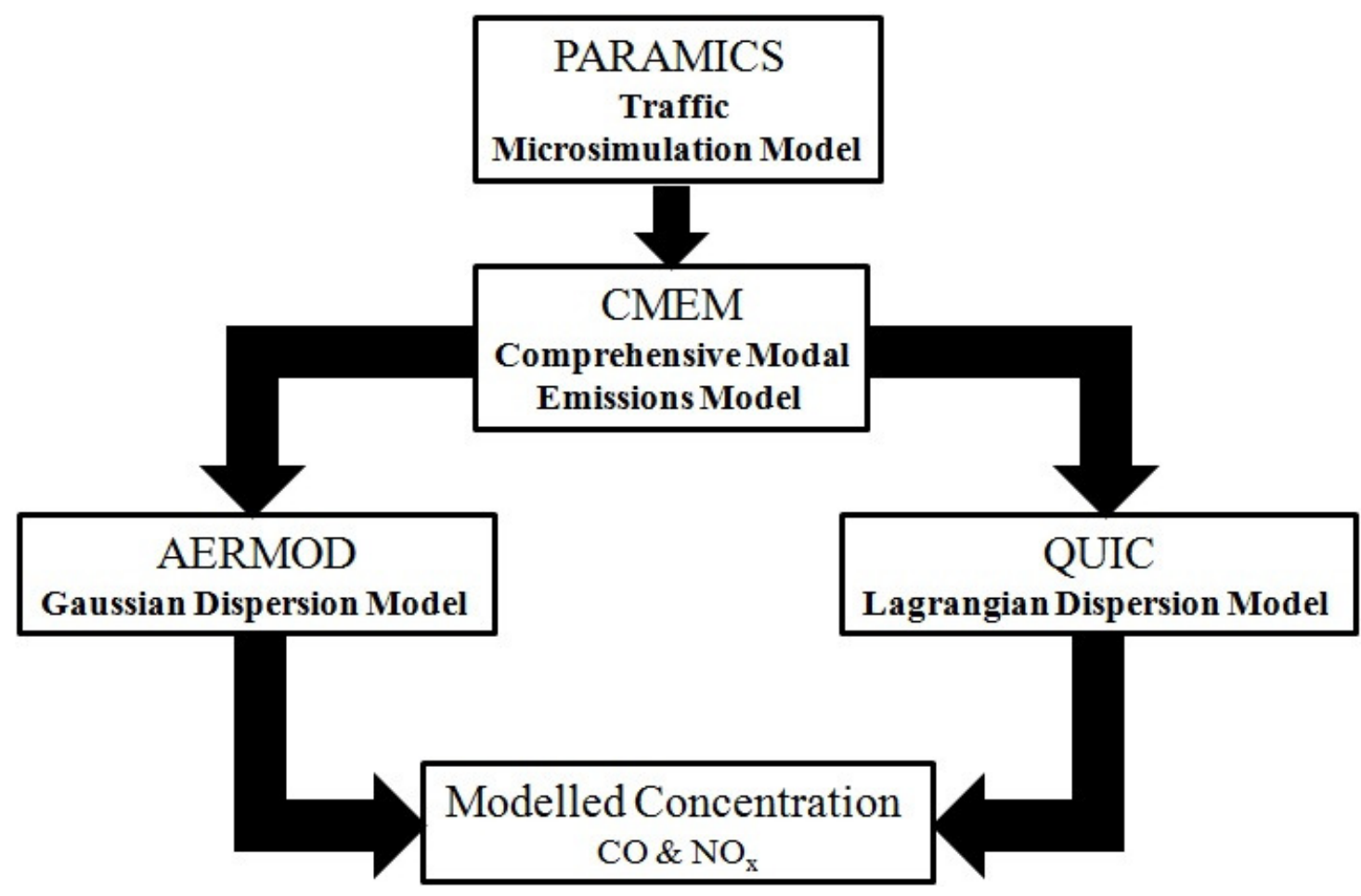

Figure 2-1 Air Quality Modelling Framework Overview 
The traffic microsimulation model simulates the movement of vehicles by capturing the spatial and temporal variation of vehicle driving characteristics (speed profile) for each vehicle travelling on the road network. Traffic microsimulation is based on road network input, origindestination matrix, and driver specific attributes related to driving behaviour. Using a distribution of vehicle types travelling on the network, CMEM estimates emission factors on different roadway links, using disaggregate vehicle operation characteristics obtained from the traffic microsimulation (PARAMICS). The emission rates are estimated analytically by breaking the emission generation process occurring in the vehicle engine into several components. Finally, AERMOD and QUIC simulate the dispersion of emissions in the atmosphere, assuming roadway links to be an emission source. Predicted concentrations are subsequently compared with sensor observed concentrations to evaluate the performance of this framework. Figure 2-2 is an extension of the 'Basic Air Quality Modelling Framework' presented in Figure 2-1. It shows primary inputs into each component of the framework. Detailed description of all components is presented in the following chapters.

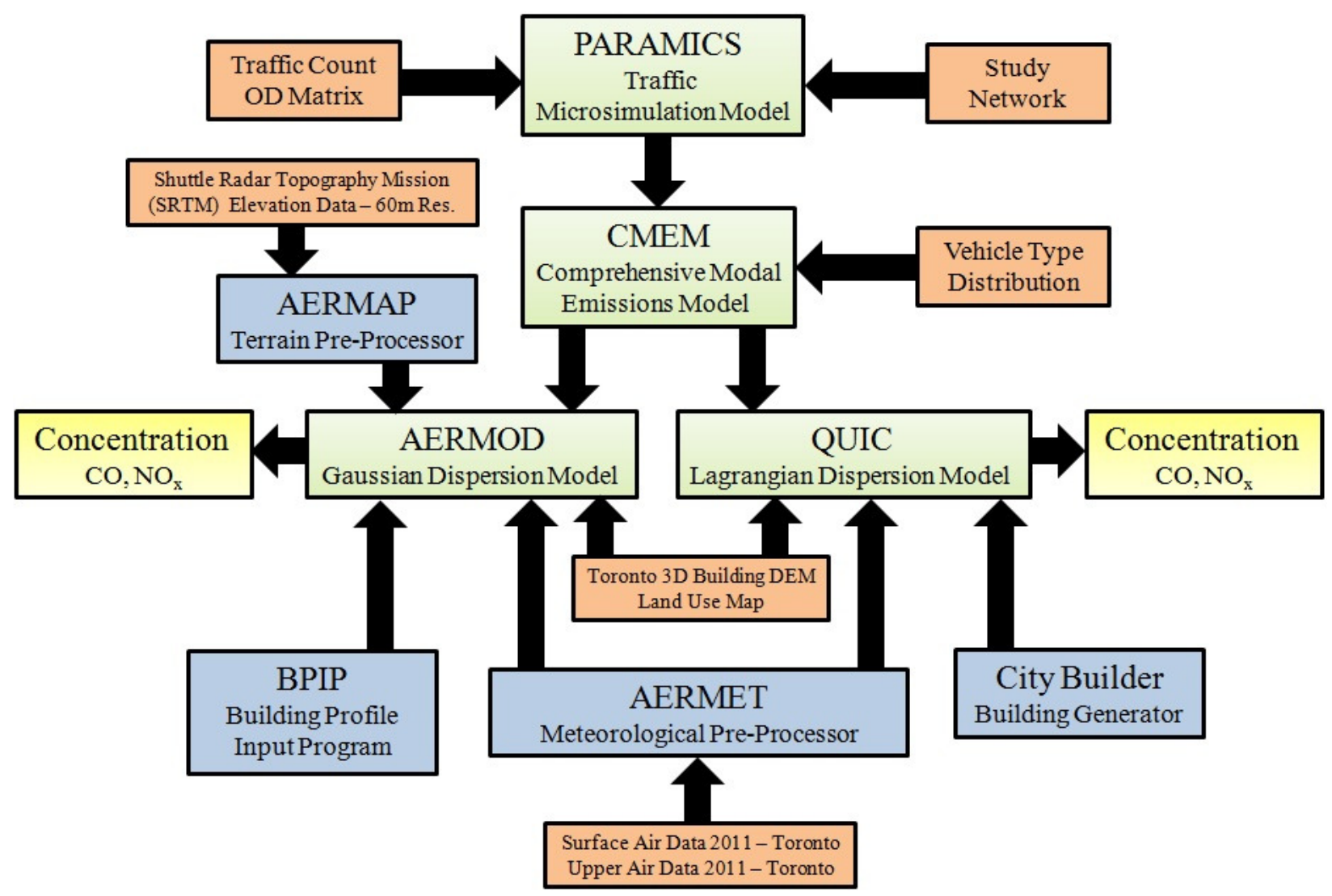

Figure 2-2 Detailed Air Quality Modelling Framework 


\subsection{Study Area Specification}

The study area selected for application of this framework is the St. George Street and College Street intersection network in downtown Toronto, Canada. It is located on the southern edge of the University of Toronto, St. George Campus. College Street is a four lane road (excluding bicycle lanes) in downtown Toronto, with an average hourly traffic volume of approximately 1,400 vehicles per hour, Southern Ontario Centre for Atmospheric Aerosol Research (SOCAAR, 2011). The other prominent road on the network is the St. George Street which has two lanes; this street changes to Beverley Street south of College. All other roads on the network have low traffic volumes.

The network is approximately $800 \mathrm{~m}$ by $600 \mathrm{~m}$ with the main intersection located at the centre. The modelled section of College Street lies between two major roads in downtown Toronto Spadina Avenue on the West and University Avenue on the East. The northern extents of the network lie slightly north of the St. George and Russell Street intersection, while the southern extents lie slightly south of the Beverley and Cecil Street intersection. There is one major intersection within the network - St. George at College Street. Other minor intersections include: College at Huron, College at Ross, College at Henry, College at King's College, Beverley at Cecil, St. George at Galbraith, and St. George at Russell. A map of the study area is shown in Figure 2-3. It also shows the location of the traffic counting sensor (south-west side of intersection) and the pollutant concentration monitoring sensor (north-east side of intersection). This network is selected for the following reasons:

1) Presence of heterogeneous building environment with varying building heights

2) Heterogeneous vehicle fleet distribution presence on College Street

3) Availability of traffic and pollutant concentration data on College Street (SOCAAR, 2011)

4) Availability of PARAMICS traffic network for the study area

5) Easy access from the University of Toronto Engineering Building for inspection of local network characteristics

Roorda, et al. (2011) used a Gaussian plume equation to show that the lateral concentration of traffic pollutants decreases rapidly as distance increases. The contribution of roadway line source 
to pollutant concentration was found to be negligible beyond a lateral distance of $~ 100$ metres from the source. This is an important consideration in setting the size of the study network. The emissions from University Avenue and Spadina Avenue do not significantly impact emission concentrations at the observed concentration sensor location.

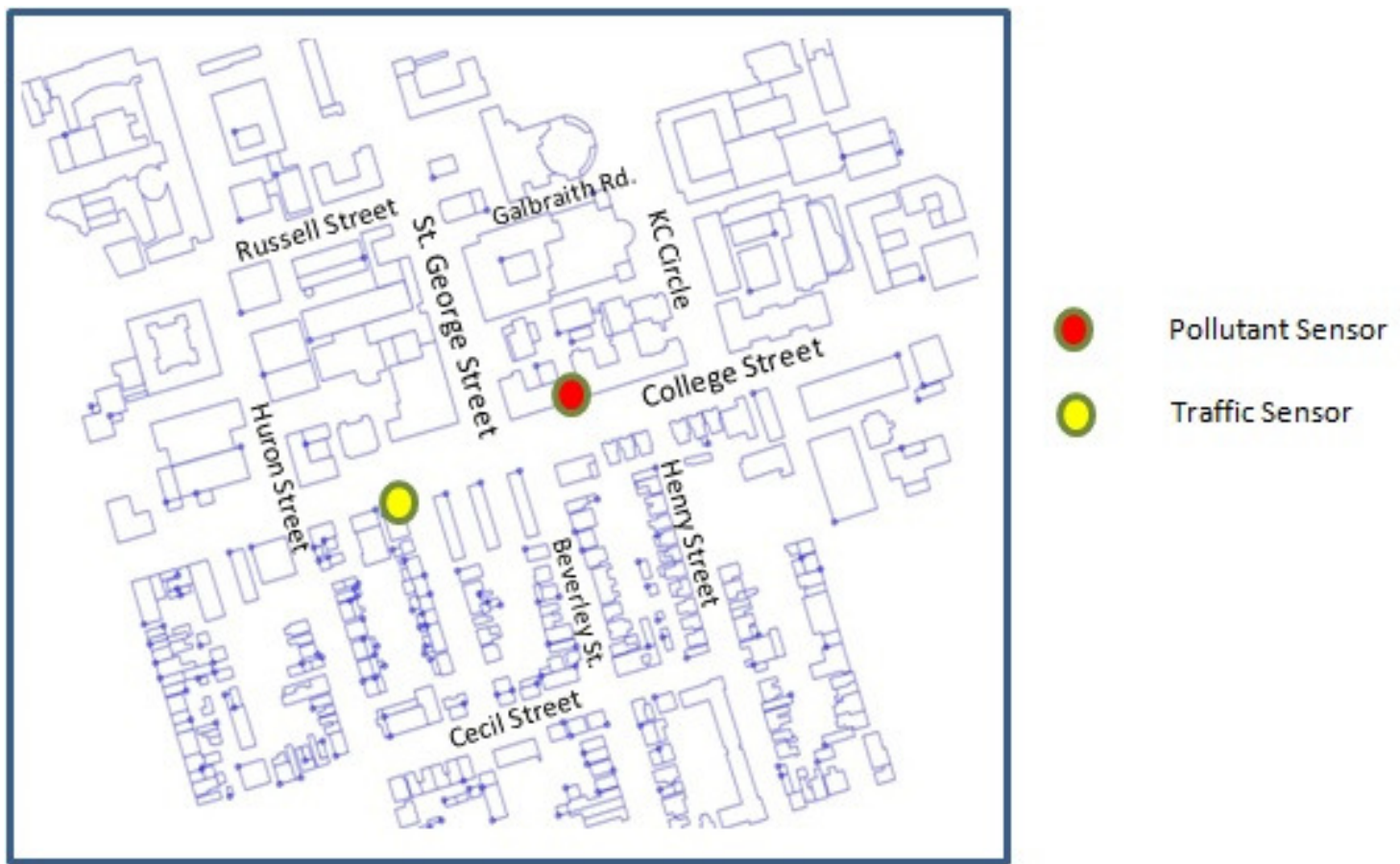

Figure 2-3 St. George Street and College Street Intersection Area (Map and Data Library, University of Toronto, 2011) (Lakes Environmental, 2012)

The morning peak period between 7:00 - 9:00 AM is analysed for the following selected weekdays in 2011:

1) June $3,13,21,28,30-\mathrm{CO}$ analysis

2) July $7,12,13,18,27-\mathrm{NO}_{\mathrm{x}}$ analysis

$\mathrm{CO}$ and $\mathrm{NO}_{\mathrm{x}}$ are only analysed for June and July respectively, due to limited observed data availability from the concentration measuring sensor.

\subsection{Concentration Terms}

Four concentration terms have been extensively used in this research. They are defined as follows: 
1) Observed or Measured Concentration: The pollutant concentration obtained from the monitoring sensor.

2) Modelled Concentration: The pollutant concentration output from the modelling framework.

3) Ambient Concentration: The background concentration that is not modelled but estimated using observed values.

4) Predicted Concentration: The sum of modelled and ambient or background concentrations.

Ambient concentrations are present due to the persistence of pollutants in the atmosphere. The modelled concentrations are only representative of the traffic emissions occurring within the morning peak period. However, the pollutant monitoring sensor can only capture total concentration in the atmosphere; it cannot distinguish between actively occurring traffic emissions (within the modelling period), and background concentrations that are present in the atmosphere (due to emissions that occurred before the modelling period). Therefore, ambient concentrations need to be estimated, so that accurate comparisons can be made between the 'predicted' and sensor observed concentrations. Separating ambient emission concentrations from active traffic emission concentrations, occurring within the modelling period only, is a challenging task. In this research, a night time observed concentration (measured between 3:00 $\mathrm{AM}-$ 5:00 $\mathrm{AM})$ is utilized to augment the modelled concentrations, and estimate predicted concentrations (for both $\mathrm{CO}$ and $\mathrm{NO}_{\mathrm{x}}$ ). This night time concentration corresponds with the minimum concentration observed during the entire day, and also occurs when hourly traffic volume on College Street is smallest for any given day. Refer to Chapter 6 for detailed graphs.

The Ontario Ministry of the Environment (MOE) has four sensors located at the east, west, north and south corners of the City of Toronto that measure pollutant concentration (Ontario Ministry of the Environment, 2012). The location of MOE sensors are:

1) TD MOE: Toronto Downtown - Bay / Wellesley - $10 \mathrm{~m}$ height intake

2) TE MOE: Toronto East - Kennedy / Lawrence Ave. East - 4 m height intake

3) TN MOE: Toronto North - Hendon (Finch) / Yonge - $5 \mathrm{~m}$ height intake

4) TW MOE Toronto West - 125 Resources Road (next to Highway 401) - 8 m height intake 
Observed concentrations available from the MOE and SOCAAR sensors are compared to test reliability of ambient concentrations estimated using the latter. Data from the MOE west sensor are not used due to its close proximity to Highway 401 where the traffic volume and patterns are expected to be markedly different from the study area. Observed concentrations for $\mathrm{CO}$ from the MOE sensors are only available for the downtown (south) sensor in 2010; appropriate comparisons have been made by using SOCAAR data from 2010 in that case. The observed concentration trends for all pollutants are shown in Figure 2-4, 2-5 and 2-6. The monthly average night time concentration pattern for both pollutants is very similar; this confirms the reliability of using SOCAAR sensor night time observed concentrations for ambient concentration estimation.

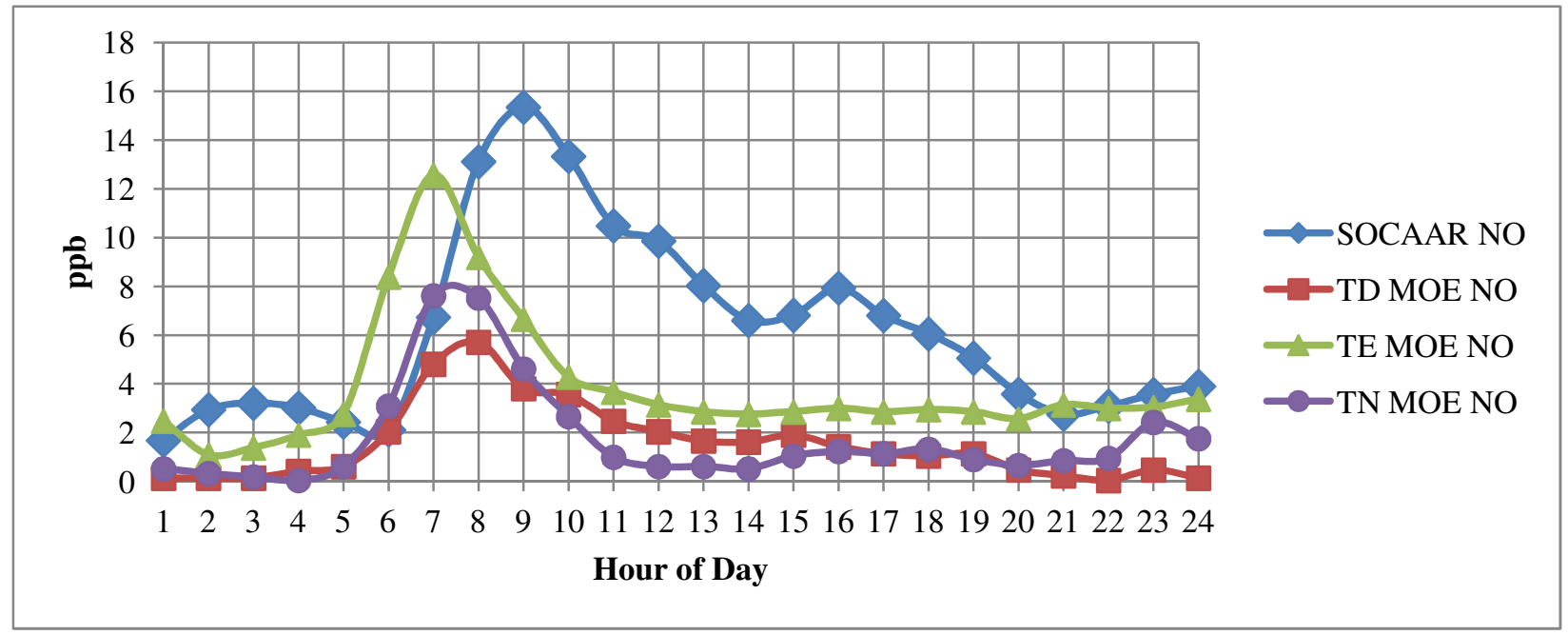

Figure 2-4 Hourly Average NO Concentration, July 2011, MOE / SOCAAR Sensor

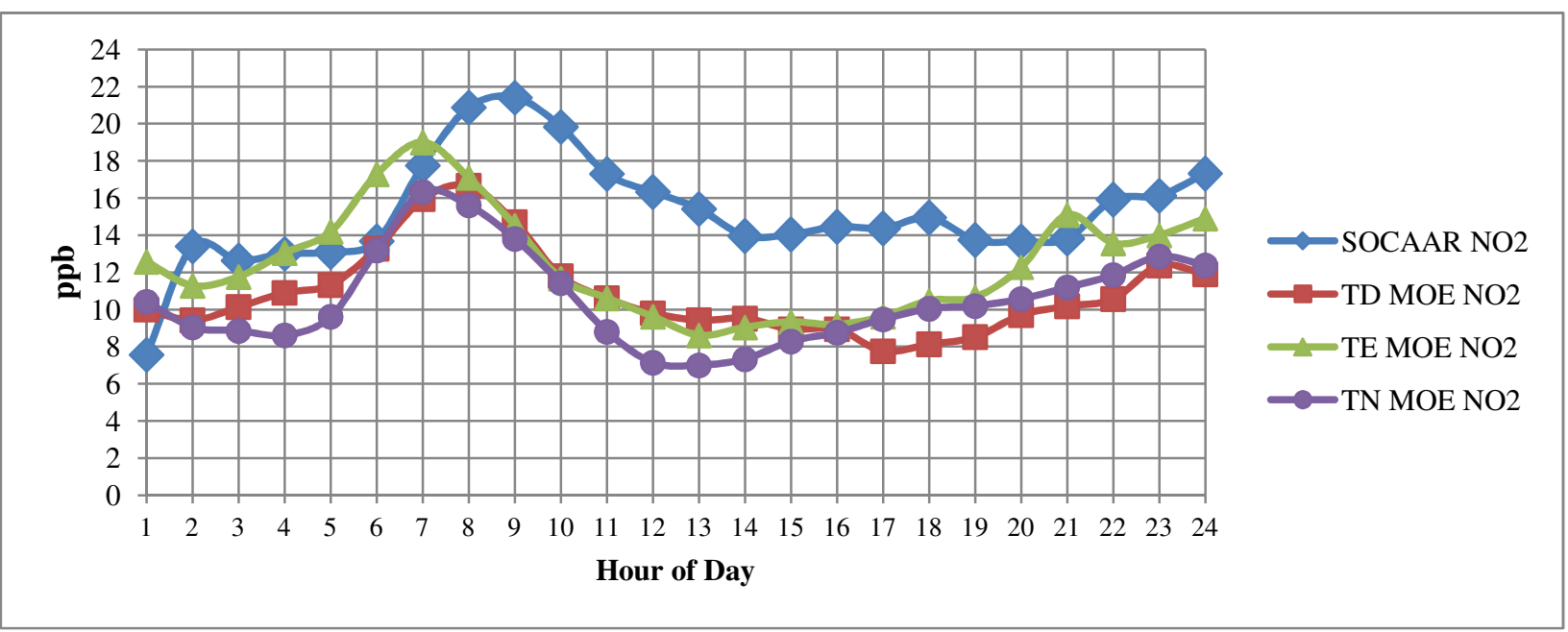

Figure 2-5 Hourly Average $\mathrm{NO}_{2}$ Concentration, July 2011, MOE / SOCAAR Sensor 


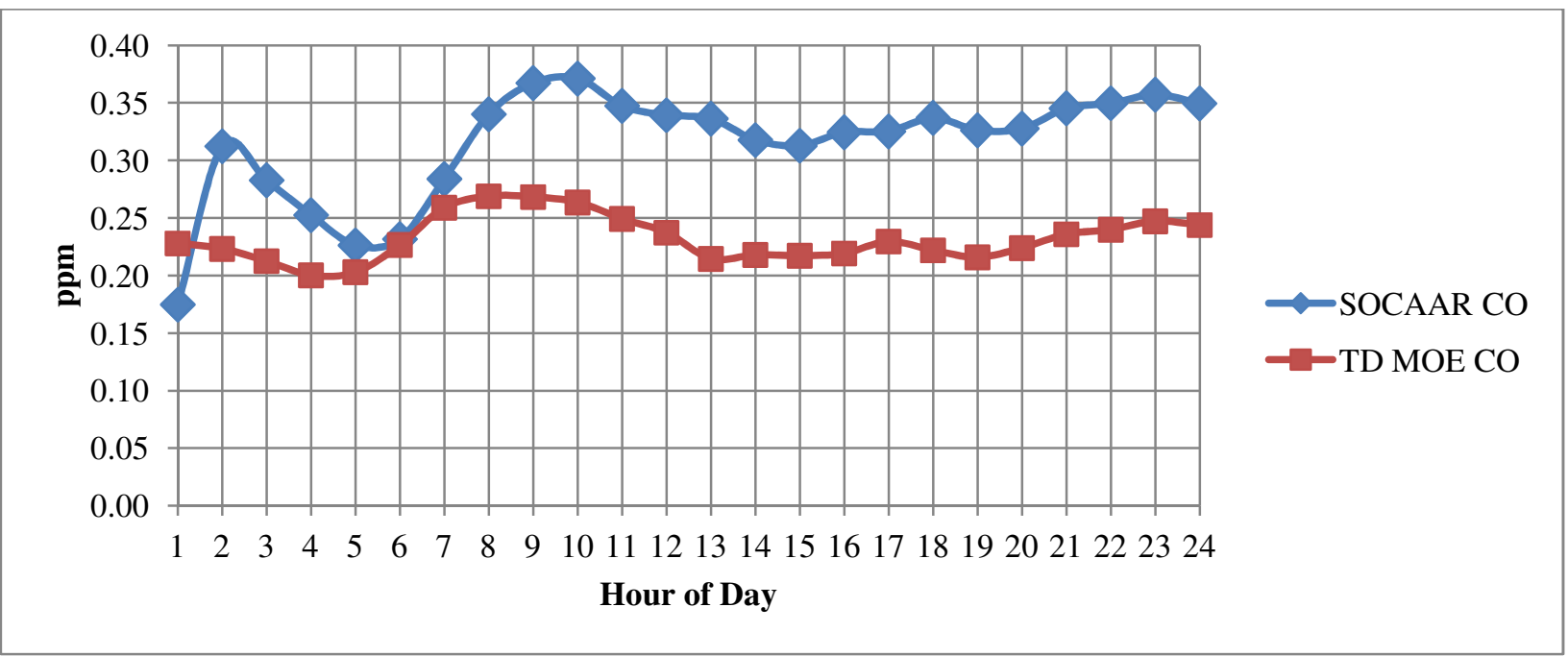

Figure 2-6 Hourly Average CO Concentration, June-July 2010, MOE / SOCAAR Sensor 


\section{Chapter 3}

\section{Traffic Microsimulation Modelling: Method}

\subsection{Introduction to Traffic Microsimulation}

Traffic microsimulation is a key component of advanced transportation modelling systems, and finds widespread application in planning and decision making. The microsimulation model used in this analysis is developed using the Quadstone PARAMICS toolkit (Quadstone Paramics, 2008).

\subsection{Traffic Modelling Review}

A traffic model can be defined as a set of mathematical algorithms based on traffic flow theory that attempts to replicate the behaviour of vehicles on a road network. It can provide valuable information (practically impossible to gather in real life), that can be used by traffic engineers and planners to solve traffic related issues.

The most common classification of traffic models is based on their level of detail, which includes macroscopic, mesoscopic, and microscopic models. Macroscopic models explain traffic flow at a high aggregation level, such that the individual vehicles cannot be distinguished. These models use parameters such as net flow / volume of traffic, density across a section of road, and average speed on road links, to explain the movement of vehicles through the network. Microscopic models, on the other hand, provide considerable disaggregation incorporating driver behaviour and route choice. These models simulate vehicle propagation by incorporating individual interaction between vehicles, and hence are much better at mimicking realistic movement of vehicles on a road link. Mesoscopic models fall between the two categories mentioned above. These models are essentially either microscopic models with some attributes of macroscopic models, or vice-versa.

The first macroscopic model was developed by Lighthill \& Whitham (1955) while the first microscopic model, called the car following model, was developed by Pipes (1953). Subsequently, several macroscopic and microscopic traffic models have been developed, building in complexity around the original idea. Other commonly used classifications of traffic 
models include process representation (deterministic or stochastic), application (intersection, links, stretches, networks), and operationalisation (analytical or simulation). Such classifications and methodologies adopted by different vehicular traffic flow models have been reviewed by Hoogendoorn \& Bovy (2001) in detail.

\subsection{Model Selection}

A traffic microsimulation model is selected over average speed models (for example, EMME) due to the inherent lack of detail in average speed models to simulate microscopic travel behaviour. Ahn \& Rakha (2008) showed that instantaneous speed is an important factor that cannot be ignored while estimating traffic emissions. An average speed model would not be able to provide a sufficient resolution in temporal and spatial variation of driving cycle characteristics, and therefore, is not adopted for this micro-modelling framework.

Several commercial and research oriented traffic microsimulation models are available for application. Papacostas \& Prevedouros (2001) classified traffic microsimulation software packages on the basis of their application into three categories. The first category consists of 'urban street network' models such as SimTraffic and NETSIM; second, 'freeways and freeway corridors' that include models such as INTRAS, FRESIM, and CARSIM; and lastly, fully integrated 'mixed network' models such as AIMSUN, CORSIM, INTEGRATION, PARAMICS, SCOT, WATSim, and VISSIM. The third category consists of the most composite traffic microsimulation models that are capable of simulating traffic in complex networks. Extensive work has been done at the University of Toronto, Department of Civil Engineering's Transportation Research Group using Quadstone PARAMICS on several research studies. A PARAMICS network of the study area was available from Hoy, et al. (2012). Therefore, PARAMICS is selected as the model of choice for microsimulating traffic.

PARAMICS incorporates a car following model which is based on parameters representing the driver's behaviour, for example, driver aggressiveness, familiarity with the network, mean driver's reaction time, and headway between the vehicles. For route choice, it uses a generalized cost equation to estimate the shortest path for the input origin-destination (O-D) matrix, and applies an all-or-nothing traffic assignment (for simpler networks) or a dynamic traffic assignment (when multiple path options between one O-D pair are available), to estimate net 
traffic flow on different links in the road network. Other inputs into the model include transit routes, lane configuration, and traffic signal timings.

\subsection{Network Development and Inputs}

The St. George Street and College Street intersection network in PARAMICS was developed by Hoy, et al. (2012) for a study that investigated dispersing microsimulated emissions using a Gaussian model for the morning peak period of a single day. The roadway topology of the network is based on satellite imagery and geometric interpolation. The traffic network is divided into 15 zones that serve as the origin or destination points for all vehicles in the traffic microsimulation.

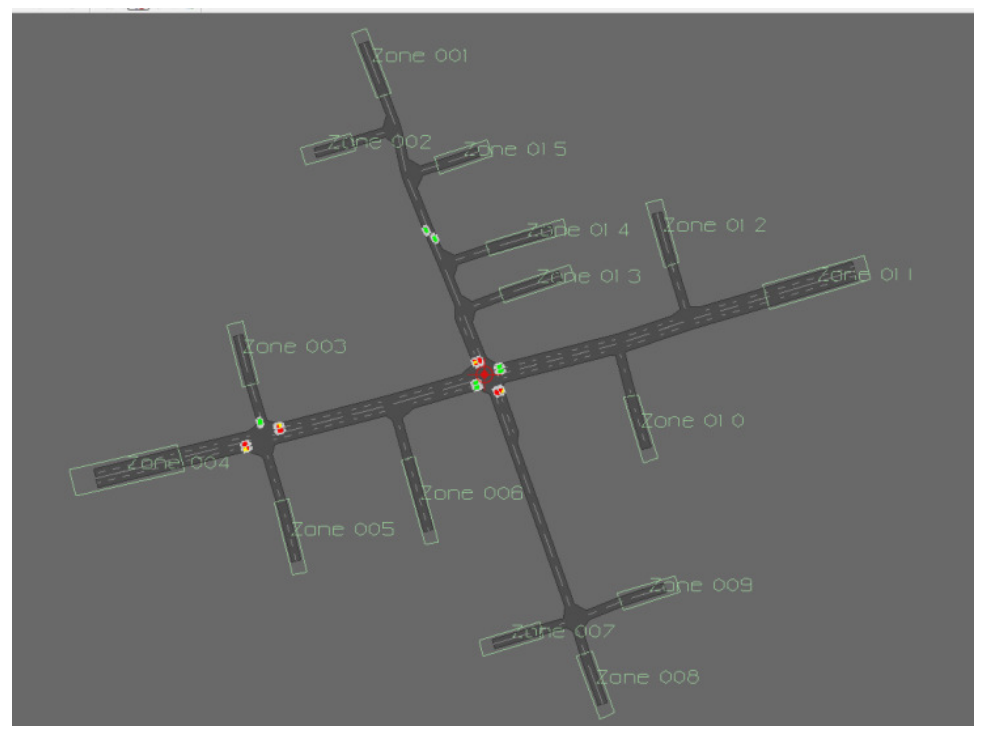

Figure 3-1 St. George Street and College Street Intersection Network in PARAMICS

All characteristics of the roadway links such as lane widths and speed limits are already incorporated within the network. The network includes a traffic control system which consists of three traffic lights that have been coded with observed traffic signal timings. Operating characteristics of the streetcar service on College Street are also coded in to the network; these characteristics include transit route specification, fixed time schedule (based on morning peak period), and streetcar stop locations. Figure 3-1 shows the study network in PARAMICS used in this research. 
The remaining inputs (and the corresponding methods used to develop those inputs) required by PARAMICS in order to perform a model run are as follows:

1) Input O-D matrix for traffic flow

a. Traffic data collection

b. Turning movement percentage and regression modelling

c. Monte Carlo simulation

2) Vehicle Type Distribution

a. Best estimate from literature

b. City of Toronto cordon count data

3) Other Core Parameters

a. Best estimate from literature

The methods adopted to estimate these inputs are discussed in the following sub-sections.

\subsubsection{Traffic Data Collection}

In order to perform a traffic microsimulation model run, a time varying O-D matrix consisting of different vehicle types is required. To generate O-D matrices, traffic data are obtained from two sources:

a) Manual traffic count performed on one day at 10 locations throughout the network

b) Automatic sensor traffic count for the entire study period (modelled weekdays in JuneJuly 2011) at College Street, west of the major intersection (one location only)

The manual traffic count was conducted on June 8, 2011 (Wednesday) from 6:30 - 9:00 AM. Traffic data were manually recorded by a team of 15 traffic counters at 5 minute intervals at 10 different locations within the network using nine different vehicle categories. The details of this survey can be found in Hoy, et al. (2012). The data obtained from this survey contain traffic flow on the network at 5 minute intervals. These data are processed to estimate average turning percentages of vehicles at all intersections within the network. These turning percentages are aggregated to 15 minute intervals for use in this project.

Carrying out detailed traffic counts for all weekdays modelled in the study is practically infeasible; therefore, traffic sensor data obtained from SOCAAR (2011) are used to generate 
estimates for vehicular flow on College Street at a fine resolution. The smart eye Traffic Data Sensor (TDS) is installed on a building close to the intersection at approximately 15 metres height, and captures traffic on all four lanes of College Street, west of the major intersection. The sensor uses video image processing techniques and classifies vehicles into two categories passenger cars and trucks, providing counts at 5 minute intervals (Smart Systems, 2008). Observed traffic data are aggregated at 15 minute intervals and organised for the modelled weekdays in June and July 2011 between 7:00 - 9:00 AM.

Analysis of traffic data obtained from the TDS indicates that traffic on College Street distinctly differs between weekdays and weekends, as shown in Figure 3-2. Data from the manual traffic count are used to synthesize traffic flow values on the network for the entire study period. Since the manual traffic count was performed on a weekday, it is considered imprudent to apply those results on weekends, due to a big difference between morning peak period traffic flows for weekdays and weekends. Therefore, weekend concentrations are not modelled in this study.

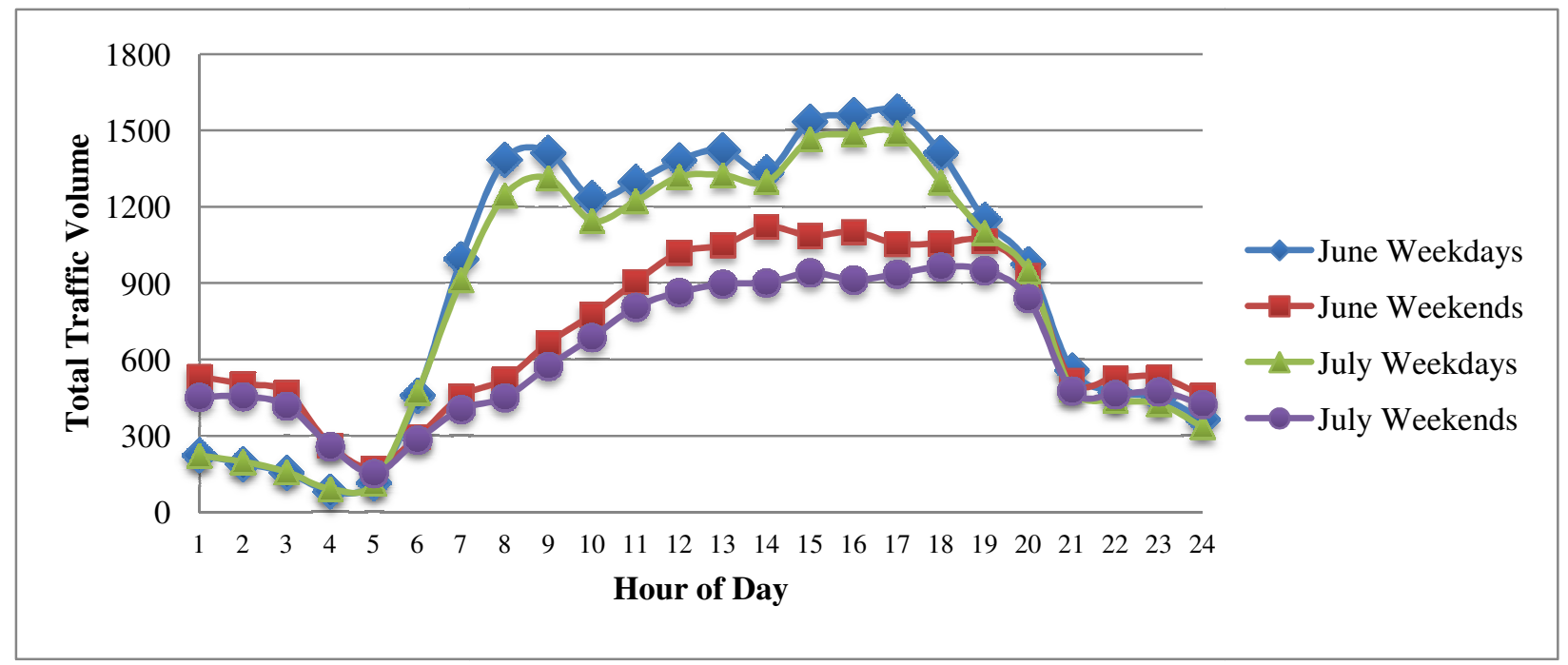

Figure 3-2 Average Hourly Sensor Observed Traffic on College Street for June and July 2011

\subsubsection{Origin-Destination (O-D) Matrix}

\subsubsection{Turning movement percentage}

Turning movement percentages are available in 5 minute intervals between 7:00 - 9:00 AM for all intersections within the network from the manual survey count. These percentages are averaged to 15 minute intervals. Minor adjustments are made to balance the total percentages at 
some intersections where the sum is not $100 \%$ upon aggregation. Different sets of turning percentage matrices are developed as follows:

1) Cars / Light Vehicles: The turning percentages are assumed to vary at 15 minute intervals, but are constant for the different days that are modelled.

2) Medium / Heavy Vehicles: The turning percentages are assumed to be constant for the entire morning peak period and also constant for the different days that are modelled.

Figure 3-3 shows a flowchart explaining the procedure followed in input O-D matrix estimation.

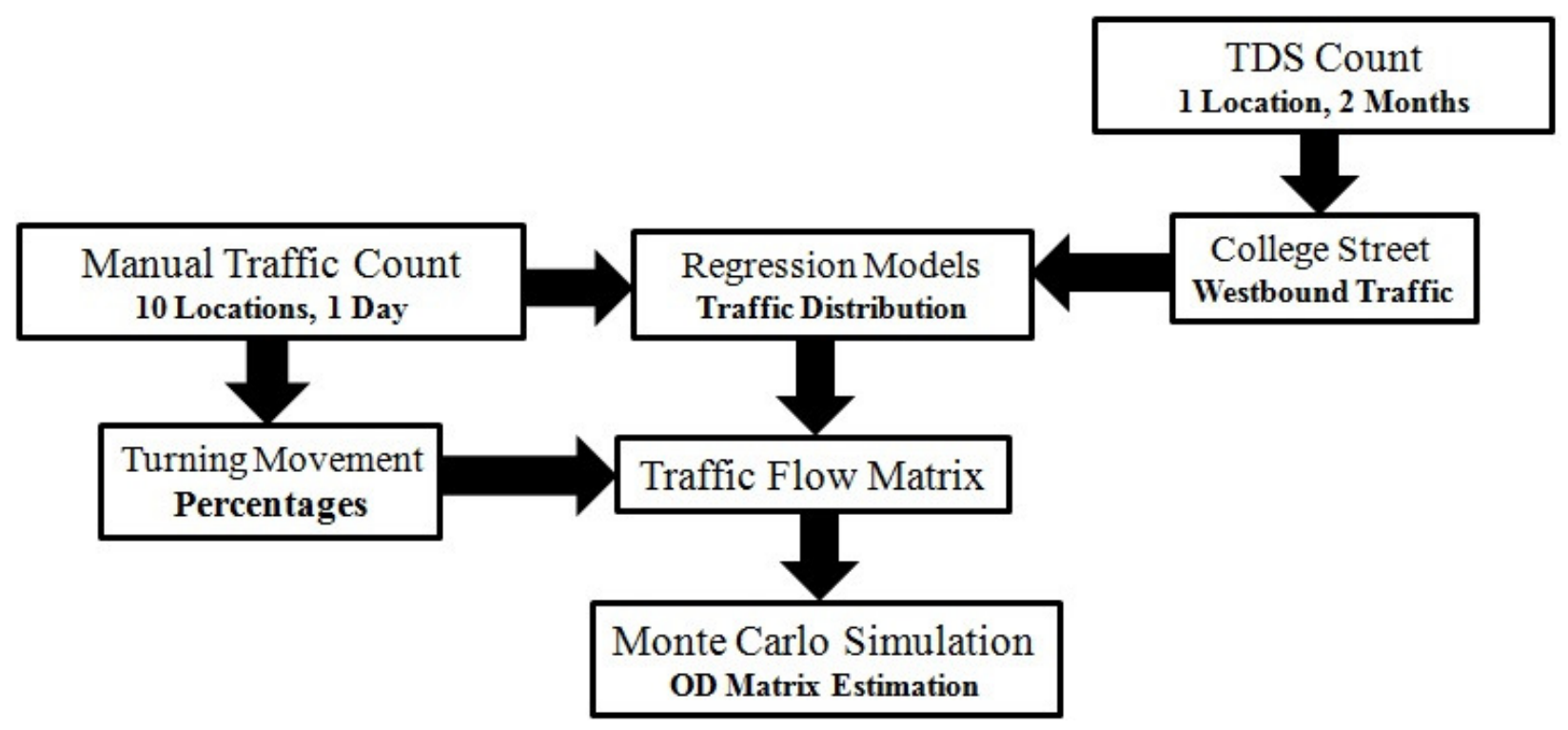

Figure 3-3 Process Flowchart: O-D Matrix Estimation

\subsubsection{Regression modelling}

The TDS only provides traffic counts on College Street; the remaining traffic flows are calculated by developing regression models. These models correlate manually counted traffic flows on College Street with traffic on other streets. To estimate traffic on other streets as a percentage of the traffic on College Street, the constant term in regression models is kept zero. A total of 15 regression models are developed; 9 for cars / light vehicles and 6 for medium / heavy vehicles. The regression models are assumed to be constant for the morning peak period of all modelled days. 
Figure 3-4 shows a typical regression model for Southbound car / light vehicle traffic on St. George Street correlated with total car / light vehicle traffic on College Street for 7:00 - 9:00 AM.

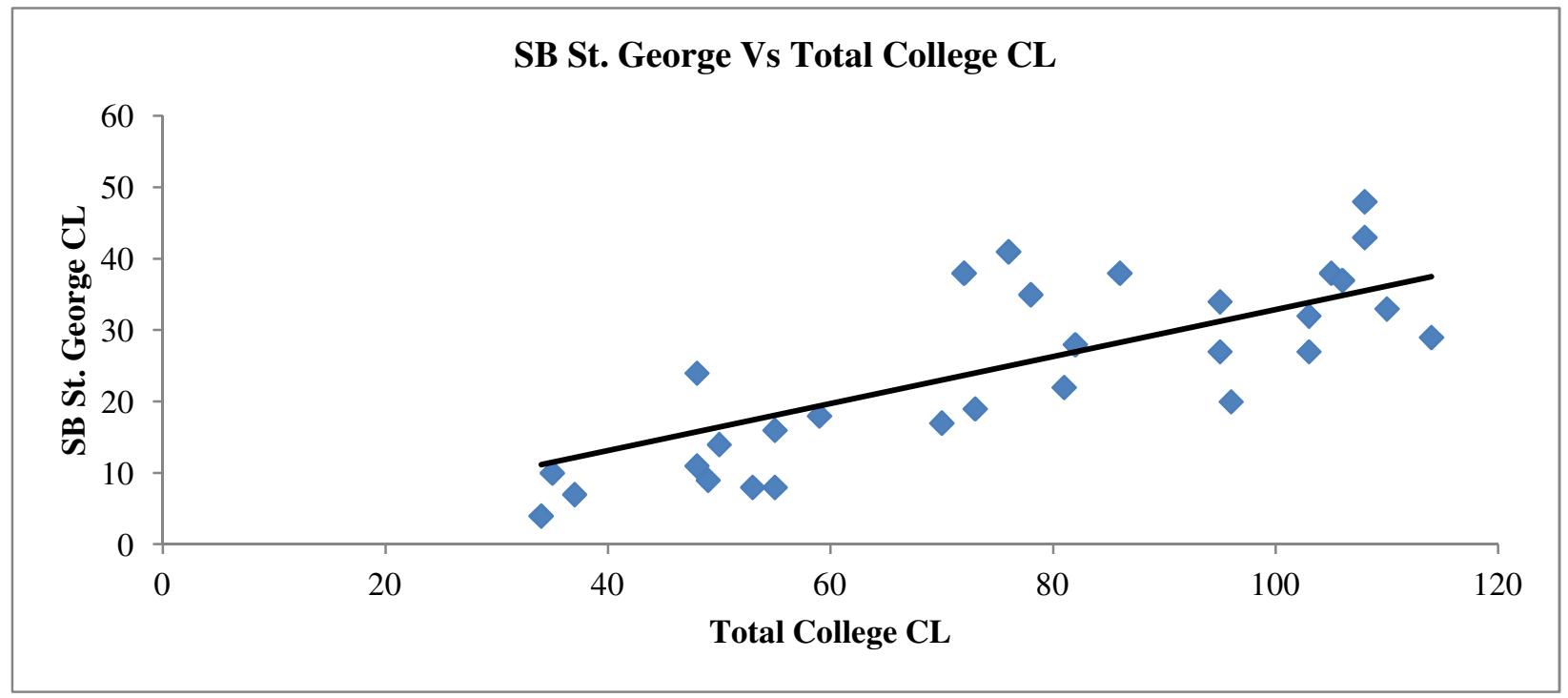

Figure 3-4 Passenger Car Model relating College St. Traffic with Southbound St. George St. Traffic; SB: Southbound; CL: Cars / light vehicles

Table 3-1 lists the regression models developed to estimate synthetic traffic volumes at different locations within the network. The models generally show good correlation and high $\mathrm{R}^{2}$ values. Medium / heavy vehicle volumes on King`s College (Southbound) and Galbraith (Westbound) are assumed to be zero since they are very small roads, and a negligible number of vehicles were counted on them during the manual traffic survey.

Next, these models are applied to generate synthetic traffic counts on the network. It is imperative to note that only the locations required to identify a traffic flow pattern on the network are modelled using regression analysis. The remaining values are estimated based on 'balancing' traffic at different intersections within the network using turning percentages obtained from the manual traffic counts. The balancing process involves keeping the net flow of vehicles through an intersection consistent. 
Table 3-1 Regression Models for Light and Heavy vehicles based on manual traffic count data

\begin{tabular}{|l|c|c|}
\hline Regression Models & Car / Light Vehicles & Medium / Heavy Vehicles \\
\hline St. George NB & $0.18 * \mathrm{~V}_{\mathrm{C}} ; \mathrm{R}^{2}=0.88$ & $0.21 * \mathrm{~V}_{\mathrm{T}} ; \mathrm{R}^{2}=0.84$ \\
\hline St. George SB & $0.33 * \mathrm{~V}_{\mathrm{C}} ; \mathrm{R}^{2}=0.93$ & $0.17 * \mathrm{~V}_{\mathrm{T}} ; \mathrm{R}^{2}=0.64$ \\
\hline Beverley NB & $0.16 * \mathrm{~V}_{\mathrm{C}} ; \mathrm{R}^{2}=0.87$ & $0.21 * \mathrm{~V}_{\mathrm{T}} ; \mathrm{R}^{2}=0.89$ \\
\hline Beverley SB & $0.24 * \mathrm{~V}_{\mathrm{C}} ; \mathrm{R}^{2}=0.89$ & $0.17 * \mathrm{~V}_{\mathrm{T}} ; \mathrm{R}^{2}=0.84$ \\
\hline Huron SB & $0.06 * \mathrm{~V}_{\mathrm{C}} ; \mathrm{R}^{2}=0.69$ & $0.08 * \mathrm{~V}_{\mathrm{T}} ; \mathrm{R}^{2}=0.53$ \\
\hline College WB & $1.09 * \mathrm{~V}_{\mathrm{CW}} ; \mathrm{R}^{2}=0.99$ & $0.52 * \mathrm{~V}_{\mathrm{TW}} ; \mathrm{R}^{2}=0.66$ \\
\hline King's College SB & $0.03 * \mathrm{~V}_{\mathrm{C}} ; \mathrm{R}^{2}=0.59$ & 0 \\
\hline Galbraith WB & $0.12 * \mathrm{~V}_{\mathrm{C}} ; \mathrm{R}^{2}=0.83$ & $0.06 * \mathrm{~V}_{\mathrm{T}} ; \mathrm{R}^{2}=0.16$ \\
\hline Russell EB & $0.08 * \mathrm{~V}_{\mathrm{C}} ; \mathrm{R}^{2}=0.86$ & 0.06 \\
\hline
\end{tabular}

$\mathrm{V}_{\mathrm{C}}$ : Total eastbound and westbound car traffic on College Street; $\mathrm{V}_{\mathrm{T}}$ : Total eastbound and westbound truck traffic on College Street; $\mathrm{V}_{\mathrm{CW}}$ : Total westbound car traffic on College Street, $\mathrm{V}_{\mathrm{TW}}$ : Total westbound truck traffic on College Street. (All observed traffic on College Street measured west of the major intersection); EB: Eastbound, WB: Westbound, SB: Southbound, NB: Northbound. * East of the intersection

\subsubsection{Monte-Carlo Simulation}

A Monte-Carlo simulation method developed by Hoy, et al. (2012) is adopted to generate the O$\mathrm{D}$ matrix. Using the traffic flow matrix and turning movement percentages, an O-D cumulative percentage matrix is created that contains the cumulative probability of a vehicle travelling between a given O-D pair. Subsequently, a Monte-Carlo simulation is applied to randomly distribute vehicles based on these probabilities. Using a Monte-Carlo simulation effectively randomizes the constant turning movements used for traffic flow development.

Eight O-D matrices are created at 15 minute intervals for 'cars / light vehicles' and 'medium / heavy vehicles' for every weekday modelled in the study period. Table 3-2 shows a sample O-D matrix generated for cars and light vehicles between 8:15 - 8:30 AM on July 7, 2011. 
Table 3-2 Sample O-D matrix generated at 15 minute interval, July 7, 2011 8:15 - 8:30 AM

\begin{tabular}{|r|r|r|r|r|r|r|r|r|r|r|r|r|r|r|r|r|}
\hline O/D & $\mathbf{1}$ & $\mathbf{2}$ & $\mathbf{3}$ & $\mathbf{4}$ & $\mathbf{5}$ & $\mathbf{6}$ & $\mathbf{7}$ & $\mathbf{8}$ & $\mathbf{9}$ & $\mathbf{1 0}$ & $\mathbf{1 1}$ & $\mathbf{1 2}$ & $\mathbf{1 3}$ & $\mathbf{1 4}$ & $\mathbf{1 5}$ & Total \\
\hline $\mathbf{1}$ & 0 & 3 & 0 & 5 & 0 & 0 & 0 & 56 & 1 & 0 & 27 & 1 & 0 & 0 & 3 & 96 \\
\hline $\mathbf{2}$ & 1 & 0 & 0 & 0 & 0 & 0 & 0 & 21 & 0 & 0 & 5 & 0 & 0 & 0 & 0 & 27 \\
\hline $\mathbf{3}$ & 0 & 0 & 0 & 0 & 18 & 0 & 0 & 0 & 0 & 0 & 0 & 0 & 0 & 0 & 0 & 18 \\
\hline $\mathbf{4}$ & 0 & 0 & 3 & 0 & 11 & 0 & 0 & 15 & 0 & 12 & 170 & 10 & 0 & 0 & 0 & 221 \\
\hline $\mathbf{5}$ & 0 & 0 & 0 & 0 & 0 & 0 & 0 & 0 & 0 & 0 & 0 & 0 & 0 & 0 & 0 & 0 \\
\hline $\mathbf{6}$ & 0 & 0 & 0 & 0 & 0 & 0 & 0 & 0 & 0 & 0 & 2 & 0 & 0 & 0 & 0 & 2 \\
\hline $\mathbf{7}$ & 0 & 0 & 0 & 0 & 0 & 0 & 0 & 0 & 0 & 0 & 0 & 0 & 0 & 0 & 0 & 0 \\
\hline $\mathbf{8}$ & 20 & 1 & 0 & 6 & 0 & 0 & 7 & 0 & 0 & 1 & 21 & 1 & 0 & 0 & 3 & 60 \\
\hline $\mathbf{9}$ & 0 & 0 & 0 & 0 & 0 & 0 & 0 & 0 & 0 & 0 & 0 & 0 & 0 & 0 & 0 & 0 \\
\hline $\mathbf{1 0}$ & 0 & 0 & 0 & 0 & 0 & 0 & 0 & 0 & 0 & 0 & 0 & 0 & 0 & 0 & 0 & 0 \\
\hline $\mathbf{1 1}$ & 20 & 5 & 6 & 101 & 3 & 0 & 0 & 0 & 0 & 9 & 0 & 9 & 0 & 0 & 2 & 155 \\
\hline $\mathbf{1 2}$ & 1 & 0 & 1 & 8 & 0 & 0 & 0 & 0 & 0 & 1 & 0 & 0 & 0 & 0 & 0 & 11 \\
\hline $\mathbf{1 3}$ & 0 & 0 & 0 & 0 & 0 & 0 & 0 & 0 & 0 & 0 & 0 & 0 & 0 & 0 & 0 & 0 \\
\hline $\mathbf{1 4}$ & 1 & 0 & 0 & 0 & 0 & 0 & 0 & 0 & 0 & 0 & 0 & 0 & 0 & 0 & 0 & 1 \\
\hline $\mathbf{1 5}$ & 33 & 8 & 0 & 0 & 0 & 0 & 0 & 1 & 0 & 0 & 0 & 0 & 0 & 0 & 0 & 42 \\
\hline Total & 76 & 17 & 10 & 120 & 32 & 0 & 7 & 93 & 1 & 23 & 225 & 21 & 0 & 0 & 8 & $\mathbf{6 3 3}$ \\
\hline
\end{tabular}

A divisor of 1.71 is used in PARAMICS to factor down the O-D matrix counts because the TDS overestimates traffic. Morning peak period data from the manual traffic count are compared with TDS data for the same day (June 8, 2011) to estimate this divisor value.

\subsubsection{Other Inputs}

PARAMICS is a stochastic model where randomness in the model results is generated using a random seed number. It is necessary to analyse the effect of different random seed inputs in the traffic microsimulation, on the output emission rates obtained from CMEM, the emissions model. Another important consideration is the vehicle type distribution which is necessary to accurately model emissions using a traffic microsimulation model. Both the vehicle type distribution and PARAMICS random seed analysis is described in subsequent chapters once the microscopic emissions model has been introduced.

Other core parameters that affect the microsimulation results are the mean headway between vehicles and the mean driver`s reaction time (Chu, et al., 2004). The mean headway is defined as the average time gap between two vehicles on the network. The mean driver's reaction time is the average time taken by the driver to respond to any 'event' on the network. Both these parameters are indicative of the driver behaviour and can vary temporally and geographically. 
Jansuwan \& Narupiti (2005) suggest that the mean headway ranges from 0.3-1.9 seconds, while Johansson \& Rumar (1971) state that the mean driver's reaction time ranges from 0.3-2.0 seconds. Other acceptable ranges include 0.6-2.2 seconds for mean headway and 0.3-1.9 seconds for mean driver`s reaction time, given by Park \& Qi (2004). A default value of 1.0 second which satisfies all the above ranges is selected for both these parameters. 


\section{Chapter 4}

\section{Emissions Modelling: Method}

\subsection{Emission Modelling Review}

Traffic emission models estimate emission factors on roadway links of a traffic network, based on attributes such as vehicular fleet composition, volume of traffic flow, vehicle operating characteristics (speed profile), and geographic terrain of the study network. Aggregate emission factor models generally calculate the average speed on each link, and use a specific vehicle type distribution, to estimate emission rates on roadway links. Emission rates for specific vehicle type, age, and speed are usually based on a sample of driving cycles that have been pre-tested in the laboratory. Other factors that may be included are driving load, air conditioner operation, and vehicle operation state. Total emission for any pollutant is then estimated by multiplying the emission rate with vehicle trip characteristics such as distance travelled, time taken, and trip count. Microscopic emission models correlate emission output and fuel consumption with independent instantaneous variables that describe vehicle operation at a fine scale. It is well established in the literature that emission models that account for variations in instantaneous vehicular speed provide more accurate results than models that cannot do so (Ahn \& Rakha, 2008) (Moulvi, 2010).

Average speed models such as MOBILE (Environmental Protection Agency, 2012), and EMFAC (California Environmental Protection Agency, 2010), cannot operate at a microscale. Newer emission models such as Comprehensive Modal Emission Model (CMEM) (Barth, et al., 1999) (Barth, et al., 2001), VT Micro (Rakha, et al., 2004), and Motor Vehicle Simulator (MOVES) (Environmental Protection Agency, 2012) are microscopic in nature, and can provide second-by-second / disaggregate emission rates for a given roadway link based on vehicle driving cycles. Driving cycle of a vehicle can be defined as a disaggregate characterisation of the speed-time profile of a vehicle, that explains detailed vehicular motion based on idling, acceleration, deceleration, and cruising activity of the vehicle. COPERT 4 is another emissions model that has been widely employed in Europe for evaluating technological and legislative decisions (EMISIA, 2011). MOVES has replaced the MOBILE6 as the new regulatory emission 
model for the US EPA, indicating an increasing interest in microsimulation of emissions from vehicles.

Bai et al. (2009) compared MOVES-HVI demo (an earlier version of MOVES with macroscopic modelling abilities) with EMFAC for carbon dioxide and methane emissions in Los Angeles, California, and concluded that MOVES represented a 'major modelling improvement' in terms of comprehensive emissions estimation; they also stressed the need for good quality local data to develop a good modelling system. Rakha, et al. (2003) compared the MOBILE 5a / 6 series models with VT-MICRO / CMEM version 2.0, using data from Oak Ridge National Laboratory and EPA for light duty gasoline vehicles. They concluded that MOBILE5a performed poorly, MOBILE6 generally had good consistency with VT-Micro results, while CMEM showed certain abnormalities in estimating $\mathrm{NO}_{\mathrm{x}}$ at high engine loads, and $\mathrm{CO}$ at low speed and high acceleration levels. Recently, Vallamsundar \& Lin (2011) compared the performance of MOVES and MOBILE for $\mathrm{NO}_{\mathrm{x}}$ and $\mathrm{CO}_{2}$ in Cook County, Illinois, and concluded that MOVES could significantly affect emission estimates at regional and project level; the paper also stressed the importance of obtaining accurate local data for making best use of the MOVES methodology. Moulvi (2010) investigated the impact of driver behaviour on exhaust emissions and demonstrated unreliability of estimates obtained using average speed calculations. The paper emphasized CMEM accuracy and showed that it is more sensitive to changes than MOVES for $\mathrm{CO}_{2}$ emissions.

Microscopic emission models can truly exploit the benefit of using a traffic microsimulation model in order to estimate a more accurate emission rate on roadway links. Evidently, average speed models are rejected for analysis of emissions in this study.

\subsection{Model Selection}

Several studies have investigated traffic emissions using microscopic traffic modelling. Chen \& Yu (2007), Nam, et al. (2003), Noland \& Quddus (2006), and Stathopoulos \& Noland (2003) used a combination of VISSIM and CMEM to evaluate emissions. The combination of PARAMICS and CMEM has also been employed in the past by Brownstone, et al. (2008) and Amirjamshidi, et al. (2012) to evaluate policy scenarios from a traffic emissions perspective. More recently, Xie, et al. (2012) used the combination of PARAMICS and MOVES to analyse impact of alternative fuel use on overall fuel reduction in Greenville, South Carolina. Both 
MOVES and CMEM represent state-of-the-art emission modelling approaches and are considered for this study. MOVES contains vehicle type distribution data for the United States, however, local Canadian fleet attributes are currently not incorporated. CMEM contains a plugin that can be integrated with PARAMICS and executed simultaneously along with the traffic microsimulation runs. The combination of PARAMICS and CMEM thus provides a robust and structured method to apply microsimulation to estimate emission rates on the roadway network; hence CMEM is selected for application in this project.

\subsubsection{Comprehensive Modal Emissions Model (CMEM)}

CMEM was developed at the University of California, Riverside. It employs a power-demand modelling approach based on mathematical representation of emission production in the vehicle engine. All emission generating physical processes associated with the vehicle operation are broken down into different stages with several different parameters characterising the nature of these processes. These parameters can be roughly classified into engine attributes (vehicle specification / engine characteristics) and vehicle operating variables (state of the vehicle and its components during operation). Vehicular operation is in turn affected by the geometric layout and grade of the roadway. CMEM can provide $\mathrm{CO}_{2}, \mathrm{CO}, \mathrm{NO}_{\mathrm{x}}, \mathrm{HC}$ (hydrocarbons) and fuel use estimates for each roadway link on the network. The current CMEM version 3.0 developed in 2005 does not include Particulate Matter (PM) emission estimation, and in spite of their import in urban air pollution, PM emissions are not evaluated in this research. CMEM currently comprises 28 light duty vehicles and 3 heavy duty vehicles. Further details on the model can be obtained from Barth, et al. (1999), Barth, et al. (2001) and Scora \& Barth (2006).

\subsection{Vehicle Type Distribution}

The vehicle type distribution is based on data obtained from Amirjamshidi, et al. (2012) who used the Canadian Vehicle Survey from Statistics Canada (2009), to predict a best estimate of the vehicle composition in Toronto. Malcolm, et al. (2003) concluded that in addition to use of average driving speeds for estimating traffic emissions, the average regional vehicle type distribution could also add to inaccuracies in emission estimates. Therefore, it is important to take the spatial variability of the vehicle type distribution into account. 
The vehicle type distribution obtained from Amirjamshidi, et al. (2012) is augmented with City of Toronto cordon count data (Data Management Group, 2004). Count data obtained for College Street west of Spadina Avenue for the time period between 7:00 - 9:00 AM are used. This location is closest to the study area where cordon count data are available. The data provide a distribution of vehicles into passenger cars (auto), light, medium and heavy duty trucks. Based on this data, a best estimate of the vehicle type distribution is developed as shown in Table 4-1. In reality, the vehicle type distribution varies by time of day and also between different modelling days. Since it is practically impossible to capture this variation, the distribution is assumed to be constant for the study period. The total traffic volume on the network is distributed into two O-D matrices (based on vehicle type) that are input into PARAMICS. One matrix consists of cars and light vehicles, while the other consists of medium and heavy vehicles. The CMEM vehicle types are then assigned to the two matrices based on the vehicle type distribution. The PARAMICS and CMEM model combination is run for the morning peak period between 7:00 - 9:00 AM for all selected weekdays in June and July 2011. Eight O-D matrices are input at 15 minute intervals for the 2 hour simulation period. The CMEM emission rate outputs are averaged at 15 minute intervals. Figure 4-1 shows a general process flowchart presenting the integration of PARAMICS and CMEM.

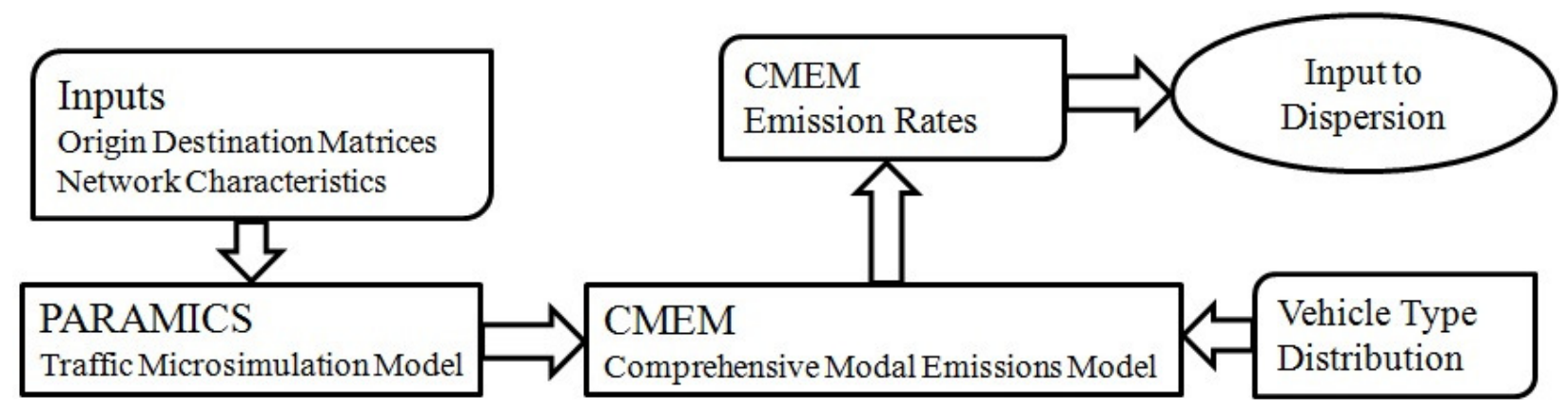

Figure 4-1 Process flowchart: Integration of PARAMICS and CMEM

\subsection{Emission Output Processing}

CMEM generates two output files - a vehicle activity summary and an emissions summary. The activity summary contains a list of average velocities and accelerations for all links on the network. It also provides link lengths and total distance travelled by vehicles on that particular link. The emissions summary file contains cumulative emissions generated for $\mathrm{CO}_{2}, \mathrm{CO}, \mathrm{HC}$, $\mathrm{NO}_{\mathrm{x}}$ and fuel usage for each 15 minute period in the 2 hour simulation period. The CMEM output 
data are processed for developing inputs to the dispersion models. This is covered in the following chapter once the dispersion modelling methodologies have been introduced.

Table 4-1 Vehicle Type Dist. (Amirjamshidi, et al., 2012) (Data Management Group, 2004) MEDIUM AND HEAVY VEHICLES MATRIX

\begin{tabular}{|c|l|c|}
\hline CMEM Category & Description & Proportion \\
\hline $\mathbf{2 5}$ & Truck, Gasoline powered, LDT $(>8500 \mathrm{GVW})$ & $10.02 \%$ \\
\hline $\mathbf{4 0}$ & Truck, Diesel powered, LDT $(>8500 \mathrm{GVW})$ & $66.45 \%$ \\
\hline $\mathbf{5}$ & HDD 1994-1997, 4 stroke engine, Electric, FI, Normal emitting & $4.80 \%$ \\
\hline $\mathbf{6}$ & HDD 1998, 4 stroke engine, Electric, FI, Normal emitting & $1.11 \%$ \\
\hline $\mathbf{7}$ & HDD 1999-2002, 4 stroke engine, Electric, FI, Normal emitting & $17.62 \%$ \\
\hline
\end{tabular}

\section{CAR AND LIGHT VEHICLES MATRIX}

\begin{tabular}{|c|l|c|}
\hline CMEM Category & Description & Proportion \\
\hline $\mathbf{8}$ & Tier 1, $>50 \mathrm{~K}$ mi, Low P/W ratio & \\
\hline $\mathbf{9}$ & Tier 1, $>50 \mathrm{~K}$ mi, High P/W ratio & $37.97 \%$ \\
\hline $\mathbf{1 9}$ & Runs Lean & $37.53 \%$ \\
\hline $\mathbf{2 0}$ & Runs Rich & $0.50 \%$ \\
\hline $\mathbf{2 1}$ & Misfire & $0.50 \%$ \\
\hline $\mathbf{2 2}$ & Bad Catalyst & $0.80 \%$ \\
\hline $\mathbf{1 6}$ & $1988-1993,>3750$ LVW & $0.50 \%$ \\
\hline $\mathbf{1 7}$ & Tier 1 LDT2/3 (3751-5750 LVW or Alt LVW) & $0.56 \%$ \\
\hline $\mathbf{4}$ & 3 way catalyst, FI, $>50 \mathrm{~K}$ mi, Low P/W ratio & $1.84 \%$ \\
\hline $\mathbf{5}$ & 3 way catalyst, FI, $>50 \mathrm{~K}$ mi, High P/W ratio & $2.69 \%$ \\
\hline $\mathbf{1 0}$ & Tier 1, $<50 \mathrm{~K}$ mi, Low P/W ratio & $10.67 \%$ \\
\hline $\mathbf{1 1}$ & Tier 1, $<50 \mathrm{~K}$ mi, High P/W ratio & $6.83 \%$ \\
\hline $\mathbf{2 6}$ & Ultra Low Emissions Vehicle & $27.31 \%$ \\
\hline & & $0.29 \%$ \\
\hline
\end{tabular}




\section{Chapter 5}

\section{Pollutant Dispersion Modelling: Method}

\subsection{Dispersion Modelling and Meteorology}

Dispersion models simulate the movement of pollutants in air by replicating physical atmospheric phenomenon, with an objective to estimate emission concentrations in a given region. Dispersion of anthropogenic air pollution occurs in the planetary boundary layer (PBL), which forms the lowest part of the troposphere that is in direct contact with the earth's surface. It is imperative to understand atmospheric characteristics in order to comprehend dispersion models and their application.

Moussiopoulos, et al. (2003) characterised nine levels of atmospheric system scales and described how pollutant modelling is primarily based on scale segmentation, as opposed to integration of several scales for a single modelling method. Tiwary \& Colls (2010) classified dispersion models on the scale of their application as macroscale (1000 kilometres/days), mesoscale (10-100 kilometres/hours), and microscale (<1 kilometre/minutes) models; Zannetti (1990) classified the different transport scales of air pollution as near-field $(<1 \mathrm{~km})$, short-range $(<10 \mathrm{~km})$, intermediate transport $(10-100 \mathrm{~km})$, long-range $(>100 \mathrm{~km})$, and global effects. Different factors affect dispersion depending on the scale of the dispersion modelling process. Macroscale dispersion is affected by general circulation of winds, upper level flows, jet streams, and other general synoptic weather systems (for example, air masses, fronts, cyclones, anticyclones, polar lows); mesoscale dispersion is affected by thermally induced circulations, sea and land breezes, monsoon circulation, urban heat island effect, and mountain/valley effects; microscale systems are affected by characteristics of the internal boundary layer and obstacle wakes (Arya, 1999). Wind flow, which is an important dispersion factor, can be mechanically generated or turbulence associated; the latter being dependent on atmospheric stability. Horizontal winds are primarily responsible for advection or transport of pollutants, while turbulence helps in dispersion or dilution of the pollutants.

The PBL can be divided into the surface layer (which includes the surface roughness layer) and the outer layer. The turbulent (sensible heat / latent heat of evaporation or condensation) and 
radiative exchange of energy between the earth's surface plays an important role in the thermal stratification of the lowest layer of the PBL, which is the surface layer. The net radiation received during the day is positive, and therefore, heat is radiated outwards from the earth's surface, developing a temperature profile decreasing with height such that the highest temperature occurs closest to the surface. During night-time, the net radiation is negative so that the earth's surface absorbs heat from the lowest layers of the atmosphere. This reverses the temperature profile such that temperature increases with height, and the lowest temperature occurs closest to the surface. Thus, usually day time is a case of active mixing, while night time is a quiet period with suppressed vertical movement in the atmosphere.

The dry adiabatic lapse rate is defined as the rate of decrease in temperature with altitude for a parcel of dry air rising under adiabatic conditions. This rate is $\sim 1$ degree decrease per kilometre increase in height. When the actual rate of decrease of temperature is greater than this value, then the surface layer is generally unstable; if it is smaller than this value, then the surface layer is generally stable. Three widely used methods to classify atmospheric stability are empirical relationships developed by Pasquill (1974), the Richardson numbers (Businger, 1966) (Pandolfo, 1966), and the Monin-Obukhov (M-O) length parameter (Monin \& Obukhov, 1954). These parameters in turn derive values from other atmospheric variables such as the surface heat flux, temperature, pressure, and specific humidity.

A diurnal cycle of meteorology, as described above, results in a daily inversion during night time which results in a stable surface layer where dispersion is restricted and higher concentrations of pollutants are likely. Such a layer is called the Stable Boundary Layer (SBL) where mechanical turbulence dominates. In the morning, as the earth's surface starts radiating heat back into the atmosphere, the stable surface erodes, and an unstable layer is formed, which eventually replaces the stable layer formed during the night. This layer is called the Convective Boundary Layer $(\mathrm{CBL})$, where convective turbulence plays a dominating role in dispersion. During the evening, net radiation of heat again becomes negative, thereby generating a stable surface layer and thus the cycle continues. The depth to which any surface layer exerts influence on dispersion in the PBL is known as the mixing height, which is an important parameter in characterising the state of atmosphere for dispersion modelling. 
Dispersion models can be classified on the basis of several different characteristics. Zannetti (1990) classified dispersion models as Gaussian, Eulerian and Lagrangian models. Khare \& Sharma (2002) classified models on the basis of their size, time horizon, and pollutants. They further described three modelling approaches, namely, deterministic mathematical, statistical, and physical modelling. A large number of dispersion models developed in the past have focused on deterministic mathematical modelling which consists of analytical models (Gaussian plume / Puff formulations) and numerical models (Lagrangian and Eulerian approaches). These models usually incorporate several empirical relationships that have been developed using physical modelling. Holmes \& Morawska (2006) classified dispersion models into Box models, Gaussian models, Lagrangian / Eulerian models, Computational Fluid Dynamics (CFD) models, and models that include Aerosol Dynamics; depending on the features of application, they also performed a detailed review of several software packages that are employed in the field.

Physical modelling involves developing 3-dimensional scaled down models of a life sized study area, and evaluating wind flow patterns in order to develop empirical relationships that are coded into analytical and numerical dispersion models. Statistical approaches apply regression and principal component analyses to develop statistical models that can generate concentration patterns based on certain input parameters.

All mathematical dispersion models can essentially be classified into Eulerian or Lagrangian models. Eulerian models investigate and observe processes at fixed points in space with the frame of reference either stationary or moving. The Lagrangian approach is to track the movement of pollutant particles in a 3-dimensional grid, subject to stochastic movement of every individual particle. Generally, such models require the specification of a mean wind component and a turbulent wind component that may be estimated using randomly generated numbers. CFD models analyse dispersion in terms of fluid flow by using the Navier-Stokes equation which describes the motion of pollutants as fluids. Box models are simplistic dispersion models that are based on the principle of conservation of mass within a box; the concentrations are calculated assuming that the pollutants are homogenously distributed inside the box. Gaussian models are popular dispersion models that use the Gaussian plume distribution equation, either in a simple form, or with a complex formulation (such as the Gaussian puff model) to disperse pollutants, and estimate concentrations at fixed receptor locations throughout the network. Gaussian based models are essentially Eulerian in their approach. 


\subsubsection{Dispersion Modelling Review and Model Selection}

Most commonly used models for near field pollutant analyses in North America include AERMOD, CAL3QHCR, and CALINE 3/4 which are all Gaussian models. A comparative review of EPA preferred dispersion models has been performed by Jungers, et al. (2006). The CALINE models were developed by Caltrans (California Department of Transportation) and have been extensively used in California to analyse traffic emissions. CAL3QHCR is based on the same line source formulation employed in CALINE3, with additional equations for queuing and estimating concentrations at roadway intersections better. CALINE3 can only handle 20 links and 20 sources at a time while CAL3QHCR can only handle 120 roadway links. Both these models are known to perform poorly in low wind conditions, and cannot explicitly model the presence of buildings around the intersection. HIWAY2 is another line source Gaussian model that has been used by EPA in the past to evaluate highway emissions. However, it cannot simulate complex terrain and obstacles similar to CALINE.

HYROAD is an EPA model with 'Alternative' status that integrates three modules (micro-scale traffic simulation, emission, and pollutant dispersion) for estimating $\mathrm{CO}$ emissions up to 500 metres from traffic intersections (Carr, et al., 2002). Two commonly used dispersion models in Europe include the Atmospheric Dispersion Modelling System (ADMS) Series developed by Cambridge Environmental Research Consultants (CERC, 2010), and the Operational Street Pollution Model (OSPM) developed in Denmark (Berkowicz, et al., 1997). The former is a 'new generation' Gaussian plume model while the latter combines the Gaussian formulation with the Box modelling approach to estimate concentrations in street canyons. The ADMS-3 is also listed as an 'Alternative' under the EPA's list of dispersion models. A review of most commonly used operational models applied for dispersion on traffic intersections can be found in Tiwary, et al. (2011).

EPA's main regulatory models are AERMOD and CALPUFF. AERMOD is a steady state Gaussian plume dispersion model which is currently the EPA regulatory model for near field dispersion (Environmental Protection Agency, 2012). It has significant modelling capacity for stationary sources; for mobile source emissions, the unwieldy nature of using AERMOD has been recognized by Jungers, et al. (2006). CALPUFF is the EPA regulatory model for far field dispersion. It is a non-steady state model that is time sensitive to concentrations as opposed to 
AERMOD which is a steady state model. The application of CALPUFF for near field analysis is prone to error (Brode \& Anderson, 2008) and it is not considered for application in this study.

Several studies have used Gaussian models to evaluate traffic emissions in the past. Batterman, et al. (2010) analysed near road concentrations using a reduced form emission / dispersion model based on MOBILE6.2 and CALINE4 for $\mathrm{CO}$ and $\mathrm{PM}_{2.5}$ predictions, and obtained reasonable agreement with observed emissions for a freeway and a traffic intersection. Marmur \& Mamane (2003) evaluated the performance of HIWAY2 and CALINE4 for $\mathrm{NO}_{\mathrm{x}}$ concentrations on a highway, and found that both models had similar predictions for at-grade road sections. Vaitiekunas \& Banaityte (2007) used AERMOD to assess traffic related emissions on a mesoscale; the emission rates input into the dispersion model were based on aggregate average values for fleet distribution and traffic flow. Zou, et al. (2009) analysed population exposure to $\mathrm{SO}_{2}$ using AERMOD for a combination of vehicular and industrial sources in Dallas. Kesarkar, et al. (2007) integrated AERMOD with a weather forecasting model to estimate $\mathrm{PM}_{10}$ emissions for a 25 square kilometre area in Pune, India; these $\mathrm{PM}_{10}$ emissions came from a wide variety of sources including vehicular exhaust, industrial operations et cetera, that were estimated using certain emission inventories. Singh, et al. (2006) evaluated the performance of AERMOD and CALINE for fine PM emissions; generally, AERMOD seemed to estimate higher emission concentrations compared to CALINE. Chen, et al. (2009) compared the performance of CALINE4, CAL3QHC and AERMOD and concluded that even though AERMOD could better simulate atmospheric processes, CALINE4 and CAL3QHC might be better when detailed meteorological data-sets (as required in AERMOD) are not available.

Lagrangian models are becoming more popular for dispersion analysis as advancement in computing technologies has reduced computational times considerably. The Quick Urban and Industrial Complex (QUIC) dispersion model is a fast response Lagrangian particle dispersion model that has been developed by Los Alamos National Laboratory (2010) to compute concentrations of pollutants in a short span of time. QUIC has been used for analysis of ultrafine particles in urban / semi-urban areas by Zwack, et al. (2011) and Bowker, et al. (2007); Fernando, et al. (2010) analysed $\mathrm{PM}_{10}$ emissions in urban areas using QUIC. However, in spite of tremendous potential to simulate micro-scale dispersion of traffic related gaseous pollutants in urban areas, no current studies that apply QUIC for such analyses are known to the author. Other 
Lagrangian models such as GRAL have been employed in the past, for example, in Oettl, et al. (2001), to analyse roadway concentrations.

Some of the most commonly applied dispersion models were introduced in this section. The reader should refer to Holmes \& Morawska (2006) for a detailed review and an all encompassing classification of various dispersion software packages available throughout the world. A brief summary of models evaluated for this research is shown in Table 5-1. (California DoT, 1989) (Environmental Protection Agency, 1995) (Berkowicz, et al., 1997) (Environmental Protection Agency, 2004) (Los Alamos National Laboratory, 2010).

Table 5-1 Brief Review of Dispersion Models Evaluated

\begin{tabular}{|c|c|c|c|c|}
\hline $\begin{array}{l}\text { DISPERSION } \\
\text { MODEL }\end{array}$ & $\begin{array}{l}\text { Gaussian Plume Models } \\
\text { (CALINE4, CAL3QHCR) }\end{array}$ & $\begin{array}{l}\text { Gaussian Plume Models } \\
\text { AERMOD/AERMET }\end{array}$ & $\begin{array}{l}\text { Gaussian Plume and } \\
\text { Box - OSPM }\end{array}$ & $\begin{array}{l}\text { Lagrangian Dispersion } \\
\text { Modelling QUIC }\end{array}$ \\
\hline Description & $\begin{array}{l}\text { Steady State Gaussian } \\
\text { Plume }\end{array}$ & $\begin{array}{l}\text { Steady state Gaussian } \\
\text { Plume. AERMET } \\
\text { meteorological pre- } \\
\text { processor ; AERMAP - } \\
\text { terrain and receptor data; } \\
\text { AERMOD - Conc. Est. }\end{array}$ & $\begin{array}{l}\text { Street canyon model; } \\
\text { Gaussian Plume } \\
\text { (Direct distribution)+ } \\
\text { Box Model (Re- } \\
\text { circulating and } \\
\text { background conc.) }\end{array}$ & $\begin{array}{l}\text { Rockle Wind Model - } \\
\text { Mean Wind Field } \\
\text { (QUIC-URB), Langevin } \\
\text { Walk Equations for } \\
\text { Turbulence (QUIC } \\
\text { PLUME) }\end{array}$ \\
\hline Scale & Local & Local, Regional & Local & Local/Regional \\
\hline Pollutants & $\begin{array}{l}\text { CALINE4 - } \mathrm{NO}_{2} \mathrm{CO} \text { TSP; } \\
\text { CAL3QHCR - CO PM NO}{ }_{\mathrm{x}}\end{array}$ & Gases / Particles & $\begin{array}{l}\mathrm{NO}_{\mathrm{x}}, \mathrm{NO}_{2}, \mathrm{O}_{3}, \mathrm{CO}, \\
\mathrm{PM}\end{array}$ & Gases / Particles \\
\hline Source Type & Line & Point, Area, Volume & Line & $\begin{array}{l}\text { Point, Line, Area, } \\
\text { Volume }\end{array}$ \\
\hline Output Freq. & $1 \mathrm{~h}$ & $1 \mathrm{~h}$ & $1 \mathrm{~h}$ & Seconds-Hours \\
\hline Building Effects & No & Yes (Limited) & Yes (Simple) & Yes (Complex) \\
\hline
\end{tabular}

Air quality impacts due to vehicular emissions have been investigated at the local, regional, and global scales extensively. However, very few studies have attempted to apply an integrated micro-modelling framework as proposed in this research, to microsimulate traffic, use microscopic emissions modelling to estimate emission rates on roadway links, and use a microsimulating dispersion model to estimate pollutant concentrations at a local level. The intent of this research is to maintain a consistent level of detail throughout the framework, such that 
none of the methodologies (traffic microsimulation, emission, and dispersion) are extensively compromised.

AERMOD and QUIC are selected for dispersion analysis in this research with two main objectives. The first is to apply a Lagrangian microscale dispersion model (QUIC), to estimate traffic emissions, and secondly, to compare results with the best available near field Gaussian dispersion model (AERMOD). AERMOD is considered an aggregate model here, since, like most other Gaussian dispersion models, it can only provide hourly resolution of concentrations, hence, would serve to average out the effect of traffic microsimulation at 15 minute intervals. AERMOD View, a software package that provides a Graphic User Interface developed by Lakes Environmental (2012) is used to perform all AERMOD related analysis. The following sections describe the dispersion models adopted in further detail and discuss the input data preparation method.

\subsection{AERMOD}

AERMOD is a steady state Gaussian plume model that uses a meteorological pre-processor called AERMET to characterise the atmospheric conditions in the PBL, and a terrain preprocessor called AERMAP to characterize terrain elevation and prepare source / receptor heights for pollutant dispersion. Gaussian models assume that pollutants originating from a plume travel in the downstream wind direction simultaneously dispersing in the vertical and horizontal directions following a Gaussian or a Normal Distribution. This distribution depends on the horizontal wind speed / direction (responsible for transport of pollutants) and turbulence (responsible for dilution in the atmosphere).

AERMET calculates several PBL parameters (for the CBL and SBL) such as friction velocity $(\mathrm{u} *)$, Monin-Obukhov (M-O) length (an atmospheric stability parameter, L), convective velocity scale (an indicator of convective turbulence in the $\mathrm{CBL}, \mathrm{W} *$ ), temperature scale $(\theta *$ ), mixing height (the maximum height in which dispersion occurs, $\mathrm{z}_{\mathrm{i}}$ ), and surface heat flux (an indicator of incoming / outgoing radiation from the earth's surface, $\mathrm{H}$ ). The inputs into AERMET are albedo (a radiation reflection coefficient), surface roughness, wind speed, wind direction, temperature, and cloud cover. 
AERMOD subsequently applies the AERMET estimated parameters to generate vertical profiles for wind speed $(\mathrm{u})$, wind direction, turbulent fluctuations in the vertical and lateral directions $\left(\sigma_{\mathrm{v}}\right.$, $\left.\sigma_{\mathrm{w}}\right)$, and potential temperature gradient $(\mathrm{d} \theta / \mathrm{dz})$, using measured data and similarity relationships. AERMAP requires formatted Digital Elevation Model (DEM) terrain data and the receptor grid location in order to process the elevation data. It provides AERMOD with source / receptor heights and terrain elevation data. AERMOD also incorporates some effects of surrounding buildings on wind flow by calculating building downwash using the Building Profile Input Program (BPIP); in effect, this restricts the ascent of pollutants in building wake regions. Finally, based on the outputs of AERMAP and BPIP, using vertical profiles for atmospheric parameters, AERMOD estimates concentrations at receptor locations for the specified emission sources using the Gaussian distribution formulation. Specifically, AERMOD uses a Gaussian distribution in vertical and horizontal directions in the SBL. In the CBL, it uses a Gaussian distribution in horizontal and a bi-Gaussian probability density function in the vertical direction. A sample equation used to estimate concentrations in a stable boundary layer (SBL) is:

$$
\begin{gathered}
C_{s}\left(x_{r}, y_{r}, z\right)=\frac{Q}{\sqrt{2 \pi} u \sigma_{z s}} F_{y} \sum_{m=-\infty}^{\infty}\left[\exp \left(-\frac{\left(z-h_{e s}-2 m z_{i e f f}\right)^{2}}{2 \sigma_{z s}^{2}}\right)+\exp \left(-\frac{\left(z+h_{e s}+2 m z_{i e f f}\right)^{2}}{2 \sigma_{z s}^{2}}\right)\right] \\
F_{y}=\frac{1}{\sqrt{2 \pi} \sigma_{y}} \exp \left(-\frac{y^{2}}{2 \sigma_{y}^{2}}\right)
\end{gathered}
$$

Where,

$\mathrm{C}_{\mathrm{s}}$ : Concentration

Q: Source strength

$\mathrm{z}$ : Receptor height

y: Lateral distance

$\mathrm{F}_{\mathrm{y}}$ : Lateral distribution function

$\mathrm{Z}_{\text {ieff }}$ : Effective mechanical mixing layer depth

$\sigma_{\mathrm{zs}}$ : Vertical dispersion coefficient

$\sigma_{\mathrm{y}}:$ Lateral dispersion coefficient

u: Wind speed

$h_{\text {es }}$ : Plume height (which includes source height + buoyant plume rise) 
The complete model formulation including algorithms, equations and full set of assumptions can be reviewed in Cimorelli, et al. (2004) and Environmental Protection Agency (2004). Figure 5-1 shows a process flowchart indicating the flow of data in AERMOD.

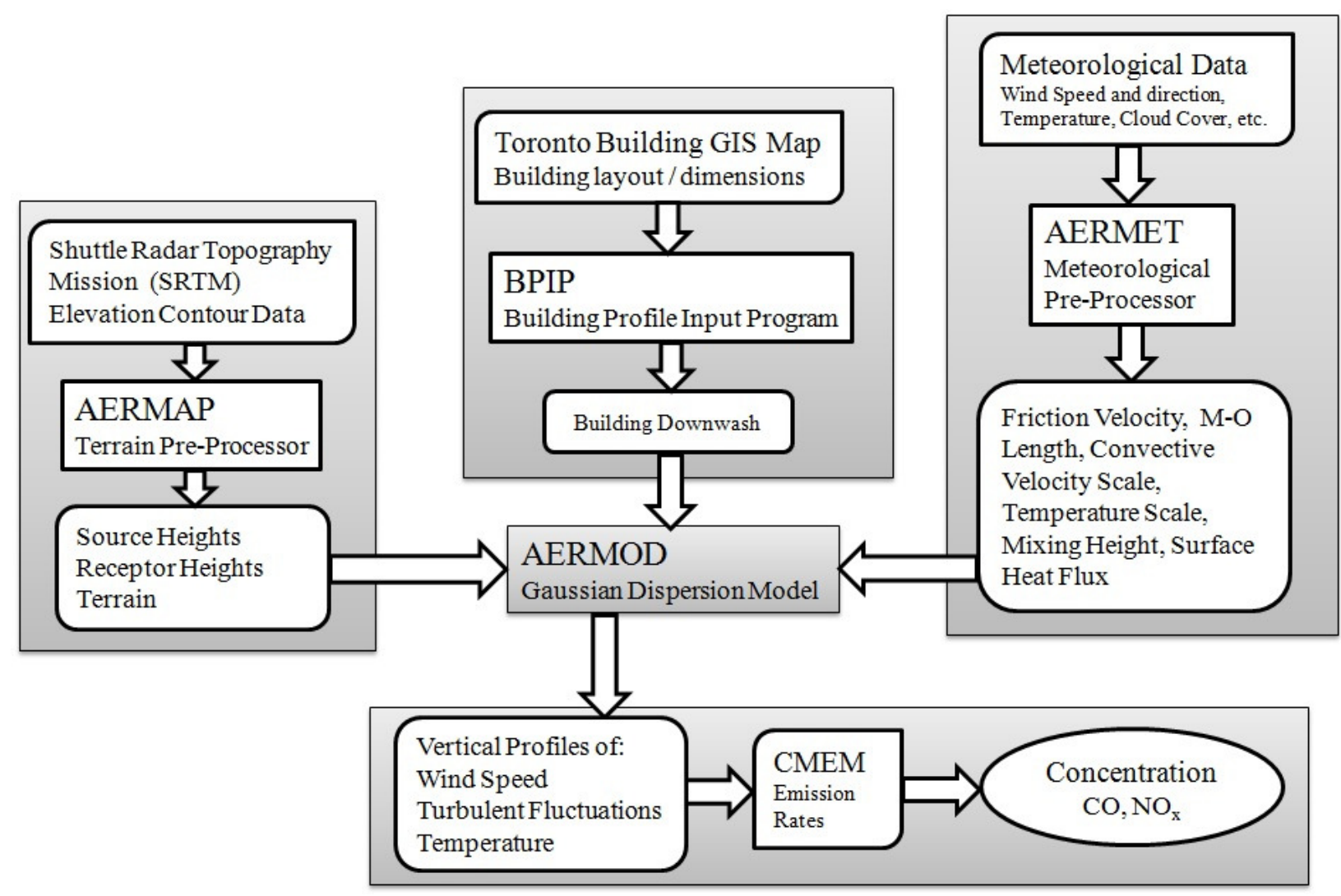

Figure 5-1 Process Flowchart: AERMOD Methodology

\subsection{Quick Urban and Industrial Complex (QUIC)}

QUIC is a fast response Lagrangian particle dispersion model that simulates the movement of pollutant particles by tracking their motion through a 3-dimensional gridded space (comprising several grid cells), under the effect of wind. QUIC version 5.8 is used for modelling purpose. It comprises two key modules - QUIC-URB and QUIC-PLUME.

QUIC-URB is a 3-dimensional wind generator that uses the Rockle (1990) formulation to simulate mean wind flow in a complex building environment. It combines building flow parameterizations and a consistent mass flow equation to obtain a time averaged wind flow for the entire network. The inputs into QUIC-URB include wind speed, wind direction, and building 
environment of the study area. The building environment can be developed using the City Builder Tool. QUIC-PLUME describes the positions of particles using the following equation:

$$
\begin{gathered}
x=x_{p}+U \Delta t+\frac{\left(u_{p}^{\prime}+u^{\prime}\right) \Delta t}{2} \\
u^{\prime}=u_{p}^{\prime}+d u
\end{gathered}
$$

Where,

$\mathrm{x}$ : $\mathrm{x}$-coordinate of particle

p: Subscript for previous position

U: Mean wind speed

u': Fluctuating component of instantaneous wind

$\Delta \mathrm{t}$ : Time step to update particle positions and grid velocities

du: Small turbulent component of velocity

Similar equations can be formulated for y / z coordinates and the corresponding velocities. 'du' is estimated using a random walk model that uses surface layer parameterization of atmospheric parameters, and the random number generator, RAN2. QUIC also incorporates turbulence associated with walls and rooftops. Other inputs into QUIC-PLUME include the inverse M-O length, temperature, surface pressure, vertical temperature profile, and relative humidity, to characterize the atmospheric conditions in PBL. Inputting a strong negative value of the inverse M-O length (indicative of unstable atmosphere) enhances turbulence within QUIC. Using the instantaneous wind comprising mean wind flow and turbulence, the model traces movement of individual particles released in the modelling domain. Based on the atmospheric input parameters, wind flow, and input emission rates, concentration contours are estimated in prespecified 'collecting boxes' in the domain. Concentration is calculated by counting the number of particles present in a given grid cell for a specific averaging time period. The equation to estimate concentrations is:

$$
\chi_{i, j, k}=\sum \frac{Q \Delta t_{c}}{n_{t o t} d x_{b} d y_{b} d z_{b} t_{a v e}}
$$

Where,

$\mathrm{X}_{\mathrm{i}, \mathrm{j}, \mathrm{k}}$ : Concentration

Q: Source strength

$\mathrm{dx}_{\mathrm{b}}, \mathrm{dy}_{\mathrm{b}}, \mathrm{dz}_{\mathrm{b}}$ : Sampling box size in $\mathrm{x}, \mathrm{y}$ and $\mathrm{z}$ direction 
$\mathrm{n}_{\text {tot }}:$ Total particles released during simulation

$\mathrm{t}_{\mathrm{ave}}$ : Sampling time

$\Delta \mathrm{t}_{\mathrm{c}}$ : Time between particle collection for concentration estimation

Further details on the QUIC model can be found in Williams, et al. (2004) and Pardyjak \& Brown (2007). Figure 5-2 shows the QUIC methodology.

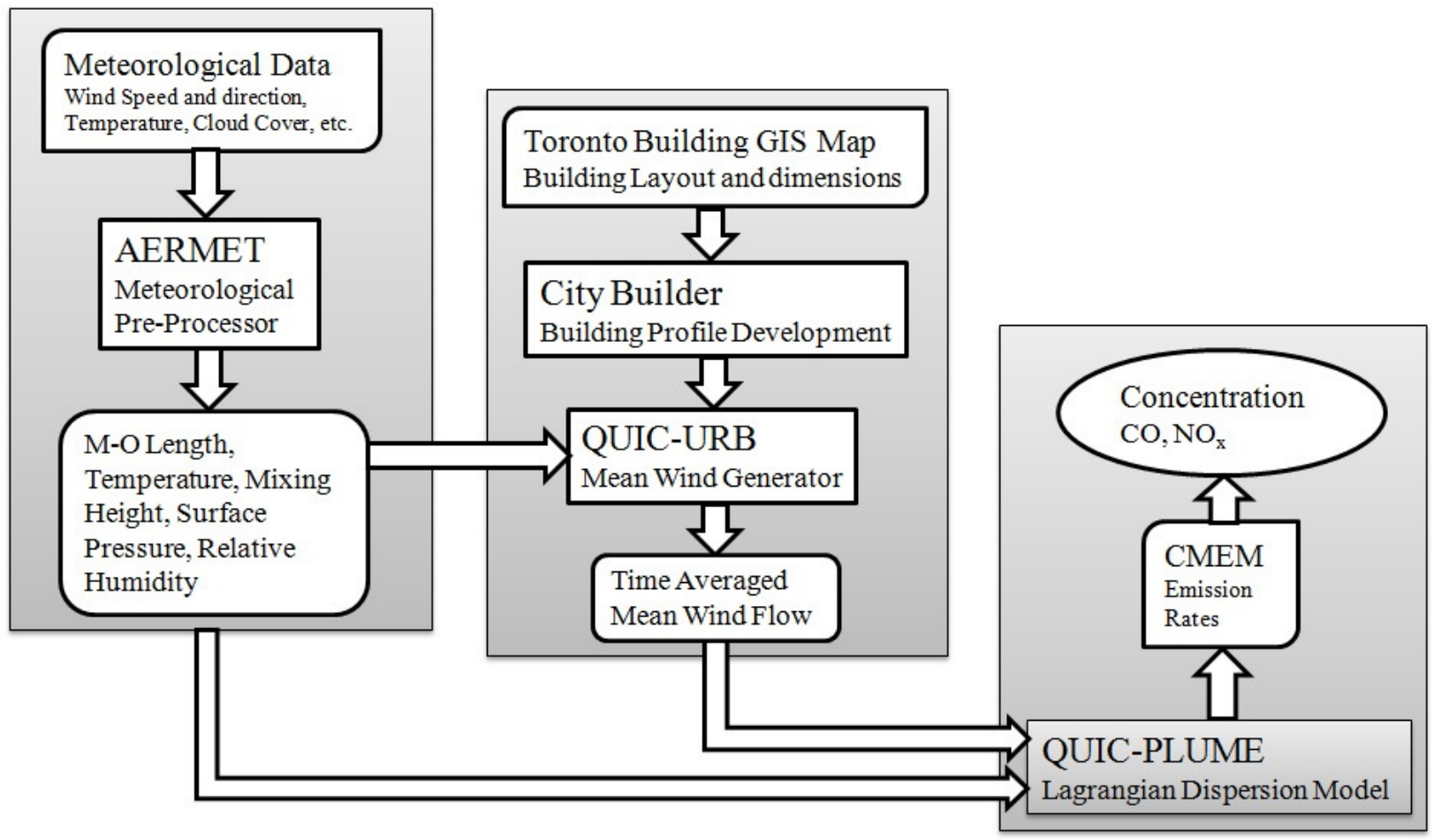

Figure 5-2 Process Flowchart: QUIC Methodology

\subsection{Dispersion Modelling Inputs: Data Processing}

The following section discusses the data inputs prepared to perform model runs using AERMOD and QUIC dispersion models.

\subsubsection{AERMOD Inputs}

\subsubsection{Emission Sources}

For traffic pollutants, roadway links are assumed to be line emission sources. Generally, roadway emission sources are modelled as a series of volume or area sources where the road is distributed into reasonably spaced volumes or areas. However, in this study, roadway links are modelled as 
a series of point sources since building downwash effects can only be estimated for point sources in AERMOD. CMEM provides emission rates for 146 links on the study network at 15 minute intervals for each day modelled. These link sources are distributed into 200 point sources on the network with an average spacing of $\sim 15$ metres. Separate point sources are created for northbound, southbound, eastbound, and westbound lanes for all roads on the network. The level of disaggregation of roadway links into point sources is limited by the building downwash computing time of the BPIP model.

CMEM outputs provide cumulative emission in grams for each link at 15 minute intervals for the 2 hour modelling period on any given day. Source emission rates are calculated by first calculating the emission rate for each 15 minute period and then aggregating these values to an hourly average (since AERMOD can only receive hourly aggregated inputs). Finally, these hourly aggregated emission rates are distributed amongst the point sources. All point sources are located at a height of 1 metre, based on the standard height for paved and unpaved road sources as recommended by Ontario Ministry of the Environment (2009). Figure 5-3 shows the point emission sources modelled on the St. George and College Street intersection.

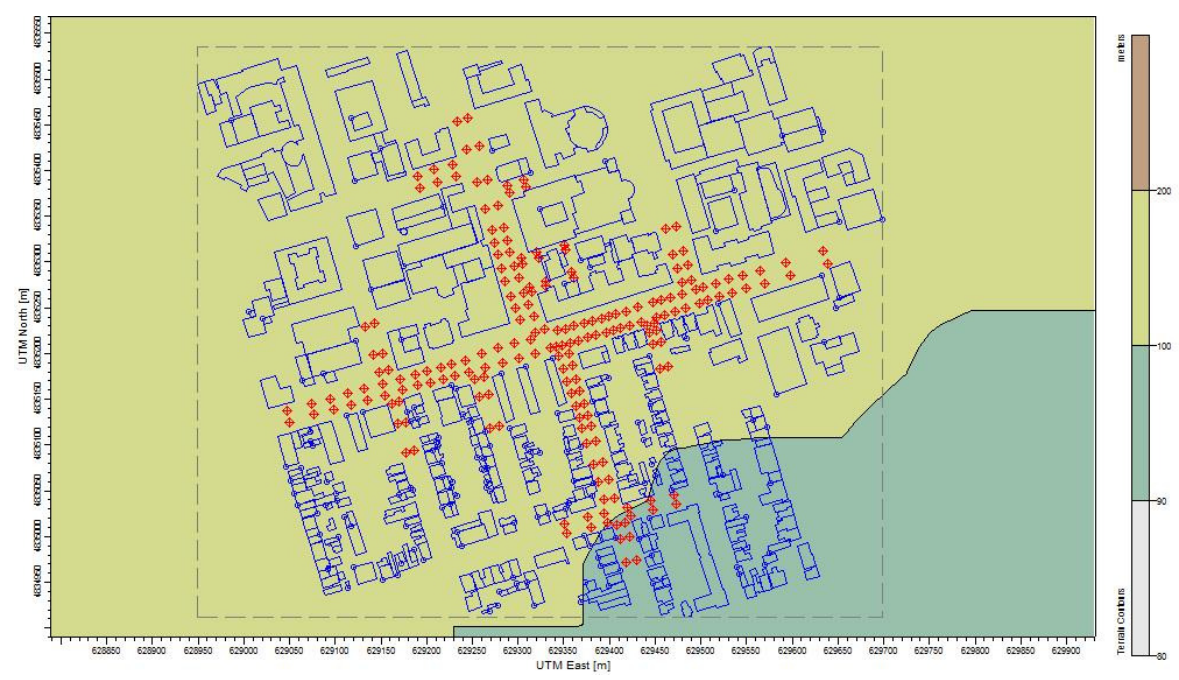

Figure 5-3 Series of point sources, AERMOD View

\subsubsection{Meteorological Data}

AERMOD has intensive meteorological data requirements. It requires upper air and surface air data sets for several atmospheric parameters in order to characterise the PBL before performing dispersion. No accurate weather station data was available for the study area. Meteorological 
data comprising surface and upper air data for the desired study period (June-July 2011) and location (St. George and College Street intersection, Geographic Coordinates: 43.67 N, 79.4 W; Baseline elevation: $107 \mathrm{~m}$ ) is purchased from Lakes Environmental (2012). This data provides a good source of local meteorological data for the study area; hourly surface meteorological data are available in the SAMSON data format and upper air meteorological data are available in NCDC TD-6201 format (WebMET, 2012).

These data are generated using MM5 prognostic wind model (PSU NCAR, 2008) that can predict mesoscale and regional scale circulation in the atmosphere; data are obtained for a hypothetical weather station located at the St. George and College intersection. Availability of site specific meteorological data is vital in modelling the atmosphere correctly, and in turn, obtaining accurate estimates of pollutant concentrations using the dispersion models. Details regarding the use of MM5 model in generating meteorological data can be found in Lakes Environmental (2010). The height of the anemometer for the surface data is 14 metres. AERMET requires classification of the modelling domain into different 'sectors' depending on land use. A single sector is specified encompassing the entire domain with 'urban' land use type. This is used to estimate the radiation reflection characteristics and surface roughness within the domain. AERMET outputs two files that contain processed meteorological data ready for input into AERMOD. Figure 5-4 shows the wind rose generated for the morning peak period in June and July 2011.
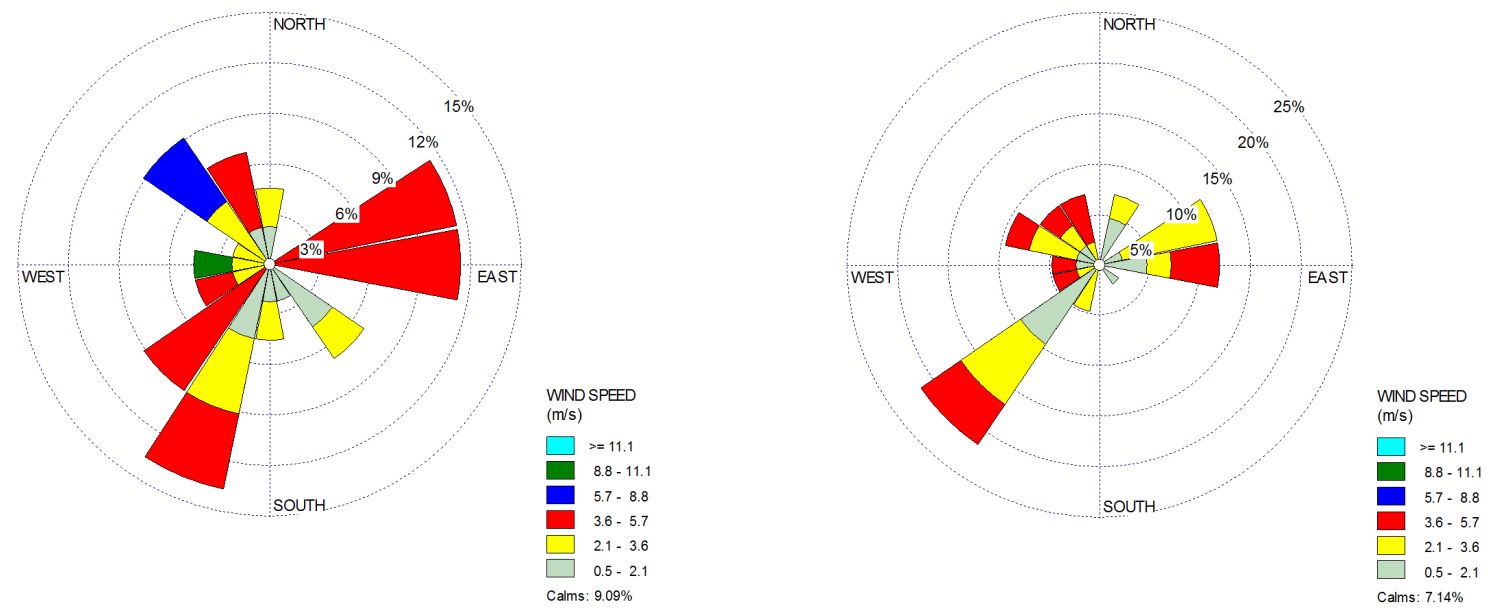

Figure 5-4 Wind Rose for Weekdays, 7:00-9:00 AM in June (left) and July (right), 2011 


\subsubsection{Land DEM and Building Data, Receptors}

The Shuttle Radio Topography Mission (SRTM) 60-second Canadian Digital Land Elevation data available from web GIS (2012) are used to obtain study area elevation. Building data are obtained from Map and Data Library, University of Toronto (2011). It consists of a GIS map containing building dimensions and layout of the study area. The domain extents are based on the roadway network developed in PARAMICS. Figure 5-5 shows the building geometry of the study area imported into AERMOD View. The ground elevation of the study network is fairly constant and is not expected to be an important factor in modelling concentrations.

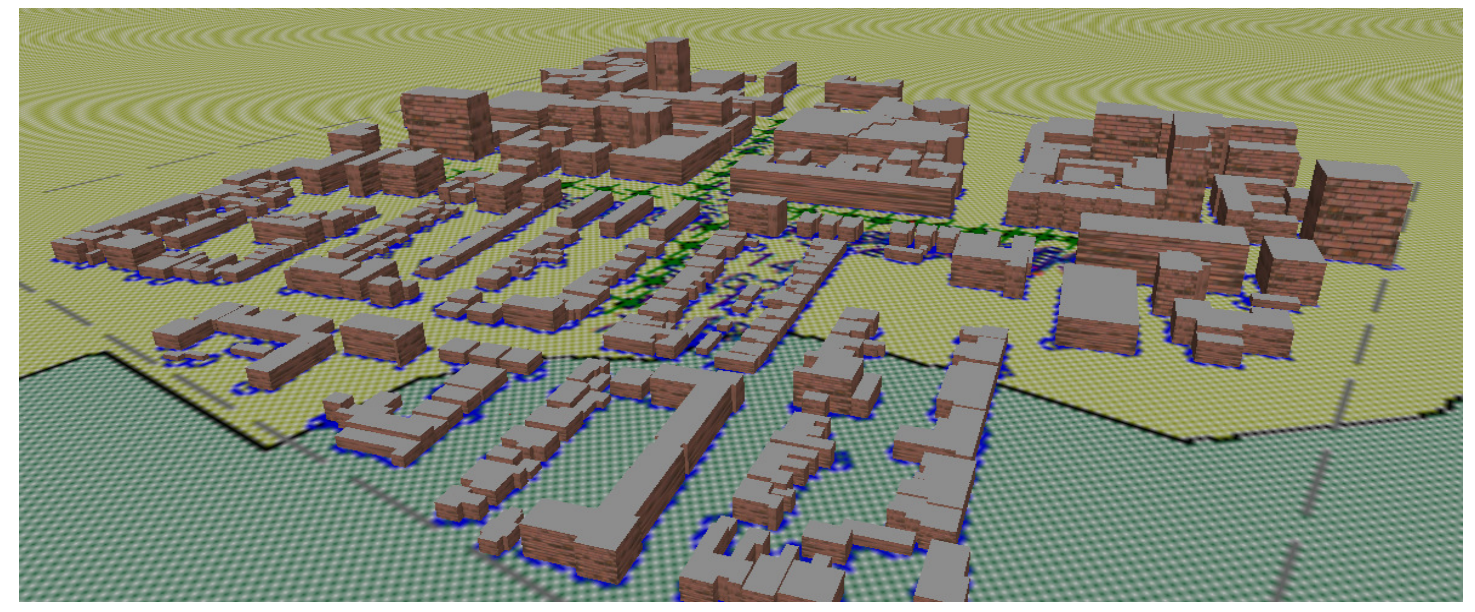

Figure 5-5 St. George Street and College Street Intersection, AERMOD View

10,000 pollutant concentration receptors are specified in a $100 \times 100$ grid matrix (each cell is 7.3 $\mathrm{m} \times 6.07 \mathrm{~m}$ ) over the study network to capture the spatial distribution of concentration for the entire network. Additionally, four (4) discrete receptors are specified at the observed sensor area located on the southern wall of the Wallberg Building, close to the intersection and approximately 20 feet from College Street. The concentrations obtained at the discrete receptor located at Universal Transverse Mercator (UTM) coordinates (629379.4, 4835244.49) are used for making comparisons to the measured values. Concentrations are estimated at two heights (3 metres and 1 metre), to observe vertical concentration variation close to the surface. Figure 5-6 shows the receptor network in AERMOD View. 


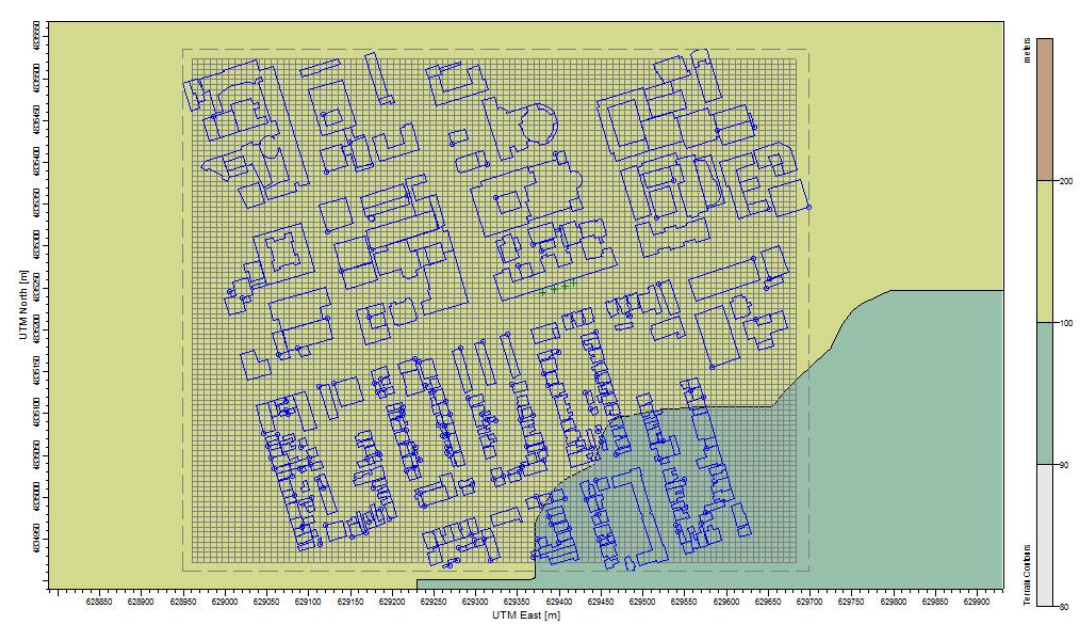

Figure 5-6 Receptors, AERMOD View

\subsubsection{QUIC Inputs}

\subsubsection{Emission Sources}

QUIC can model source geometry as spherical shell, rectangular area / volume, moving point, line and cylinder. The roadway links from CMEM are aggregated into 17 line emission sources (12 - major, 5 - minor). These emission sources are aggregated based on their proximity to the St. George and College Street intersection such that model complexity and runtime are reduced, without diluting emissions over a very large source length. For minor source contributors, the roadway links in both directions are merged and represented by a single line source as shown in Figure 5-7. The latter assumption does not affect modelled concentrations at the observed sensor location significantly due to extremely low emission rates for these unified links. The temporal variability of line sources is modelled by replicating the 12 major line sources at 15 minute intervals; the minor line sources are aggregated for the 2 hour modelling period. Each emission source is a finite duration continuous release only 'operating' or releasing pollutant particles for the 15 minute period it corresponds to. Thus, a total of 101 sources are specified in the domain, with $12 \times 8$ line sources (for eight 15 minute periods in the two hour simulation) for major contributors and 5 line sources for minor contributors. Both $\mathrm{CO}$ and $\mathrm{NO}_{\mathrm{x}}$ are assumed to be unreactive, non-decaying ideal gases during dispersion. 


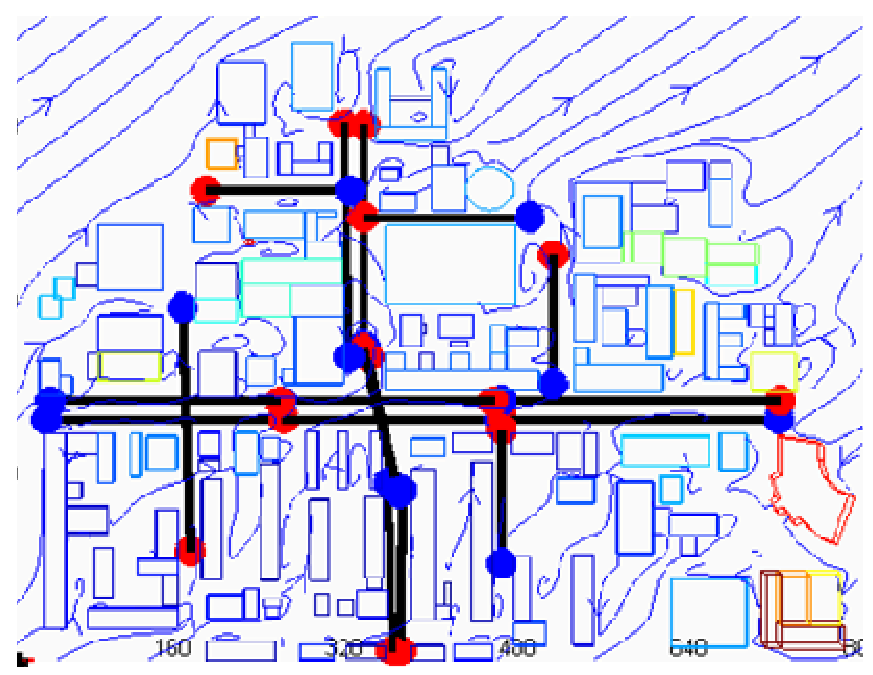

Figure 5-7 Line emission sources, QUIC

\subsubsection{Meteorological and Other Data}

All meteorological data inputs for QUIC are obtained from AERMET outputs. Wind profile obtained for a single station within the study area is used to generate mean wind flow in QUICURB. The station is located on the Southwest corner of the intersection; coordinates of the station in the QUIC City Builder framework are $(\mathrm{X}=353.6 \mathrm{~m}, \mathrm{Y}=222.7 \mathrm{~m})$. A logarithmic vertical wind profile is adopted for mean wind computation. The inputs required by QUIC-URB are inverse $\mathrm{M}-\mathrm{O}$ length, wind speed, wind direction, reference height for wind measurement, and surface roughness. A surface roughness of 1 metre is used based on Engineering Sciences Data Unit (1972). QUIC-PLUME also requires the inverse M-O length to characterise atmospheric stability.

The domain size is $760 \mathrm{~m} \times 540 \mathrm{~m} \times 150 \mathrm{~m}$. This space is divided into 2,565,000 cells, each of size $4 \mathrm{~m} \times 3 \mathrm{~m} \times 2 \mathrm{~m}$ for computation of particle movement. Other inputs include convective boundary layer height, surface and ambient temperature (assumed to be equal), ambient relative humidity, and ambient pressure. The total number of particles released during the simulation is 145,440 . Each particle is associated with a dose of the pollutant. Total concentration in any given grid cell is computed by counting the number of particles present in that cell for a specific averaging time period. A simulation time step of 5 seconds is used as recommended in the QUIC manual (Los Alamos National Laboratory, 2010). 


\subsubsection{Land DEM, Building Data and Receptors}

The topography of the study network is assumed to be flat. Building data, obtained from Map and Data Library, University of Toronto (2011) is used to manually generate 3-dimensional building environment using the City Builder tool. The modelling domain developed is shown in Figure 5-8. The extent of the domain is based on the roadway network developed in PARAMICS. QUIC does not require specification of a receptor location before dispersion. Upon completion of the dispersion process, all concentrations are measured at the grid box with QUIC City Builder coordinates $(\mathrm{X}=406 \mathrm{~m}, \mathrm{Y}=247.5 \mathrm{~m})$ as shown by the vertical line segment in Figure $5-8$.

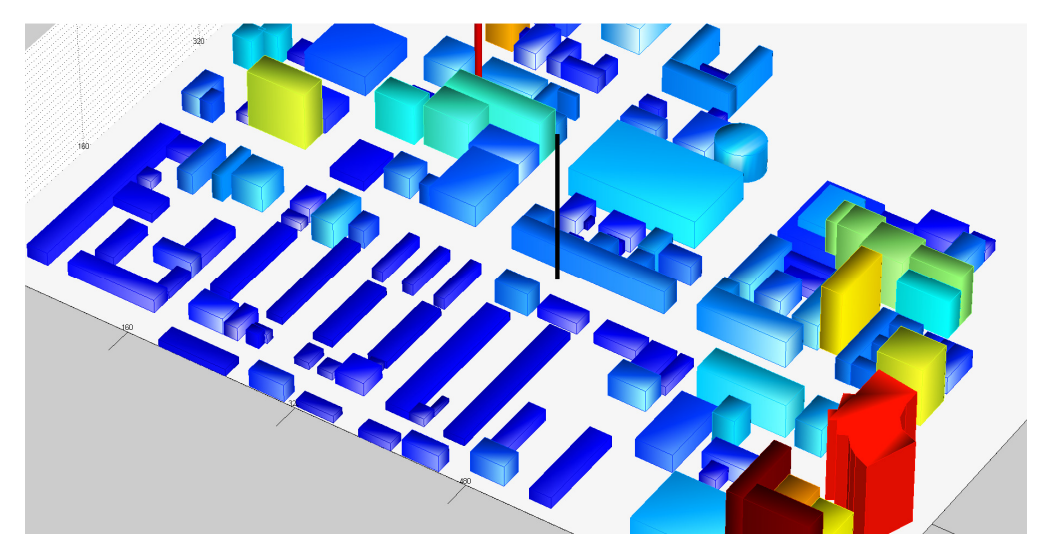

Figure 5-8 St. George Street and College Street Intersection, QUIC City Builder

\subsection{Sensitivity of Traffic Microsimulation Random Seed}

As discussed previously, PARAMICS requires a random number input that generates stochasticity in the model. For each day modelled in the study period, several realisations (of the random seed) are ideally required to obtain a distribution of emission rate outputs from CMEM that vary spatially and temporally. Processing a large number of realisations for PARAMICS is practically infeasible. Due to time constraints on model runs, a sensitivity analysis is performed to estimate the coefficient of variation (ratio of standard deviation and sample mean, $\mathrm{CV}$ ) for emission rates input into AERMOD and QUIC due to change in the PARAMICS random number seed. June 20, 2011 is randomly selected to perform this analysis. A separate evaluation for July 2011 (for $\mathrm{NO}_{\mathrm{x}}$ ) is not considered, since the traffic patterns observed on College Street for both months are identical (Figure 3-2). Five replications are generated and the CV's for input emission rates for AERMOD and QUIC are analysed. Large coefficients are observed for 
extremely low emission rates. QUIC emission rate input variations are generally smaller than AERMOD. Due to difference in source geometry, CV values are different for QUIC and AERMOD, although they have been generated using the same CMEM emission rate outputs. Figure 5-9, 5-10, 5-11, and 5-12 show the coefficient of variation graphs obtained from the sensitivity analysis. Five PARAMICS / CMEM runs are performed for each modelling day; for significant emission rates, the confidence interval and error on mean input emission rate are estimated for use in the validation process. The values computed are as follows:

1) QUIC CO Inputs: 95\% Confidence interval with 6.5\% error

2) QUIC $\mathrm{NO}_{\mathrm{x}}$ Inputs: $95 \%$ Confidence interval with $10 \%$ error

3) AERMOD CO Inputs: $75 \%$ Confidence interval with $22.5 \%$ error

4) AERMOD $\mathrm{NO}_{\mathrm{x}}$ Inputs: $95 \%$ Confidence interval with $14 \%$ error

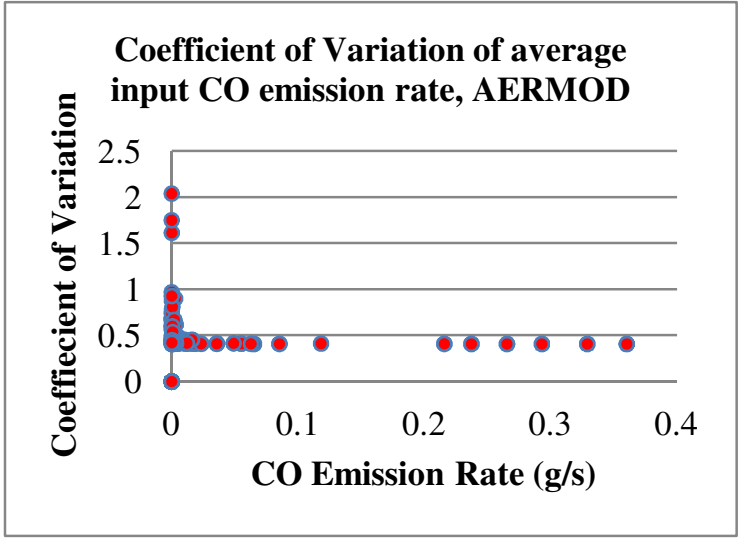

Figure 5-9 AERMOD CO Inputs CV

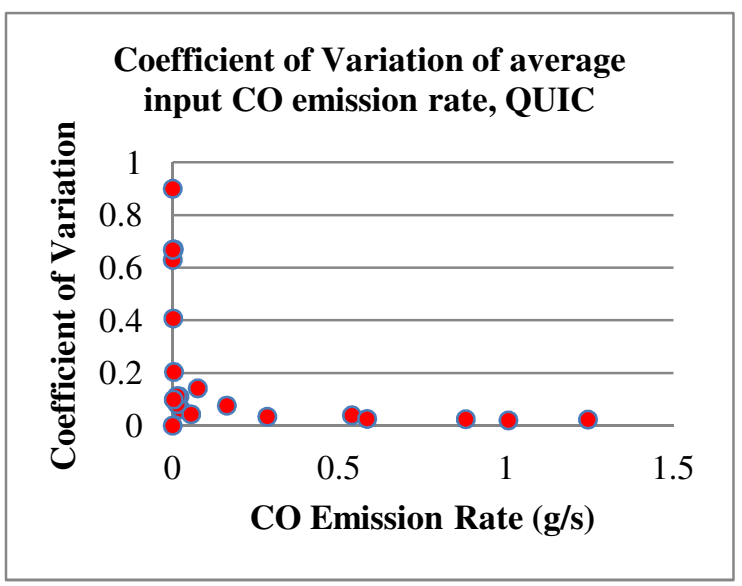

Figure 5-11 QUIC CO Inputs CV

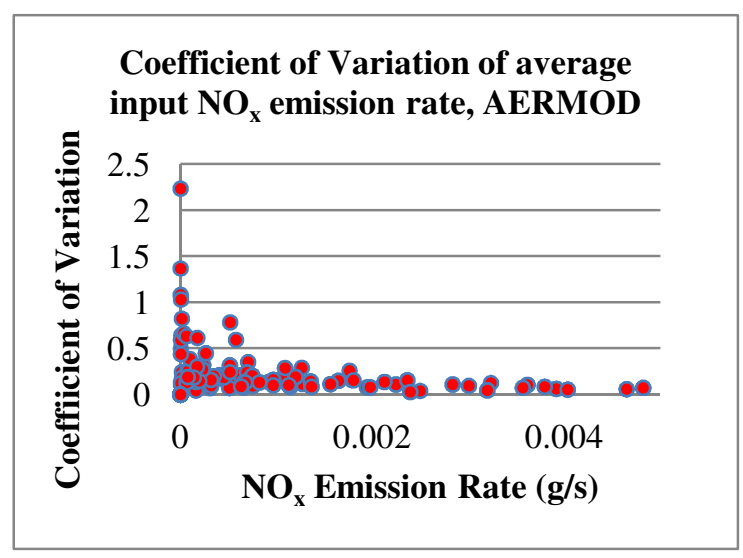

Figure 5-10 AERMOD $\mathrm{NO}_{\mathrm{x}}$ Inputs CV

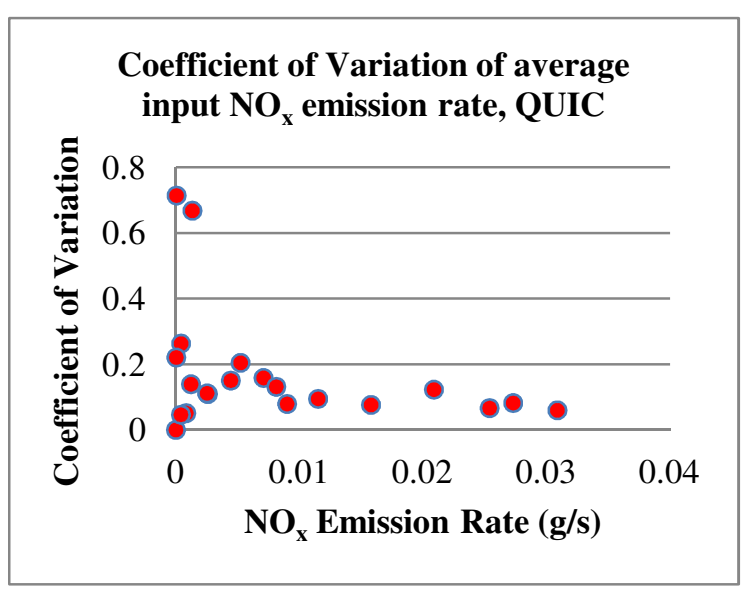

Figure 5-12 QUIC $\mathrm{NO}_{\mathrm{x}}$ Inputs CV 


\section{Chapter 6}

\section{Model Results and Analysis}

This chapter presents results obtained from the modelling framework. $\mathrm{CO}$ and $\mathrm{NO}_{\mathrm{x}}$ concentrations, predicted using the modelling framework, are compared with sensor measured concentrations and the validity of framework is established.

\subsection{Pollutant Dispersion Analysis}

\subsubsection{Observed Pollutant Data}

The observed pollutant data are obtained from the Southern Ontario Centre for Aerosol Atmospheric Research Laboratory (SOCAAR, 2011). Air samples are collected from the Wallberg Building located on the north-east corner of St. George and College Street intersection. The height of collection is $\sim 3$ metres. Figure 6-1 shows the location of the sampling site.

$\mathrm{CO}$ concentration is analysed using the Teledyne Gas Filter Correlation CO Analyzer Model 300E (Teledyne Instruments). It can measure a minimum of 0.04 parts per million (ppm), with an error of $\sim 15 \%$ for a range of 0-5 ppm. $\mathrm{NO}_{\mathrm{x}}$ concentration is analysed using the Thermo Scientific Trace Level $\mathrm{NO}_{\mathrm{x}}$ Analyzer, Model 42i-TL (Thermo Scientific). It can measure a minimum of 50 parts per trillion (ppt), with an error of $\sim 15 \%$ at a range of $0-500$ parts per billion (ppb) (SOCAAR, 2012). $\mathrm{CO}$ and $\mathrm{NO} / \mathrm{NO}_{2}$ concentration data, available at 1 minute intervals for June and July 2011 respectively, are used for analysis. Observed concentrations are averaged to hourly values for comparison with AERMOD predicted concentrations, and to 15 minute intervals for comparison with QUIC predicted concentrations.

It can be seen in Figure 6-2 and 6-3 that both $\mathrm{CO}$ and $\mathrm{NO}_{\mathrm{x}}$ show increase in concentrations during the morning peak traffic period between 7:00 - 9:00 AM. It is also observed that the evening peak traffic period does not generate a similar increase; this may be because the evening peak period is spread over a longer time period compared to the morning peak. The next sub section briefly describes some characteristics of the pollutants modelled. 


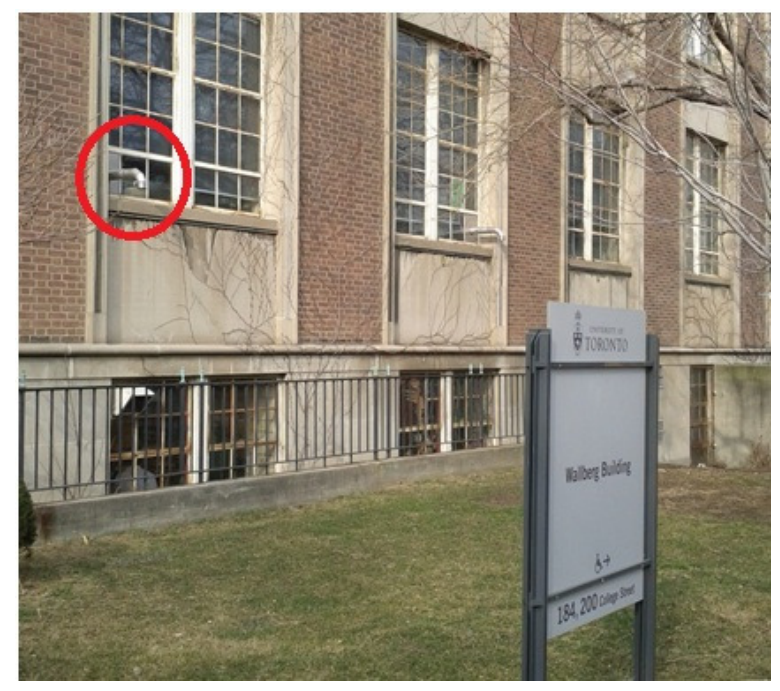

Figure 6-1 Sampling Site Location: Southern wall of Wallberg Building facing College Street.

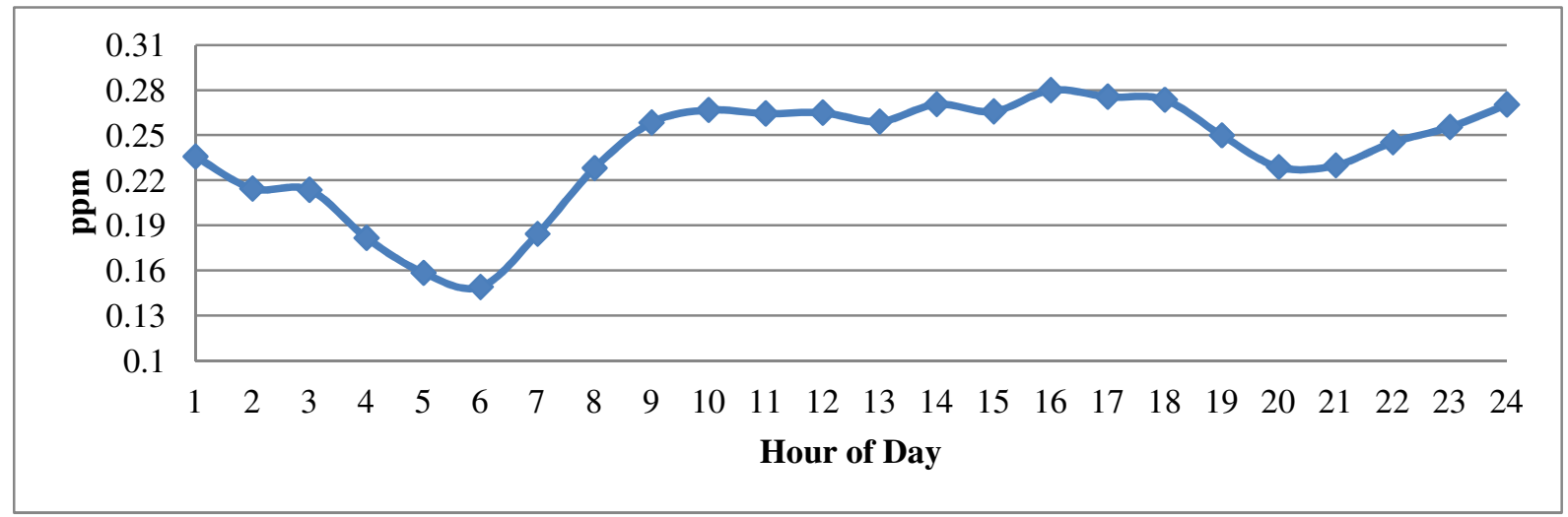

Figure 6-2 Average Hourly CO Concentration, Weekdays, June 2011

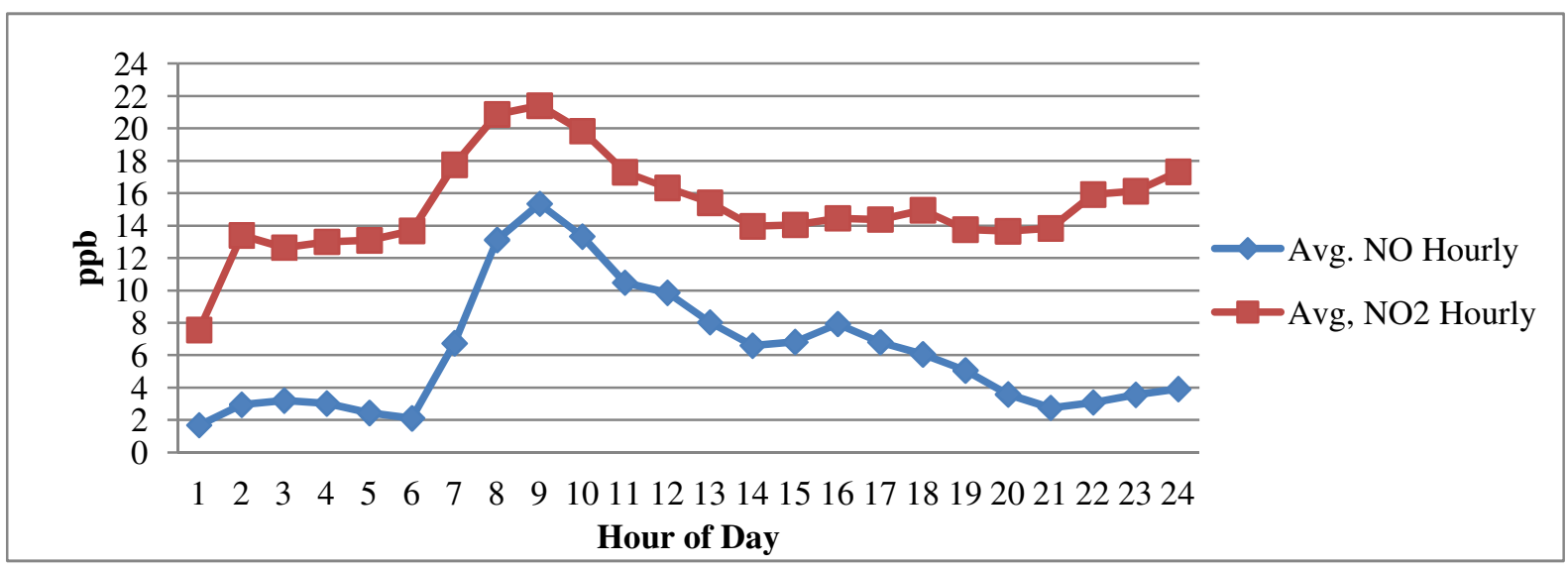

Figure 6-3 Average Hourly NO/NO 2 Concentration, Weekdays, July 2011 


\subsubsection{Pollutant Characteristics}

Nitrogen oxide is composed of seven different compounds, the most common ones being $\mathrm{N}_{2} \mathrm{O}$ (nitrous oxide), $\mathrm{NO}$ (nitric oxide), and $\mathrm{NO}_{2}$ (nitrogen dioxide). $\mathrm{N}_{2} \mathrm{O}$ is greenhouse gas while $\mathrm{NO} / \mathrm{NO}_{2}$ is important from an emissions perspective, due to the associated health risks. Most atmospheric $\mathrm{NO}_{2}$ is released in the form of $\mathrm{NO}$ from the tailpipes of vehicles. This NO rapidly oxidizes to form $\mathrm{NO}_{2}$ in approximately two hours (Environmental Protection Agency, 1999). Subsequently, $\mathrm{NO}_{2}$ undergoes several chemical reactions to form $\mathrm{O}_{3}$ and reaches a "photostationary state' where repetitive cyclical chemical reactions occur in the presence of sunlight. However, in the presence of volatile organic compounds (VOC's), these chemical reactions result in net accumulation of tropospheric ozone (Arya, 1999). The equations are as follows:

$$
\begin{gathered}
\mathrm{NO}_{2}+\text { hv (sunlight) } \rightarrow \mathrm{NO}+\mathrm{O} \\
\mathrm{O}+\mathrm{O}_{2} \rightarrow \mathrm{O}_{3} \\
\mathrm{O}_{3}+\mathrm{NO} \rightarrow \mathrm{NO}_{2}+\mathrm{O}_{2} \\
\mathrm{NO}+\mathrm{VOC} \rightarrow \mathrm{NO}_{2}
\end{gathered}
$$

Yao, et al. (2005) estimated that the direct contribution of $\mathrm{NO}_{2}$ emissions to atmospheric $\mathrm{NO}_{2}$ concentration is small, indicating that $\mathrm{NO}$ is a main component of $\mathrm{NO}_{\mathrm{x}}$ emissions, that eventually oxidizes to form $\mathrm{NO}_{2}$. This observation is corroborated by the sensor measured $\mathrm{NO} / \mathrm{NO}_{2}$ concentration graph. During the peak traffic period between 7:00 - 9:00 AM, approximately 40\% of all measured $\mathrm{NO}_{\mathrm{x}}$ consists of $\mathrm{NO}$, compared to 5:00 AM in the morning, when only 13\% of all measured $\mathrm{NO}_{\mathrm{x}}$ consists of NO. This is shown in Figure 6-4.

In comparison, $\mathrm{CO}$ is not associated with similar complex chemical transformations; although $\mathrm{CO}$ oxidizes to $\mathrm{CO}_{2}$ in the presence of the hydroxyl radical in the atmosphere. $\mathrm{CO}_{2}$ even though important from a greenhouse gas perspective, does not have any significant adverse health effects associated with it. 


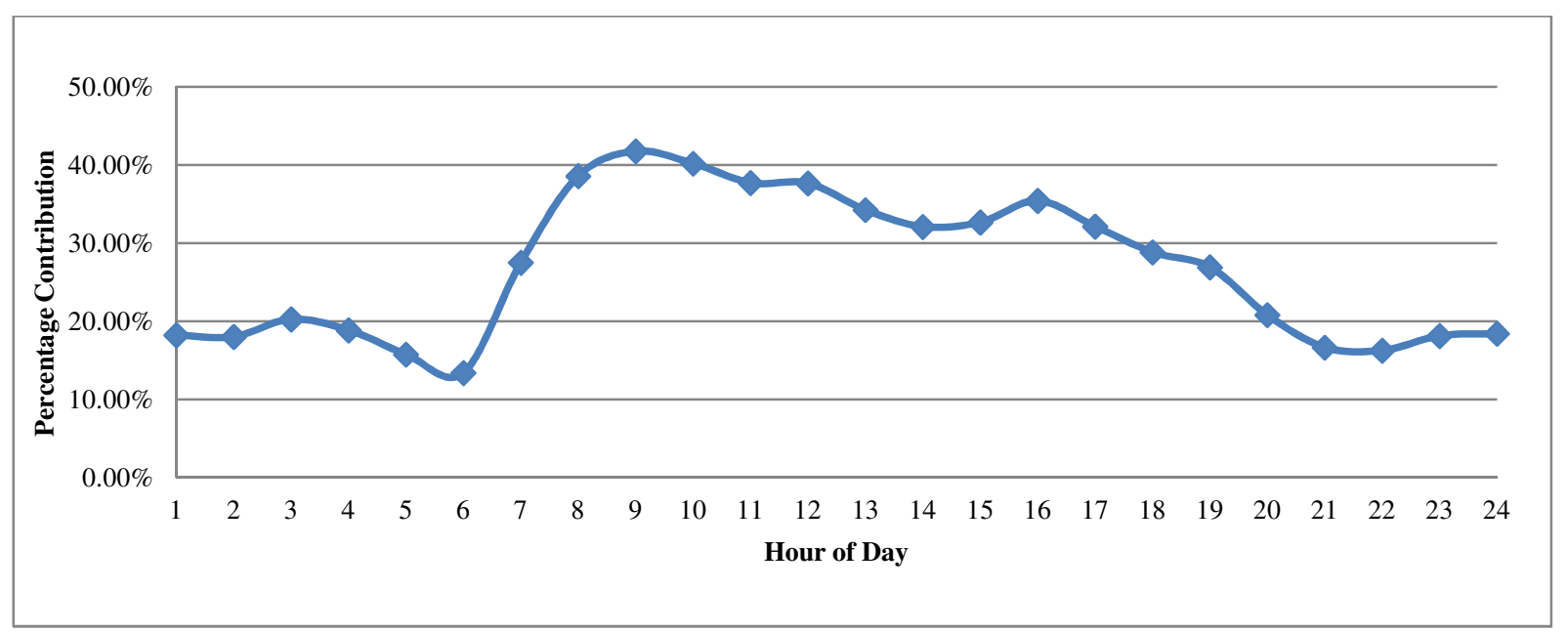

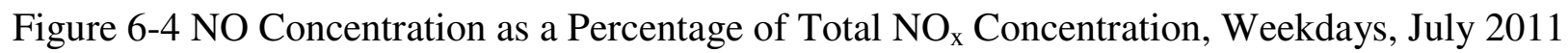

The following sections present the analysis of AERMOD and QUIC predicted concentrations. Wind speed is a significant dispersion parameter as shown in Chapter 7, Sensitivity Analyses. Therefore, residual concentration (the difference between predicted and observed concentration) is plotted with wind speed to notice any patterns, in each comparison.

\subsubsection{AERMOD Results}

Hourly averaged concentration contours are generated for the study period. Figures 6-5, 6-6, 6-7, and 6-8 show the hourly averaged spatial distribution of $\mathrm{CO}$ and $\mathrm{NO}_{\mathrm{x}}$ for a typical weekday in June and July 2011 respectively for 1 metre and 3 metres heights. Note the difference in scales of the legend for the different height contours. 


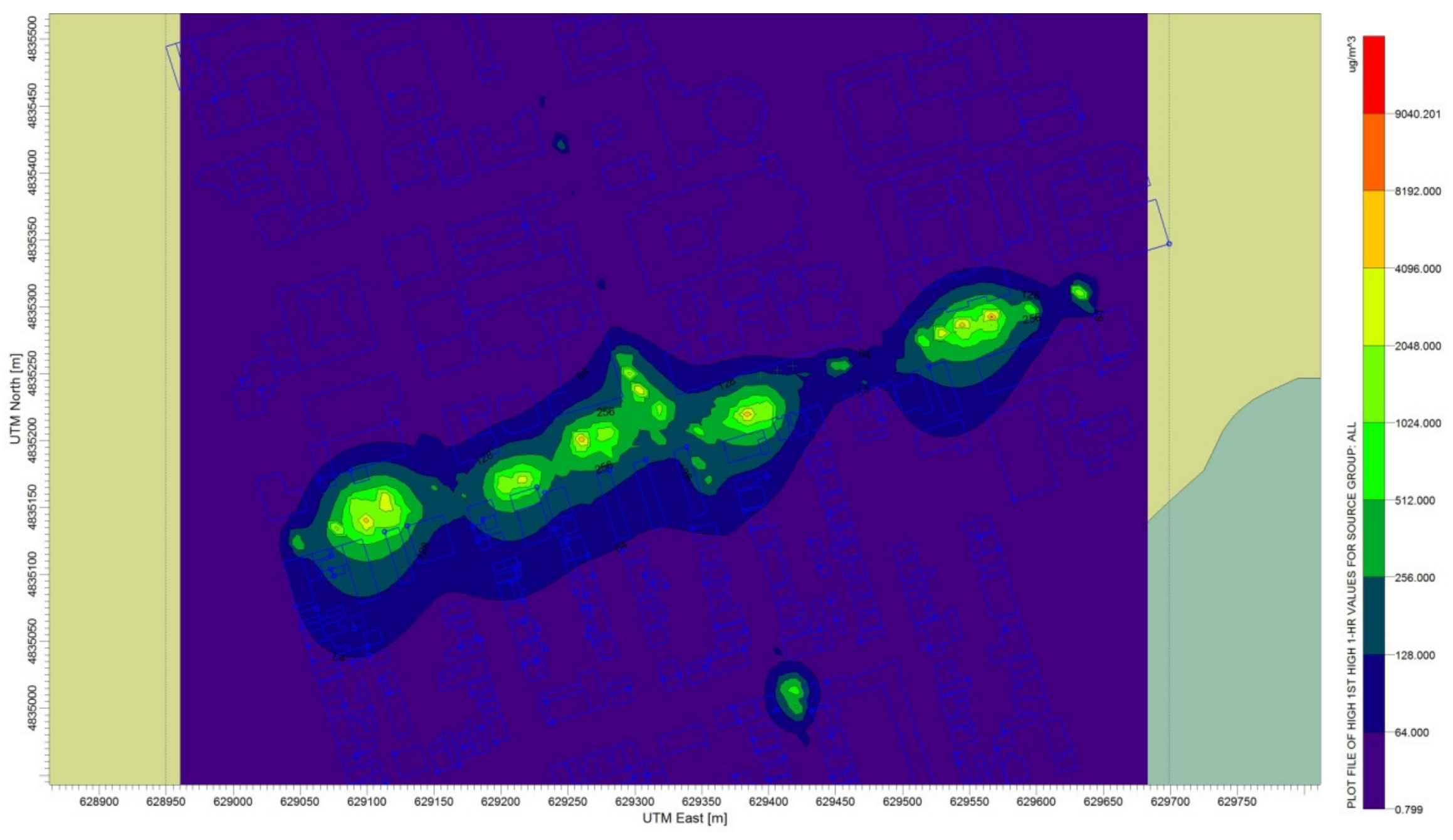

Figure 6-5 Avg. CO Conc., St. George and College Street, June 3, 8:00 - 9:00 AM, 1m height 


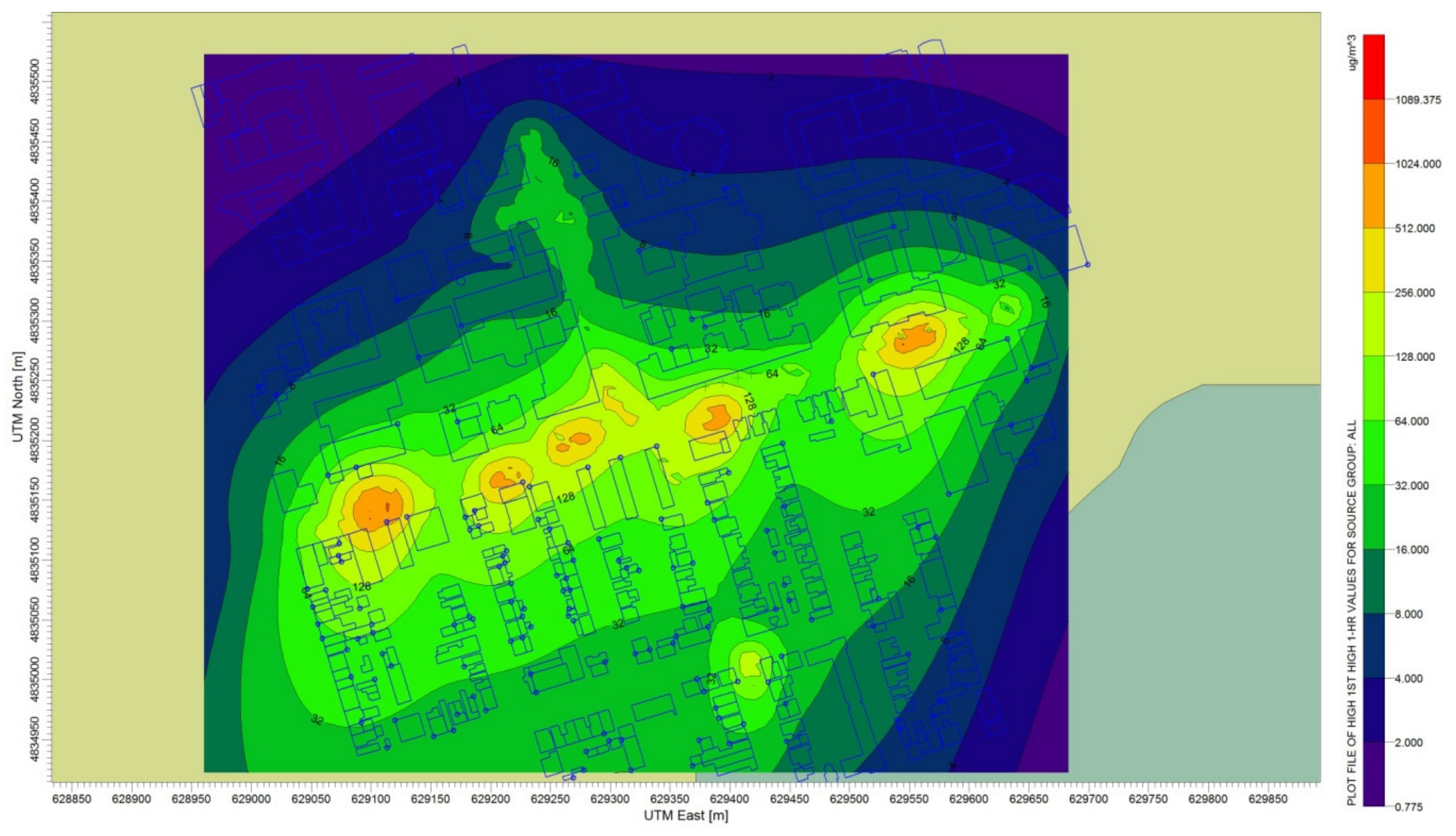

Figure 6-6 Avg. CO Conc., St. George and College Street, June 3, 8:00 - 9:00 AM, 3m height 


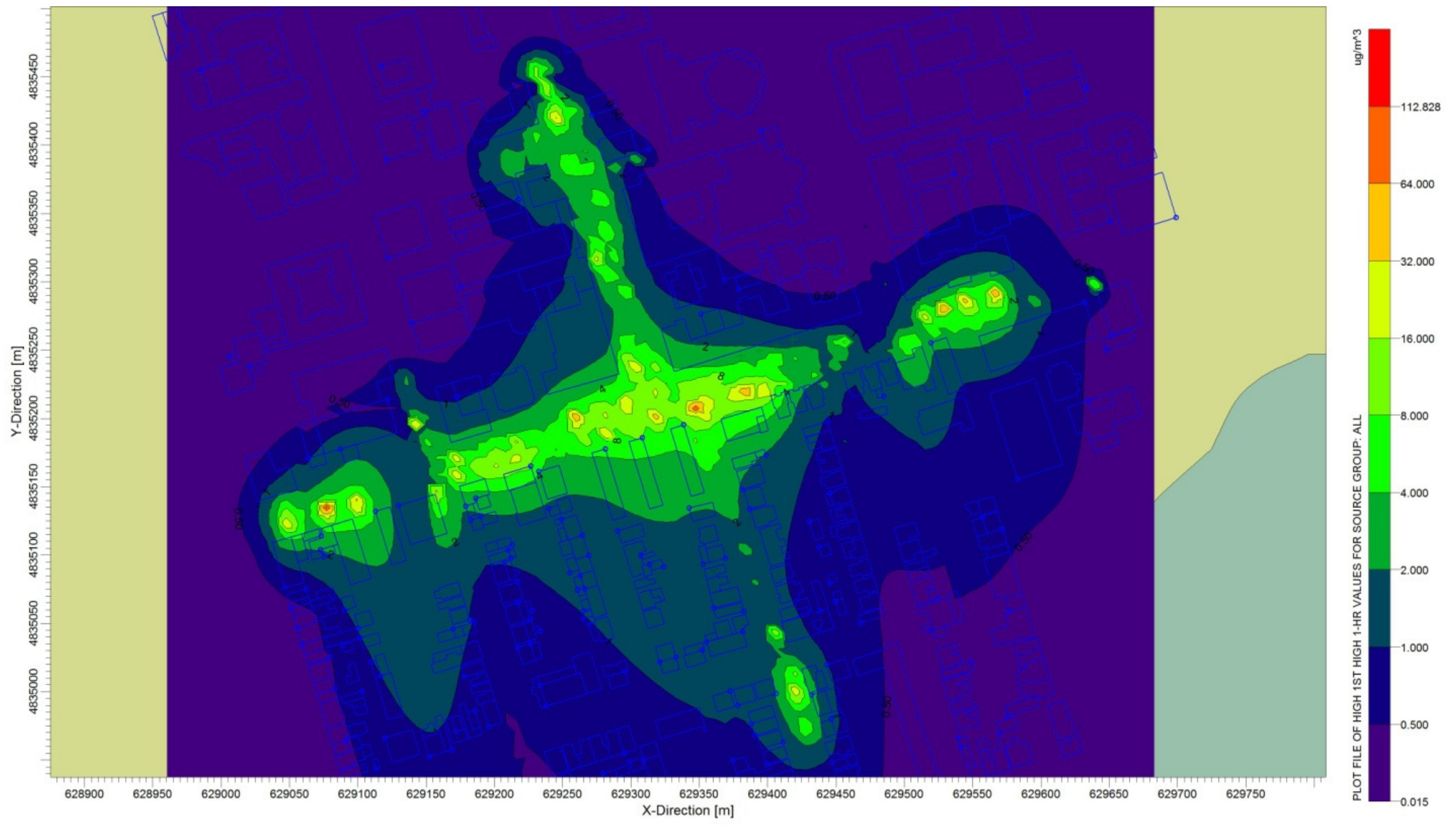

Figure 6-7 Avg. $\mathrm{NO}_{\mathrm{x}}$ Conc., St. George and College Street, July 13, 7:00 - 8:00 AM, 1m height 


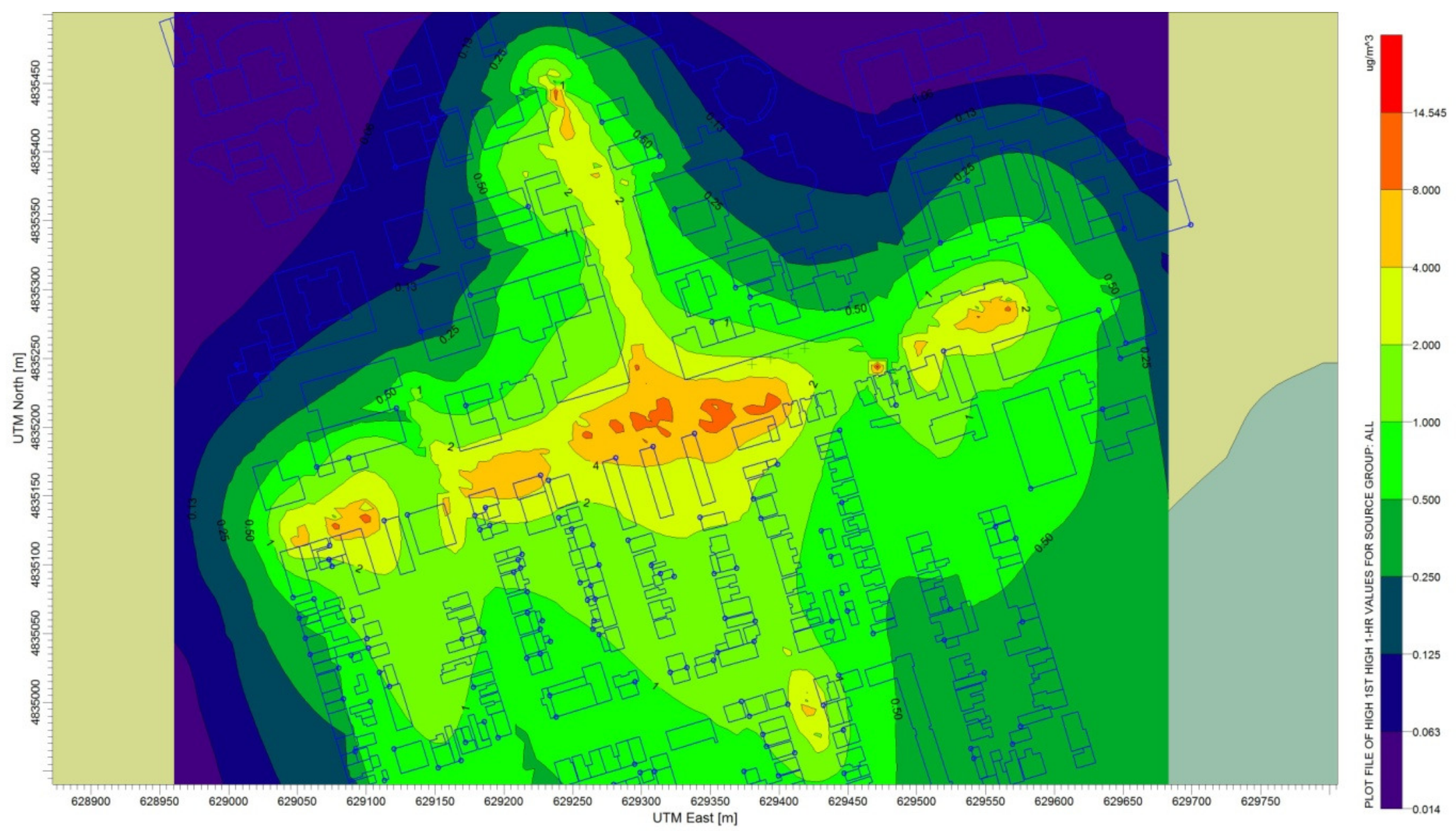

Figure 6-8 Avg. $\mathrm{NO}_{\mathrm{x}}$ Conc., St. George and College Street, July 13, 7:00 - 8:00 AM, 3m height 
Higher concentrations are observed along College Street which has higher traffic volumes than all other roadways on the network. Extremely high concentrations are observed very close to the point sources on the roadway network. This needs to be considered when evaluating the overall performance of the model. It is observed that the pollutant concentrations decrease rapidly as one moves away laterally from the roadways; concentrations also decrease considerably as height increases. AERMOD does not consider the presence of buildings explicitly during the dispersion process. Even though the effect of building downwash has been incorporated, recirculation of pollutants in the street canyon is not captured by AERMOD completely. Since AERMOD is a steady state model, concentrations are not time sensitive; therefore, concentrations in each hour are independent of the values estimated in the previous hour.

\subsubsection{CO - AERMOD Predicted Vs Sensor Observed}

For each modelled weekday in June 2011, AERMOD computes two average hourly CO concentration values at the receptor location. These two values correspond to the average concentration between 7:00 - 8:00 AM and 8:00 - 9:00 AM. Street level concentrations are a combination of the concentration due to traffic flow and background (or ambient) concentrations (Hatzopoulou, 2012). Atmospheric residence times of CO can span up to a few months (Weinstock, 1969). Therefore, emission estimates from the morning traffic period cannot fully account for the sensor observed concentrations. To account for the accumulation of background concentration from the previous hours / days / months, ambient values are added to the modelled values to obtain the final predicted concentrations. The ambient values for $\mathrm{CO}$ are calculated based on analysis of the daily observed $\mathrm{CO}$ concentrations and observed traffic volume on College Street. As shown in Figure 3-2, the least average hourly traffic observed on College Street is between 3:00 - 5:00 AM. Further, Figure 6-2 and 2-6 show that for the corresponding time period, observed $\mathrm{CO}$ concentration also reaches a minimum. Therefore, the average observed CO concentration between 3:00 - 5:00 AM, on any given day in the study period, is assumed to be representative of the ambient $\mathrm{CO}$ concentration for that particular day. This ambient concentration is used to make a proper comparison between final predicted and total measured concentrations.

Modelled and observed CO data points are plotted together as shown in Figure 6-9. 100\% of the predicted values are within a factor of two of the observed values. The 'factor of two' 
comparison is a widely used measure to explain the significance of predicted concentrations (Arya, 1999). The error on observed concentrations is $\sim 15 \%$. This error is also applied to the ambient component of the predicted values since ambient observed concentrations also have $\sim 15 \%$ error. The 'factor of two' envelope is shown in Figure 6-10. Residual concentrations are plotted against wind speed as shown in Figure 6-11 to observe if the residual values have any correlation with the wind speed. Typically, at low wind speeds, higher residual concentrations should be observed, compared to high wind speed cases. For the five days modelled, the residual concentrations increase with wind speed. This suggests that wind direction is possibly influencing the modelled concentrations. A further testing of wind speed and direction is performed in Chapter 7.

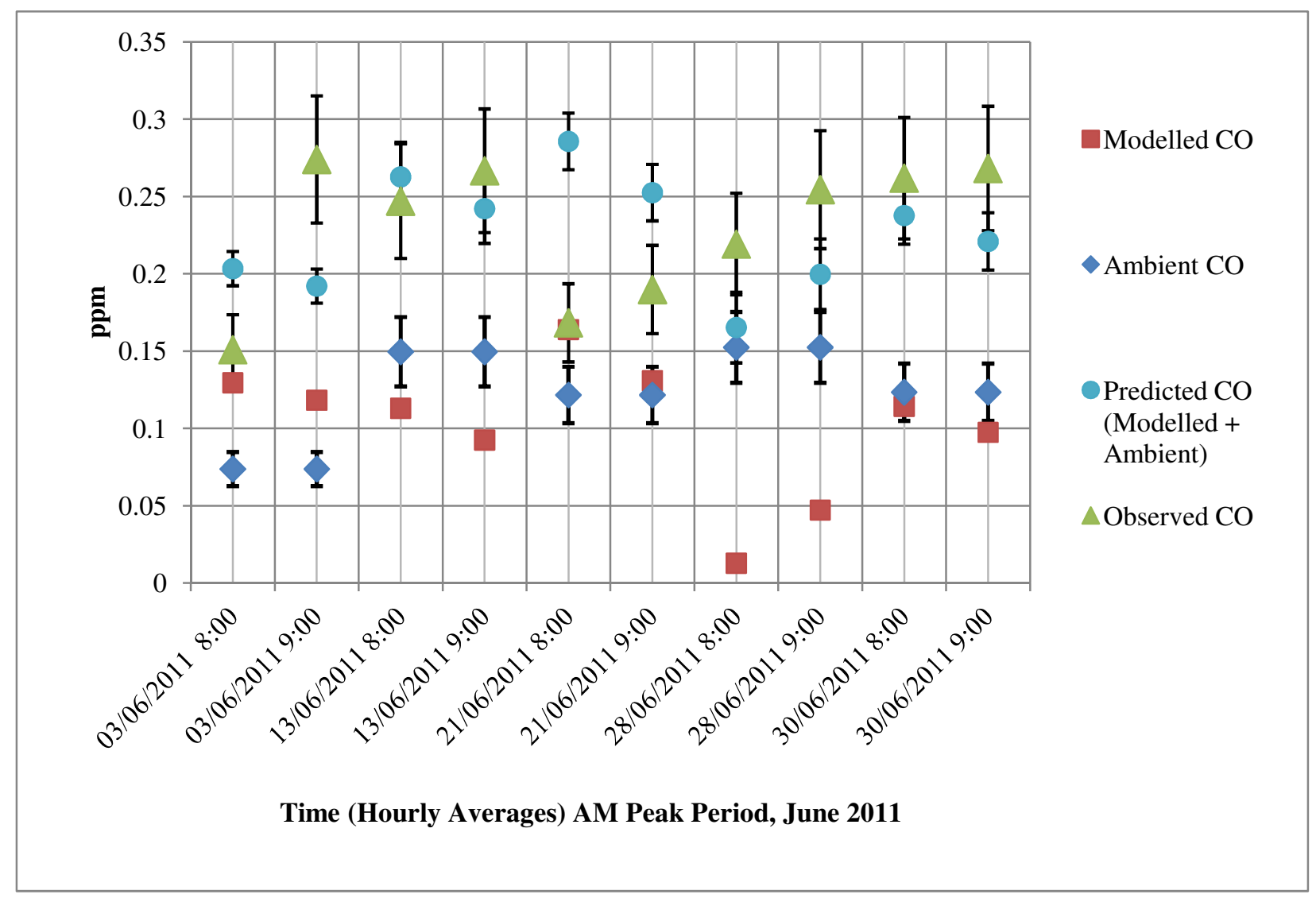

Figure 6-9 Observed Vs AERMOD Predicted Hourly Average CO Concentration 


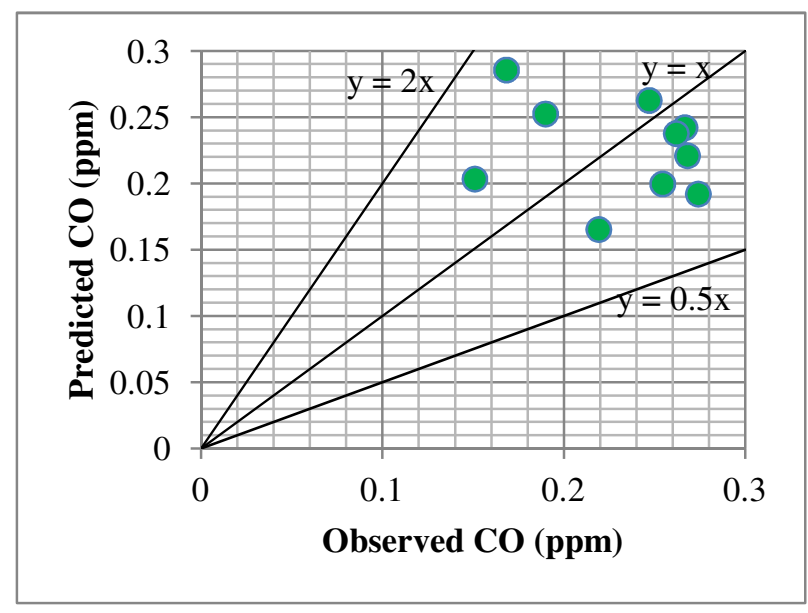

Figure 6-10 AERMOD CO: Predicted Vs Observed Concentration

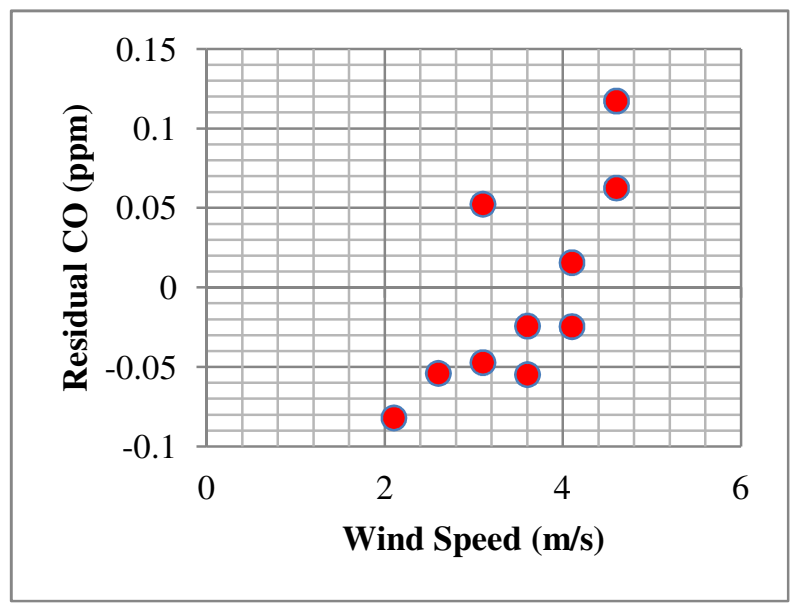

Figure 6-11 AERMOD Residual CO Concentration Vs Wind Speed

\subsubsection{2 $\mathrm{NO}_{\mathrm{x}}-\mathrm{AERMOD}$ Predicted Vs Observed}

Similar to CO, for every modelled weekday in July 2011, AERMOD computes two hourly average $\mathrm{NO}_{\mathrm{x}}$ concentrations at the receptor location between 7:00 - 9:00 AM. $\mathrm{NO}_{\mathrm{x}}$ can persist in the atmosphere for at least several days (Environmental Protection Agency, 1999) and therefore, estimating ambient concentrations is essential to improve compatibility of comparison with total measured concentrations. Figure 6-3, 2-4 and 2-5 show that the minimum concentrations for $\mathrm{NO}_{\mathrm{x}}$ occur around 3:00 - 5:00 AM, which correspond with the lowest traffic levels on College Street (Figure 3-2). Therefore, the average $\mathrm{NO}_{\mathrm{x}}$ concentration between 3:00 - 5:00 AM, for any given day, is assumed to be representative of the ambient concentration present for that particular day. The highly reactive $\mathrm{NO}$ comprises only $\sim 13 \%$ of $\mathrm{NO}_{\mathrm{x}}$ during the night; therefore, this is a fair assumption for estimating total ambient $\mathrm{NO}_{\mathrm{x}}$. All observed $\mathrm{NO}_{\mathrm{x}}$ (comprising $\mathrm{NO}$ and $\mathrm{NO}_{2}$ ) and modelled $\mathrm{NO}_{\mathrm{x}}$ data points are plotted as shown in Figure 6-12. Observed concentrations have $\sim 15 \%$ error which is also applied to the ambient component of predicted observations since the latter consists of observed night time $\mathrm{NO}_{\mathrm{x}}$ concentrations. $60 \%$ of the predicted concentrations are within a 'factor of two' of the observed concentrations as shown in Figure 6-13. Model performance for $\mathrm{NO}_{\mathrm{x}}$ is worse compared to $\mathrm{CO}$ as shown by the 'factor of two' envelope. The model under-predicts concentrations throughout; modelled $\mathrm{NO}_{\mathrm{x}}$ concentrations do not explain the difference between observed $\mathrm{NO}_{\mathrm{x}}$ concentration in the $\mathrm{AM}$ peak and the ambient $\mathrm{NO}_{\mathrm{x}}$ concentration. $\mathrm{NO}_{2}$ contribution from traffic sources to total atmospheric $\mathrm{NO}_{2}$ concentrations is 
small as shown by Yao, et al. (2005); since atmospheric $\mathrm{NO}_{2}$ is a major component of $\mathrm{NO}_{\mathrm{x}}$ in the atmosphere (about $60 \%$ for the morning peak period based on observed sensor data), this could explain some of the difference between modelled and observed concentrations.

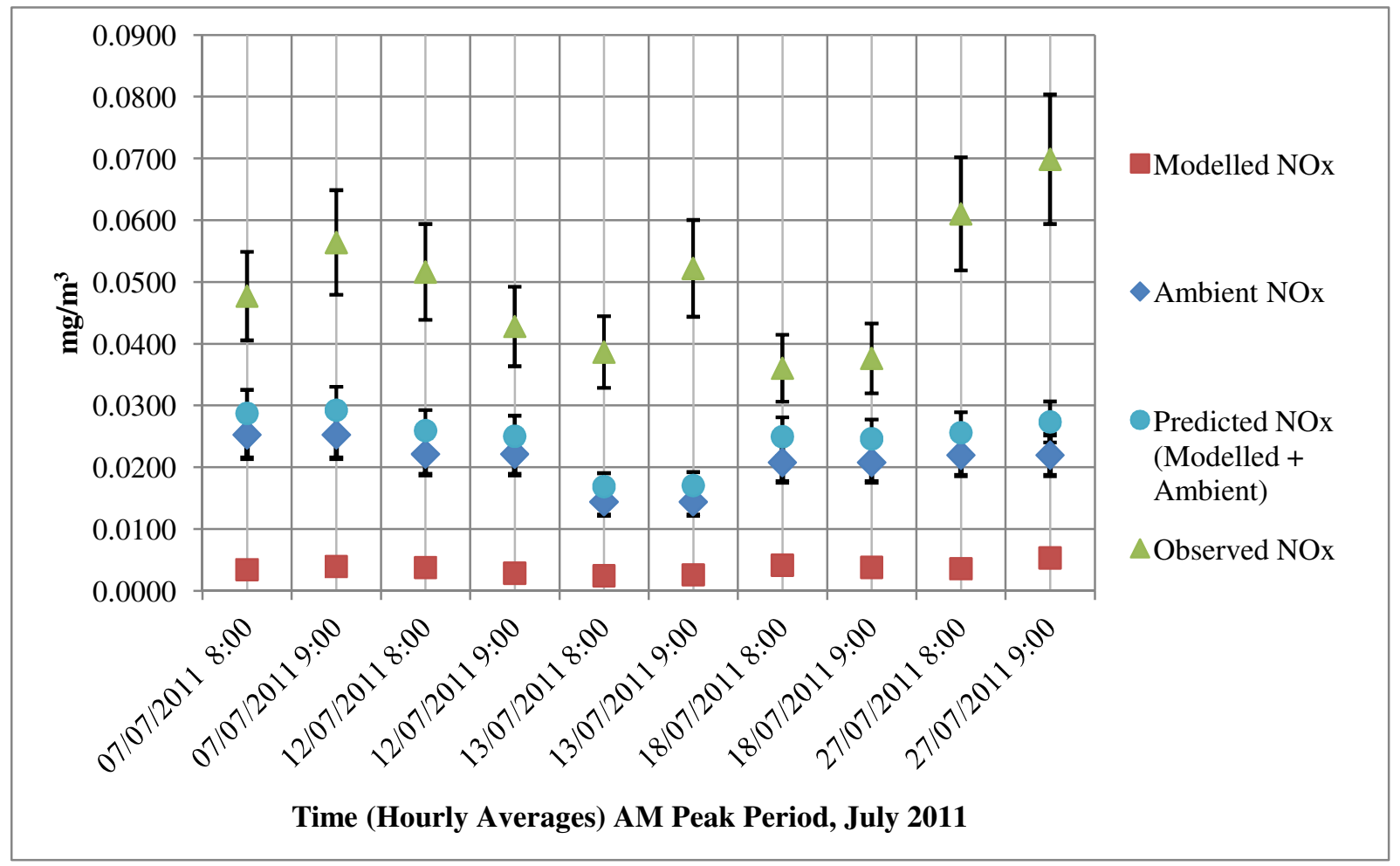

Figure 6-12 Observed Vs AERMOD Predicted Hourly Average $\mathrm{NO}_{\mathrm{x}}$ Concentration

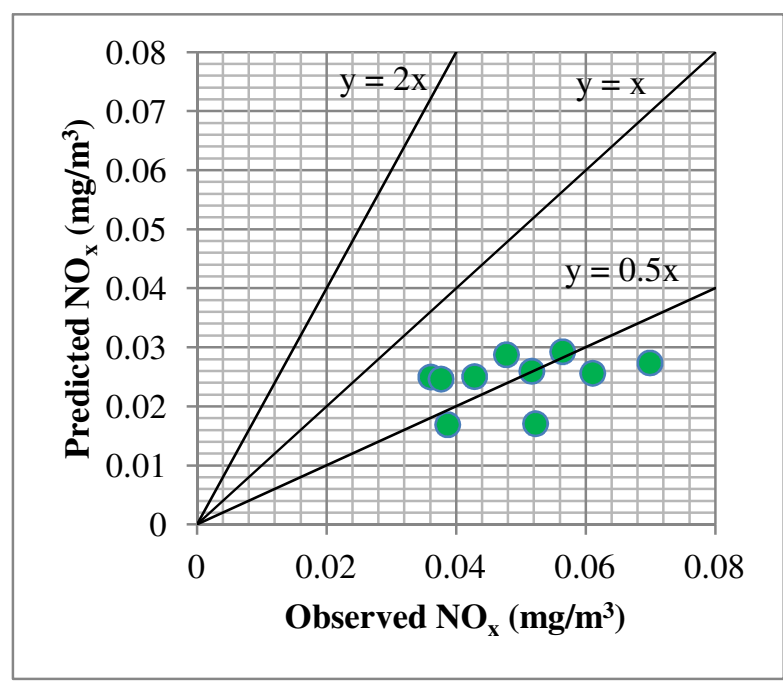

Figure 6-13 AERMOD NO : Predicted Vs Observed Concentration

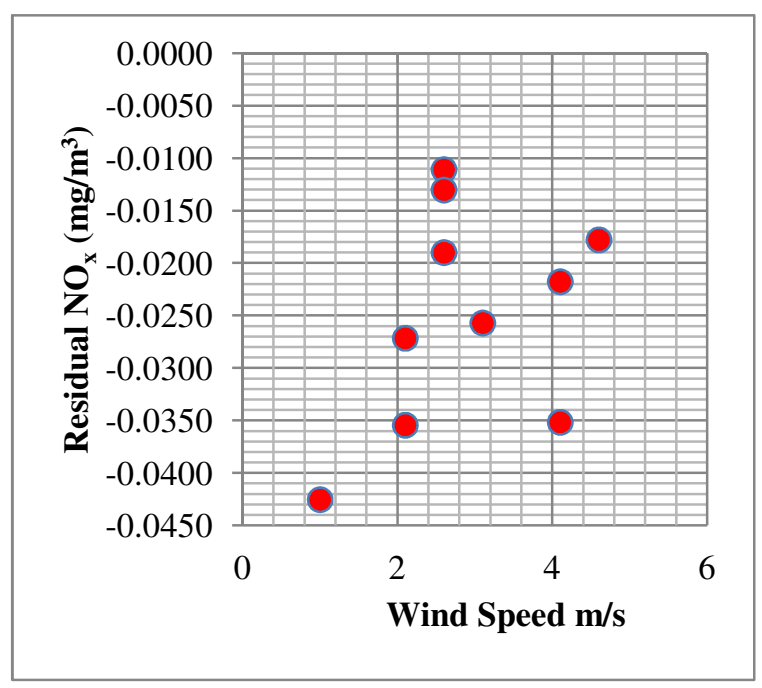

Figure 6-14 AERMOD Residual $\mathrm{NO}_{\mathrm{x}}$ Concentration Vs Wind Speed 
Figure 6-14 shows the plots of residual concentration with wind speeds. AERMOD constantly under-predicts for $\mathrm{NO}_{\mathrm{x}}$ concentrations for all wind speeds, indicating that the model may have a bias that is not being captured.

\subsubsection{QUIC Results}

QUIC generates average concentrations at 15 minute intervals in the modelling domain, for selected weekdays in June 2011 (for CO) and selected weekdays in July 2011 (for $\mathrm{NO}_{\mathrm{x}}$ ). Eight data points are generated for each modelling day, corresponding with the eight ' 15 minute intervals' for the 2 hour simulation period between 7:00 - 9:00 AM. The concentrations are analysed at heights of 3 metres and 1 metre. All comparisons with observed concentrations are made for the 3 metre height. Figures 6-15, 6-16, 6-17, and 6-18 show the spatial distribution of $\mathrm{CO}$ and $\mathrm{NO}_{\mathrm{x}}$ for a typical weekday in June and July 2011 respectively. The spatial distribution of pollutants shows that highest emissions are concentrated along the roadway line sources. The concentrations decrease rapidly as the lateral distance from the roadway source increases. It is also observed that concentrations decrease with height.

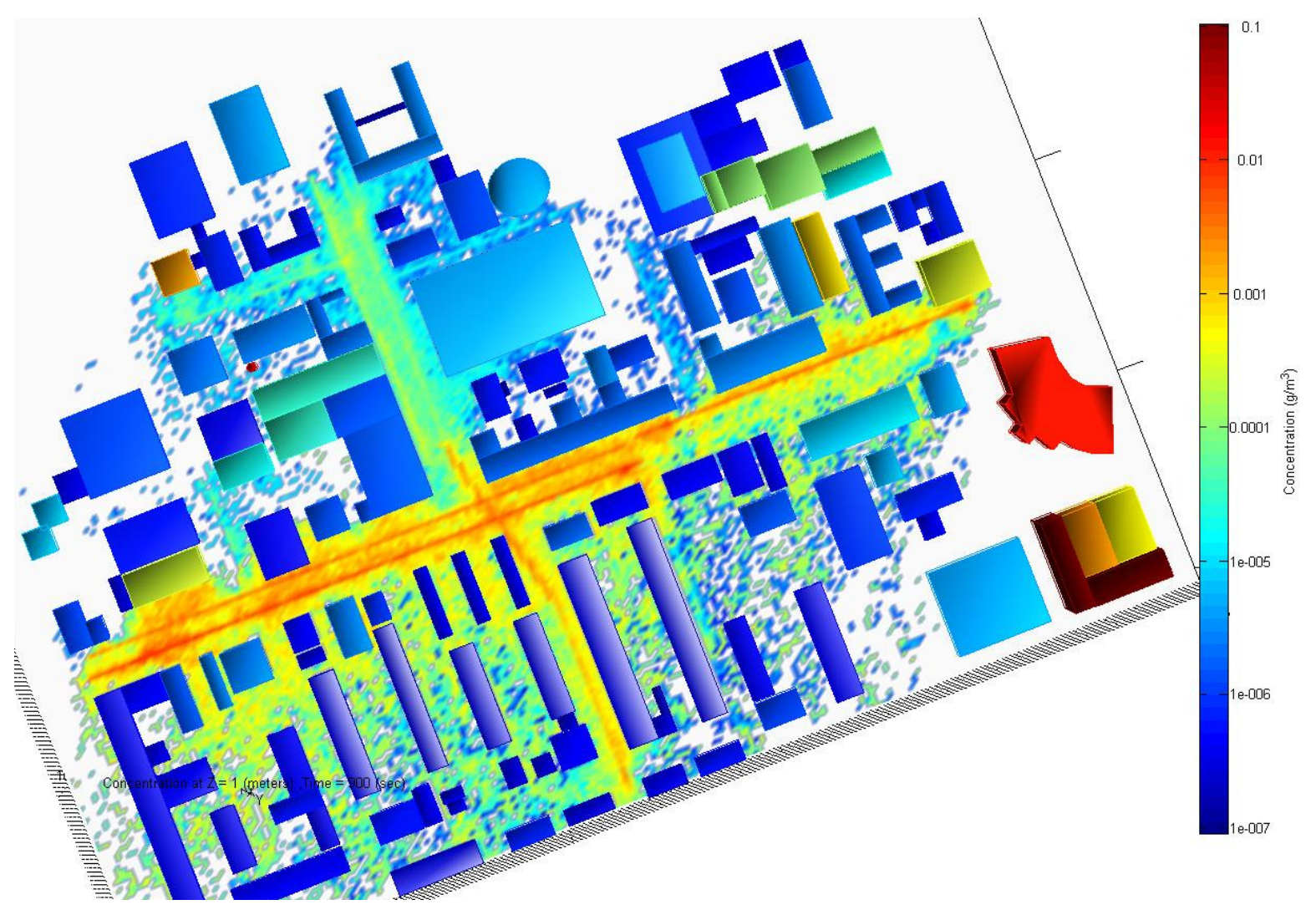

Figure 6-15 Avg. CO Conc., St. George and College Street, June 3, 7:00 - 7:15 AM, 1m height 


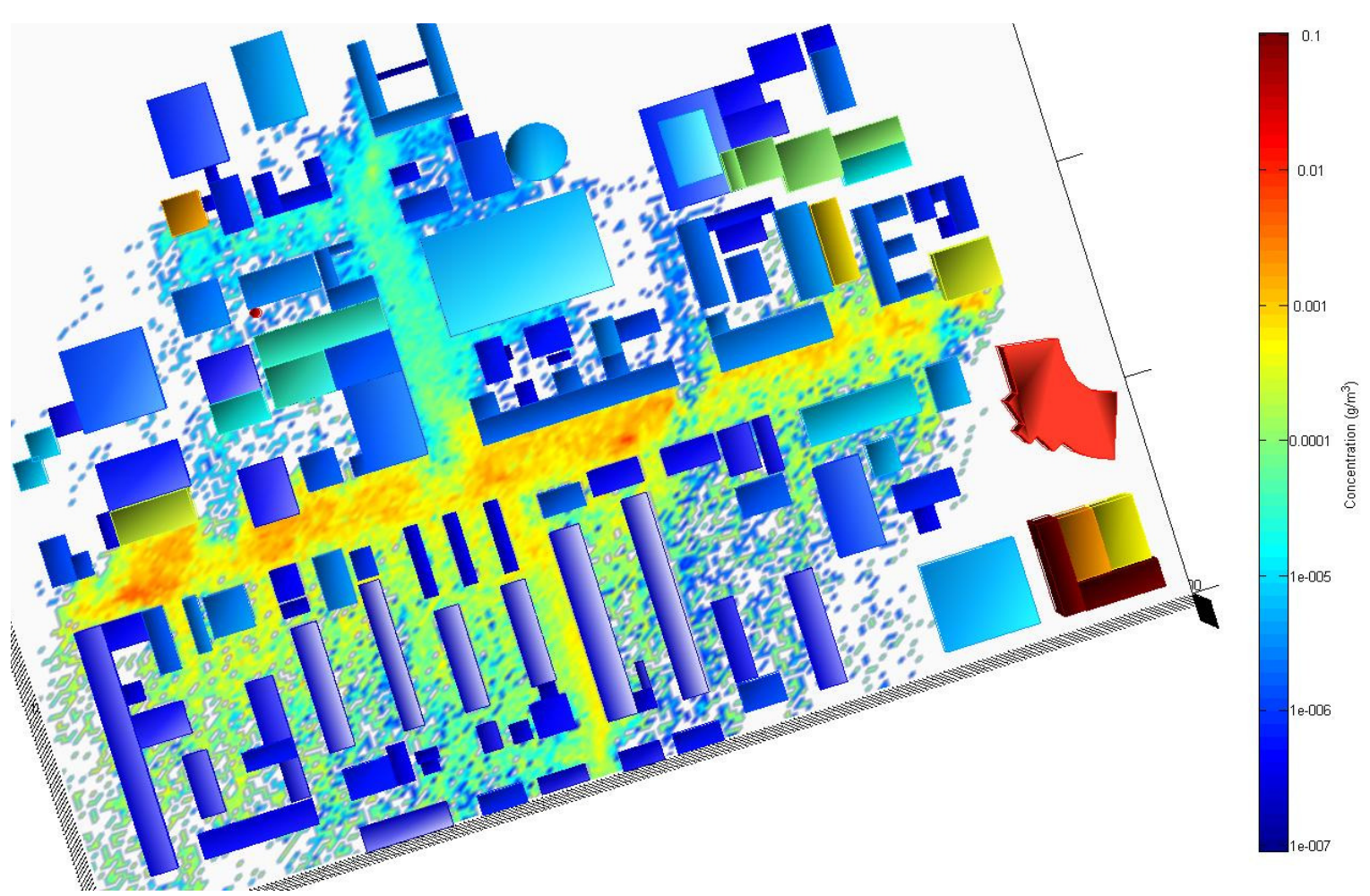

Figure 6-16 Avg. CO Conc., St. George and College Street, June 3, 7:00 - 7:15 AM, 3m height

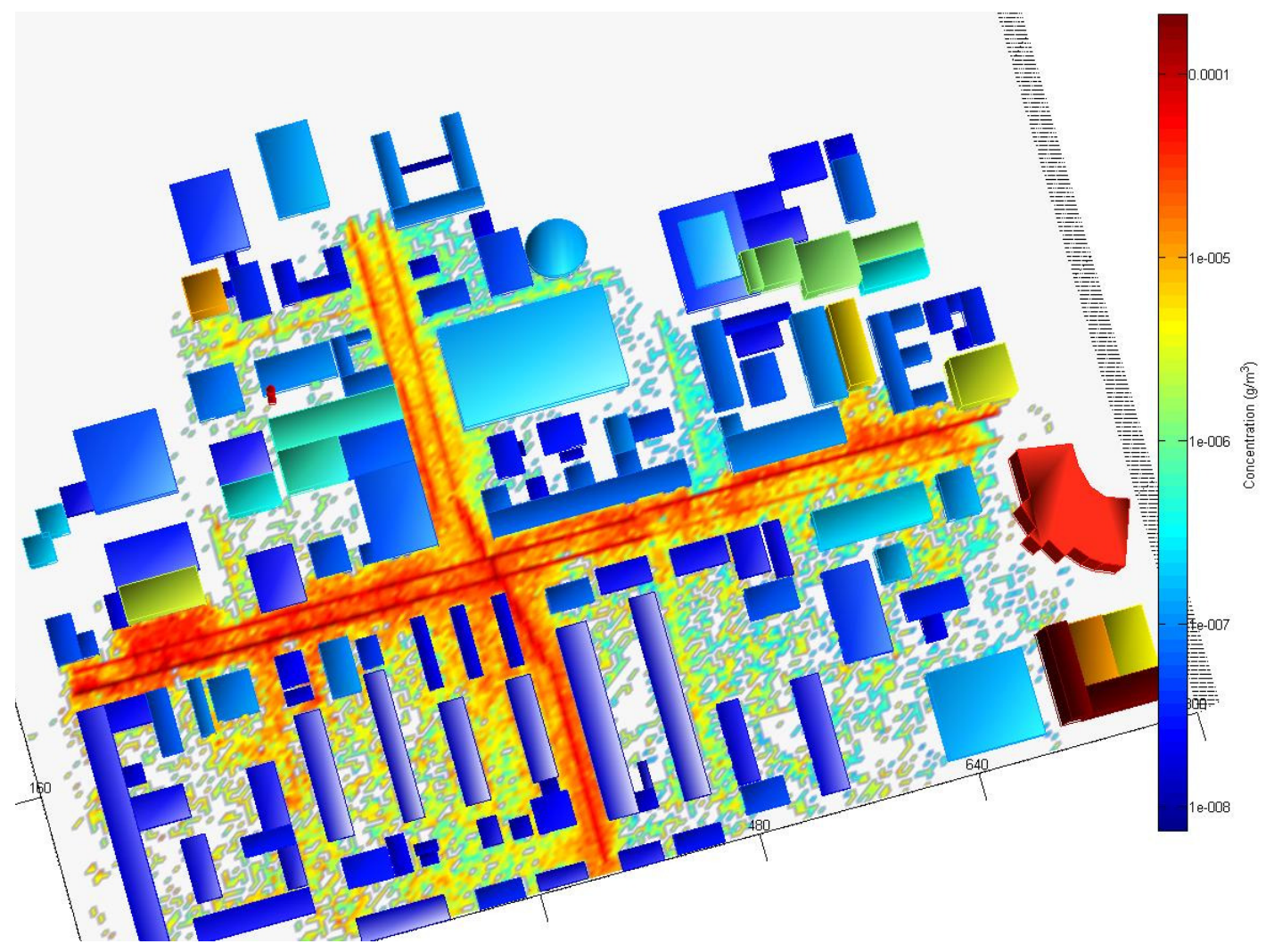

Figure 6-17 Avg. $\mathrm{NO}_{\mathrm{x}}$ Conc., St. George and College Street, July 13, 8:45 - 9:00 AM, 1m height 


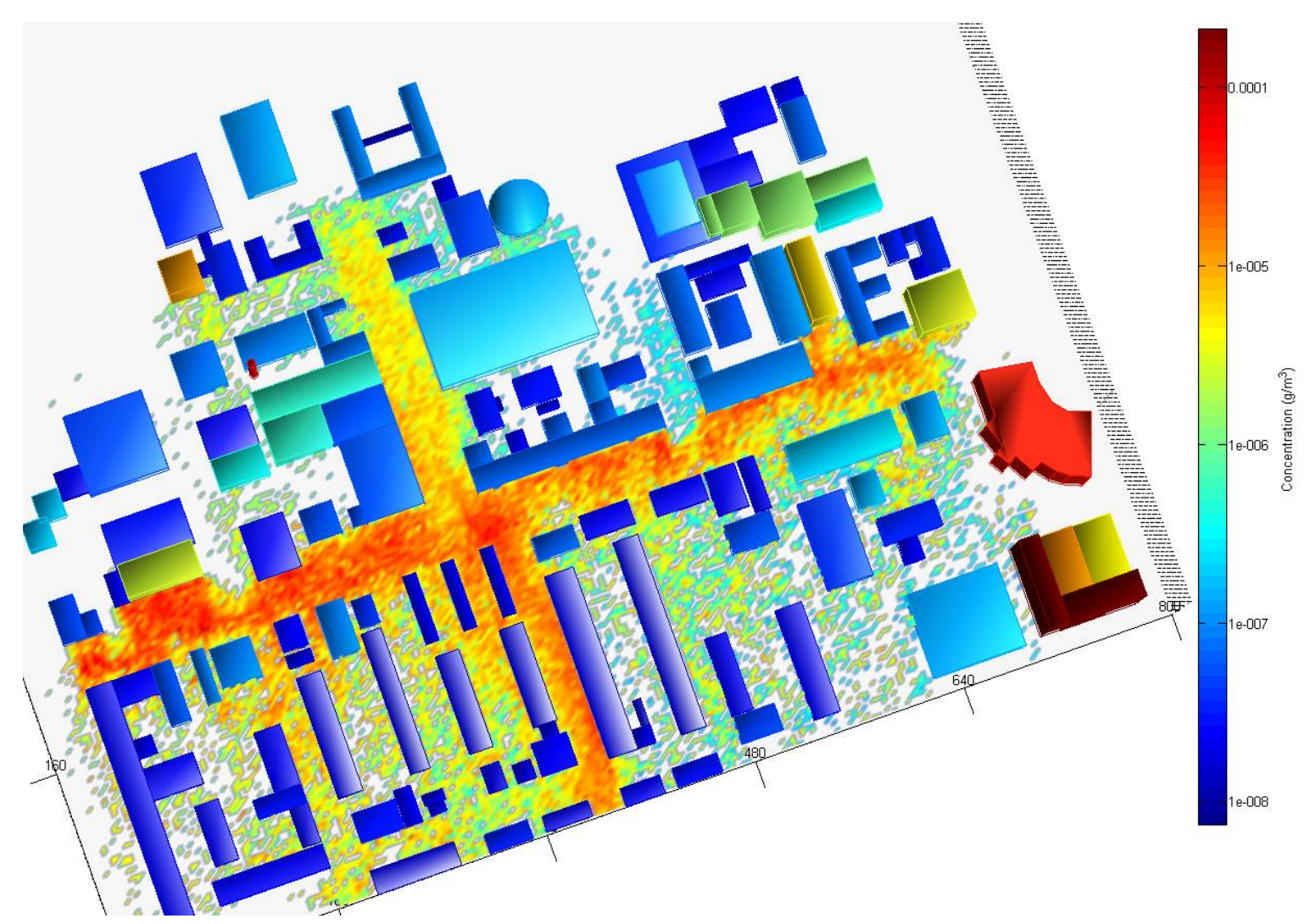

Figure 6-18 Avg. $\mathrm{NO}_{\mathrm{x}}$ Conc., St. George and College Street, July 13, 8:45 - 9:00 AM, 3m height

QUIC explicitly takes building geometry and associated wind effects into account. QUIC is a non-steady state model, where concentrations in the previous 15 minute interval affect the concentrations in the following time interval. As opposed to AERMOD, QUIC is a stochastic model since it computes the turbulent component of velocity using a random number generator. Even though the change in concentration due to different random seed inputs is generally very small, notable variations could occur in the tail of a plume due to higher variability (Los Alamos National Laboratory, 2010). The combined effect of several emission sources that are active for any given 15 minute period in the study, on modelled concentrations at the sensor location, could be substantial for different random number sets. Therefore, 30 model runs are performed, using different random number realisations, to estimate a distribution of modelled concentrations for both pollutants at the receptor location. June 3 and July 13 are randomly chosen for $\mathrm{CO}$ and $\mathrm{NO}_{\mathrm{x}}$ analysis, respectively. 16 distributions are generated (8 15 minute time periods for $\mathrm{CO}, 815$ minute time periods for $\mathrm{NO}_{\mathrm{x}}$ ). Each distribution consists of 30 modelled concentrations at the receptor location. Since modelled concentrations are generated at 15 minute intervals, for the 2 hour simulation period, 8 distributions are evaluated for each pollutant. The Kolmogorov- 
Smirnov test is used to check every distribution for a normal shape. At 98\% confidence, all 16 distributions pass the test for a normal distribution. Figure 6-19 shows sample normal distribution curves for modelled $\mathrm{CO}$ and $\mathrm{NO}_{\mathrm{x}}$ concentrations for one 15 minute interval. The mean and the standard deviation of each distribution are then calculated to obtain an average coefficient of variation for each pollutant. This coefficient of variation is 0.26 for the $\mathrm{CO}$ sample and 0.35 for the $\mathrm{NO}_{\mathrm{x}}$ sample.
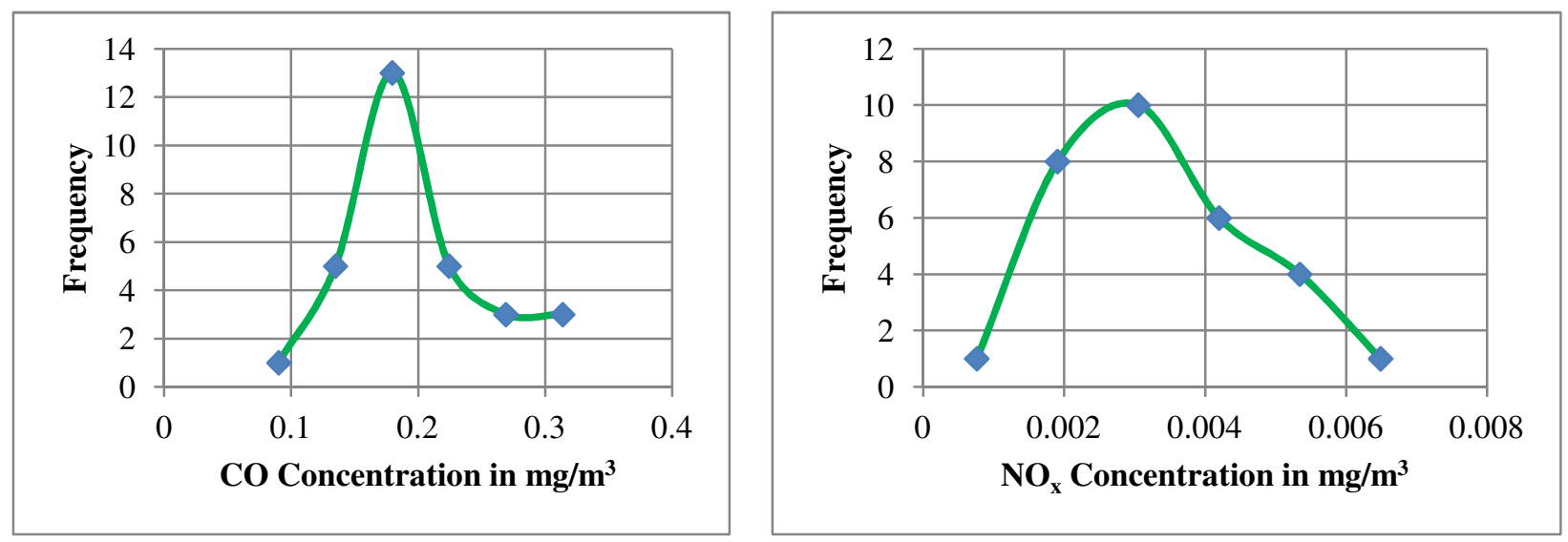

Figure 6-19 Sample Normal Distribution for QUIC Modelled Concentration at the Observed Sensor location for June 3, 2011 (7:15 - 7:30 AM, CO) and July 13, 2011 (8:30 - 8:45 AM, $\mathrm{NO}_{\mathrm{x}}$ )

Even though QUIC is a fast response model, due to the complexity of the modelling domain, number of sources and simulation time period, the model runs are time consuming and resource intensive. For a complete analysis of the selected weekdays in June and July 2011, the total run time using a Microsoft Windows PC with 4GB RAM and $2.2 \mathrm{GHz}$ processor is approximately 20 hours. It is practically infeasible to generate distributions of concentration values for each modelled day based on the analysis described above, since it would take approximately 600 hours of run time alone. Therefore, a margin of error due to random variation is computed on the modelled results, using the average coefficient of variations calculated above. For a single model run:

1) QUIC CO Analysis: With $75 \%$ confidence, the modelled concentration for a single replication is within $\pm 30 \%$ of the expected value of the modelled concentration

2) QUIC $\mathrm{NO}_{\mathrm{x}}$ Analysis: With $70 \%$ confidence, the modelled concentration for a single replication is within $\pm 37 \%$ of the expected value of the modelled concentration 
In calculating these intervals and error values, it is assumed that the coefficient of variation remains constant for all modelling days that belong to the same month. This assumption is justifiable since input atmospheric conditions for the morning peak period do not vary significantly within a month; note that a sample of eight different 15 minute interval traffic conditions has been tested with two wind speeds / directions (hourly averages) for each pollutant to estimate the average coefficient of variation.

Margin of error on QUIC modelled concentration presented in the following subsections are based on variability due to stochasticity within QUIC only. These bars do not include error in CMEM generated outputs due to random seed variation in PARAMICS. The confidence interval and margin of error calculated above also applies to modelled results developed in the sensitivity analyses described in Chapter 7.

\subsubsection{CO - QUIC Predicted Vs Observed}

For every weekday modelled in June 2011, QUIC estimates CO concentrations for eight 15 minute intervals spread over the 7:00 - 9:00 AM simulation period. Ambient CO concentrations are added to modelled values to estimate final predicted concentrations for comparison with the sensor observations. Based on this analysis, each modelled and observed $\mathrm{CO}$ data point is plotted together as shown in Figure 6-20. 20\% of the predicted values are within a 'factor of two' of the observed values as shown in Figure 6-21. 


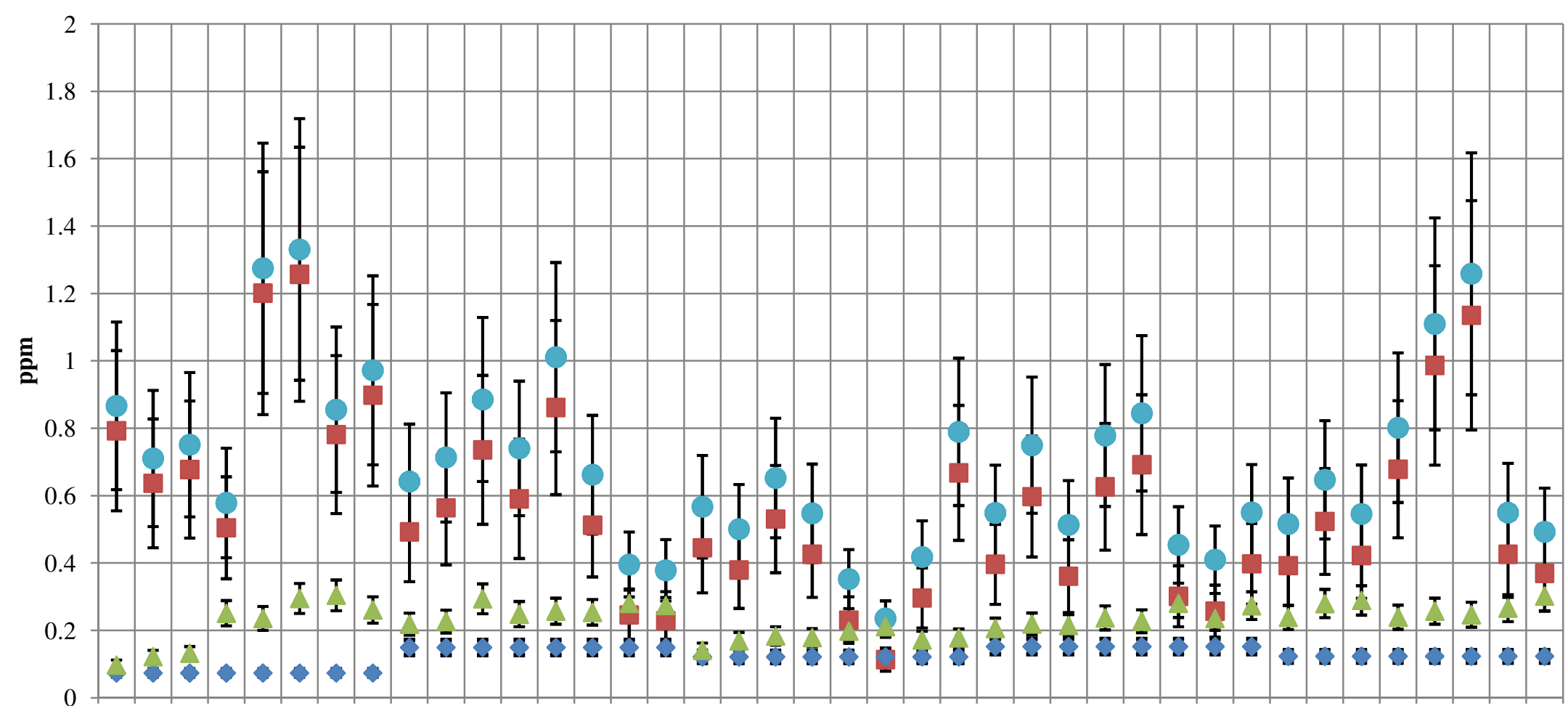

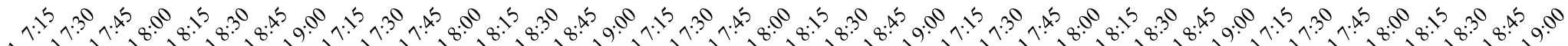

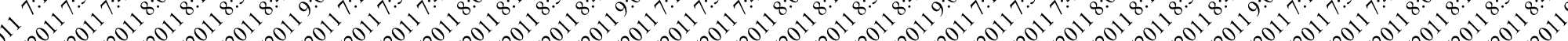

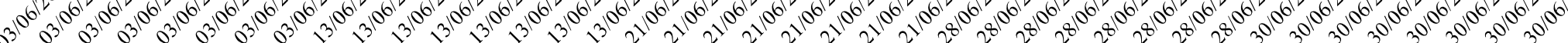

Time (15 minute averages) AM Peak Period

Modelled CO June 2011

$\checkmark$ Ambient $\mathrm{CO}$

- Predicted CO (Modelled + Ambient) $\triangle$ Observed CO

Figure 6-20 Observed Vs QUIC Predicted, 15 minute averaged CO Concentration 


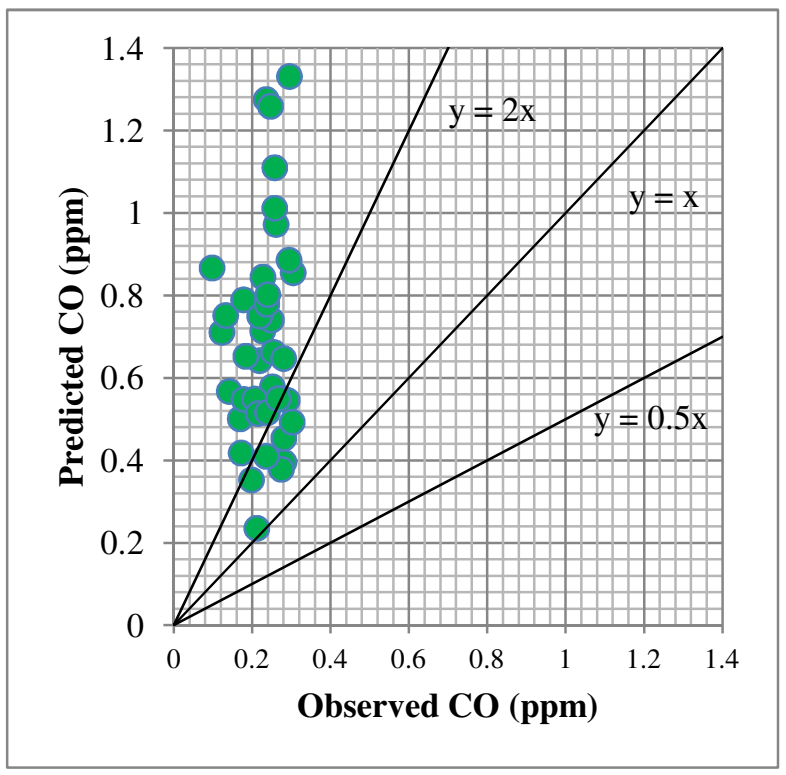

Figure 6-21 QUIC CO: Predicted Vs Observed Concentration

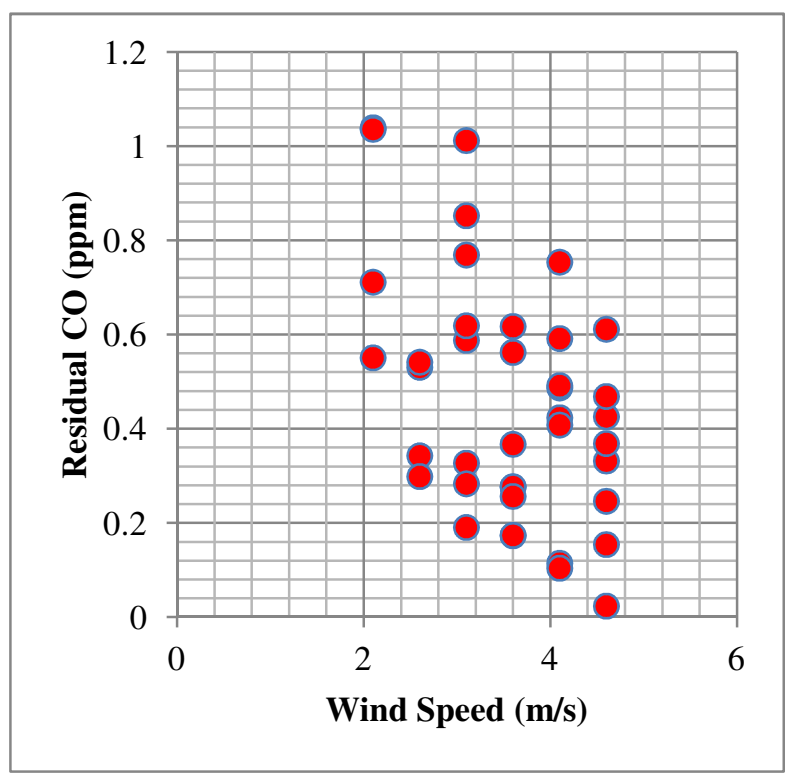

Figure 6-22 QUIC Residual CO Concentration Vs Wind Speed

The predicted $\mathrm{CO}$ concentrations are generally higher than the observed values indicating that QUIC is consistently over predicting. The plot of residual concentration against wind speed, as shown in Figure 6-22, highlights the fact that as wind speed increases, the residual concentration value decreases. One of the possible reasons for QUIC over predicting CO concentrations could be error in the vehicle type distribution.

\subsubsection{2 $\mathrm{NO}_{\mathrm{x}}-$ QUIC Predicted Vs Observed}

For the 5 weekdays modelled in July 2011, $\mathrm{NO}_{\mathrm{x}}$ concentration estimates are generated by QUIC for eight 15 minute intervals spread over 7:00 - 9:00 AM simulation period. Background concentrations for $\mathrm{NO}_{\mathrm{x}}$ are estimated using the same methodology applied for AERMOD. All modelled and observed $\mathrm{NO}_{\mathrm{x}}$ concentrations are plotted in Figure 6-23. The predicted and sensor observed concentration follow similar patterns and the differences are generally within the range of measurement / simulation error. $97 \%$ of predicted values are within a 'factor of two' of the observed values as shown in Figure 6-24. The QUIC model performance for $\mathrm{NO}_{\mathrm{x}}$ is better than for CO. Figure 6-25 shows that as the wind speed increases the residual concentration decreases, suggesting that the model predicts higher concentrations at low wind speeds and vice-versa. 


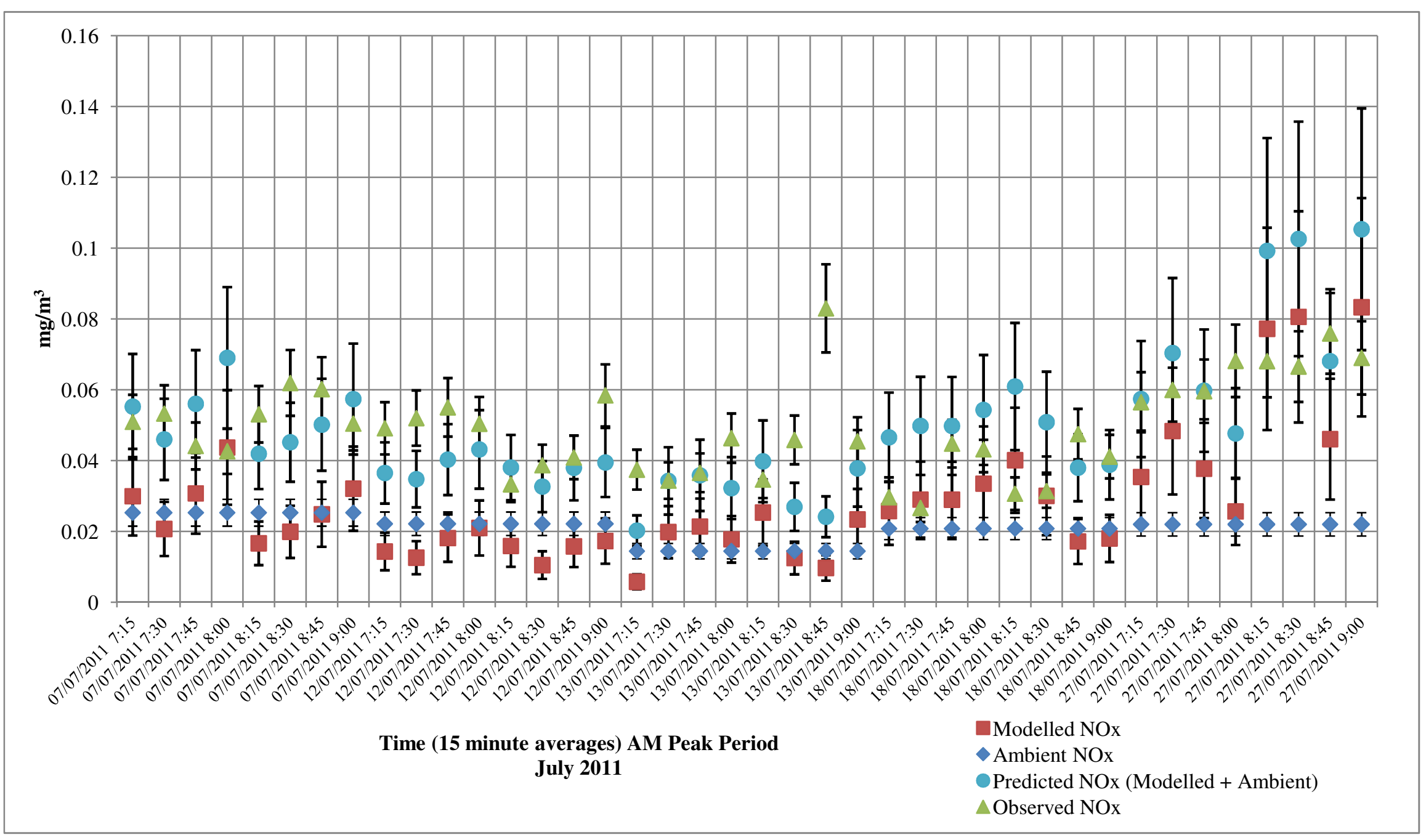

Figure 6-23 Observed Vs QUIC Predicted, 15 minute averaged, $\mathrm{NO}_{\mathrm{x}}$ Concentration 


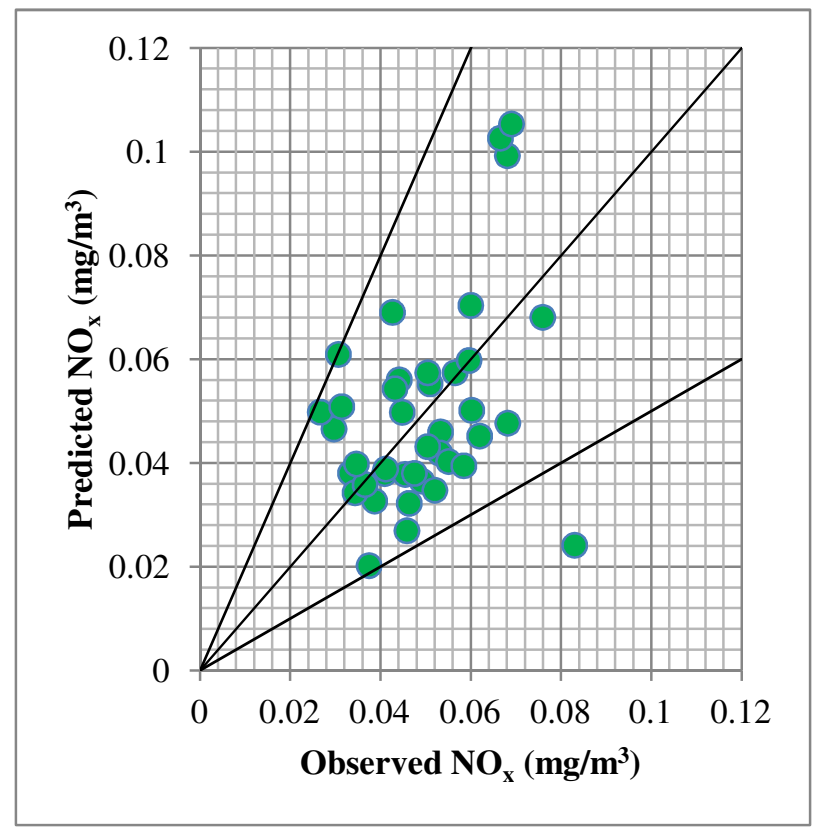

Figure 6-24 QUIC $\mathrm{NO}_{\mathrm{x}}$ : Predicted Vs

Observed Concentration

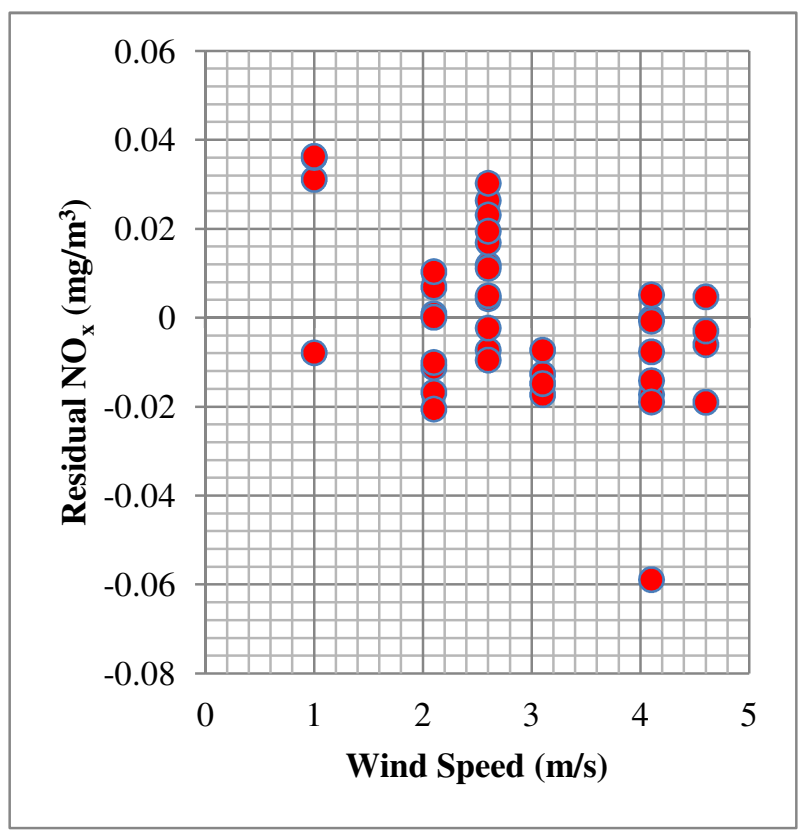

Figure 6-25 QUIC Residual $\mathrm{NO}_{\mathrm{x}}$

Concentration Vs Wind Speed

\subsection{Performance Evaluation}

\subsubsection{Introduction}

To make a consistent comparison between AERMOD and QUIC results, QUIC generated 15 minute average concentrations are aggregated to hourly values as plotted in Figure 6-26 (CO) and Figure 6-27 $\left(\mathrm{NO}_{\mathrm{x}}\right)$. Two important observations are:

1) For $\mathrm{CO}$, none of the QUIC predicted hourly averaged concentration values are within the 'factor of two' envelope, compared to AERMOD which has all its hourly averaged values within this factor.

2) For $\mathrm{NO}_{\mathrm{x}}$, all of the QUIC predicted hourly averaged values are within the 'factor of two' envelope compared to only $60 \%$ of AERMOD predicted hourly averaged values.

This indicates the modelling framework performs better for CO using AERMOD and for NOx using QUIC. However, these mean values are being tested for only one location in the modelling domain. A visual analysis of the spatial distribution of pollutants (refer to Appendix B, Figure B3, B4, and B5 for sample graphs), shows that AERMOD occasionally estimates unrealistically 
high concentration for both $\mathrm{CO}$ and $\mathrm{NO}_{\mathrm{x}}$ on the roadway. These high concentration regions are located very close to the point sources modelled in AERMOD. Increasing the number of point sources could help spread the concentration better; however, model run time would increase considerably in that case. In comparison, the spatial distribution of pollutant concentrations modelled using QUIC looks more realistic. Specifically, QUIC results do not exhibit peaks / troughs of extremely high or low concentrations as observed for AERMOD results. Due to limited observed data, a comparison between the 'modelling framework' predicted concentrations and observed concentrations is not performed.

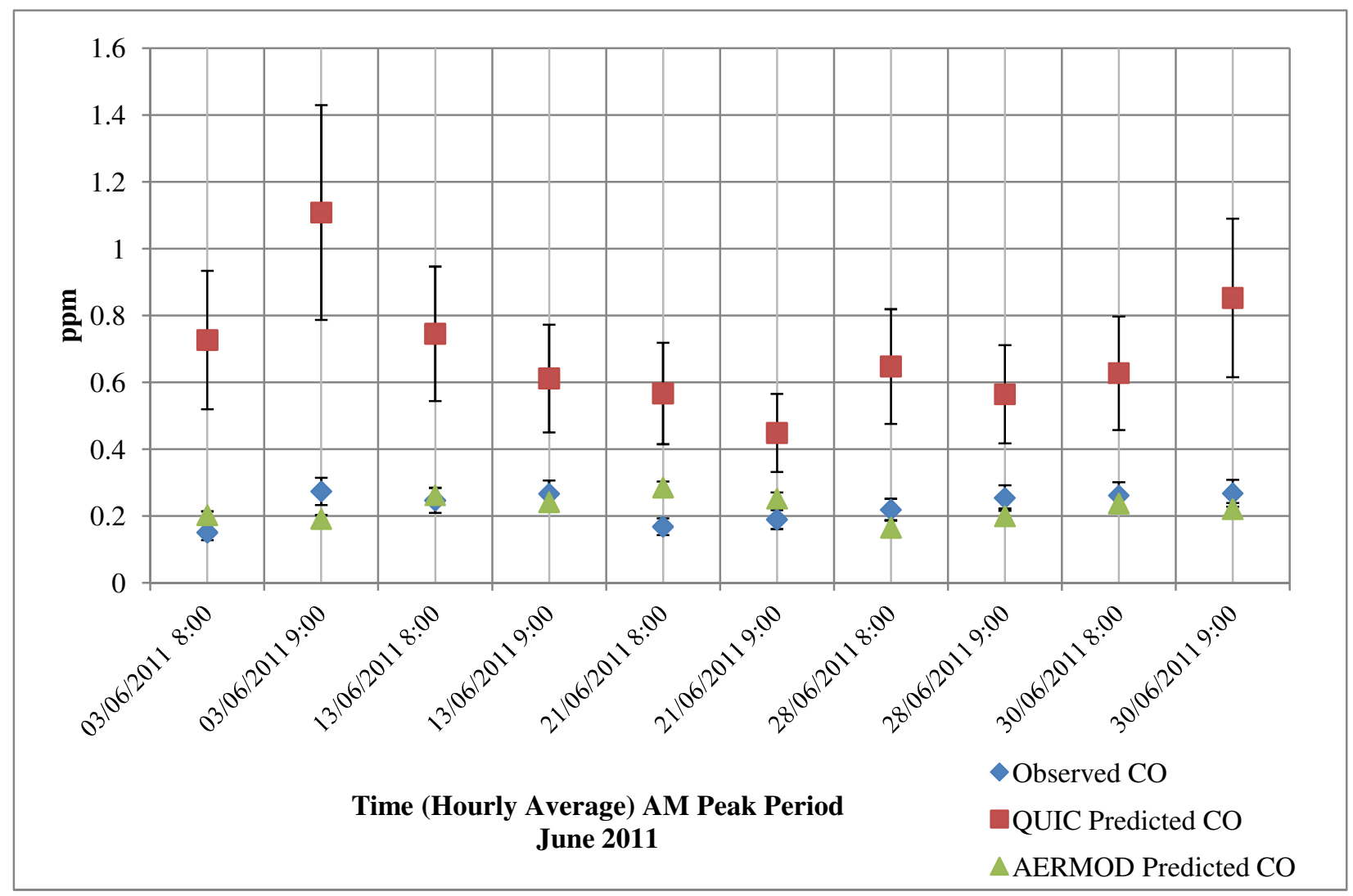

Figure 6-26 Hourly Average CO Concentrations, AERMOD Vs QUIC Vs Observed 


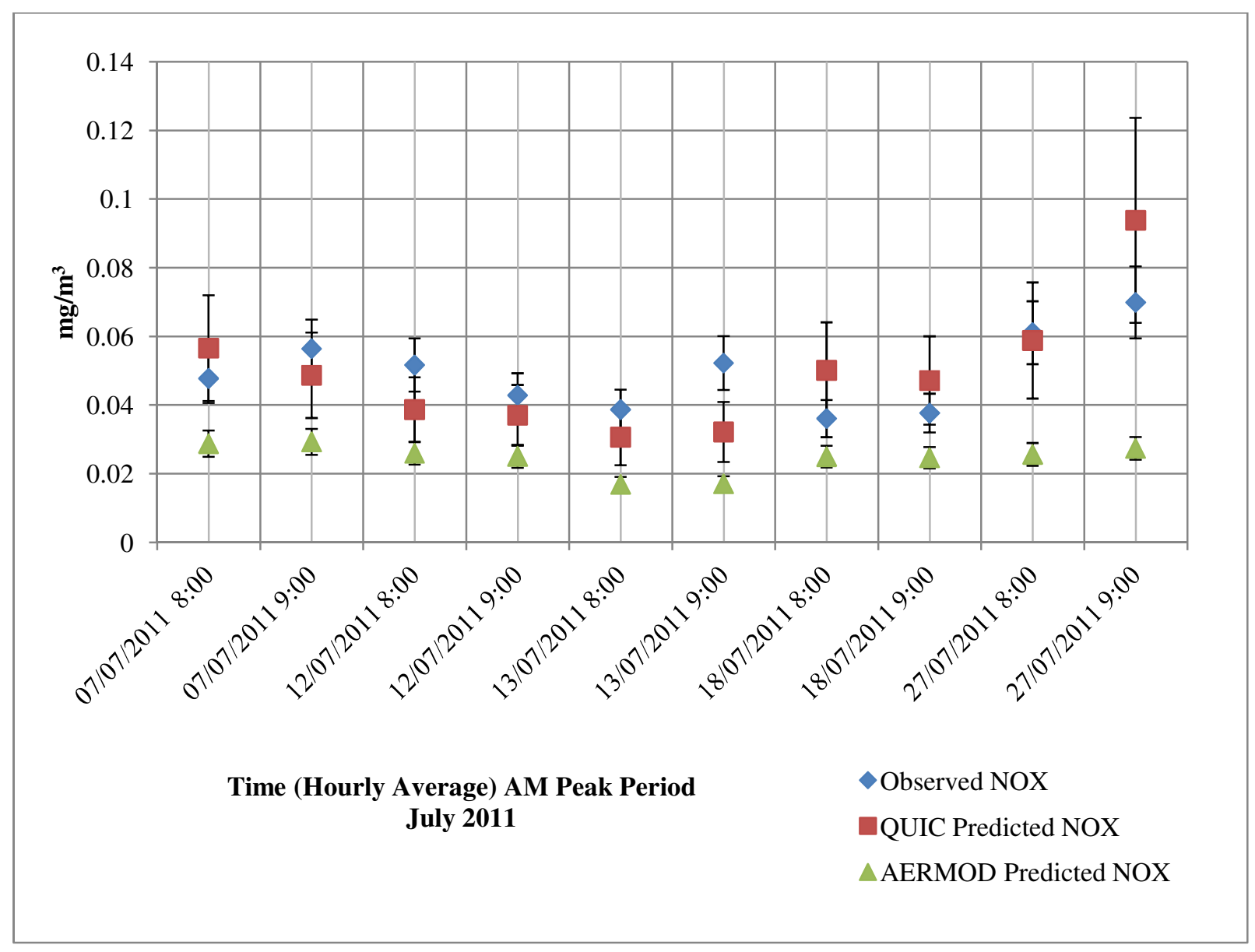

Figure 6-27 Hourly Average $\mathrm{NO}_{\mathrm{x}}$ Concentrations, AERMOD Vs QUIC Vs Observed

QUIC can model intra hour variability in concentrations. For example, in the case of $\mathrm{NO}_{\mathrm{x}}$, the coefficient of variation $(\mathrm{CV})$ of predicted and observed concentrations calculated within the 2 hour modelling period is expressed as a percentage for the five days modelled as shown in Figure 6-28; a high CV value demonstrates the significance of modelling pollutants at finer averaging time periods, to capture high variability in concentrations. This graph suggests that concentrations can vary substantially within the hour; therefore, it would be useful to model pollutants at smaller averaging periods to capture the true variability in concentrations; the graph shows that on an average, QUIC can model the variation well (18\%) compared to observed concentration (19\%). 


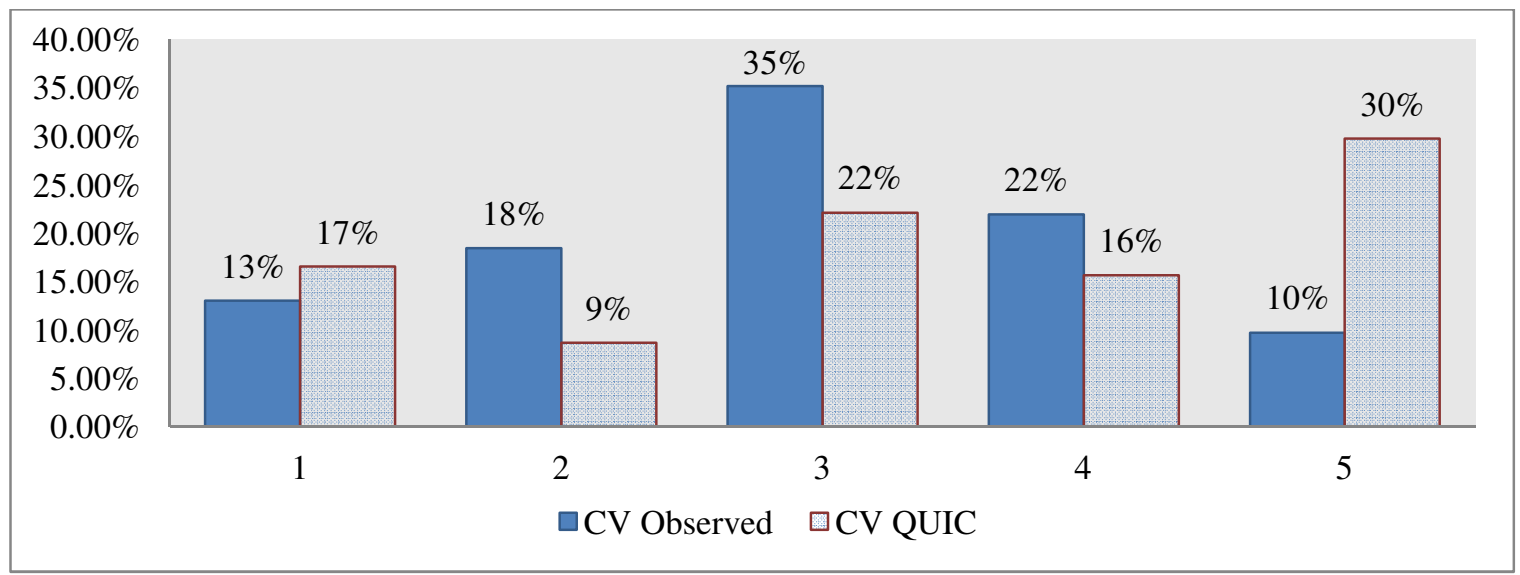

Figure 6-28 Coefficient of Variation of Hourly Concentration for QUIC Modelled and Sensor Observed Values, $\mathrm{NO}_{\mathrm{x}}$, Five Weekdays, July 2011

It is not possible to perform a similar analysis using AERMOD, since the minimum concentration output time resolution is 1 hour. An intra hour variation in concentration could be useful to analyse areas where higher pollutant concentrations are observed, and air pollution standards are frequently exceeded; QUIC would be more useful than AERMOD for that purpose.

\subsubsection{Performance Evaluation}

Performance measures can generally be divided into statistical measures of difference, and correlation measures comparing modelled and observed data points (Arya, 1999). Several statistical parameters have been proposed to evaluate predicted and observed concentrations since the 1980 AMS Workshop on Dispersion Model Performance (Fox, 1981). Weil, et al. (1992) conducted a detailed review of methods used to evaluate air-quality models. The most commonly suggested evaluation parameters are the bias (d) between predicted and observed concentrations, the gross error (GE, bias of the absolute difference between the predicted and observed concentrations), and variance of the difference (Arya, 1999). The bias and gross error are defined as:

$$
\begin{gathered}
\mathrm{d}=(\mathrm{m}-\mathrm{o})_{\mathrm{n}} \\
\mathrm{GE}=\operatorname{Mod}\left|(\mathrm{m}-\mathrm{o})_{\mathrm{n}}\right|
\end{gathered}
$$

Where, m: nth reading of modelled concentration o: nth reading of observed concentration 
Other measures that are widely used include the fractional bias (FB) (Irwin \& Smith, 1984) and the fractional scatter (FS) (Cox \& Tikvart, 1985). FB and FS specify the ability of the model to reproduce the average, and the breadth of the observed concentrations, respectively. They are defined as follows:

$$
F B=2 \frac{M-O}{M+O} \quad F S=2 \frac{S_{m}-S_{o}}{S_{m}+S_{o}}
$$

Where,

M: Mean modelled concentration

O: Mean observed concentration

$\mathrm{S}_{\mathrm{m}}:$ Standard deviation of modelled concentration

$\mathrm{S}_{\mathrm{o}}$ : Standard deviation of observed concentration

For the calculation of FB and FS, typically, only the highest 25 concentrations are evaluated in an unpaired state of time and location. This means that the highest predicted and observed concentrations are evaluated regardless of their time of occurrence or location of measurement. Such a comparison is scientifically flawed and has been criticised by Zannetti (1990). A more stringent measure is a paired comparison where the time and location of predicted and observed concentrations are fixed. The latter is adopted in for both FB and FS estimation. Additionally, instead of only measuring the top 25 concentrations, all data records are evaluated to provide a stricter test for the modelling framework performance. FB and FS values range from +2 (indicating high over-prediction) to -2 (indicating high under-prediction). It is important to note that in case of AERMOD only 10 concentration values are predicted for each pollutant, therefore, only those values have been used for estimation of these statistical parameters.

Zannetti (1990) proposed several methods for evaluating dispersion models including the Pearson correlation coefficient (R), the regression line passing through the origin, and frequency distribution analyses of the residual values, among others. The Pearson correlation coefficient is an indicator of the strength of the linear relationship between the predicted and the observed concentration value. Ideally this value should equal 1 for perfect replication of observed concentrations by the model. The regression line captures the fit of the observed data to the predicted value; the slope of the line generally indicates whether the model is over-predicting or under-predicting. Additional measures include the normalized mean square error (NMSE) 
(Hanna \& Heinold, 1985) and the 'factor of two' comparison (F2) (introduced earlier in this chapter). The NMSE is defined as follows:

$$
N M S E=\frac{\overline{(m-o)^{2}}}{M . O}
$$

Where,

M: Mean modelled concentration

O: Mean observed concentration

$\mathrm{m}$ : Modelled concentration for one reading

o: Observed concentration for one reading (the bar on numerator indicates values are averaged over all data records)

Table 6-1 provides a summary of all the statistical performance evaluation parameters analysed for comparison between AERMOD and QUIC. Hourly results for QUIC are generated by aggregating the 15 minute averaged results for better comparison with AERMOD. ' $d$ ' and 'GE' represent the average value for the complete data record; these values are in ppm for $\mathrm{CO}$ and $\mathrm{mg} / \mathrm{m}^{3}$ for $\mathrm{NO}_{\mathrm{x}}$. The Pearson correlation coefficient $\left(\mathrm{R}_{\mathrm{p}}\right)$ measures the correlation between observed and predicted concentrations.

The performance of both dispersion models varies for both pollutants. QUIC performs better for $\mathrm{NO}_{\mathrm{x}}$, while AERMOD performs better for CO. However, AERMOD has a negative correlation for $\mathrm{CO}$ concentrations indicating that as observed concentrations increase, AERMOD predicted concentrations decrease; QUIC, on the other hand, has a positive correlation. This indicates that even though the 'factor of two' performance of AERMOD is better than QUIC, it is not able to accurately replicate the observed trends of $\mathrm{CO}$ concentrations. For $\mathrm{CO}$, QUIC has a high positive FB and FS value indicating over-prediction; whereas AERMOD has a negative value for FB and FS indicating under-prediction; the NMSE is large for QUIC and quite small for AERMOD. QUIC has a higher correlation with predicted values for $\mathrm{NO}_{\mathrm{x}}$ than AERMOD; the smaller FB and FS values confirm that QUIC performs better than AERMOD for $\mathrm{NO}_{\mathrm{x}}$. 
Table 6-1 Statistical Performance Evaluation of AERMOD and QUIC

\begin{tabular}{|c|c|c|c|c|c|c|}
\hline $\begin{array}{l}\text { Statistical } \\
\text { Parameter }\end{array}$ & $\begin{array}{l}\text { AERMOD } \\
\text { CO Hourly }\end{array}$ & $\begin{array}{c}\text { AERMOD } \\
\mathrm{NO}_{\mathrm{x}} \\
\text { Hourly }\end{array}$ & $\begin{array}{l}\text { QUIC } \\
\text { CO 15- } \\
\text { min }\end{array}$ & $\begin{array}{c}\text { QUIC } \\
\mathrm{NO}_{\mathrm{x}} 15- \\
\min \end{array}$ & $\begin{array}{c}\text { QUIC } \\
\text { CO } \\
\text { Hourly }\end{array}$ & $\begin{array}{c}\text { QUIC } \\
\mathrm{NO}_{\mathrm{x}} \\
\text { Hourly }\end{array}$ \\
\hline $\mathrm{D}\left(\mathrm{ppm}\right.$ or $\left.\mathrm{mg} / \mathrm{m}^{3}\right)$ & -0.004 & -0.025 & 0.460 & -0.00006 & 0.460 & -0.00006 \\
\hline $\mathrm{GE}$ (ppm or $\left.\mathrm{mg} / \mathrm{m}^{3}\right)$ & 0.053 & 0.025 & 0.460 & 0.014 & 0.460 & 0.011 \\
\hline Var. & 0.004 & 0.0001 & 0.066 & 0.0003 & 0.029 & 0.0002 \\
\hline $\mathrm{R}_{\mathrm{p}}$ & -0.204 & 0.353 & 0.122 & 0.392 & 0.432 & 0.674 \\
\hline $\mathrm{F} 2$ & $100 \%$ & $60 \%$ & $20 \%$ & $97.5 \%$ & $0 \%$ & $100 \%$ \\
\hline FB & -0.017 & -0.671 & 1.000 & -0.001 & 1.000 & -0.001 \\
\hline FS & -0.211 & -0.880 & 1.333 & 0.365 & 1.213 & 0.499 \\
\hline NMSE & 0.071 & 0.587 & 1.736 & 0.139 & 1.497 & 0.068 \\
\hline
\end{tabular}

\subsection{Comments}

The proposed micro-modelling framework is validated for both AERMOD and QUIC at their respective scale of averaging concentrations for both pollutants with some reservations. Following are key remarks on this validation process:

1) AERMOD performs better than QUIC for $\mathrm{CO}$, although, it has negative correlation between predicted and measured concentration values.

2) QUIC performs very well for $\mathrm{NO}_{\mathrm{x}}$ with a fairly high positive correlation between the predicted and measured concentration values.

3) QUIC predicts higher concentrations compared to AERMOD for both pollutants possibly because it can explicitly take the effect of street canyon into account. Therefore, the recirculation of pollutants is modelled more comprehensively by QUIC. 


\section{Chapter 7}

\section{Sensitivity Analyses}

Sensitivity analyses is undertaken to better understand the behaviour of the QUIC dispersion model and observe the scale of variation in modelled concentrations as input parameters are altered. QUIC is selected for the following reasons:

1) The validation results obtained for $\mathrm{CO}$ and $\mathrm{NO}_{\mathrm{x}}$ indicate that QUIC outperforms AERMOD for $\mathrm{NO}_{\mathrm{x}}$. Although AERMOD performs better for $\mathrm{CO}$, it has a negative correlation indicating that pollutant trends are not being modelled properly by AERMOD. A visual analysis of the overall spatial distribution suggests that concentration contours in QUIC are much more realistic and do not exhibit peaks / troughs of extremely high / low concentrations as observed for AERMOD results.

2) Using QUIC, concentration plots can be generated at a fine time scale, that could be used to analyse 'hot-spots' of population exposure within a given peak hour period. Such an analysis is not possible in AERMOD due to hourly average concentration outputs.

3) The finer time averaging period exploits the benefit of using a traffic microsimulation model to simulate traffic movement better. Thus, QUIC seems to have functionality that better suits a micro-modelling approach.

\subsection{Input Parameters}

Randomly selected weekdays are used to perform these sensitivity analyses. All modelled concentrations are generated at the observed sensor location. Ambient concentrations are not added to the modelled concentrations, since the intent of this analysis is to only capture the scale of variation in modelled concentrations. The following parameters are analysed:

1) Horizontal Wind Speed / Direction

2) Total Traffic Volume

3) Vehicle Type Distribution

4) Atmospheric Stability

5) Time Step 


\subsubsection{Mean Wind Speed and Direction}

The hourly mean horizontal wind speed is specified at the St. George and College Street intersection at $(\mathrm{X}=353.6 \mathrm{~m}, \mathrm{Y}=222.7 \mathrm{~m})$ in the QUIC modelling domain. The experimental design for this sensitivity is given in Table 7-1. 12 different cases are analysed for different wind speeds and directions. The range of wind speeds to be tested is based on observed wind data analysis. Approximately 90\% of all observed winds, for the morning peak period between 7:00 9:00 AM for June and July 2011, are in the range of $0.5 \mathrm{~m} / \mathrm{s}-5.7 \mathrm{~m} / \mathrm{s}$. It should be noted that the wind speed / direction values are hourly averages, even though concentrations are being averaged at 15 minute intervals in QUIC. June 3, 2011 is randomly selected for this analysis. All input parameters, including traffic volume and other meteorological data are kept constant, and the wind speed / direction are varied based on the experimental design. The results obtained are shown in Figure 7-1.

Table 7-1 Wind Speed Sensitivity Experimental Design

\begin{tabular}{|c|c|c|c|}
\hline $\begin{array}{c}\text { Wind Speed / Direction (blowing from, } \\
\text { clockwise from north) }\end{array}$ & $1 \mathrm{~m} / \mathrm{s}$ & $3 \mathrm{~m} / \mathrm{s}$ & $6 \mathrm{~m} / \mathrm{s}$ \\
\hline $0^{\circ}$ & $\checkmark$ & $\checkmark$ & $\checkmark$ \\
\hline $90^{\circ}$ & $\checkmark$ & $\checkmark$ & $\checkmark$ \\
\hline $180^{\circ}$ & $\checkmark$ & $\checkmark$ & $\checkmark$ \\
\hline $270^{\circ}$ & $\checkmark$ & $\checkmark$ & $\checkmark$ \\
\hline
\end{tabular}

As observed, QUIC is highly sensitive to wind conditions. The highest concentrations are observed for $1 \mathrm{~m} / \mathrm{s}$ wind speed, while the lowest concentrations are observed at the highest wind speed of $6 \mathrm{~m} / \mathrm{s}$ due to transport of pollutants away from the modelling receptor location. The $270^{\circ}$ wind angle results in the highest concentration for a given wind speed possibly due to effect of recirculation of pollutants in the street canyon at that wind angle and location of the measuring sensor on the north side of College Street. The standard deviation of concentration obtained for different wind speed and direction combinations is plotted at 15 minute intervals as shown in Figure 7-2. The standard deviation values imply that the variation in modelled concentration is high for different wind conditions. This implies that horizontal wind speed is a critical factor in 
pollutant dispersion. The average coefficient of variation is very high (0.96), which highlights the underlying need to accurately model wind for a dispersion analysis.

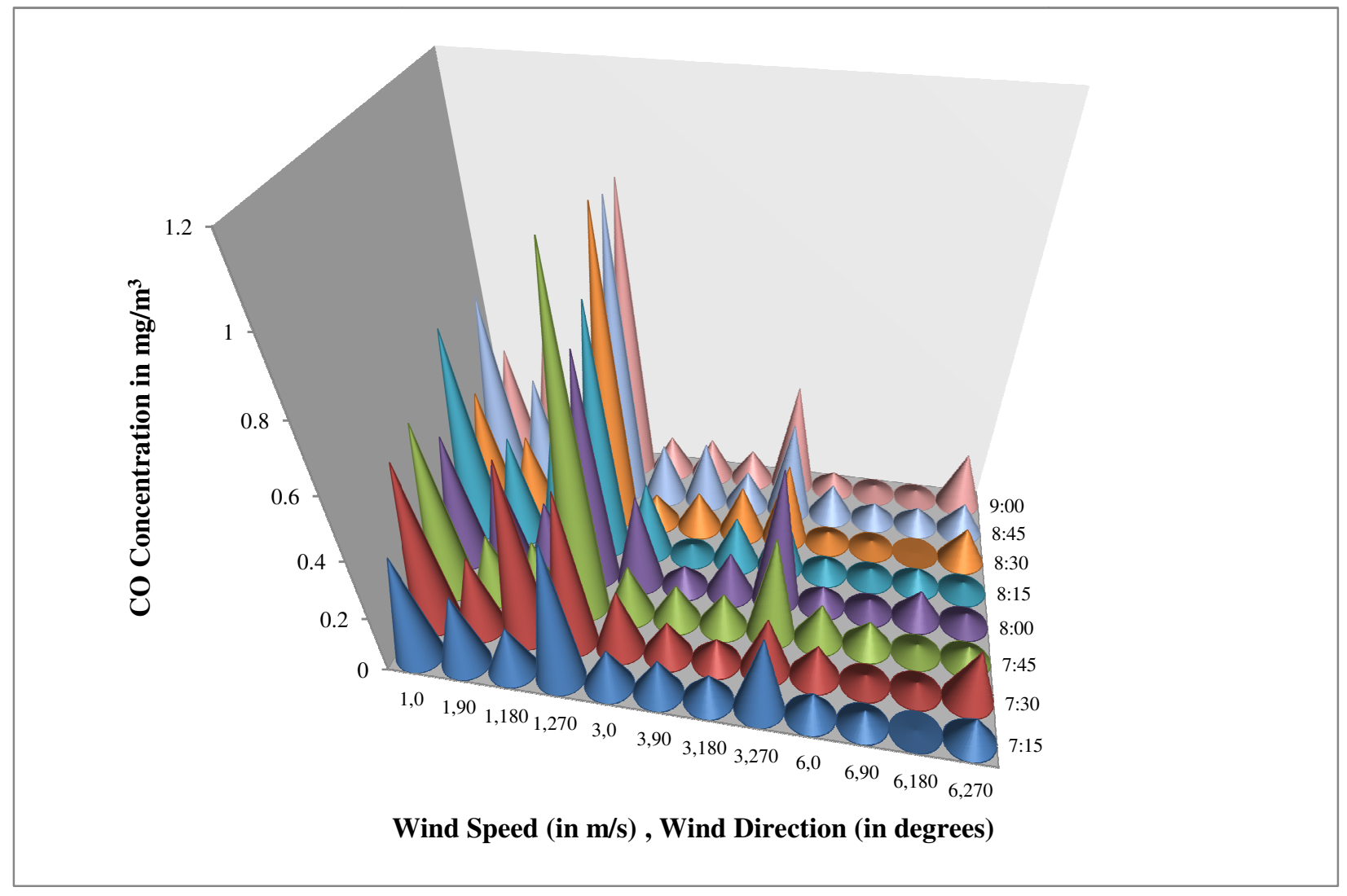

Figure 7-1 Wind Sensitivity, QUIC Modelled CO Concentrations, June 3, 2011

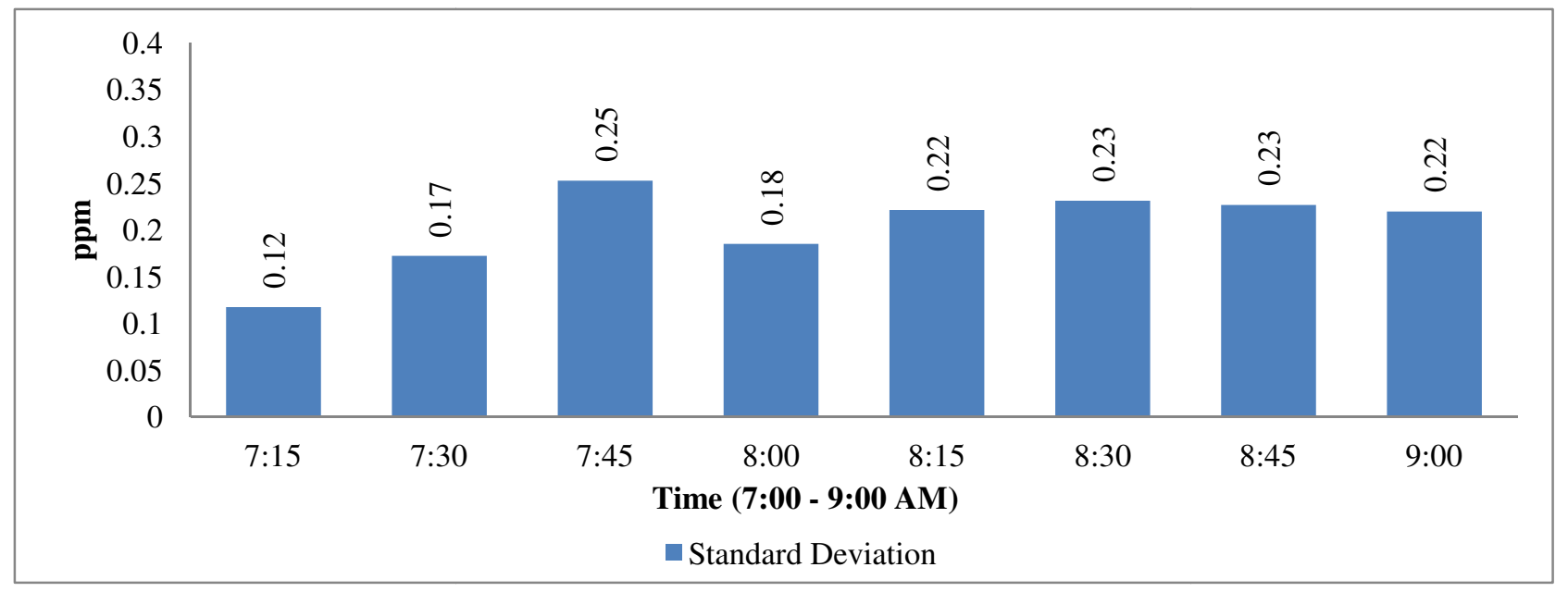

Figure 7-2 Wind Speed, Standard Deviation, June 3, 2011 


\subsubsection{Traffic Volume}

The total traffic volume on the network can be varied by changing the divisor of the O-D matrix in PARAMICS. Modelled concentrations are analysed using five traffic volumes for randomly selected days in June (for $\mathrm{CO}$ ) and July (for $\mathrm{NO}_{\mathrm{x}}$ ). The following cases are evaluated:

1) $70 \%$ of current traffic $(0.7 \mathrm{x}$, where $\mathrm{x}=$ current $\mathrm{O}-\mathrm{D}$ matrix input $)$

2) $80 \%$ of current traffic $(0.8 x)$

3) $100 \%$ of current traffic (1x, existing O-D matrix input)

4) $120 \%$ of current traffic $(1.2 x)$

5) $130 \%$ of current traffic $(1.3 x)$

The results obtained are shown in Figure 7-3 and 7-4. Since all other input parameters are kept constant, if the total traffic volume is increased, the total emissions on the network should increase. Both $\mathrm{CO}$ and $\mathrm{NO}_{\mathrm{x}}$ generally show this trend. A few anomalies are observed in $\mathrm{NO}_{\mathrm{x}}$ results; however, it should be noted that $\mathrm{NO}_{\mathrm{x}}$ concentrations are generated at $70 \%$ confidence interval with $37 \%$ error on mean. Nonetheless, the $\mathrm{NO}_{\mathrm{x}}$ analysis is redone with a different random seed input and the results are plotted again as shown in Figure 7-5. The new $\mathrm{NO}_{\mathrm{x}}$ results show the expected trend of increasing concentrations with increase in traffic.

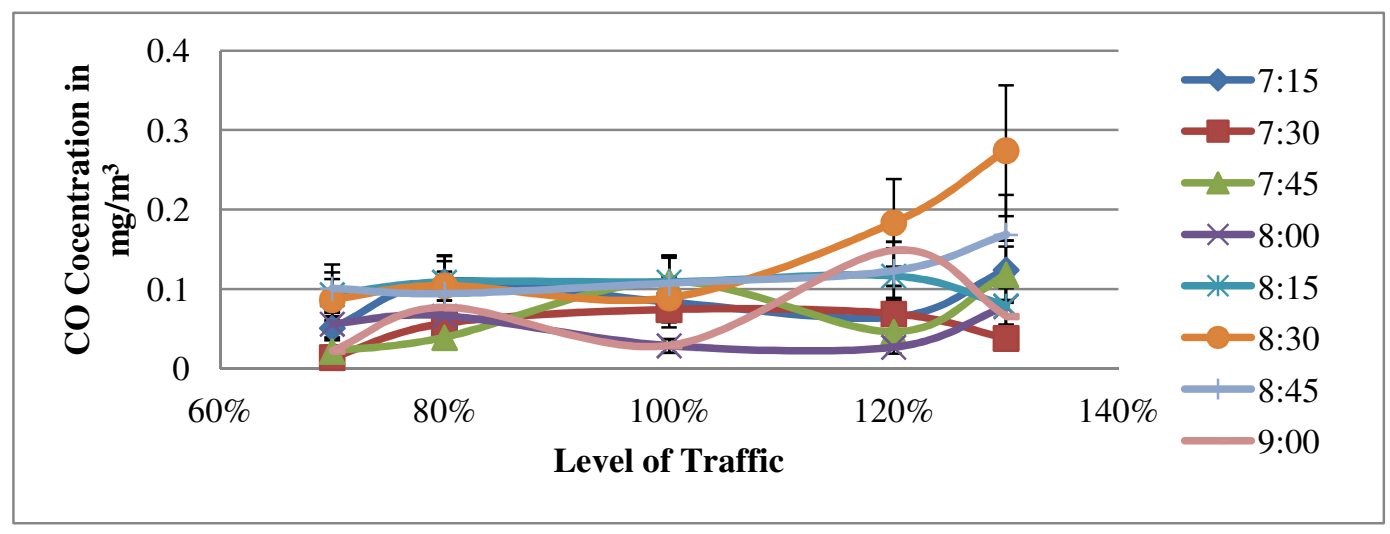

Figure 7-3 Impact of Traffic Change on CO Concentration, June 24, 2011

The average coefficient of variation is 0.45 for $\mathrm{CO}$ and 0.36 (-100 random seed) / 0.41 (-367 random seed) for $\mathrm{NO}_{\mathrm{x}}$. This indicates that emission variations due to traffic are roughly half of the variations observed due to changing wind speed. The variation observed for $\mathrm{NO}_{\mathrm{x}}$ concentrations is smaller than $\mathrm{CO}$, likely due to a very small presence of heavy vehicle / trucks 
(which are a major source of $\mathrm{NO}_{\mathrm{x}}$ ) on the network; the net increase in total heavy vehicle traffic for the five traffic conditions analysed is insignificant, causing the modelled concentrations to not vary a lot.

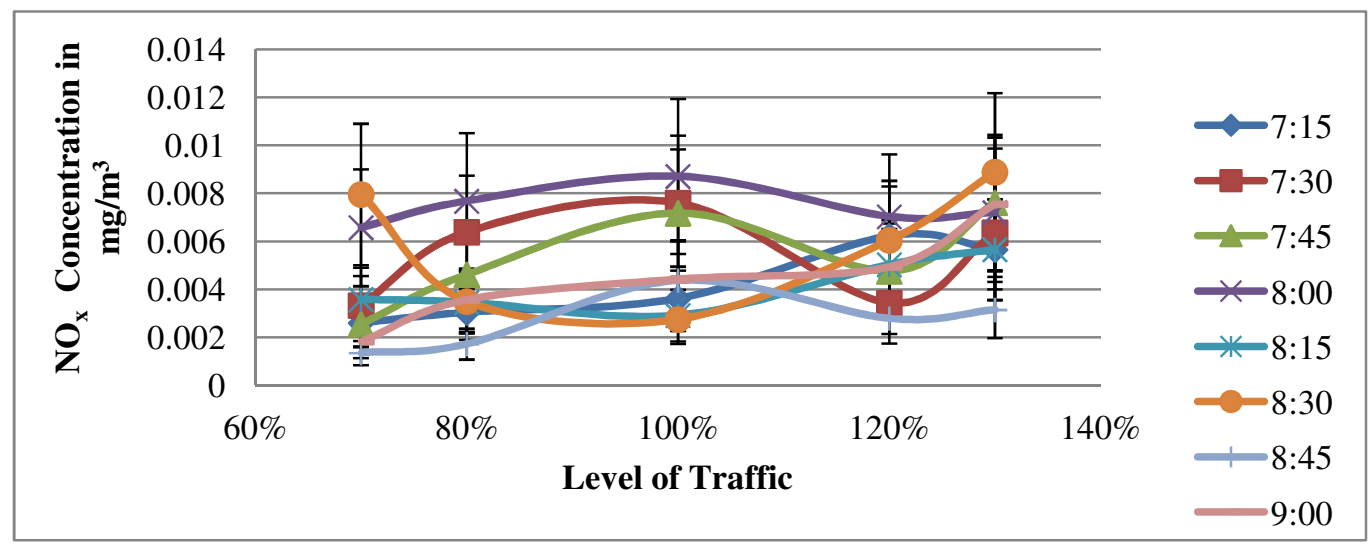

Figure 7-4 Impact of Traffic Change on $\mathrm{NO}_{\mathrm{x}}$ Concentration, July 12, 2011; Random No. -100

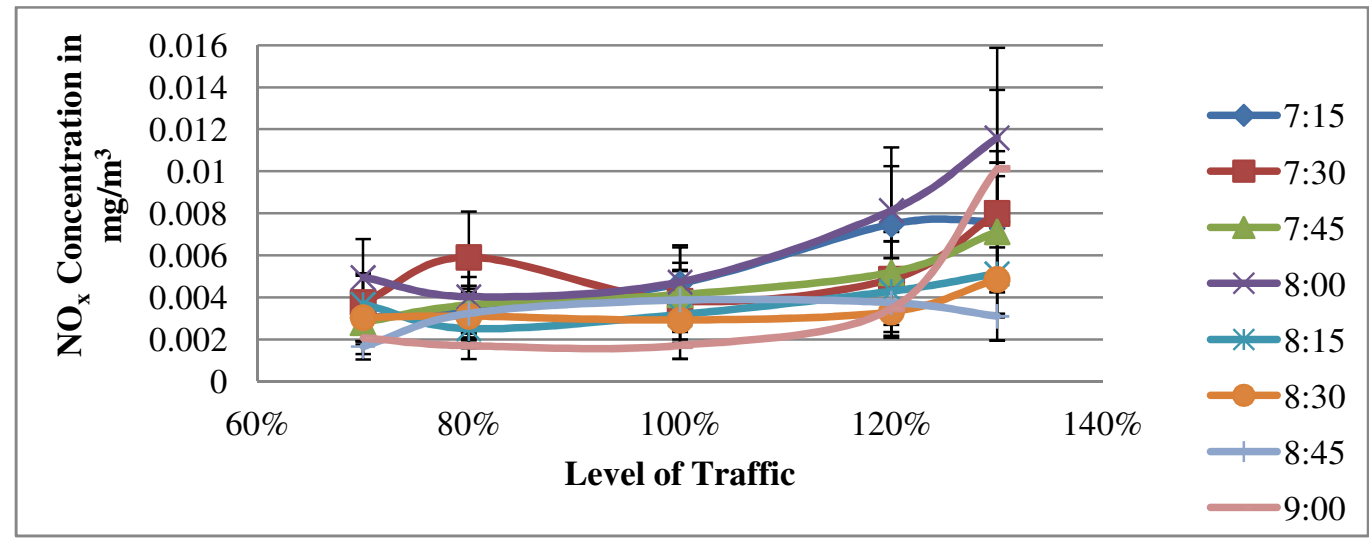

Figure 7-5 Impact of Traffic Change on $\mathrm{NO}_{\mathrm{x}}$ Concentration, July 12, 2011; Random No.-367

\subsubsection{Vehicle Type Distribution}

The objective of this sensitivity is to test the impact of varying the distribution of vehicle types on modelled concentration. The randomly chosen days for this analysis are June 10 (CO) and July $27\left(\mathrm{NO}_{\mathrm{x}}\right), 2011$. The different vehicle distributions used are shown in Table 7-2. Four cases are analysed as follows:

1) The base case represents the original vehicle type distribution used for validation.

2) Case 1 is a 'clean' scenario where $65.13 \%$ of vehicles in Light Vehicle (LV) matrix are ultra low emissions vehicle. The tier 1, High P/W passenger car (CMEM categories 9 and 
11) proportion is reduced to zero in LV matrix. All heavy duty trucks are assigned to CMEM category 7 in the Medium/Heavy Vehicle (MHV) matrix, which is the latest version of heavy duty truck available in CMEM.

3) Case 2 is a 'very clean' scenario where $97.59 \%$ of vehicles in LV matrix are ultra low emissions vehicle. All medium duty trucks are assigned to CMEM Category 40, which is a diesel powered truck, in MHV matrix.

4) Case 3 is an 'unclean' scenario where the ultra low emission vehicle proportion from Case 2 is distributed among all the other vehicle categories within LV matrix. MHV matrix composition is unchanged from Case 2.

Table 7-2 Vehicle Type Distribution for Sensitivity Analyses

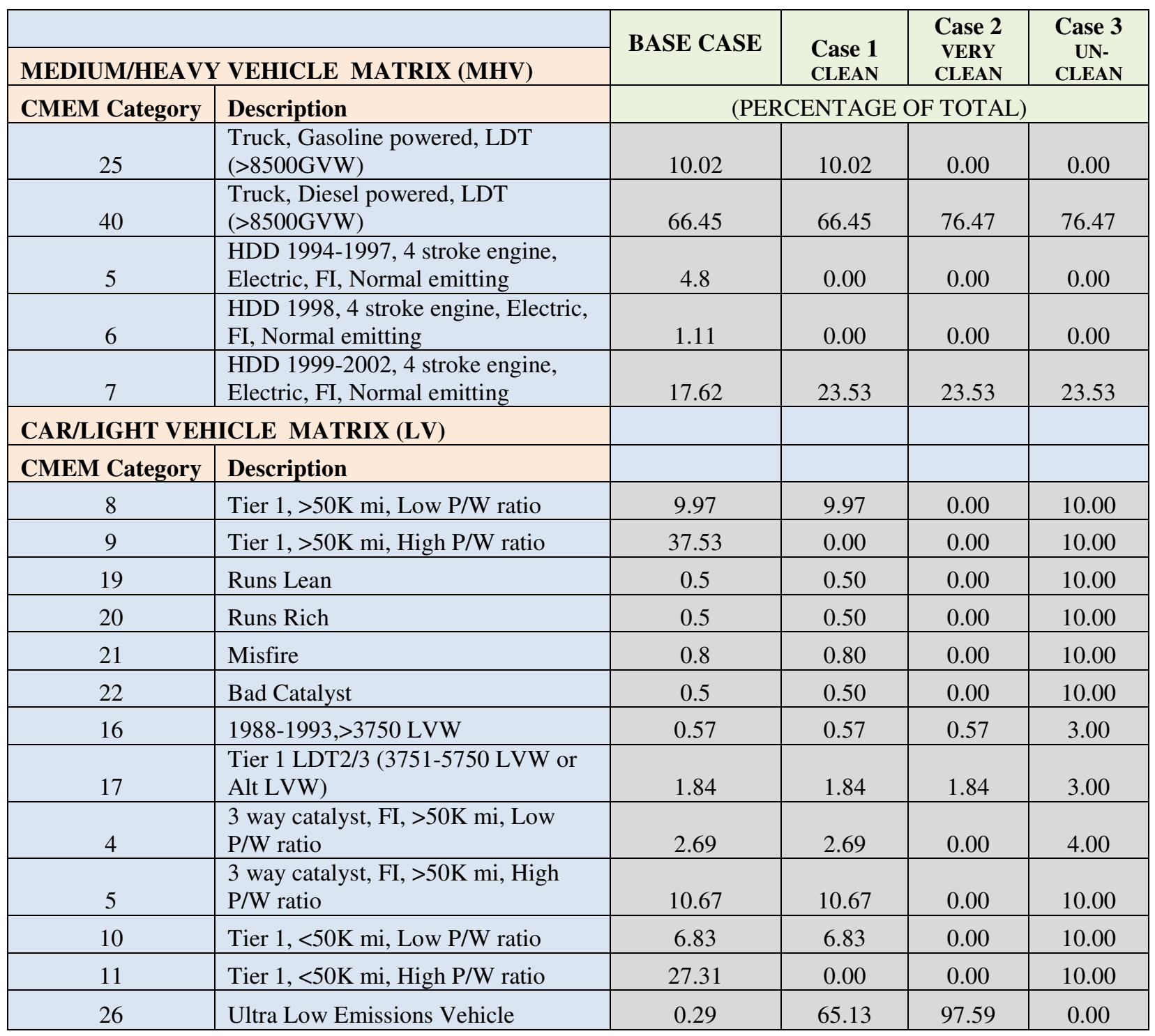




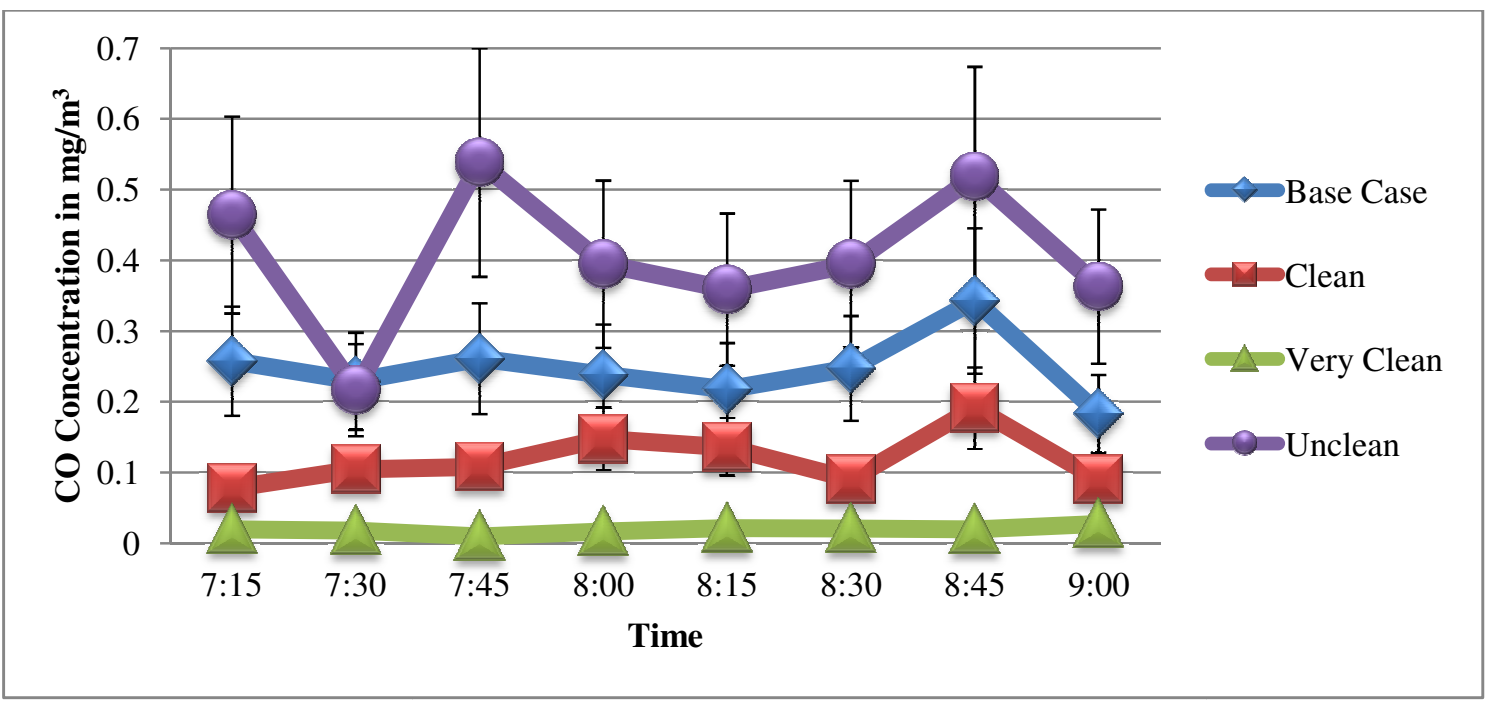

Figure 7-6 Vehicle Type Distribution Sensitivity, CO Concentration, June 10, 2011

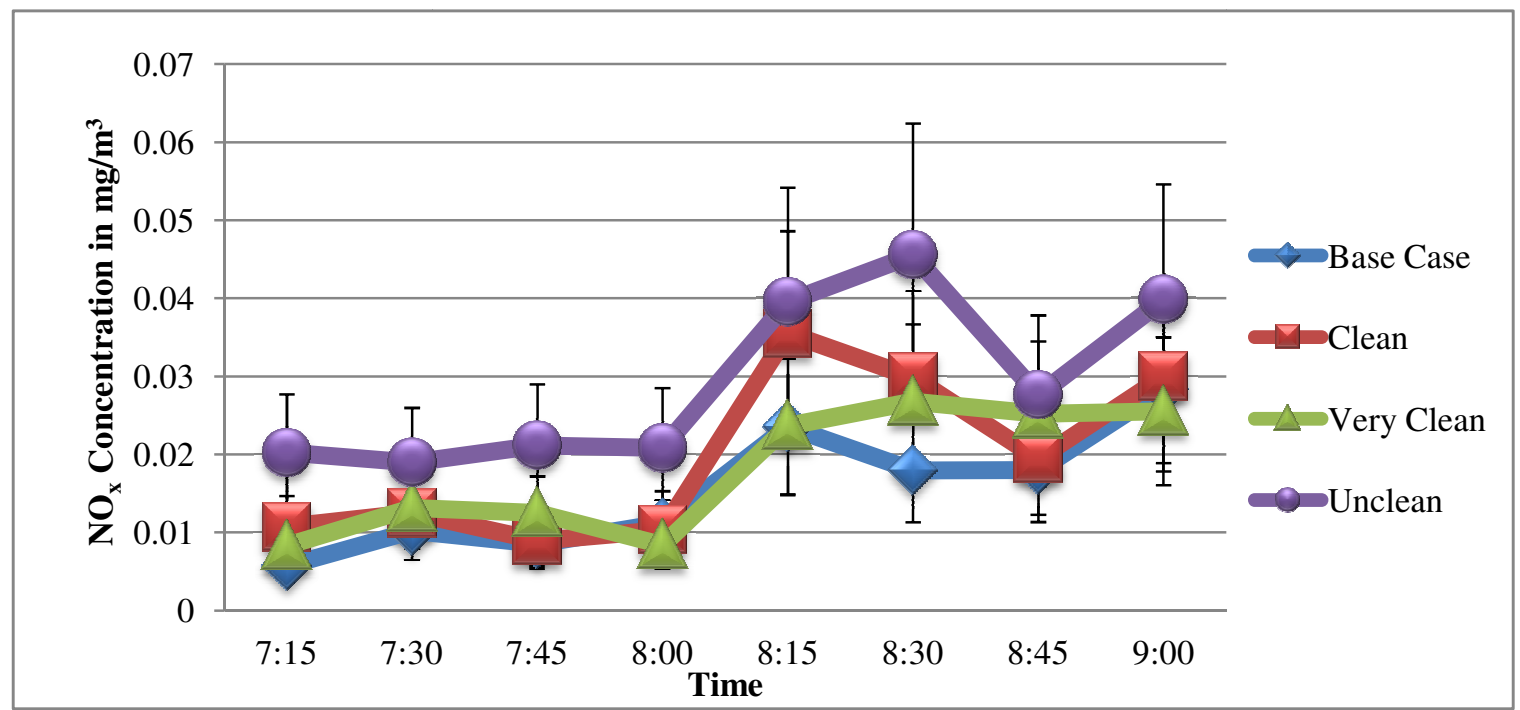

Figure 7-7 Vehicle Type Distribution Sensitivity, $\mathrm{NO}_{\mathrm{x}}$ Concentration, July27, 2011

Figure 7-6 and 7-7 show the modelled concentration estimates for the different cases evaluated for $\mathrm{CO}$ and $\mathrm{NO}_{\mathrm{x}}$. The highest concentrations for both pollutants are observed for Case 3, when the high emitting passenger car proportion is increased and ultra low emission vehicle percentage decreased. The lowest concentrations are obtained for Case 2 which has the cleanest mix of vehicles. The average coefficient of variation for $\mathrm{CO}$ is 0.85 and for $\mathrm{NO}_{\mathrm{x}}$ is 0.35 . The difference in variation can be attributed to the fact that the distribution of MHV matrix is not varied very much compared to the LV matrix. Since trucks are the chief contributors of $\mathrm{NO}_{\mathrm{x}}$, the corresponding coefficient of variation for $\mathrm{NO}_{\mathrm{x}}$ is less compared to $\mathrm{CO}$. 


\subsubsection{Atmospheric Stability}

Five different stability conditions, ranging from 'highly unstable' to 'highly stable', are developed for input into QUIC as shown in Table 7-3. Golder (1972) developed empirical relationships, relating the inverse Monin-Obukhov (M-O) length with surface roughness and stability classes defined by Pasquill (1974), which are employed by QUIC. The inverse M-O length is also used to develop the mean vertical wind profile in QUIC-URB. The potential temperature profile is developed based on the vertical variation in temperature. This vertical variation is assumed such that it generally represents the corresponding atmospheric stability.

Table 7-3 Atmospheric Stability Sensitivity Analysis Inputs

\begin{tabular}{|l|c|l|}
\hline Stability Class & Inverse M-O length $\left(\mathrm{in}^{-1}\right.$ ) & Vertical Variation in temperature \\
\hline Highly Unstable & -0.1 & -0.8 degrees $/ 50 \mathrm{~m}$ height increase \\
\hline Slightly Unstable & -0.01 & -0.8 degrees $/ 50 \mathrm{~m}$ height increase \\
\hline Neutral & 0 & -0.5 degrees $/ 50 \mathrm{~m}$ height increase \\
\hline Slightly Stable & 0.01 & +0.8 degrees $/ 50 \mathrm{~m}$ height increase \\
\hline Highly Stable & 0.1 & +0.8 degrees $/ 50 \mathrm{~m}$ height increase \\
\hline
\end{tabular}

The randomly selected day for this analysis is June 22, 2011. The results obtained from this analysis are presented in Figure 7-8. Apart from one high concentration value observed for the neutral condition, modelled concentrations are in the range of $0.5-2.0 \mathrm{mg} / \mathrm{m}^{3}$ for all stability classes. Theoretically, highly stable conditions may cause higher concentrations due to low turbulence in the atmosphere; however, the results obtained do not reciprocate this particularly well. The average coefficient of variation is 0.56 , which suggests that atmospheric stability is an important parameter, however no clear trend is observed from the graphical analysis. It is recommended to generate distributions for each estimated value in order to reduce error on modelled values and develop a more accurate graph depicting the pollutant concentration trend. 


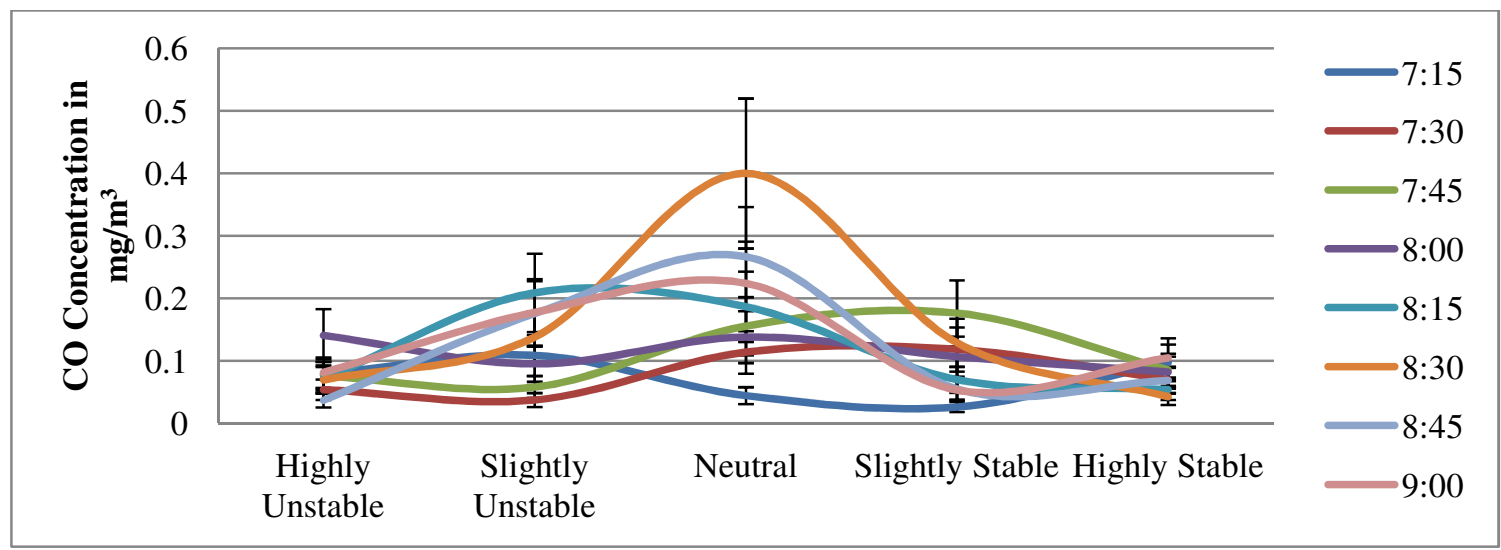

Figure 7-8 Atmospheric Stability Sensitivity, CO Concentration, June 22, 2011

\subsubsection{QUIC Simulation Time Step}

The simulation time step defines the interval after which the random walk model updates particle positions and turbulent velocities. When the modelling domain scale is of the order of life-sized buildings, it is recommended to use a time step of a few seconds (Los Alamos National Laboratory, 2010). For validation purposes, a fixed time step of 5 seconds is used, as described in Chapter 5. To test the sensitivity of the simulation time step, five cases are analysed; the value of the time step is varied from $0.1-8$ seconds. The average coefficient of variation is 0.12 which illustrates that simulation time step is relatively less significant than other parameters evaluated in this study. However, care should be taken while selecting the time step. It is recommended to err on the positive side of time step due to presence of auto time step reduction algorithms within QUIC (Los Alamos National Laboratory, 2010).

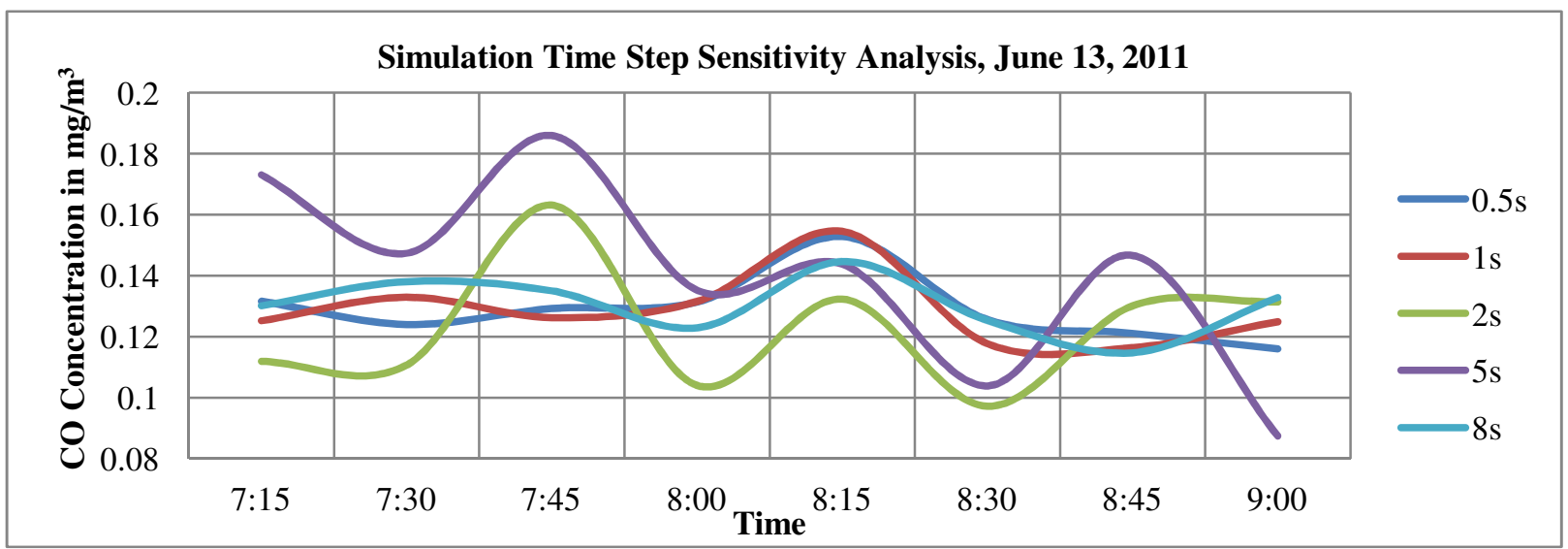

Figure 7-9 Simulation Time Step Sensitivity, CO Concentration, June 13, 2011 


\subsection{Summary of Effects}

The QUIC model was selected for further sensitivity analysis on account of its comprehensive methodology and applicability to the study area. Model sensitivity analysis indicates that horizontal wind speed is the most critical component in dispersion and hence, estimating this parameter correctly is essential to performing a satisfactory dispersion modelling study.

Characterising the full scale of variability caused due to each of these parameters is a cumbersome process. The complexity of comparing different parameters on the same scale is accentuated by the difference in sample space for each parameter. This sample space could be based on either scientific principles (for example, wind speed) or data limitations (for example, limited vehicle type distribution data availability). Future work includes reducing variability in estimates by generating distributions for each modelled concentration value to reduce stochastic model error. The summary of sensitivity analyses is illustrated in Table 7-4. Key remarks on each of these sensitivities are as follows:

1) The horizontal wind speed and direction is evidently the most dominating effect during dispersion of pollutants; the high coefficient of variation suggests that the impact of higher traffic volume or a polluting vehicle type distribution can be possibly offset by favourable wind characteristics that accelerate dispersion.

2) Vehicle type distribution is found to be a fairly significant input; only four cases are evaluated to obtain the coefficient of variations. These cases attempt to capture the maximum variation possible within the fleet; however, it is limited by the vehicle type availability within CMEM and practical considerations (for example, not all vehicles on the network can be heavy duty trucks).

3) Traffic volume is a significant factor when modelling traffic emissions. The coefficient of variations calculated for $\mathrm{CO}$ and $\mathrm{NO}_{\mathrm{x}}$ are considerably high, indicating the need to have a good estimate of traffic volumes for input into traffic microsimulation.

4) The coefficient of variation for atmospheric stability is high. Theoretically, high instability should result in increased turbulence and better dilution of pollutants while high stability should result in calm periods where higher concentrations are observed. 
Results obtained using QUIC do not show any clear trend. Performing a spatial distribution assessment coupled with better estimation of modelled concentration (with reduced error), could possibly provide a better understanding of the net impact of stability on overall concentrations in QUIC.

5) The simulation time step is observed to be the least significant among the factors analysed. Nonetheless, selecting a reasonable time step value is essential to obtain correct results in QUIC.

Table 7-4 Summary of Sensitivities and Average Coefficient of Variations

\begin{tabular}{|l|c|c|c|}
\hline & $\begin{array}{c}\text { Randomly Selected } \\
\text { Day }\end{array}$ & $\begin{array}{c}\text { Number of cases } \\
\text { evaluated }\end{array}$ & $\begin{array}{c}\text { Average Coefficient } \\
\text { of Variation }\end{array}$ \\
\hline $\begin{array}{l}\text { Horizontal Wind } \\
\text { Speed/Direction }\end{array}$ & June 3 & 12 & 0.96 \\
\hline Traffic Volume & June 24, July 12 & 5 & $0.45(\mathrm{CO}), 0.41\left(\mathrm{NO}_{\mathrm{x}}\right)$ \\
\hline Fleet Distribution & June 10, July 27 & 4 & $0.85(\mathrm{CO}), 0.35\left(\mathrm{NO}_{\mathrm{x}}\right)$ \\
\hline Atmospheric Stability & June 22 & 5 & 0.56 \\
\hline Simulation Time Step & June 13 & 5 & 0.12 \\
\hline
\end{tabular}




\section{Chapter 8}

\section{Limitations and Perspective}

This chapter discusses the data errors and limitations within the modelling framework. It also contains a comparison of the predicted concentrations, with the National Ambient Air Quality Objective (NAAQO) standards of Environment Canada. This comparison is performed to give some perspective on the scale at which the modelling framework is estimating emissions.

\subsection{Errors}

Any model is an attempt to simulate processes that occur in real life using mathematical expressions. The air quality modelling framework proposed in this research uses three models to simulate the concentration of traffic pollutants in the study area. Inaccuracies are present in each model of the framework.

Modelling errors can be generally classified into data errors and model formulation errors. A quantitative analysis of all errors within the modelling framework is beyond the scope of this research. However, a subjective analysis is performed. Data errors associated with the modelling framework are listed in Table 8-1. The errors are classified into primary (errors that originate at a certain juncture in the methodology), and secondary (errors that are carried downstream in the process flow). The main secondary errors that form inputs to a downstream process in the methodology are italicized in the table.

It is difficult to quantify the errors associated with the mathematical behaviour of models individually. Each mathematical formulation that is used in the process of simulating emissions across all three modelling methodologies is subject to errors, and every equation contributes some error to the total value. There is likely some effect of 'negative' and 'positive' biases cancelling each other. Some of the mathematical model errors include - use of car following model to simulate driver behaviour (in PARAMICS), power demand modelling to estimate emission rates on roadway links (in CMEM), Gaussian formulation for approximating pollutant plume (in AERMOD), and Lagrangian formulation / parameterisation of turbulence for pollutant dispersion (in QUIC). 
Table 8-1 Sources of Data Errors

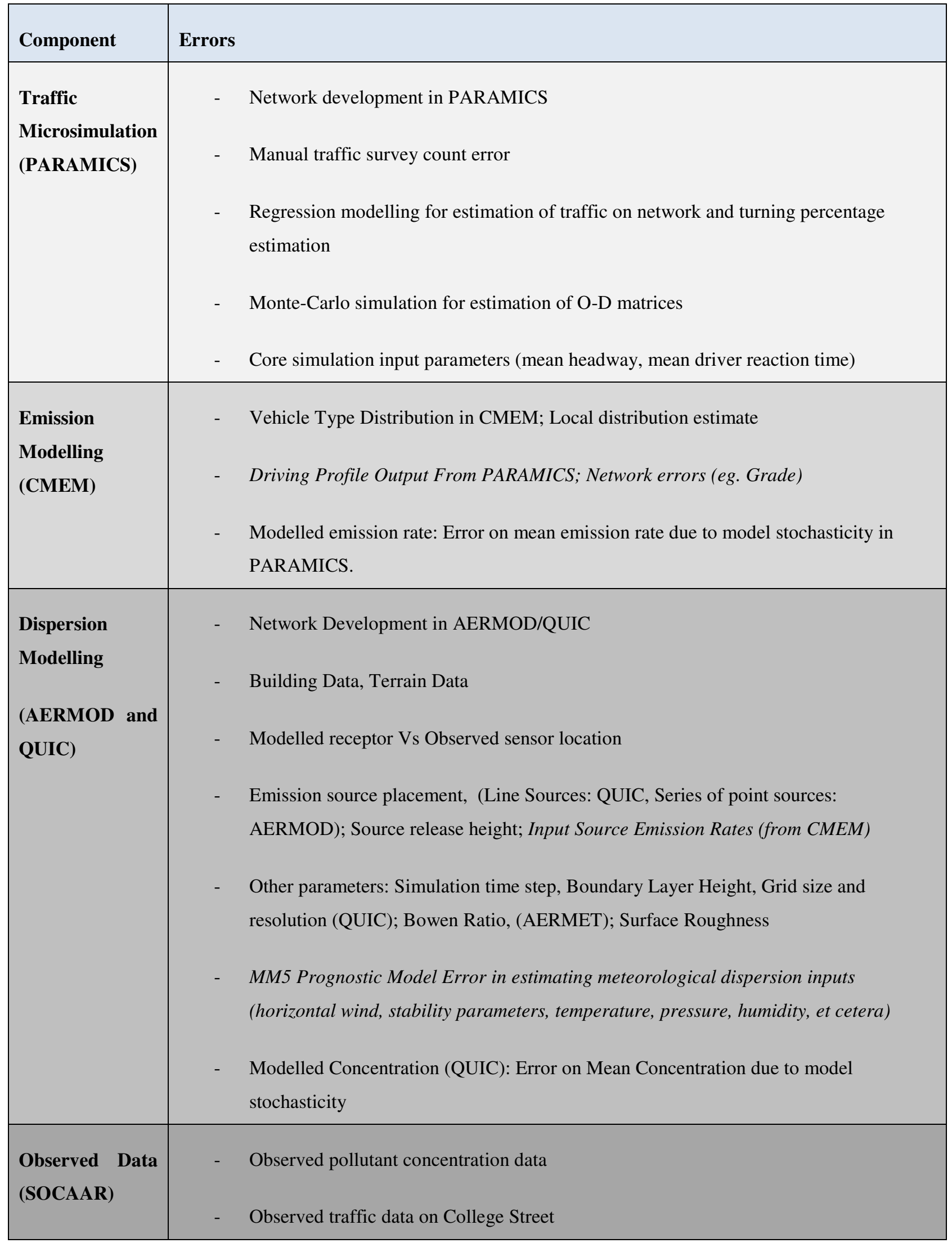




\subsection{General Limitations}

In addition to the limitations associated with data availability and data quality listed in Table 8-1, other general limitations of the study include the following:

1) The complex chemistry of $\mathrm{NO}_{\mathrm{x}}$ transformation in the atmosphere is not modelled.

2) Dry and wet deposition of pollutants is not considered. Wet deposition is not relevant to this study, especially, due to negligible or no rain during the study period.

3) Only the morning peak traffic period between 7:00 - 9:00 AM is evaluated for ten selected weekdays during the months of June and July 2011. A continuous daily analysis is not performed due to restrictions on detailed traffic data availability for other periods of time.

4) All modelled concentrations are compared with sensor observations for a single location; spatial distribution of pollutants is not analysed in this study.

5) Traffic induced turbulence is not accounted for, even though it can be a significant parameter in urban pollutant dispersion (Kastner-Klein, et al., 2003).

\subsubsection{Comparison of Dispersion Models}

QUIC and AERMOD form the most significant component of this modelling framework. A comparison of the two methodologies gives some insight on which model is better for dispersing traffic pollutants in urban areas. Some of the major differences and limitations in methodologies are highlighted in the following sub sections.

\subsubsection{AERMOD}

1) AERMOD is steady state Gaussian model; therefore, it is insensitive to time in modelling concentrations. The model is run separately for each of the two hours during the morning peak period, such that concentrations in the following hour are not affected by concentrations from the previous hour.

2) AERMOD simulates atmospheric phenomena much more comprehensively than QUIC. However, it uses a single value of wind speed, turbulent coefficients, and temperature 
gradient to represent the layer in which dispersion occurs. Thus, vertical inhomogeneity is diluted to obtain 'effective' values.

3) AERMOD provides better results for $\mathrm{CO}$ (albeit with a negative correlation compared to observed concentrations), but estimates unrealistically high concentrations very close to the emission source. This is a result of modelling line sources as a series of point sources.

4) In AERMOD, building downwash is only estimated for point sources; the effect of buildings cannot be incorporated with volume / area sources, which are better representative of roadway emissions. The effect of buildings is not modelled entirely in AERMOD.

5) AERMOD model runs are faster. Total runtime for simulating morning peak period traffic emissions for two pollutants for ten weekdays is $\sim 10$ hours.

\subsubsection{QUIC}

1) QUIC is a Lagrangian particle model and tracks the movement of individual pollutant particles using a non-steady state approach. Thus, modelled concentrations are sensitive to previous time periods.

2) For continuous dispersion analysis of an entire day, the input meteorological parameters in QUIC would need to be revised (since their values change during the day); in such a case, some assumptions would have to be made regarding the dissipation of pollutants, so that model runs can be staggered to incorporate a longer continuous time period.

3) QUIC computes varying mean wind flow and turbulent velocity for each grid in the space, and stores that value for use during the dispersion computation. It has seemingly more realistic flow characterisation around buildings.

4) Consequently, QUIC concentration contours look visually reasonable compared to AERMOD. Concentration close to source does not increase to extremely high values as in AERMOD. The ability to model roadway links as line sources is an advantage in QUIC.

5) QUIC can model flow around buildings much more comprehensively than AERMOD and this makes it more relevant, as a dispersion tool, to be applied in urban areas; on the micro-scale, QUIC seems to be a promising tool for estimating traffic pollutant concentration. 
6) QUIC model runs are slower compared to AERMOD. Total runtime for simulating morning peak period traffic emissions for two pollutants for ten weekdays is $\sim 20$ hours.

\subsection{Comparison with NAAQO Standards}

The performance evaluation of the modelling framework suggests that for the given receptor location, AERMOD and QUIC perform better for $\mathrm{CO}$ and $\mathrm{NO}_{\mathrm{x}}$, respectively. It is imperative to acknowledge the scale of concentration at which the modelling framework is operating. Interpreting model results is a challenging task, and therefore, predicted values are compared with air pollution standards to give some perspective on modelling framework results.

The hourly threshold values for the Maximum Acceptable Level (MAL) and for $\mathrm{CO}$ and $\mathrm{NO}_{2}$ as specified in the National Ambient Air Quality Objectives (NAAQO) of Canada (Environment Canada, 2010) are plotted against the predicted and sensor observed values in Figure 8-1 and 82. $\mathrm{NO}_{\mathrm{x}}$ emissions are compared to $\mathrm{NO}_{2}$ values in the absence of separate criteria for total $\mathrm{NO}_{\mathrm{x}}$ concentrations.

The predicted and observed CO concentrations are approximately 30 times smaller than the NAAQO MAL. The difference between predicted concentrations (both QUIC and AERMOD generated) and observed concentrations becomes indistinguishable at this scale. For $\mathrm{NO}_{2}$, the MAL is approximately 8 times larger than the observed and predicted concentrations, yet again, setting the difference between observed and predicted values into perspective. 


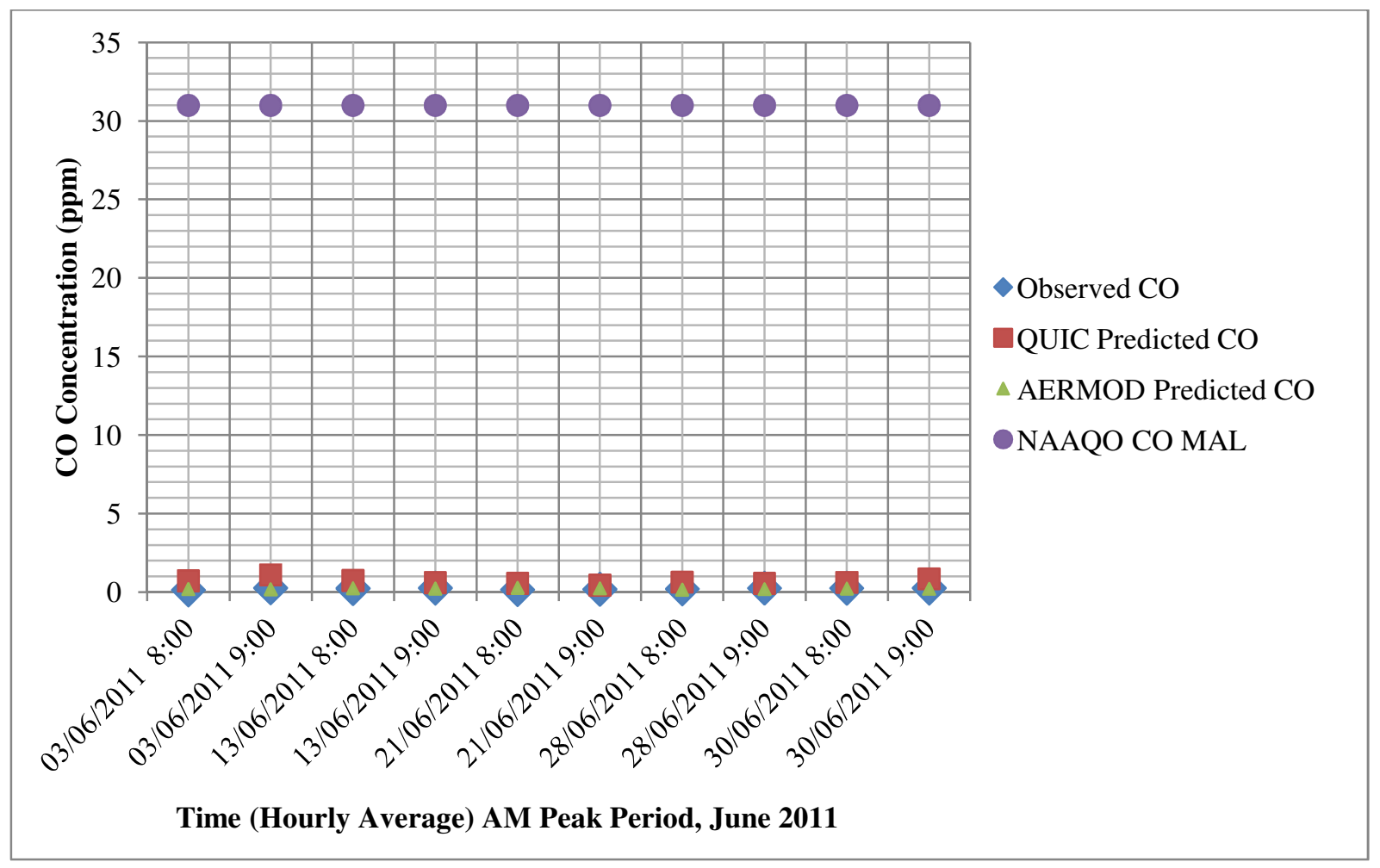

Figure 8-1 Predicted, Observed and NAAQO Hourly MAL, CO concentration

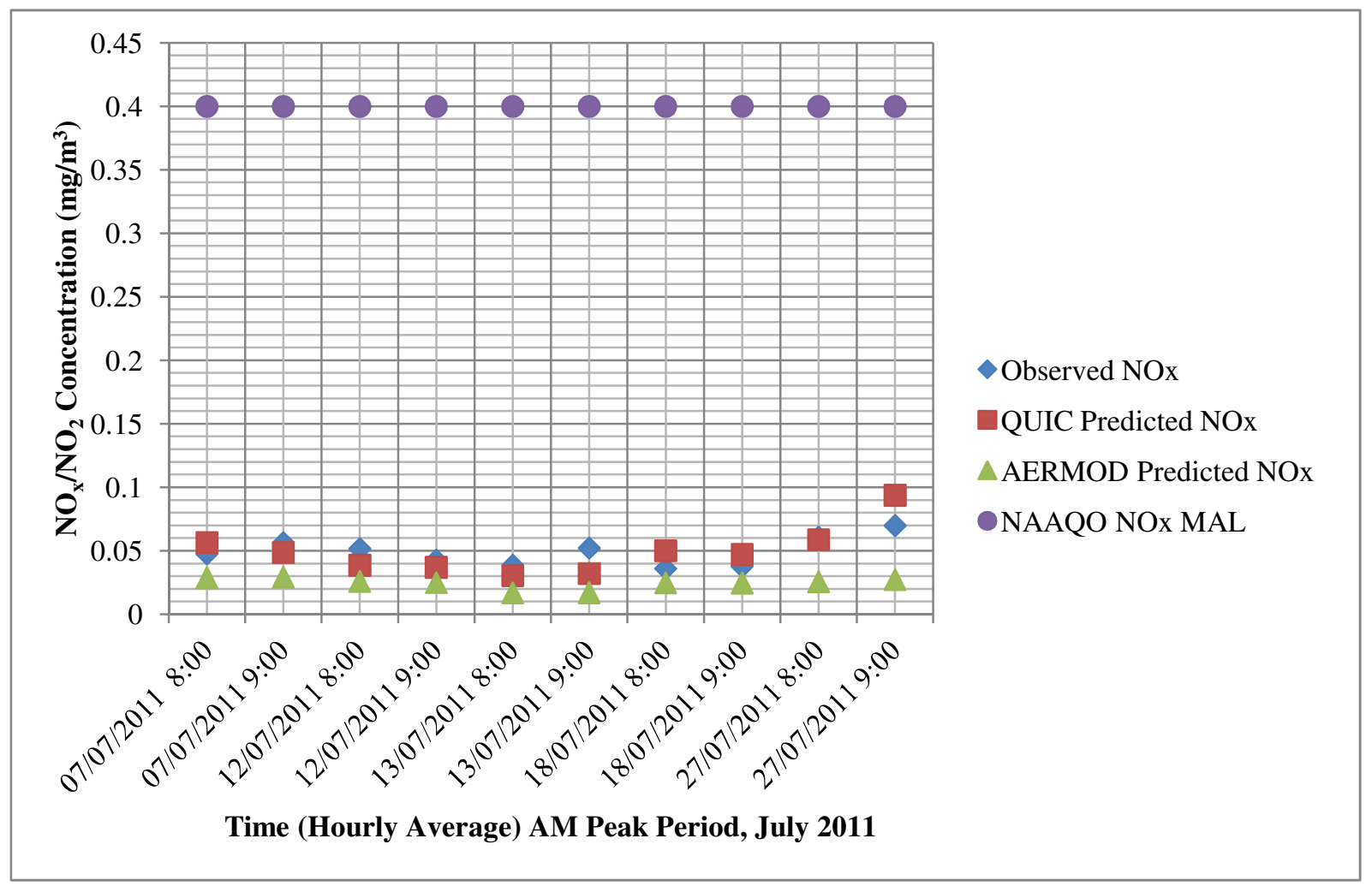

Figure 8-2 Predicted, Observed $\left(\mathrm{NO}_{\mathrm{x}}\right)$ and NAAQO Hourly MAL $\left(\mathrm{NO}_{2}\right)$ concentration 


\section{Chapter 9}

\section{Conclusion}

Urban air pollution modelling is an important exercise towards quantifying the adverse effects of traffic emissions on people. As the world population increases and more people begin to live in highly urbanized, densely populated cities, measuring the health impact of poor urban air quality has become extremely significant. With advancements in computing technologies that reduce model runtime, use of complex integrated methodologies for evaluating urban emissions is becoming a major area of research. This research applies a similar integrated methodology to evaluate emissions on a traffic network in Toronto with some encouraging results.

Pielke (1979) spoke of air pollution not just being an issue of poor emissions, but an inter-related weather associated phenomenon, a weather hazard. The integrated micro-modelling methodology adopted in this research stands in agreement with this observation. Horizontal wind is found to be the most significant factor causing advection and dispersion of pollutants, which is capable of negating the adverse impact of higher traffic volume or polluting engine technologies.

Availability of good quality observed pollutant concentration data is important and therefore accurate data monitoring continues to remain a key component of traffic emission modelling. Meteorological data quality is also of utmost importance to air pollutant dispersion studies. For a micro-modelling approach operating on a fine time resolution, availability of disaggregate weather data is useful to avoid generating erroneous outputs and inferring incorrect conclusions.

\subsection{Summary and Contribution}

Following is a list of key points summarising the work, contribution and findings of this research:

1) An integrated approach to estimate traffic related emissions on the micro-scale is adopted and successfully executed. The modelling framework consists of a combination of traffic microsimulation model, microscopic emissions model, and two dispersion modelling methodologies such that a consistent level of detail is maintained throughout the modelling framework. 
2) Regression modelling is combined with a manual traffic count survey to generate synthetic micro scale traffic flows on the network for the entire study period for input into traffic microsimulation model.

3) The performance of AERMOD and QUIC, two different dispersion modelling methodologies is evaluated. AERMOD performs better for $\mathrm{CO}$ while QUIC performs well for $\mathrm{NO}_{\mathrm{x}}$. AERMOD predicts unrealistically high concentration levels very close to the roadway point source.

4) The applicability of the proposed modelling framework by comparing predicted concentrations for $\mathrm{CO}$ and $\mathrm{NO}_{\mathrm{x}}$ with sensor observed concentrations is validated. Model predicted results are compared with sensor observed values with reasonable accuracy. Due to absence of multiple pollutant observing sensors on the network, a comprehensive analysis of the spatial variation of the pollutant concentrations could not be performed.

5) Comparison of results with the NAAQO standards brings the difference between observed and predicted concentrations into perspective for both pollutants and signifies the fine scale at which the modelling framework is estimating emissions.

6) A sensitivity analyses is performed on input factors and their effects on modelled concentrations. The key parameters are organised in accordance with their degree of importance to the modelling framework. It is affirmed that the horizontal mean wind speed is the most significant important parameter for dispersion.

7) Ambient concentration estimates are useful in making a consistent comparison between predicted and observed concentrations. Estimates of ambient concentrations from local monitoring stations confirm the reliability of using these values to augment modelled value to compute final 'predicted' values. If a correct estimate of ambient concentrations is available, the proposed modelling framework can be applied to estimate morning peak hour traffic emissions for other local areas. The location of the monitoring stations used for ambient concentration estimation should ideally represent similar traffic conditions / environment as the modelling area.

\subsection{Future Work}

There is significant benefit in amalgamating modelling systems that have historically been separated from each other. A robust system that could integrate micro-modelling methodologies for urban air pollution estimation will be valuable for jurisdictions across the world to analyse 
local air quality, and take informed decisions to comply with air pollution standards. It is however important to acknowledge that model errors may increase with intensive input data requirements. This research is a step towards a truly integrated approach of micro-modelling exposure of population to pollutants in a dynamically changing environment where numerous parameters exhibit temporal and spatial variations. This research forms the first component of the street level exposure modelling framework shown in Figure 9-1.

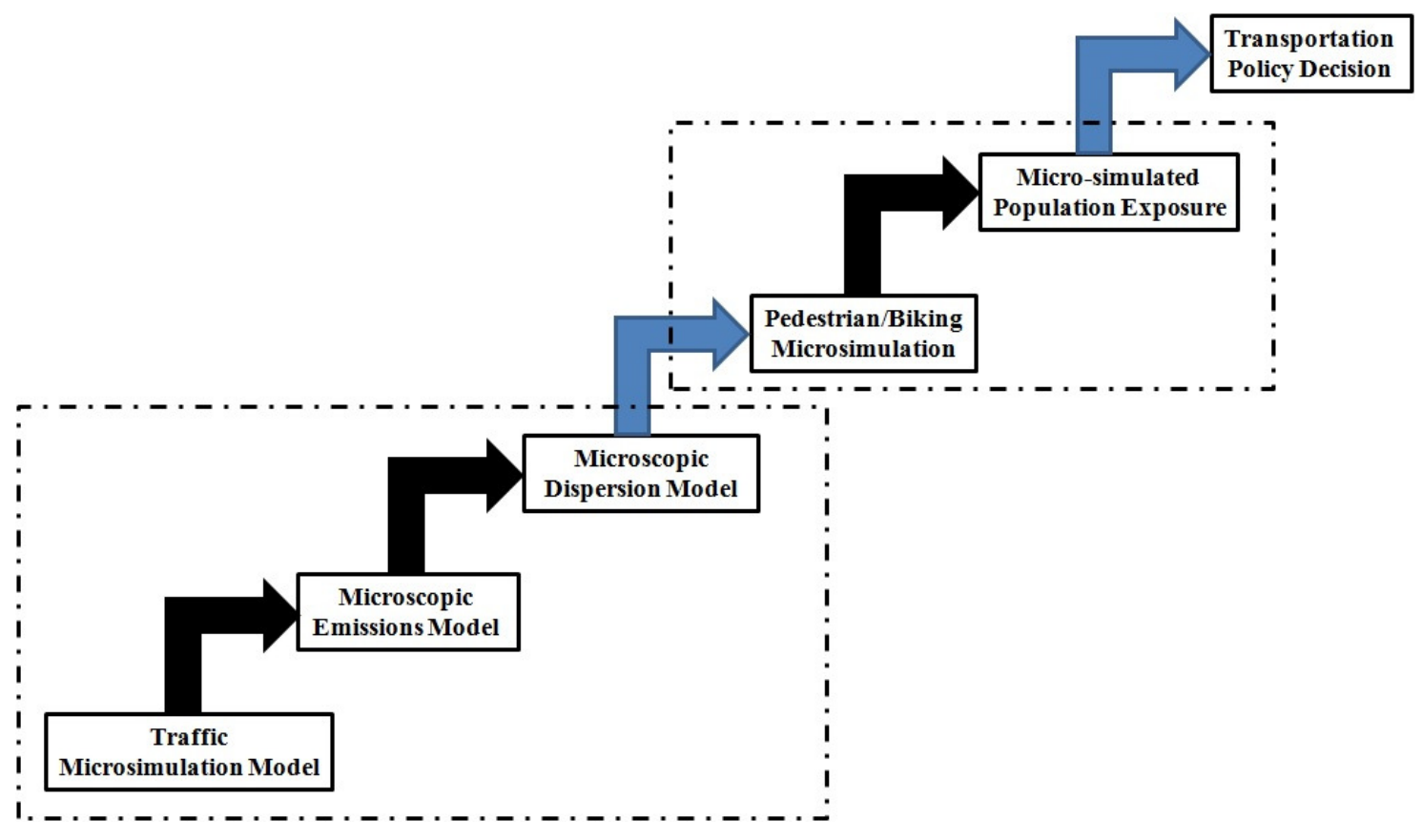

Figure 9-1 Street Level Exposure Micro-Modelling Framework

One important area that requires further attention in this field is developing methods for estimating accurate local vehicle type distribution including corresponding emission data. This research warrants a further investigation into each component of the modelling framework to develop a better understanding of the complexity involved in modelling urban traffic emissions. This work could be further developed by installing multiple sensors in the study area and validating spatial patterns of air pollutants. Spatial microsimulation of pollutants for sustained periods of time can provide useful data that could be used for evaluation of population exposure to local traffic emissions. This requires a fourth component that deals with data collection and modelling of pedestrian movements on the street network. It is a strong hope that this research will lead to the development of a comprehensive, well defined population exposure modelling system for traffic emissions. 


\section{References}

Ahn, K., \& Rakha, H. (2008). The effects of route choice decision on vehicle energy consumption and emissions. Transportation Research D, 13(3), 151-167.

Amirjamshidi, G., Roorda, M., Mostafa, T., \& Misra, A. (2012). Microsimulating Emissions and Population Exposure in Downtown Toronto. Canadian Transportation Research Forum, 47th Annual Conference. Calgary.

Arnold, S., et al. (2004). Introduction to the DAPPLE Air Pollution Project. Science of the Total Environment, 332(1-3), 139-153.

Arya, S. (1999). Air Pollution Meteorology and Dispersion. Raleigh, NC: Oxford University Press.

Bai, S., Eisinger, D., \& Niemeier, D. (2009). MOVES Vs EMFAC: A Comparison of Greenhouse Gas Emissions Using Los Angeles County. TRB 2009 Annual Meeting CD ROM, Washington D.C.

Barth, M., An, F., Younglove, T., Scora, G., Levine, C., Ross, M., \& Wenzel, T. (1999). The development of a Comprehensive Modal Emissions Model. Final report to the National Cooperative Highway Research Program.

Barth, M., Malcolm, C., Younglove, T., \& Hill, N. (2001). Recent Validation efforts for a Comprehensive Modal Emissions Model. Transportation Research Record (1750), 13-23.

Batterman, S., Zhang, K., \& Kononowech, R. (2010). Prediction and analysis of near-road concentrations using a reduced-form emission/dispersion model. Environmental Health, 9, 29.

Berkowicz, R.; Hertel, O.; Larsen, S.E.; Sorensen, N.N.; Nielsen, M. (1997). Modelling traffic pollution in streets. Dept. of Atm. Env. NERI, Denmark, Dept. of Met. and Wind Energy, Riso National Laboratory, Denmark.

Borrego, C., Tchepel, O., Costa, A., Amorim, J., \& Miranda, A. (2003). Emission and dispersion modelling of Lisbon air quality at local scale. Atmospheric Environment, 37(37), 5197-5205. 
Bowker, G., Baldauf, R., Isakov, V., Khlystov, A., \& Petersen, W. (2007). The effects of roadside structures on the transport and dispersion of ultrafine particles from highways. Atmospheric Environment, 41(37), 8128-8139.

Brode, R.W.; Anderson, B. (2008). Technical Issues Related to Use of the CALPUFF Modeling System for Near-field Applications. Environmental Protection Agency. Retrieved January 2012, from http://www.epa.gov/scram001/7thconf/calpuff/calpuff_nearfield_technical_issues_092608.pdf

Brownstone, D., Chu, L., Golob, T., Nesamani, K., \& Recker, W. (2008). Evaluation of Incorporating Hybrid Vehicle Use of HOV Lanes. California Path Program, Institute of Transportation Studies, University of California, Berkeley.

Businger, J. (1966). Transfer of heat and momentum in the atmospheric layer. Proceedings of Arctic Heat Budget and Atmospheric Circulation, (pp. 305-332). Santa Monica, California.

Cadle, S. (1997). Particulate Matter Emission from on-road Light Duty Vehicles. Proceedings of the 1997 Diesel Engine Emissions Reduction Workshop. La Jolla, California.

California DoT. (1989). CALINE4 - A dispersion model for predicting air pollution concentrations near roadways. State of California, Department of Transportation, Division of New Technology and Research.

California Environmental Protection Agency. (2010). EMFAC Release, Moving Cooler: An Analysis of Transportation Strategies for Reducing Greenhouse Gas Emissions (Executive Summary). Cambridge Systematics I, 2009.

Campbell, M., Benson, B., \& Muir, M. (1995). Urban air quality and human health: A Toronto Perspective. Canadian Journal of Public Health, 86(5), 351-357.

Carr, E., Johnson, R., \& Ireson, R. (2002). Hyroad Model Formulation. Systems Applications International, KLD Associates, NCHRP .

CERC. (2010). CERC. Retrieved January 2012, from Cambridge Environmental Research Consultants: http://www.cerc.co.uk/environmental-software.html 
Chen, H., Bai, S., Eisinger, D., Niemeier, D., \& Claggett, M. (2009). Predicting Near-Road PM2.5 Concentrations: Comparative Assessment of CALINE4, CAL3QHC and AERMOD. Transportation Research Record(2123), 26-37.

Chen, K., \& Yu, L. (2007). Microscopic Traffic-Emission Simulation and Case Study for Evaluation of Traffic Control Strategies. Journal of Transportation Systems Engineering and Information Technology, 7(1), 93-100.

Chu, L., Liu, H., Oh, J., \& Recker, W. (2004). A Calibration Procedure for Microscopic Traffic Simulation. Transportation Research Board 83rd Annual Meeting, Preprint CD-ROM, Washington D.C.

Cimorelli, A., Perry, S., Venkatram, A., Weil, J., Paine, R., Wilson, R., et al. (2004). AERMOD: A Dispersion Model for Industrial Source Applications. Part I: General Model Formulation and Boundary Layer Characterization. Journal of Applied Meteorology, 44(5), 682-693.

Cox, W., \& Tikvart, J. (1985). Assessing the performance level of air quality models. Paper V.3 at 15th Int. Tech. Meeting on Air Pollution Modelling and its Applications NATO/CCMS.

Data Management Group. (2004). Cordon Count Data Retrieval System (CCDRS) Users Manual. University of Toronto, Joint Program in Transportation.

EMISIA. (2011). COPERT 4. Retrieved January 2012, from EMISIA Mission For Environment: http://www.emisia.com/copert/General.html

Engineering Sciences Data Unit. (1972). Characteristics of wind speed in the lower layers of the atmosphere near the ground: strong winds (neutral atmosphere), ESDU Data Item No 72026. London.

Environment Canada. (2010). National Ambient Air Quality Objectives. Retrieved March 2012, from Environment Canada: http://www.ec.gc.ca/rnspa-naps/default.asp?lang=En\&n=24441DC41

Environment Canada. (2012). National Pollutant Release Inventory (NPRI), CAC Trends. Retrieved 2011 December, from http://www.ec.gc.ca/inrpnpri/default.asp?lang=En\&n=4A577BB9-1 
Environmental Protection Agency. (1995). User's Guide to CAL3QHC Version 2.0 A Modeling Methodology for Predicting Pollutant Concentrations Near Roadway Intersections. US EPA, Office of Air Quality Planning and Standards. Retrieved December 2011, from http://nepis.epa.gov/Exe/ZyPURL.cgi?Dockey=000033I9.txt

Environmental Protection Agency. (1999). Technical Bulletin: Nitrogen Oxides (NOx), Why and how they are controlled. US EPA, Office of Air Quality Planning and Standards. Retrieved January 2012, from http://www.epa.gov/ttn/catc/dir1/fnoxdoc.pdf

Environmental Protection Agency. (2004). AERMOD: Description of Model Formulation. US Environmental Protection Agency. Retrieved December 2011, from http://www.epa.gov/scram001/7thconf/aermod/aermod_mfd.pdf

Environmental Protection Agency. (2004). User's Guide for the AMS/EPA Regulatory Model AERMOD. US Environmental Protection Agency, Office of Air Quality Planning and Standards. Retrieved December 2011, from http://www.epa.gov/scram001/7thconf/aermod/aermodugb.pdf

Environmental Protection Agency. (2012). MOBILE6 Vehicle Emission Modeling Software. Retrieved November 2011, from http://www.epa.gov/otaq/m6.htm

Environmental Protection Agency. (2012). MOVES Motor Vehicle Emission Simulator. Retrieved December 2011, from http://www.epa.gov/otaq/models/moves/index.htm

Environmental Protection Agency. (2012). Preferred/Recommended Models (Dispersion). Retrieved November 2011, from US Environmental Protection Agency: http://www.epa.gov/scram001/dispersion_prefrec.htm

Environmental Protection Agency. (2012). Six Common Air Pollutants. Retrieved November 2011, from US EPA: http://epa.gov/airquality/urbanair/

Fernando, H., Zajic, D., Sabatino, S., Dimitrova, R., Hedquist, B., et al. (2010). Flow, turbulence, and pollutant dispersion in urban atmospheres. Physics of Fluids, 22(5).

Fox, D. (1981). Judging air quality model performance. Bulletin of the American Meteorological Society, 62, 599-609. 
Golder, D. (1972). Relations among stability parameters in the surface layer. Boundary Layer Meteorology, 3(1), 47-58.

Hanna, S., \& Heinold, D. (1985). Development and application of a simple method for evaluating air quality models. American Petroleum Institute Publication 4409.

Hatzopoulou, M. (2008). Multicriteria Appraisal of Strategic Transport Plans: Internalizing Sustainability Objectives in Decision-making. Doctoral Thesis, University of Toronto.

Hatzopoulou, M. (2012). Transportation and Air Quality. Canadian Institute of Transportation Engineers, National Transportation Engineering Course Lecture, March 29, 2012. Montreal.

Hatzopoulou, M., \& Miller, E. (2010). Linking an activity-based travel demand model with traffic emission and dispersion models: Transport's contribution to air pollution in Toronto. Transportation Research D, 15(6), 315-325.

Hoek, G., Meliefste, K., Cyrys, J., Lewne, M., Bellander, T., Brauer, M., et al. (2002). Spatial Variability of fine particle concentrations in three European areas. Atmospheric Environment, 36(25), 4077-4088.

Holmes, N., \& Morawska, L. (2006). A review of dispersion modelling and its application to the dispersion of particles: An overview of different dispersion models available. Atmospheric Environment, 40(30), 5902-5928.

Hoogendoorn, S., \& Bovy, P. (2001). State-of-the-art of Vehicular Traffic Flow Modelling. Special Issue on Road Traffic Modelling and Control of the Journal of Systems and Control Engineering, 283-303.

Hoy, G., Misra, A., Mostafa, T., Roorda, M., \& MacLean, H. (2012). Verifying the Accuracy of Emissions Modelling in an Urban Setting using Microsimulation. Canadian Transportation Research Forum, 47th Annual Conference. Calgary.

Irwin, J., \& Smith, M. (1984). Potentially useful additions to the rural model performance evaluation. Bulletin of the American Meteorological Society, 65, 559-568. 
Ishaque, M., \& Noland, R. (2008). Simulated pedestrian travel and exposure to vehicle emissions. Transportation Research D, 13(1), 27-46.

Jansuwan, S., \& Narupiti, S. (2005). Assessment of Area Traffic Control System in Bangkok. Proceedings of the Eastern Asia Society for Transportation Studies, 5, pp. 1367 - 1378.

Johansson, G., \& Rumar, H. (1971). Drivers`Brake Reaction Times. Human Fact, 3, 23-27.

Jungers, B., Kear, T., \& Eisinger, D. (2006). A Survey of Air Quality Dispersion Models for Project-Level Conformity Analysis. Prepared for The California Department of Transportation.

Karim, M., \& Matsui, H. (1998). A mathematical model of wind flow, vehicle wake, and pollutant concentration in urban road microenvironments, Part 1: Model Description. Transportation Research D, 3(2), 81-92.

Karim, M., Matsui, H., \& Guensler, R. (1998). A mathematical model of wind flow, vehicle wake, and pollutant concentration in urban road microenvironments. Part II: Model results. Transportation Research D, 3(3), 171-191.

Kastner-Klein, P., Fedorovich, E., Ketzel, M., Berkowicz, R., \& Britter, R. (2003). The Modelling of Turbulence from Traffic in Urban Dispersion Models - Part II: Evaluation Against Laboratory and Full-Scale Concentration Measurements in Street Canyons. Environmental Fluid Mechanics, 3(2), 145-172.

Kesarkar, A., Dalvi, M., Kaginalkar, A., \& Ojha, A. (2007). Coupling of the Weather Research and Forecasting Model with AERMOD for pollutant dispersion modeling. A case study for PM10 dispersion over Pune, India. Atmospheric Environment, 41(9), 1976-1988.

Khare, M., \& Sharma, P. (2002). Modelling Urban Vehicle Emissions. WIT Press .

Lakes Environmental. (2010). MM5 Modeling at Lakes Environmental.

Lakes Environmental. (2012). Lakes Environmental Software, AERMOD View. Retrieved November 2011, from http://www.weblakes.com/products/aermod/index.html 
Lighthill, M., \& Whitham, G. (1955). On kinematic waves II. A theory of traffic flow on long crowded roads. Proceedings of the Royal Society of London, 229A, pp. 317-345.

Los Alamos National Laboratory. (2010). The Quick Urban \& Industrial Complex (QUIC) Dispersion Modeling System, QUIC Start Guide v 5.8. Los Alamos National Laboratory.

Malcolm, C., Younglove, T., Barth, M., \& Davis, N. (2003). Mobile-Source Emissions. Analysis of Spatial Variability in Vehicle Activity Patterns and Vehicle Fleet Distributions. Transportation Research Record(1842), 91-98.

Map and Data Library, University of Toronto. (2011). Toronto Building Outlines (with heights), clutter data, dem, contours, places, and roads. Retrieved November 2011, from http://maps.library.utoronto.ca

Marmur, A., \& Mamane, Y. (2003). Comparison and evaluation of several mobile-source and line-source models in Israel. Transportation Research D, 8(4), 249-265.

Metrolinx. (2008). The Big Move, Transforming Transportation in the Greater Toronto and Hamilton Area. Retrieved January 2012, from http://www.metrolinx.com/thebigmove/Docs/big_move/TheBigMove_020109.pdf

Monin, A., \& Obukhov, A. (1954). Basic laws of turbulent mixing in the ground layer of the atmosphere. Trans. Geophys. Inst. Akad. Nauk USSR, 24(151), 163-187.

Moulvi, I. (2010). Driver behavior variability and its effect on vehicle exhaust emissions. Proceedings of the Air and Waste Management Association's 103rd Annual Conference and Exhibition, AWMA, 5, pp. 4121-4138. Calgary.

Moussiopoulos, N., Schlunzen, H., \& Louka, P. (2003). Modelling Urban Air Pollution (Chapter 6) Air Quality in Cities, Moussiopoulos, Ed., Springer-Verlag, Berlin Heidelberg . Germany.

Nam, E., Gierczak, C., \& Butler, J. (2003). A Comparison Of Real-World and Modeled Emissions Under Conditions of Variable Driver Aggressiveness. TRB 2003 Annual Research Meeting CD ROM, Washington D.C. 
Nesamani, K., Chu, L., McNally, M., \& Jayakrishnan, R. (2007). Estimation of vehicular emission by capturing traffic variations. Atmospheric Environment, 41(14), 2996-3008.

Noland, R., \& Quddus, M. (2006). Flow improvements and vehicle emissions: Effects of trip generation and emission control technology. Transportation Research D, 11(1), 1-14.

Oettl, D., Kukkonen, J., Almbauer, R., Sturm, P., Pohjola, M., \& Harkonen, J. (2001). Evaluation of a Gaussian and a Lagrangian model against a roadside data set, with emphasis on low wind speed conditions. Atmospheric Environment, 35(12), 2123-2132.

Ontario Ministry of the Environment. (2009). Procedure for preparing an emission summary and dispersion modelling report, Version 3.0. MOE. Retrieved December 2011, from http://ia601206.us.archive.org/14/items/std01079006.ome/std01079006.pdf

Ontario, Ministry of the Environment. (2012). Air Quality Ontario. Retrieved January 2012, from http://www.airqualityontario.com/

Pandolfo, J. (1966). Wind and temperature for constant flux boundary layers in lapse conditions with a variable eddy conductivity to eddy viscosity ratio . Journal of Atmospheric Science, 23, 495-502.

Papacostas, C., \& Prevedouros, P. (2001). Transportation Engineering \& Planning, Third Edition. Honululu: Prentice Hall.

Pardyjak, E., \& Brown, M. (2007). QUIC URB v. 1.1 Theory and Users Guide. Los Alamos National Laboratory .

Park, B., \& Qi, H. (2004). Development and evaluation of a calibration and validation procedure for microscopic simulation models. FHWA/VTRC 05-CR1, Virginia Transportation Research Council, Charlottesville.

Pasquill, F. (1974). Atmospheric Diffusion, 2nd Edition. New York: Halsted Press of John Wiley \& Sons.

Pielke, R. (1979). Air Pollution - a national concern. Bulletin of the American Meteorological Society, 60, 1461. 
Pipes, L. (1953). An operation dynamics of traffic dynamics. Journal of Applied Physics , 24 (3), 174-181.

PSU, NCAR. (2008). MM5 Community Model. Retrieved January 2012, from Pennsylvania State University, National Center for Atmospheric Research: http://www.mmm.ucar.edu/mm5/mm5home.html

Quadstone Paramics. (2008). Modeller user manual, V6.5. Retrieved December 2011, from http://www.paramics-online.com/

Rakha, H., Ahn, K., \& Trani, A. (2003). Comparison of MOBILE5a, MOBILE6, VT-MICRO, and CMEM models for estimating hot-stabilized light-duty gasoline vehicle emissions. Canadian Journal of Civil Engineering, 30(6), 1010-1020.

Rakha, H., Ahn, K., \& Trani, A. (2004). Development of VT-Micro model for estimating hot stabilized light duty vehicle and truck emissions. Transportation Research D, 9(1), 49-74.

Rockle, R. (1990). Bestimmung der stomungsver-haltnisse im Bereich Komplexer Bebauugsstruk-turen. Doctoral Thesis. Vom Fachbereich Mechanik, der Technischen Hochschule Darmstadt. Germany.

Roorda, M., Amirjamshidi, G., Mostafa, T., \& Misra, A. (2011). A Truck Emissions Simulation Tool for Evaluating Green Commercial Vehicle Policy. Prepared for Toronto Atmospheric Fund, Ministry of Transportation of Ontario.

Scora, G., \& Barth, M. (2006). Comprehensive Modal Emissions Model (CMEM) Version 3.01. University of California, Riverside, Center for Environmental Research and Technology.

Singh, R., Desloges, C., \& Sloan, J. (2006). Application of a Microscale Emission Factor Model for Particulate Matter to Calculate Vehicle-Generated Contributions to Fine Particulate Emissions. Journal of Air \& Waste Management Association, 56(1), 37-47.

Smart Systems. (2008). User Manual, smart eye - TDS, Traffic Data Sensor, Version 1.2.

SOCAAR. (2011). University of Toronto, Southern Ontario Centre for Atmospheric Aerosol Research (SOCAAR). Retrieved August 2011, from www.socaar.utoronto.ca 
SOCAAR. (2012). Email Correspondence with Cheol-Heon Jeong, Research Associate, Southern Ontario Centre for Atmospheric Aerosol Research, University of Toronto.

Sokhi, R., et al. (2008). An integrated multi-model approach for air quality assessment: Development and evaluation of the OSCAR Air Quality Assessment System. Environmental Modelling \& Software, 23(3), 268-281.

Stathopoulos, F., \& Noland, R. (2003). Induced Travel and Emissions from Traffic Flow Improvement Projects. Transportation Research Record(1842), 57-63.

Statistics Canada. (2009). Canadian Vehicle Survey: Annual. Retrieved 2012 January, from http://www.statcan.gc.ca/pub/53-223-x/53-223-x2009000-eng.pdf

Teledyne Instruments. Model 300E Gas Filter Correlation CO Analyzer. Retrieved February 2012, from http://www.teledyne-api.com/pdfs/300e.pdf

Thermo Scientific. Thermo Scientific Trace Level NOx Analyzer, Model 42i-TL, Product Specifications. Retrieved February 2012, from https://www.thermo.com/eThermo/CMA/PDFs/Product/productPDF_30698.pdf

Tiwary, A., \& Colls, J. (2010). Air Pollution Measurement, modelling and mitigation, Third Edition. Routledge.

Tiwary, A., Robins, A., Namdeo, A., \& Bell, M. (2011). Air flow and concentration fields at urban road intersections for improved understanding of personal exposure. Environment International, 37(5), 1005-1018.

Vaitiekunas, P., \& Banaityte, R. (2007). Modeling of motor transport exhaust pollutant dispersion. Journal of Environmental Engineering and Landscape Management, 15(1), 39-46.

Vallamsundar, S., \& Lin, J. (2011). MOVES vs MOBILE: A Comparison of GHG and Criteria Pollutant Emissions. Transportation Research Record(2233), 27-35.

web GIS. (2012). web GIS. Retrieved March 2012, from http://www.webgis.com/ 
WebMET. (2012). Met Data Guide. Retrieved March 2012, from

http://www.webmet.com/metguide.html

Weil, J., Sykes, R., \& Venkatram, A. (1992). Evaluating Air-Quality Models: Review and Outlook. Journal of Applied Meteorology, 31(10), 1121-1145.

Weinstock, B. (1969). Carbon Monoxide: Residence Time in the Atmosphere. Science, New Series, 166(3902), 224-225.

Williams, M., Brown, M., Singh, B., \& Boswell, D. (2004). QUIC-PLUME Theory Guide. Los Alamos National Laboratory.

Xie, Y., Chowdhury, M., Bhavsar, P., \& Zhou, Y. (2012). An integrated modeling approach for facilitating emission estimations of alternative fueled vehicles. Transportation Research D, $17(1), 15-20$.

Yao, X., Lau, N., Chan, C., \& Fang, M. (2005). The use of tunnel concentration profile data to determine the ratio of NO2/NOx directly emitted from vehicles. Atmospheric Chemistry and Physics Discussions, 5(6), 12723-12740.

Zannetti, P. (1990). Air Pollution Modeling. Norway: Van Nostrand Reinhold.

Zou, B., Wilson, J., Zhan, F., \& Zeng, Y. (2009). Spatially differentiated and source-specific population exposure to ambient urban air pollution. Atmospheric Environment, 43(26), 39813988.

Zwack, L., Hanna, S., Spengler, J., \& Levy, J. (2011). Using advanced dispersion models and mobile monitoring to characterize spatial patterns of ultrafine particles in an urban area. Atmospheric Environment, 45(28), 4822-4829. 


\section{Appendices}

\section{Appendix A}

\section{A1. O-D Matrix Estimation}

Regression models developed to generate synthetic traffic flows on the study network based on traffic sensor observations made on the College Street (slightly west of the intersection) are shown. CL: Cars / Light Vehicles (CL), MH: Medium / Heavy Vehicles. 'Total College' = total eastbound and westbound traffic observed west of the intersection; EB: Eastbound, WB: Westbound, SB: Southbound, NB: Northbound; the straight line denotes the regression model predictions.

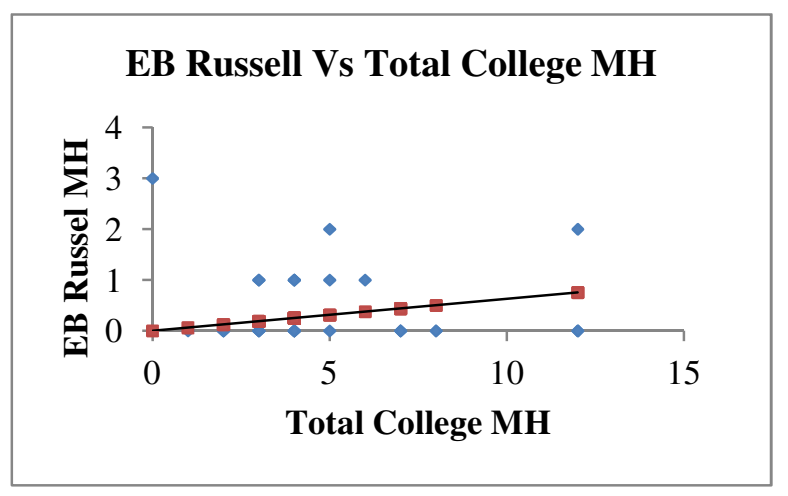

MH EB Russell

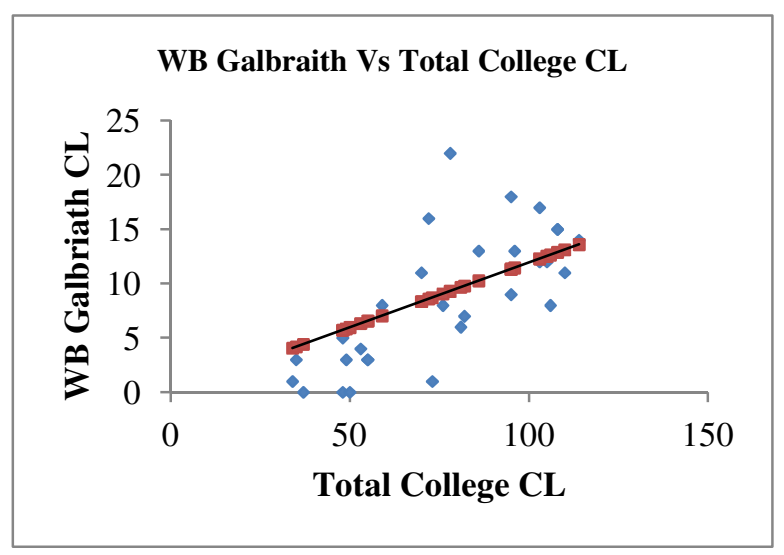

CL WB Galbraith

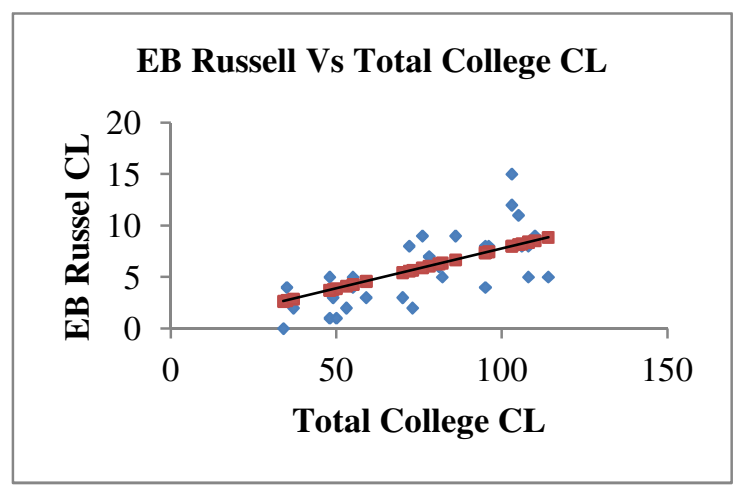

CL EB Russell

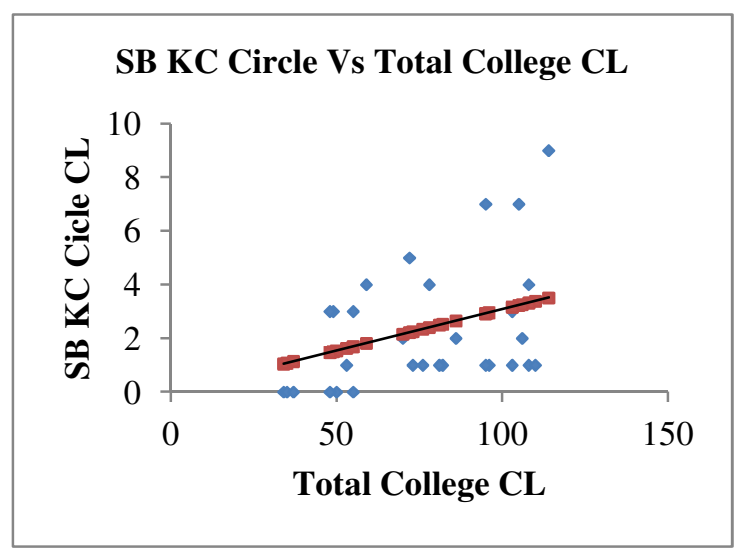

CL SB KC Circle 


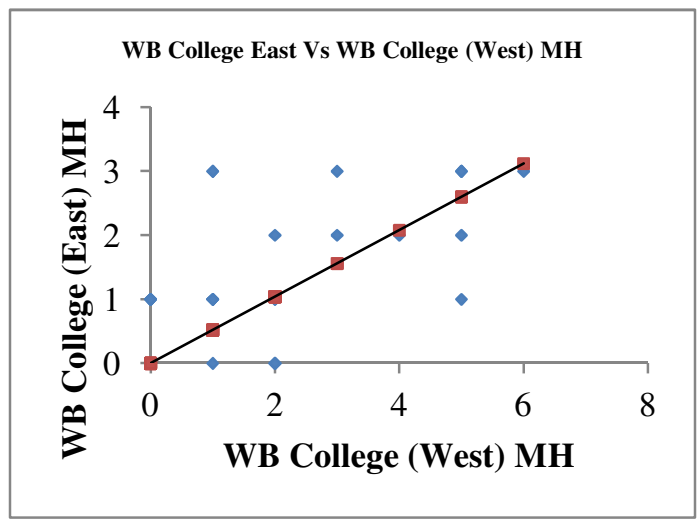

MH WB College (East of Intersection)

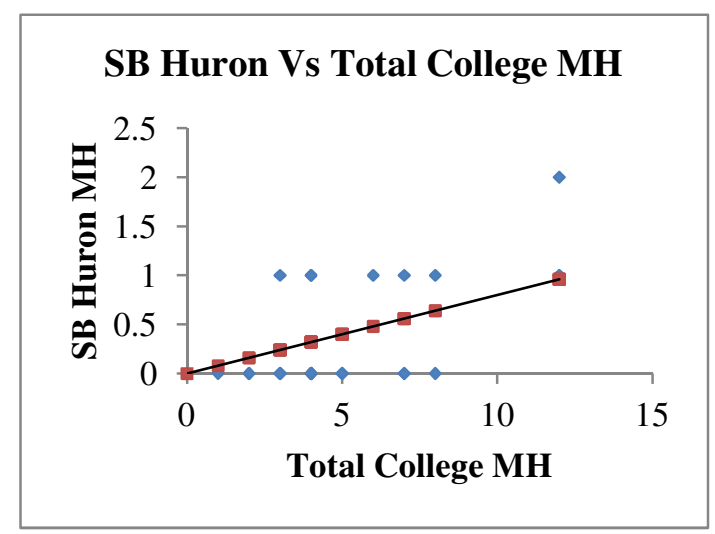

MH SB Huron

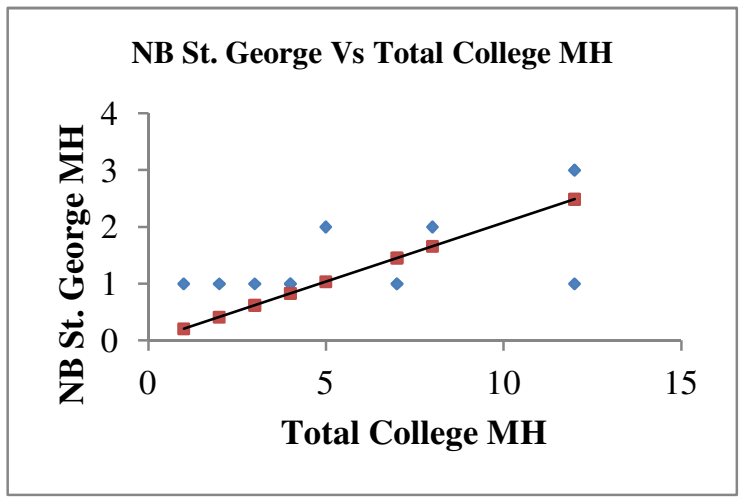

NB St. George MH

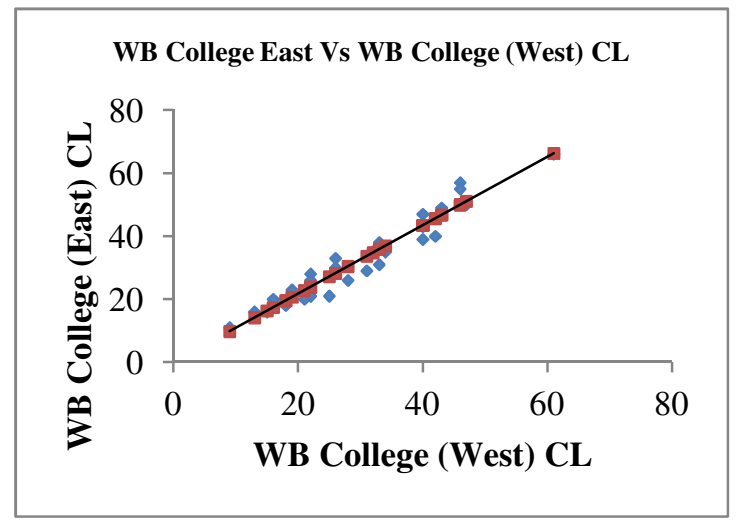

CL WB College (East of Intersection)

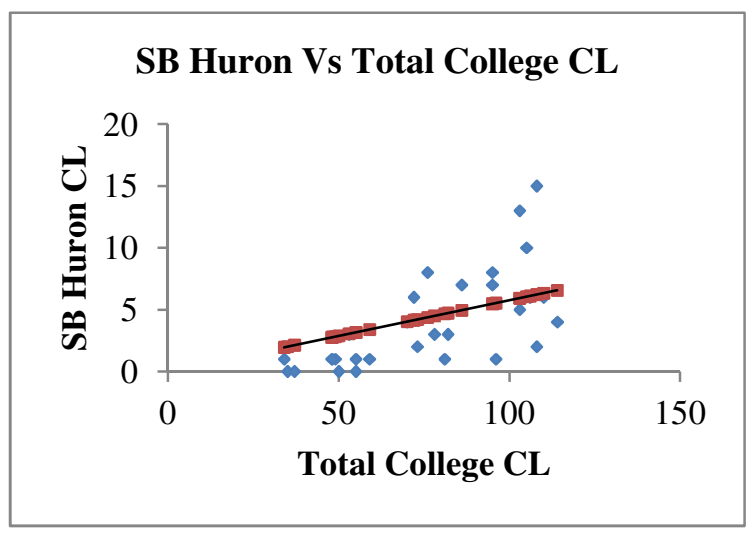

CL SB Huron

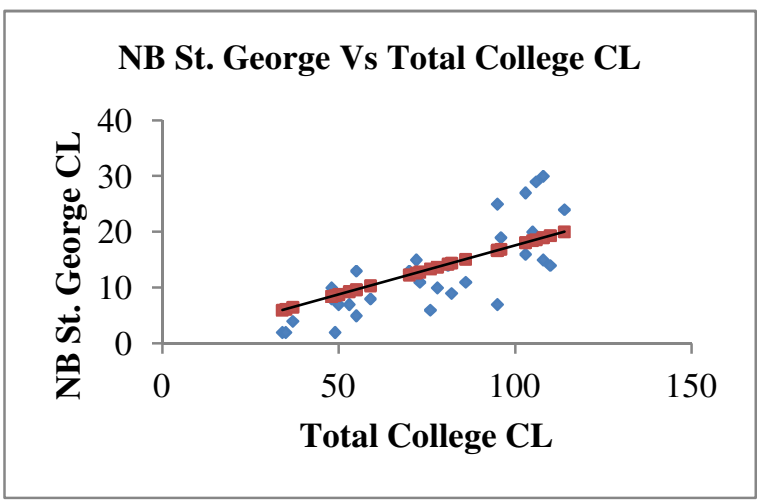

NB St. George CL 


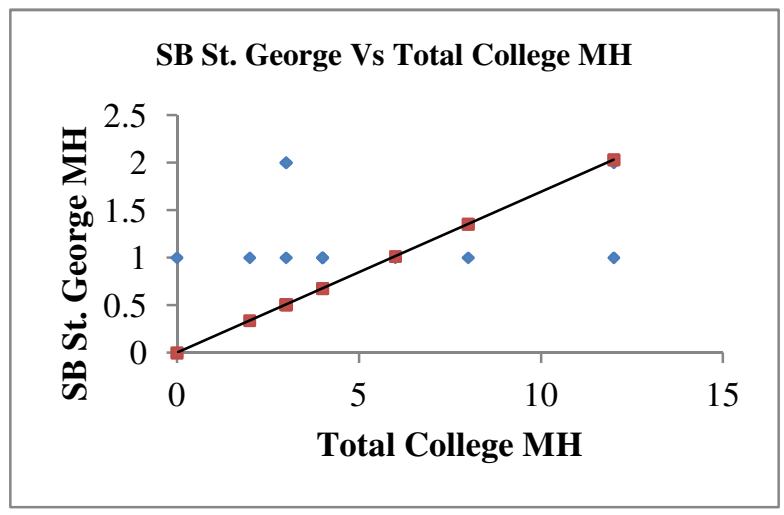

SB St. George MH

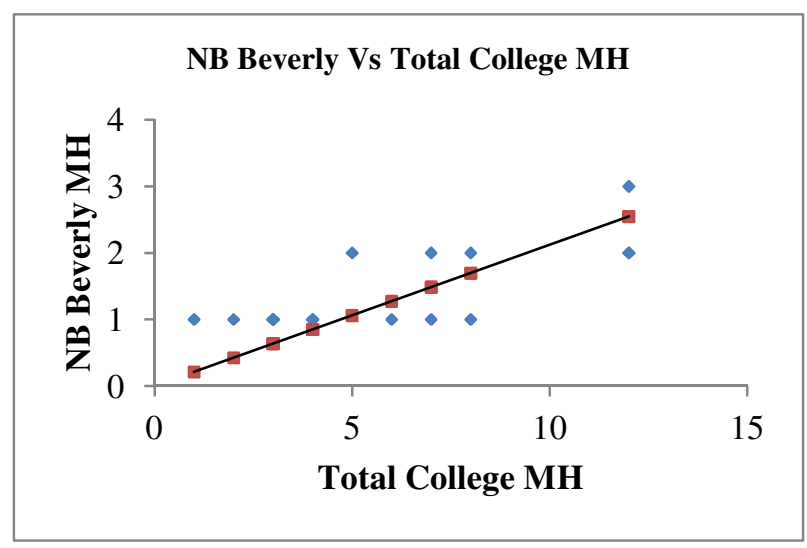

NB Beverley MH

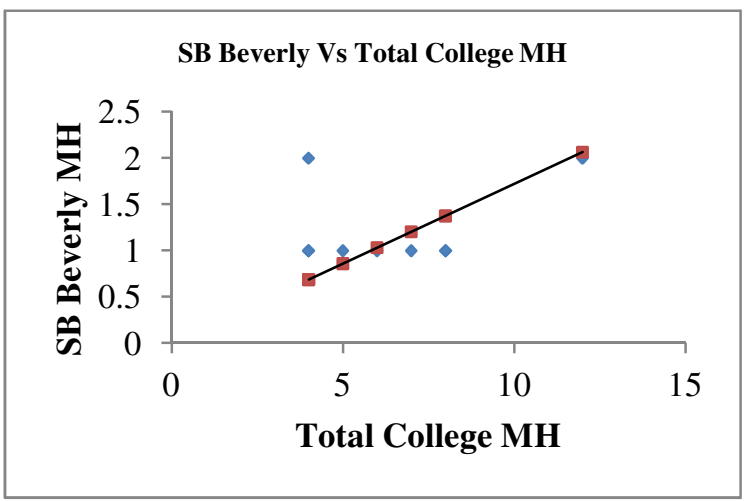

SB Beverley MH

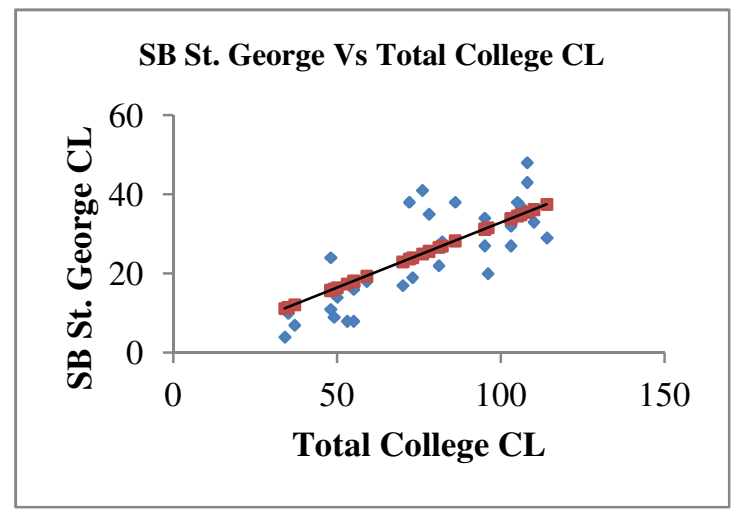

SB St. George CL

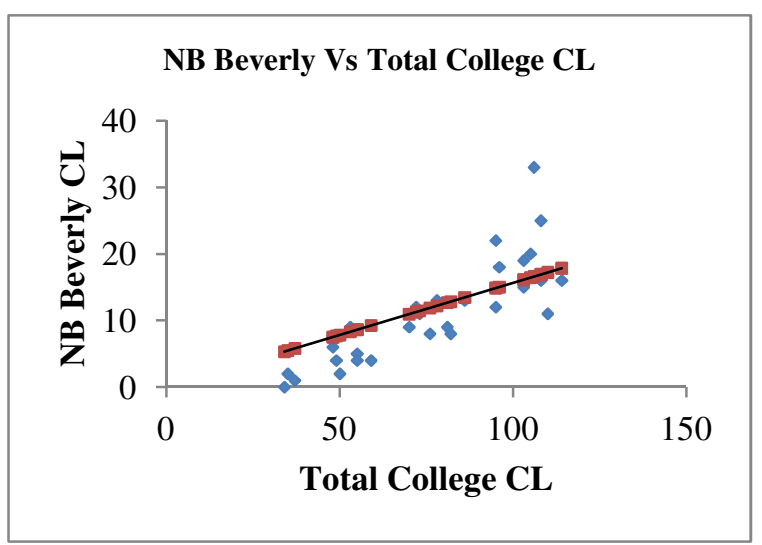

NB Beverley CL

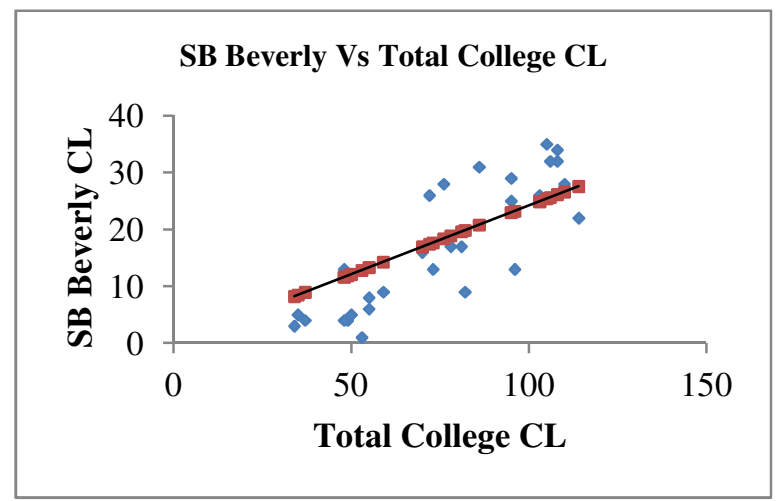

SB Beverley CL

Figure A1 Regression Models for OD Matrix Estimation 
For truck regression models, only data with non-zero values are used for estimation. All estimated traffic volumes are rounded down to the lower integer value; a sample of the table generated for some locations within the network for the June 3, 7:00-8:00 AM is shown below.

Table A1 Synthetic Traffic Generated using Regression Models (some locations)

\begin{tabular}{|c|c|c|c|c|c|c|c|c|c|c|c|c|c|c|c|c|}
\hline Time & CL & MH & CL & MH & CL & MH & CL & MH & CL & MH & CL & MH & CL & MH & CL & MH \\
\hline Date/Time & $\begin{array}{l}\text { EB } \\
\text { Colle }\end{array}$ & & $\begin{array}{l}\text { WB } \\
\text { Colle }\end{array}$ & & $\begin{array}{l}\text { NB } \\
\text { Geo }\end{array}$ & & $\begin{array}{l}\text { SB St } \\
\text { Geor }\end{array}$ & & $\begin{array}{l}\text { NB } \\
\text { Beve }\end{array}$ & & $\begin{array}{l}\text { SB } \\
\text { Beve }\end{array}$ & & SB I & Iuron & $\begin{array}{l}\text { SB } \\
\text { Circ }\end{array}$ & \\
\hline $\begin{array}{r}03 / 06 / 2011 \\
7: 15\end{array}$ & 177 & 1 & 144 & 4 & 56 & 1 & 106 & 0 & 50 & 1 & 77 & 0 & 18 & 0 & 9 & 0 \\
\hline $\begin{array}{r}03 / 06 / 2011 \\
7: 30 \\
\end{array}$ & 215 & 1 & 128 & 6 & 60 & 1 & 113 & 1 & 53 & 1 & 82 & 1 & 19 & 0 & 10 & 0 \\
\hline $\begin{array}{r}03 / 06 / 2011 \\
7: 45 \\
\end{array}$ & 200 & 1 & 162 & 8 & 63 & 1 & 119 & 1 & 56 & 1 & 87 & 1 & 20 & 0 & 11 & 0 \\
\hline $\begin{array}{r}03 / 06 / 2011 \\
8: 00\end{array}$ & 227 & 2 & 132 & 7 & 63 & 1 & 118 & 1 & 56 & 1 & 86 & 1 & 20 & 0 & 11 & 0 \\
\hline
\end{tabular}

Table A2 Sample Turning Percentage for Cars and Light Duty Vehicles between 7:15 - 7:30 AM; S: South, W: West, E: East, N: North; L: Left, R: Right, T: Through

\begin{tabular}{|l|l|l|l|l|l|l|l|l|l|l|l|l|l|}
\hline & & & STI & & & WTI & & & NTI & & ETI & \\
\hline & & SL & ST & SR & WL & WT & WR & NL & NT & NR & EL & ET & ER \\
\hline Russell & In & & & & & & & & & & & & \\
\hline Russell & & & 0.87 & 0.13 & & & & 0.12 & 0.88 & & 0.00 & & 1.00 \\
\hline Galbraith & In & & & & & & & & & & & & \\
\hline Galbraith & & 0.20 & 0.80 & & 0.15 & & 0.85 & & 0.96 & 0.04 & & & \\
\hline ISC N & In N & & & & & & & & & & & & \\
\hline ISC S & In & & & & & & & & & & & & \\
\hline ISC S & & 0.00 & 1.00 & & 0.00 & & 0.00 & & 1.00 & 0.00 & & & \\
\hline College & In & & & & & & & & & & & & \\
\hline College & & 0.48 & 0.44 & 0.08 & 0.01 & 0.75 & 0.24 & 0.27 & 0.51 & 0.22 & 0.01 & 0.93 & 0.06 \\
\hline Cecil & In & & & & & & & & & & & & \\
\hline Cecil & & 0.06 & 0.91 & 0.03 & 0.00 & 0.00 & 0.00 & 0.09 & 0.85 & 0.07 & 0.33 & 0.17 & 0.50 \\
\hline Huron & In & & & & & & & & & & & & \\
\hline Huron & & 0.33 & 0.33 & 0.33 & 0.06 & 0.80 & 0.14 & & & & 0.01 & 0.97 & 0.02 \\
\hline Ross & In & & & & & & & & & & & & \\
\hline Ross & & & & & & 1.00 & & 0.00 & & 0.00 & & 1.00 & \\
\hline Henry & In & & & & & & & & & & & & \\
\hline Henry & & & & & 0.02 & 0.98 & & & & & & 0.99 & 0.01 \\
\hline King's & In & & & & & & & & & & & & \\
\hline King's & & 0.00 & & 1.00 & & 0.92 & 0.08 & & & & 0.02 & 0.98 & \\
\hline
\end{tabular}


Table A3 Traffic Distribution on College Street East of Bathurst - City of Toronto Cordon Count Data (Database: toro09)

Table A3 City of Toronto Cordon Count Data

\begin{tabular}{|c|c|c|c|c|c|c|c|c|c|c|c|c|c|c|c|c|}
\hline & $\begin{array}{l}\text { start } \\
\text { time }\end{array}$ & $\begin{array}{l}\text { end } \\
\text { time }\end{array}$ & \multicolumn{9}{|c|}{ CAR and LIGHT TRUCKS } & \multicolumn{5}{|c|}{ MEDIUM AND HEAVY DUTY TRUCKS } \\
\hline $\begin{array}{l}225 \mathrm{E} \\
\mathrm{EB}\end{array}$ & 701 & 900 & 803 & 353 & 17 & 4 & 97 & 11 & 5 & 0 & 25 & 17 & 11 & 0 & 6 & 11 \\
\hline $\begin{array}{l}225 \mathrm{~W} \\
\mathrm{~EB}\end{array}$ & 701 & 900 & 413 & 136 & 2 & 2 & 124 & 15 & 1 & 0 & 54 & 9 & 5 & 1 & 3 & 5 \\
\hline
\end{tabular}

\section{Appendix B}

\section{B1. CMEM Emission Output Processing}

Snapshot of emission summary file below shows the first time step of 15 minutes from 7:00-7:15 AM for July 7, 2011 (PARAMICS random seed 6)

Time Slice: 1 Time Gap 900 (sec.) Simulation Time 900 (sec.)

Cummulative Emissions (grams)

\begin{tabular}{|c|c|c|c|c|c|c|}
\hline Link ID: & Sample Size: & $\mathrm{CO} 2$ & $\mathrm{CO}$ & $\mathrm{HC}$ & NOx & Fuel \\
\hline $1: 59$ & 135 & 826.46 & 4.33 & 0.20 & 2.64 & 261.56 \\
\hline $1: 74$ & 342 & 1338.51 & 11.75 & 0.40 & 1.56 & 428.19 \\
\hline $1: 60$ & 85 & 401.37 & 3.76 & 0.14 & 0.54 & 128.54 \\
\hline $1: 44$ & 390 & 1870.05 & 16.28 & 0.70 & 2.57 & 598.30 \\
\hline $2: 73$ & 193 & 295.56 & 5.46 & 0.11 & 0.20 & 95.99 \\
\hline $2: 74$ & 396 & 607.90 & 1.49 & 0.11 & 0.47 & 192.48 \\
\hline $3: 71$ & 18 & 30.91 & 0.12 & 0.02 & 0.03 & 9.82 \\
\hline $3: 70$ & 285 & 767.54 & 7.99 & 0.39 & 0.82 & 246.33 \\
\hline $3: 69$ & 39 & 160.36 & 1.69 & 0.03 & 0.18 & 51.42 \\
\hline $3: 72$ & 389 & 1318.60 & 26.32 & 0.79 & 2.07 & 429.54 \\
\hline $4: 5$ & 15 & 19.69 & 0.02 & 0.00 & 0.01 & 6.21 \\
\hline $6: 7$ & 12 & 18.33 & 0.03 & 0.00 & 0.00 & 5.80 \\
\hline $6: 71$ & 295 & 389.24 & 3.68 & 0.23 & 0.37 & 124.77 \\
\hline $7: 6$ & 24 & 82.10 & 0.57 & 0.04 & 0.14 & 26.20 \\
\hline $8: 9$ & 130 & 197.96 & 0.39 & 0.15 & 0.14 & 62.76 \\
\hline $8: 70$ & 236 & 1767.30 & 320.71 & 3.28 & 3.55 & 719.46 \\
\hline $9: 8$ & 285 & 1839.34 & 47.61 & 1.06 & 3.39 & 604.52 \\
\hline $10: 64$ & 93 & 645.20 & 1.50 & 0.14 & 3.14 & 202.45 \\
\hline $10: 66$ & 1 & 0.85 & 0.00 & 0.00 & 0.00 & 0.27 \\
\hline $10: 67$ & 37 & 57.56 & 0.13 & 0.01 & 0.01 & 18.22 \\
\hline $10: 65$ & 8 & 7.77 & 0.00 & 0.00 & 0.00 & 2.45 \\
\hline $11: 12$ & 1 & 0.85 & 0.00 & 0.00 & 0.00 & 0.27 \\
\hline $11: 66$ & 0 & 0.00 & 0.00 & 0.00 & 0.00 & 0.00 \\
\hline $12: 11$ & 0 & 0.00 & 0.00 & 0.00 & 0.00 & 0.00 \\
\hline $13: 67$ & 74 & 1084.31 & 22.83 & 0.43 & 3.99 & 351.89 \\
\hline $13: 14$ & 15 & 24.86 & 0.05 & 0.00 & 0.00 & 7.87 \\
\hline $14: 13$ & 78 & 422.70 & 2.28 & 0.11 & 1.20 & 134.09 \\
\hline $15: 65$ & 0 & 0.00 & 0.00 & 0.00 & 0.00 & 0.00 \\
\hline $15: 16$ & 7 & 6.46 & 0.00 & 0.00 & 0.00 & 2.04 \\
\hline
\end{tabular}




\begin{tabular}{|c|c|c|c|c|c|c|}
\hline $16: 15$ & 0 & 0.00 & 0.00 & 0.00 & 0.00 & 0.00 \\
\hline $17: 68$ & 0 & 0.00 & 0.00 & 0.00 & 0.00 & 0.00 \\
\hline $18: 17$ & 0 & 0.00 & 0.00 & 0.00 & 0.00 & 0.00 \\
\hline $19: 20$ & 204 & 752.95 & 4.44 & 0.19 & 1.92 & 239.13 \\
\hline $19: 58$ & 145 & 203.33 & 0.37 & 0.03 & 0.06 & 64.31 \\
\hline $19: 25$ & 105 & 150.99 & 0.46 & 0.04 & 0.11 & 47.86 \\
\hline $20: 23$ & 118 & 228.85 & 0.43 & 0.05 & 0.64 & 72.16 \\
\hline $20: 57$ & 39 & 155.01 & 0.96 & 0.05 & 0.23 & 49.39 \\
\hline $20: 19$ & 316 & 731.01 & 4.23 & 0.18 & 0.69 & 232.72 \\
\hline $21: 22$ & 18 & 23.49 & 0.04 & 0.01 & 0.02 & 7.43 \\
\hline $21: 57$ & 37 & 306.39 & 3.79 & 0.11 & 0.48 & 98.57 \\
\hline $22: 21$ & 24 & 54.83 & 0.23 & 0.01 & 0.06 & 17.41 \\
\hline $23: 24$ & 57 & 125.13 & 0.29 & 0.02 & 0.36 & 39.47 \\
\hline $23: 20$ & 122 & 648.45 & 11.36 & 0.36 & 1.12 & 210.42 \\
\hline $24: 23$ & 148 & 736.25 & 7.08 & 0.29 & 1.35 & 235.90 \\
\hline $25: 19$ & 83 & 106.20 & 0.15 & 0.01 & 0.03 & 33.56 \\
\hline $25: 26$ & 47 & 52.51 & 0.09 & 0.01 & 0.01 & 16.60 \\
\hline $26: 25$ & 33 & 96.61 & 0.39 & 0.02 & 0.10 & 30.66 \\
\hline $27: 47$ & 139 & 282.77 & 9.65 & 0.14 & 0.17 & 94.07 \\
\hline $27: 53$ & 7 & 25.57 & 0.27 & 0.01 & 0.05 & 8.21 \\
\hline $27: 48$ & 221 & 367.66 & 0.85 & 0.05 & 0.09 & 116.37 \\
\hline $28: 29$ & 3 & 3.70 & 0.01 & 0.00 & 0.00 & 1.17 \\
\hline $30: 51$ & 36 & 80.15 & 0.35 & 0.03 & 0.12 & 25.47 \\
\hline $30: 48$ & 195 & 413.28 & 2.10 & 0.09 & 0.34 & 131.41 \\
\hline $30: 49$ & 168 & 299.61 & 0.73 & 0.04 & 0.10 & 94.85 \\
\hline $31: 32$ & 23 & 30.90 & 0.10 & 0.01 & 0.02 & 9.79 \\
\hline $31: 52$ & 18 & 19.33 & 0.02 & 0.00 & 0.00 & 6.11 \\
\hline $32: 31$ & 18 & 43.02 & 0.14 & 0.01 & 0.04 & 13.64 \\
\hline $33: 50$ & 129 & 1392.03 & 329.69 & 3.13 & 3.03 & 605.46 \\
\hline $33: 34$ & 171 & 314.11 & 0.73 & 0.07 & 0.17 & 99.45 \\
\hline $34: 33$ & 249 & 1599.36 & 32.83 & 0.67 & 2.61 & 521.14 \\
\hline $35: 43$ & 162 & 343.24 & 0.82 & 0.10 & 1.40 & 108.03 \\
\hline $35: 36$ & 209 & 532.60 & 3.56 & 0.20 & 0.63 & 169.87 \\
\hline $35: 56$ & 0 & 0.00 & 0.00 & 0.00 & 0.00 & 0.00 \\
\hline $36: 35$ & 129 & 234.80 & 0.48 & 0.05 & 0.61 & 74.08 \\
\hline $36: 59$ & 219 & 759.07 & 43.94 & 0.54 & 1.05 & 261.62 \\
\hline $36: 55$ & 0 & 0.00 & 0.00 & 0.00 & 0.00 & 0.00 \\
\hline $38: 56$ & 4 & 4.27 & 0.00 & 0.00 & 0.00 & 1.35 \\
\hline 38:39 & 0 & 0.00 & 0.00 & 0.00 & 0.00 & 0.00 \\
\hline 39:38 & 4 & 6.65 & 0.01 & 0.00 & 0.00 & 2.10 \\
\hline $40: 55$ & 0 & 0.00 & 0.00 & 0.00 & 0.00 & 0.00 \\
\hline $40: 41$ & 0 & 0.00 & 0.00 & 0.00 & 0.00 & 0.00 \\
\hline $41: 40$ & 0 & 0.00 & 0.00 & 0.00 & 0.00 & 0.00 \\
\hline 37:61 & 65 & 138.63 & 0.31 & 0.03 & 0.41 & 43.72 \\
\hline $37: 62$ & 44 & 67.02 & 0.12 & 0.01 & 0.01 & 21.19 \\
\hline $42: 60$ & 142 & 230.02 & 0.44 & 0.09 & 0.50 & 72.67 \\
\hline $42: 61$ & 43 & 58.61 & 0.11 & 0.02 & 0.03 & 18.56 \\
\hline $43: 58$ & 103 & 586.98 & 1.22 & 0.12 & 3.08 & 184.23 \\
\hline $43: 35$ & 171 & 414.32 & 1.71 & 0.11 & 0.49 & 131.57 \\
\hline $44: 1$ & 884 & 1226.94 & 3.19 & 0.22 & 0.64 & 388.57 \\
\hline $44: 45$ & 135 & 942.26 & 64.41 & 0.81 & 1.45 & 329.79 \\
\hline $45: 44$ & 350 & 526.98 & 1.52 & 0.11 & 0.50 & 166.99 \\
\hline $45: 46$ & 200 & 1652.36 & 367.53 & 3.66 & 3.42 & 706.83 \\
\hline $46: 45$ & 172 & 271.12 & 6.67 & 0.10 & 0.22 & 88.88 \\
\hline $46: 47$ & 148 & 212.62 & 0.56 & 0.17 & 0.15 & 67.48 \\
\hline $47: 46$ & 141 & 236.41 & 7.74 & 0.12 & 0.21 & 78.48 \\
\hline $47: 27$ & 177 & 283.69 & 0.59 & 0.08 & 0.13 & 89.80 \\
\hline
\end{tabular}




\begin{tabular}{|c|c|c|c|c|c|c|}
\hline $48: 27$ & 141 & 373.14 & 21.63 & 0.25 & 0.37 & 128.61 \\
\hline $48: 30$ & 251 & 412.59 & 0.91 & 0.06 & 0.11 & 130.58 \\
\hline $49: 30$ & 103 & 171.46 & 0.31 & 0.03 & 0.09 & 54.23 \\
\hline 49:50 & 171 & 328.60 & 0.83 & 0.05 & 0.22 & 104.05 \\
\hline 50:49 & 146 & 448.59 & 52.29 & 0.58 & 0.63 & 167.93 \\
\hline $50: 33$ & 165 & 267.81 & 0.69 & 0.13 & 0.18 & 84.90 \\
\hline 51:52 & 28 & 31.09 & 0.07 & 0.00 & 0.00 & 9.84 \\
\hline 51:30 & 19 & 25.98 & 0.04 & 0.00 & 0.01 & 8.21 \\
\hline $52: 31$ & 31 & 34.83 & 0.07 & 0.00 & 0.00 & 11.02 \\
\hline $52: 51$ & 19 & 21.17 & 0.03 & 0.00 & 0.00 & 6.69 \\
\hline 53:54 & 3 & 20.42 & 1.00 & 0.02 & 0.05 & 6.95 \\
\hline $54: 28$ & 5 & 5.18 & 0.01 & 0.00 & 0.00 & 1.64 \\
\hline $55: 36$ & 0 & 0.00 & 0.00 & 0.00 & 0.00 & 0.00 \\
\hline $55: 40$ & 0 & 0.00 & 0.00 & 0.00 & 0.00 & 0.00 \\
\hline $56: 35$ & 3 & 3.21 & 0.00 & 0.00 & 0.00 & 1.01 \\
\hline $56: 38$ & 0 & 0.00 & 0.00 & 0.00 & 0.00 & 0.00 \\
\hline $57: 21$ & 25 & 103.57 & 1.32 & 0.04 & 0.13 & 33.34 \\
\hline $57: 20$ & 48 & 86.39 & 0.28 & 0.04 & 0.07 & 27.41 \\
\hline $58: 19$ & 65 & 451.85 & 2.43 & 0.13 & 1.48 & 143.07 \\
\hline $58: 43$ & 189 & 300.33 & 0.60 & 0.04 & 0.13 & 95.01 \\
\hline $59: 36$ & 61 & 195.77 & 0.54 & 0.04 & 0.67 & 61.69 \\
\hline $59: 1$ & 763 & 1346.70 & 156.77 & 1.64 & 1.53 & 503.92 \\
\hline 60:1 & 540 & 1024.68 & 12.67 & 0.28 & 2.11 & 328.43 \\
\hline 60:42 & 38 & 194.20 & 12.94 & 0.13 & 0.27 & 67.77 \\
\hline 61:42 & 69 & 157.91 & 0.45 & 0.04 & 0.47 & 49.88 \\
\hline 61:37 & 43 & 62.63 & 0.12 & 0.01 & 0.01 & 19.81 \\
\hline $62: 37$ & 64 & 139.10 & 0.30 & 0.03 & 0.39 & 43.86 \\
\hline $62: 63$ & 52 & 83.33 & 0.18 & 0.01 & 0.02 & 26.37 \\
\hline $63: 62$ & 76 & 159.15 & 0.33 & 0.03 & 0.47 & 50.17 \\
\hline 63:64 & 42 & 72.39 & 0.16 & 0.01 & 0.04 & 22.91 \\
\hline 64:63 & 50 & 91.44 & 0.21 & 0.03 & 0.28 & 28.88 \\
\hline $64: 10$ & 41 & 58.59 & 0.11 & 0.01 & 0.02 & 18.53 \\
\hline $65: 10$ & 0 & 0.00 & 0.00 & 0.00 & 0.00 & 0.00 \\
\hline $65: 15$ & 10 & 9.82 & 0.01 & 0.00 & 0.01 & 3.10 \\
\hline $66: 11$ & 2 & 1.70 & 0.00 & 0.00 & 0.00 & 0.54 \\
\hline $66: 10$ & 0 & 0.00 & 0.00 & 0.00 & 0.00 & 0.00 \\
\hline $67: 10$ & 36 & 552.16 & 57.39 & 0.59 & 1.95 & 202.33 \\
\hline $67: 13$ & 30 & 46.27 & 0.09 & 0.00 & 0.00 & 14.63 \\
\hline $68: 2$ & 0 & 0.00 & 0.00 & 0.00 & 0.00 & 0.00 \\
\hline $69: 4$ & 27 & 77.96 & 0.26 & 0.02 & 0.10 & 24.72 \\
\hline $70: 8$ & 171 & 1382.46 & 234.71 & 2.46 & 2.80 & 554.68 \\
\hline $70: 3$ & 535 & 784.97 & 26.48 & 0.63 & 0.59 & 261.23 \\
\hline $71: 6$ & 19 & 26.41 & 0.05 & 0.00 & 0.01 & 8.36 \\
\hline $71: 3$ & 515 & 594.85 & 1.29 & 0.13 & 0.17 & 188.29 \\
\hline $72: 3$ & 395 & 522.13 & 0.96 & 0.09 & 0.20 & 165.17 \\
\hline $72: 73$ & 209 & 1541.32 & 255.13 & 2.68 & 2.86 & 615.11 \\
\hline $73: 72$ & 217 & 347.10 & 0.66 & 0.04 & 0.10 & 109.78 \\
\hline $73: 2$ & 230 & 332.59 & 3.61 & 0.23 & 0.25 & 106.87 \\
\hline $74: 2$ & 237 & 1672.73 & 285.26 & 2.78 & 2.97 & 671.56 \\
\hline $74: 1$ & 1341 & 1857.38 & 9.45 & 0.38 & 1.25 & 590.58 \\
\hline $2: 68$ & 0 & 0.00 & 0.00 & 0.00 & 0.00 & 0.00 \\
\hline $4: 69$ & 0 & 0.00 & 0.00 & 0.00 & 0.00 & 0.00 \\
\hline $5: 4$ & 0 & 0.00 & 0.00 & 0.00 & 0.00 & 0.00 \\
\hline $17: 18$ & 0 & 0.00 & 0.00 & 0.00 & 0.00 & 0.00 \\
\hline 28:54 & 0 & 0.00 & 0.00 & 0.00 & 0.00 & 0.00 \\
\hline $29: 28$ & 0 & 0.00 & 0.00 & 0.00 & 0.00 & 0.00 \\
\hline $53: 27$ & 0 & 0.00 & 0.00 & 0.00 & 0.00 & 0.00 \\
\hline
\end{tabular}




$\begin{array}{ccccccc}54: 53 & 0 & 0.00 & 0.00 & 0.00 & 0.00 & 0.00 \\ 68: 17 & 0 & 0.00 & 0.00 & 0.00 & 0.00 & 0.00 \\ 69: 3 & 0 & 0.00 & 0.00 & 0.00 & 0.00 & 0.00\end{array}$

These values are input into an Excel Spreadsheet Model that calculates emission rates for the point / line sources specified in AERMOD / QUIC. These models output the following:

1) Formatted excel input emissions worksheet (for AERMOD)

2) Input text emissions file 'QP_source.inp' (for QUIC)

Emission rate is specified as mass flow rate for both dispersion models, therefore the cumulative emissions are divided by the 'time gap' to obtain effective grams released per second for the particular time interval. In case of AERMOD, line sources are replaced by either single or double point sources evenly spaced across the line source. The emission rate is equally split for cases with two point sources for a single line source.

Table B1 Sample Emission Rates in g/s for AERMOD, July 7, 2011 7:00-8:00 AM

\begin{tabular}{|l|l|l|}
\hline & $\mathrm{CO}$ & $\mathrm{NO}_{\mathrm{x}}$ \\
\hline P1 & 0.0020 & 0.0005 \\
\hline P2 & 0.0085 & 0.0012 \\
\hline P3 & 0.0037 & 0.0004 \\
\hline P4 & 0.0113 & 0.0016 \\
\hline P5 & 0.0023 & 0.0002 \\
\hline P6 & 0.0045 & 0.0004 \\
\hline P7 & 0.0010 & 0.0001 \\
\hline P8 & 0.0035 & 0.0007 \\
\hline P9 & 0.0016 & 0.0002 \\
\hline P10 & 0.0091 & 0.0011 \\
\hline
\end{tabular}

Snapshot of the input emissions text file for QUIC is shown below:

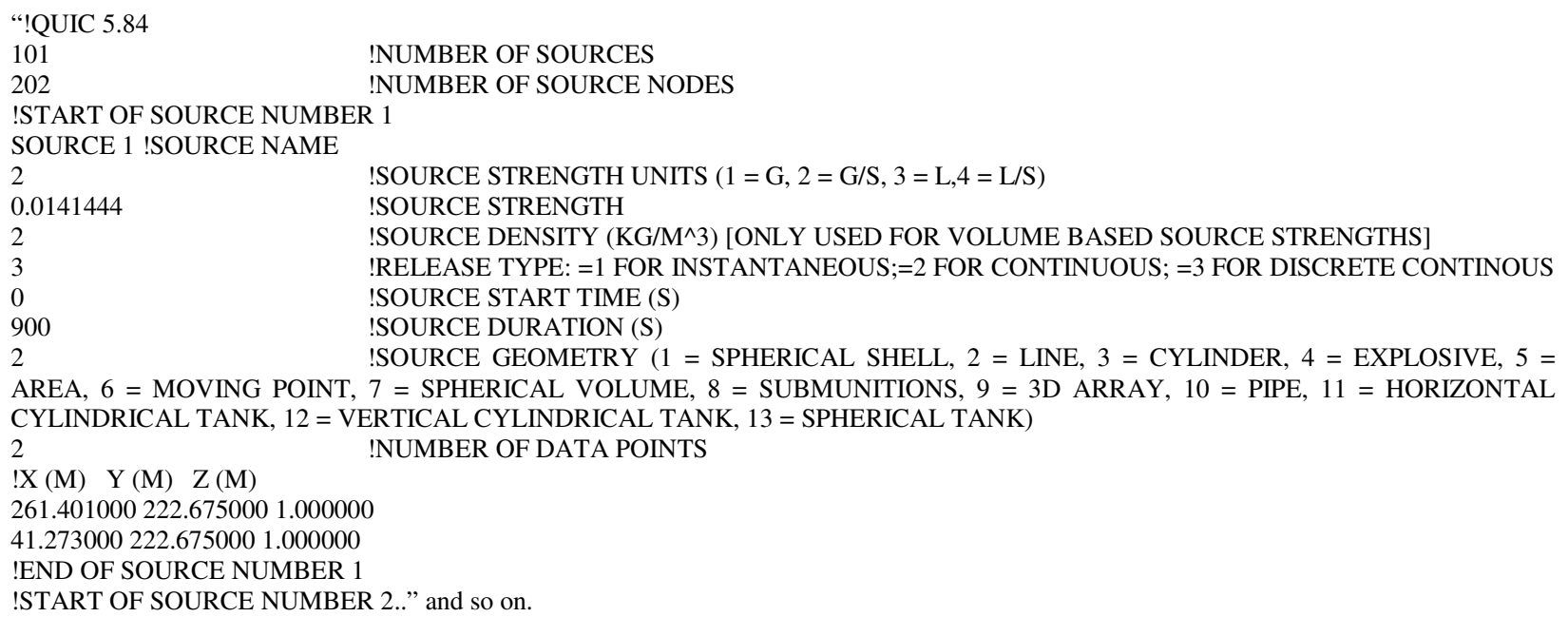




\section{B2. AERMET Outputs}

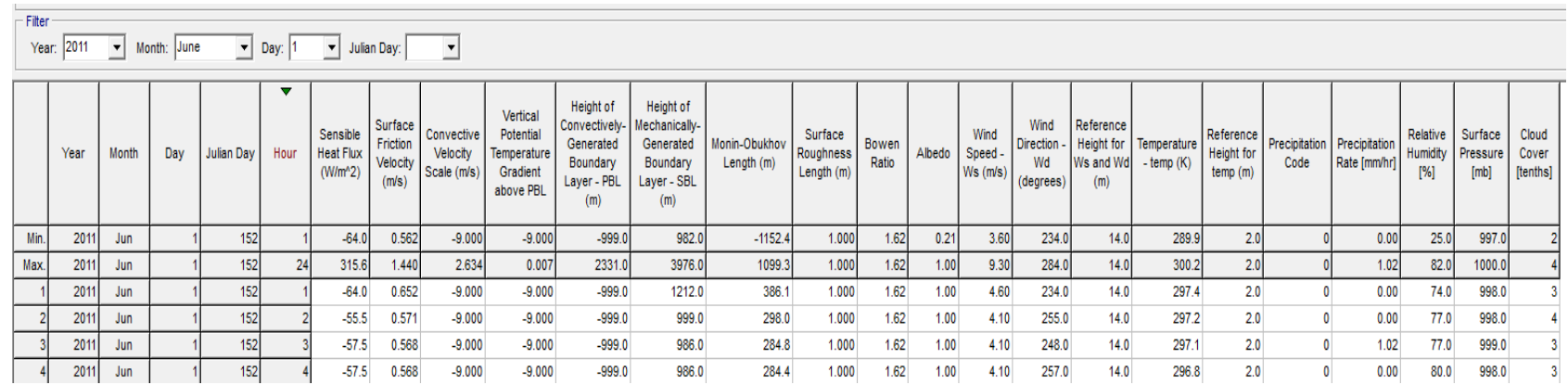

Figure B1 Sample Surface File, AERMET View Output, June 1, 2011 0:00 - 4:00 AM

Table B2 Atmospheric Parameter Characteristics from Surface File for June and July 2011

\begin{tabular}{|l|l|c|l|c|c|c|}
\hline & & $\begin{array}{l}\text { Surface } \\
\text { Pressure } \\
\text { (atm) }\end{array}$ & $\begin{array}{l}\text { Wind } \\
\text { Speed } \\
\mathbf{m} / \mathbf{s}\end{array}$ & $\begin{array}{l}\text { Inv. MO } \\
\text { Length } \\
(\mathbf{1 / m})\end{array}$ & $\begin{array}{l}\text { Wind } \\
\text { Direction } \\
\text { (degrees) }\end{array}$ & $\begin{array}{l}\text { Temp. } \\
(\mathbf{C})\end{array}$ \\
\hline \multirow{2}{*}{$\begin{array}{l}\text { JUNE 2011 } \\
\text { Atmospheric } \\
\text { Parameters }\end{array}$} & Standard Deviation & 0.0048 & 1.7524 & 0.1109 & 99.1770 & 3.4783 \\
\cline { 2 - 7 } & Average & 0.9850 & 3.2295 & -0.0528 & 186.7955 & 294.2114 \\
\cline { 2 - 7 } $\begin{array}{l}\text { JULY 2011 } \\
\text { Atmospheric } \\
\text { Parameters }\end{array}$ & Coefficient of Var. & 0.0048 & 0.5426 & -2.0985 & 0.5309 & 0.0118 \\
\cline { 2 - 7 } & Standard Deviation & 0.0045 & 1.3037 & 0.0889 & 99.9236 & 3.0994 \\
\cline { 2 - 7 } & Average & 0.9846 & 2.4738 & -0.0542 & 193.0000 & 298.0476 \\
\cline { 2 - 7 } & Coefficient of Var. & 0.0046 & 0.5270 & -1.6414 & 0.5177 & 0.0104 \\
\hline
\end{tabular}
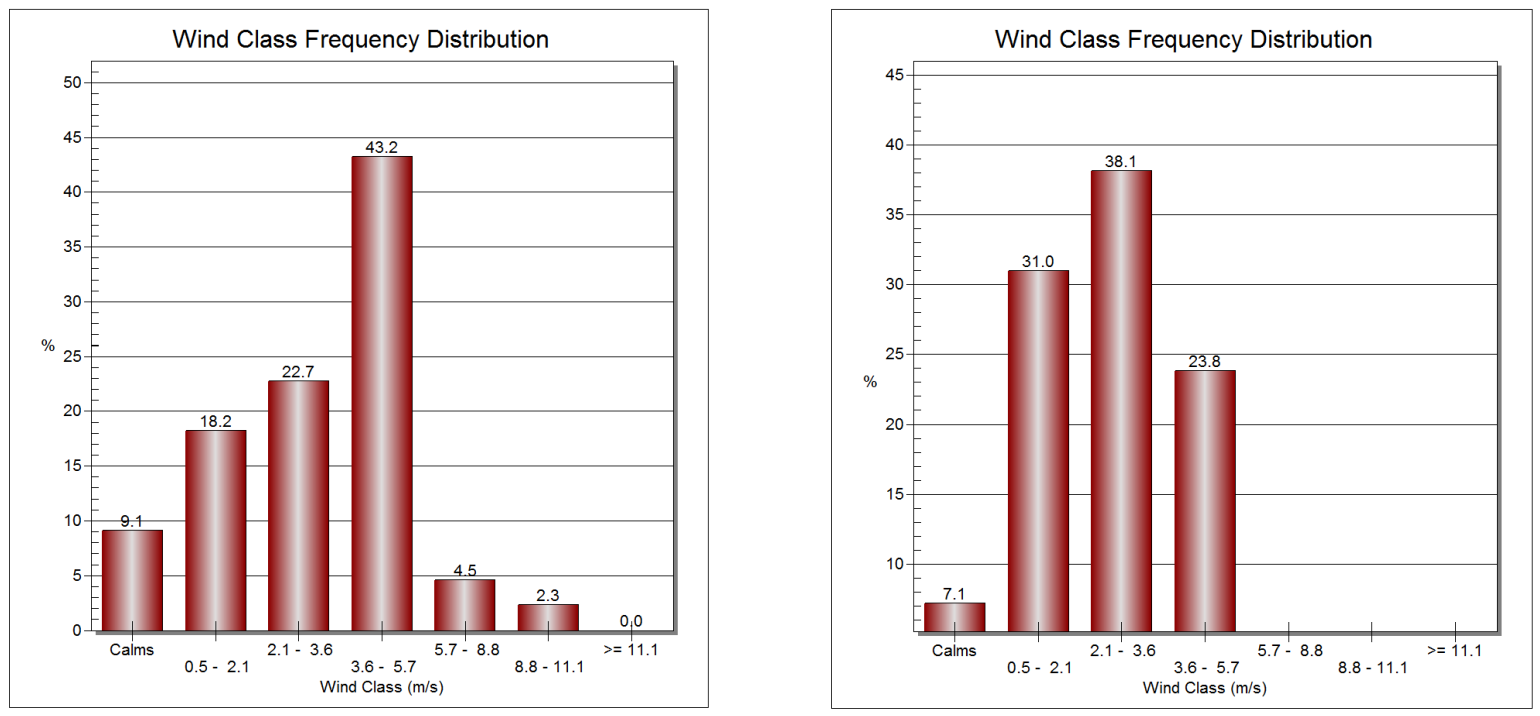

Figure B2 Wind Frequency Distribution for June 2011 (left) and July 2011 (right) 


\section{B3. Source Attributes}

Table B3 AERMOD and QUIC Source Attributes

\begin{tabular}{|l|c|c|}
\hline Attribute & AERMOD & QUIC \\
\hline Type & Point & Line \\
\hline Release Height/ type & $1 \mathrm{~m}$, horizontal & $1 \mathrm{~m}$, directionless \\
\hline Exit Temperature & $500 \mathrm{~K}$ & Ambient \\
\hline Diameter of Point Source & $0.0762 \mathrm{~m}(\sim 3$ inches $)$ & Not applicable \\
\hline
\end{tabular}

\section{B4. Reporting Results}

Sensor observed data are available in volumetric units $\left(\mathrm{CO}-\mathrm{ppm}, \mathrm{NO}_{\mathrm{x}}-\mathrm{ppb}\right)$. Modelled data from AERMOD and QUIC are in gravimetric units $\left(\mathrm{CO}, \mathrm{NO}_{\mathrm{x}}-\mathrm{mg} / \mathrm{m}^{3}\right)$. Conversion between the two unit systems is carried out using the following formulas:

$$
\begin{gathered}
m=R \frac{T}{P} \\
C_{p p m}=C_{m g / m^{3}} \times \frac{m}{M}
\end{gathered}
$$

Where, m: molar volume; R: Universal Gas Constant; T: Temperature; P: Pressure; M: Molecular Weight; C: Concentration (subscript denotes type of unit)

Temperature and pressure values obtained from AERMET are used for these calculations. CO comparisons are made in ppm while $\mathrm{NO}_{\mathrm{x}}$ comparisons are in $\mathrm{mg} / \mathrm{m}^{3}$. This is because $\mathrm{NO}_{\mathrm{x}}$ comprises $\mathrm{NO}$ and $\mathrm{NO}_{2}$ which have different molecular weights. Since modelled concentrations are only available in $\mathrm{mg} / \mathrm{m}^{3}$, observed concentrations (in ppb) are converted to that unit.

\section{B5. Coefficient of Variation Analysis QUIC}

$$
n^{\prime}=(C V)^{2} \frac{(C F)^{2}}{(\%)^{2}}
$$

Where, n': Sample size, CV: Coefficient of Variation, CF: Confidence Factor obtained from the normal distribution curve; \%: percent error on mean. Average coefficient of variation is obtained 
from eight 15 minute intervals (one each for June and July). A hit and trial method is then used to estimate the percentage error for one model run. To estimate the mean and standard deviation of the sample, the distribution is initially established to be of the normal form. This is done using the Kolmogorov-Smirnov (K-S) test. The K-S test compares observed frequency with cumulative function of a known distribution (normal in this case) to test whether a given sample of data belongs to a particular distribution. Observed data is arranged in increasing order,

$$
\begin{gathered}
S_{n}=\frac{k}{n} \\
D_{n}=S_{n}-F_{e}
\end{gathered}
$$

Where, $\mathrm{k}=$ current index, $\mathrm{n}=$ total sample number; $\mathrm{F}_{\mathrm{e}}=$ Theoretical cumulative function; If $\max$ $\left(D_{n}\right) \leq D_{n}^{\alpha}(\alpha$ : significance value), then proposed theoretical distribution is accepted.

Table B4 K-S Test Sample, $\mathrm{NO}_{\mathrm{x}}$ Concentration, 8:45 - 9:00 AM, July 13, 2011

\begin{tabular}{|c|c|c|c|c|}
\hline $\mathrm{n}$ & GEH & $\mathrm{Sn}$ & $\mathrm{FE}$ & $\mathrm{Dn}$ \\
\hline 1 & 0.0016 & 0.0333 & 0.0417 & 0.0084 \\
\hline 2 & 0.0020 & 0.0667 & 0.0816 & 0.0150 \\
\hline$\ldots$ & $\ldots$ & $\ldots$ & $\ldots$ & $\ldots$ \\
\hline$\ldots$ & $\ldots$ & $\ldots$ & $\ldots$ & $\ldots$ \\
\hline 30 & 0.0076 & 1.0000 & 0.9984 & 0.0016 \\
\hline Mean= & 0.0038 & St. Dev. $=$ & 0.0013 & \\
\hline Normal & Max Dn= & 0.07364 & $\mathrm{D} 45=$ & 0.277513 \\
\hline & & & $\alpha=0.05$ & Accepted \\
\hline
\end{tabular}

\section{B6. Sensitivity Analyses Methodology Characteristics:}

A single run is performed for the PARAMICS / CMEM combination for sensitivity analyses. No divisor is used to scale down the PARAMICS input O-D matrix for any of the sensitivity or random seed analyses. QUIC Emission rates are averaged over links that are aggregated to each of the 17 line sources for all sensitivity analyses and additionally, for the QUIC random seed analysis. The intent of sensitivity testing is to estimate the coefficient of variation as opposed to validating actual measurements. 


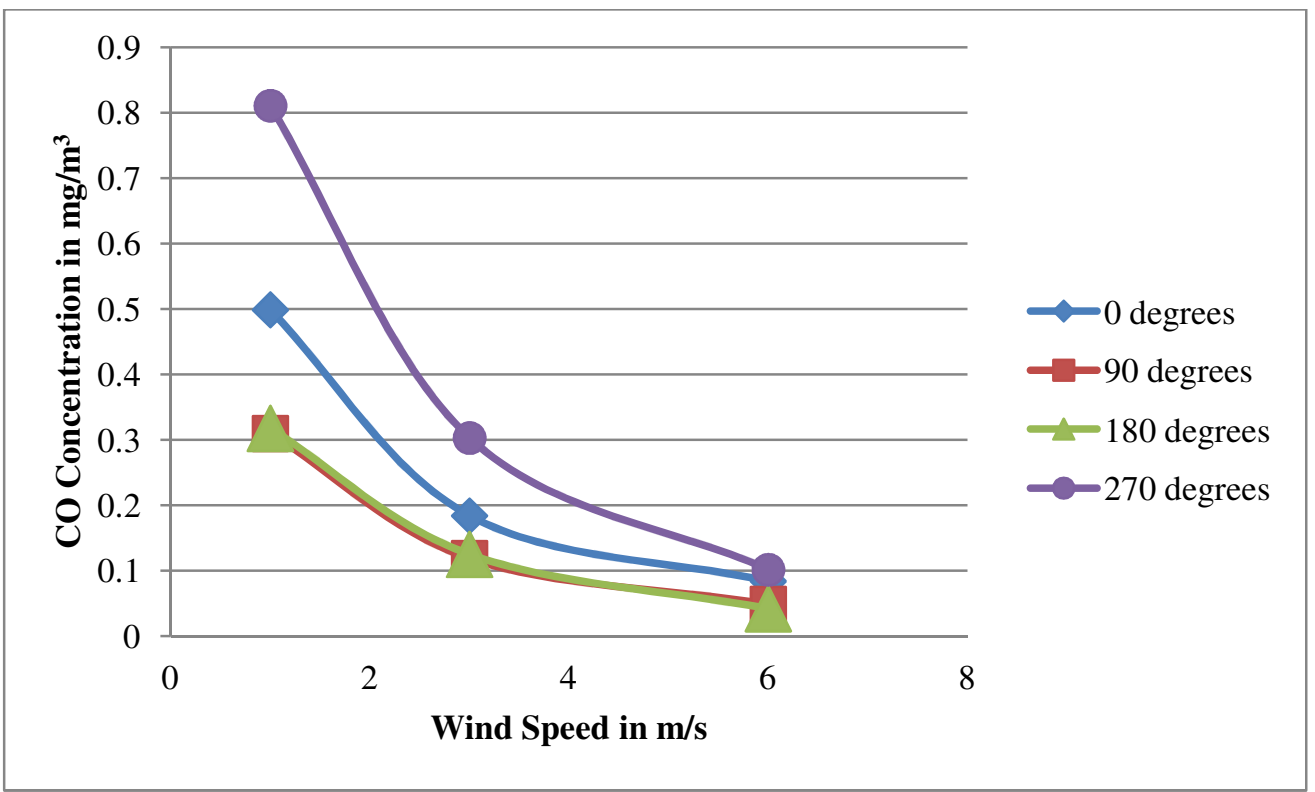

Figure B3 Relationship between QUIC Modelled CO Concentration and Wind speed for different wind directions. 


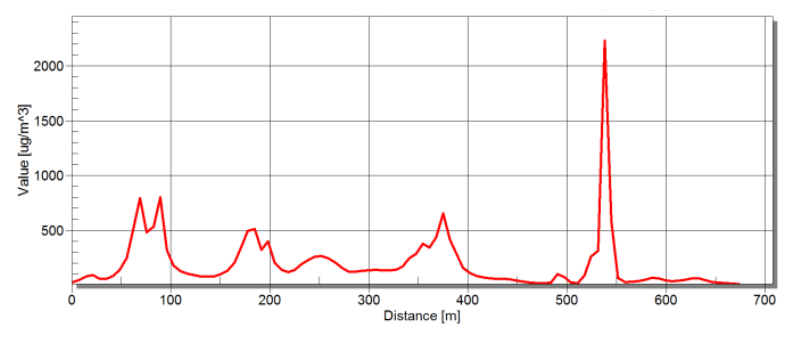

EB College, $\sim$ Sidewalk CO

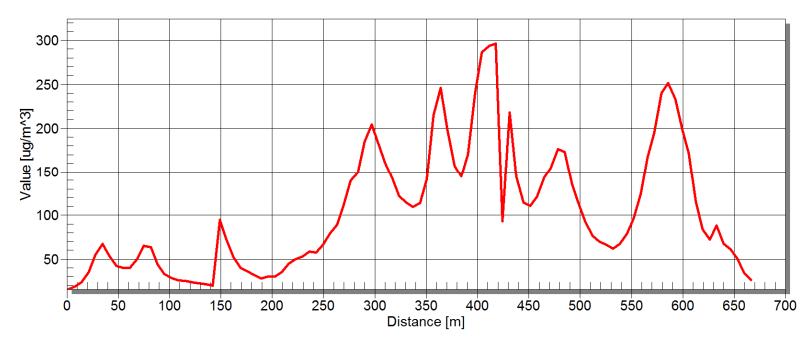

WB College, $\sim$ Sidewalk CO

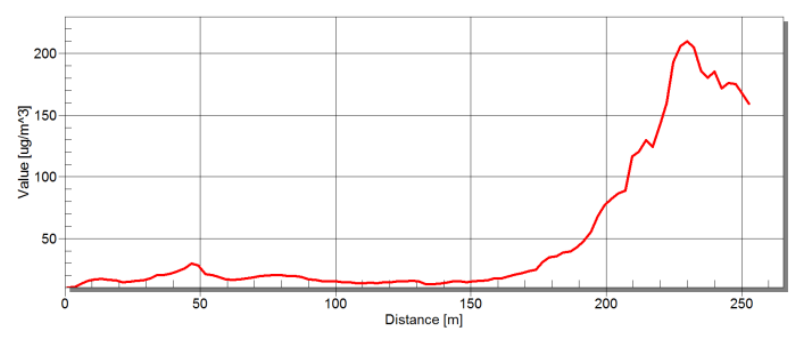

SB St. George, $\sim$ Sidewalk CO

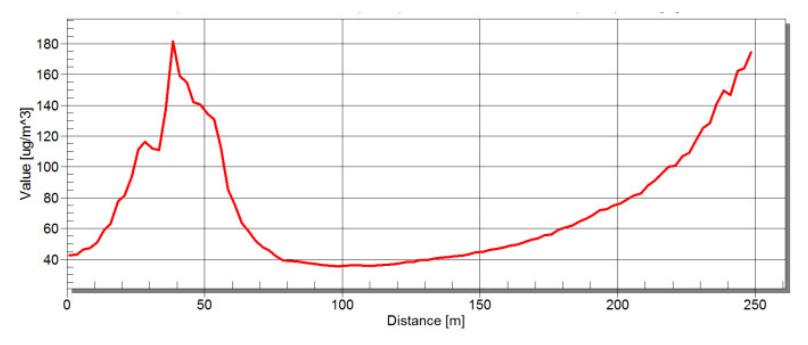

NB Beverley, Sidewalk CO

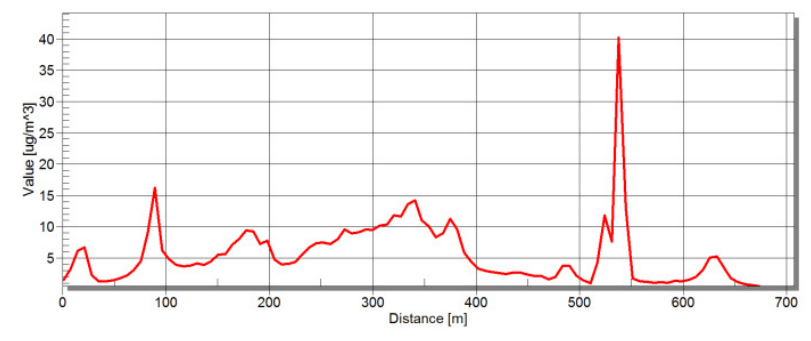

EB College, $\sim$ Sidewalk $\mathrm{NO}_{x}$

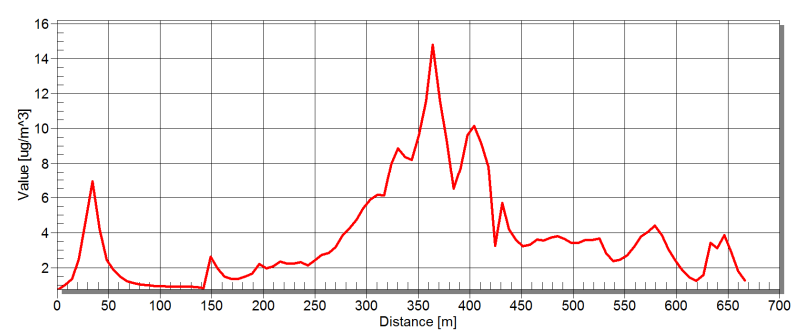

WB College, $\sim$ Sidewalk $\mathrm{NO}_{\mathrm{x}}$

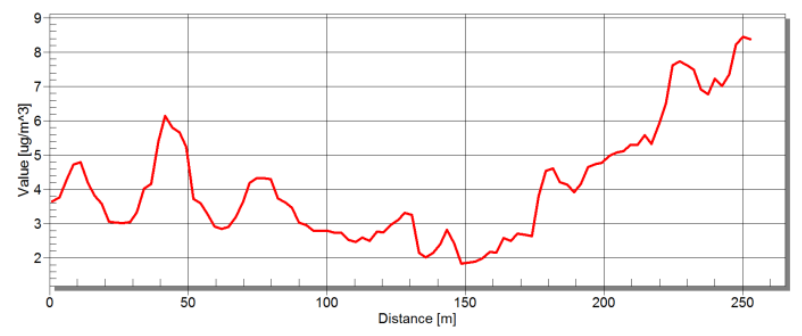

SB St. George, $\sim$ Sidewalk $\mathrm{NO}_{\mathrm{x}}$

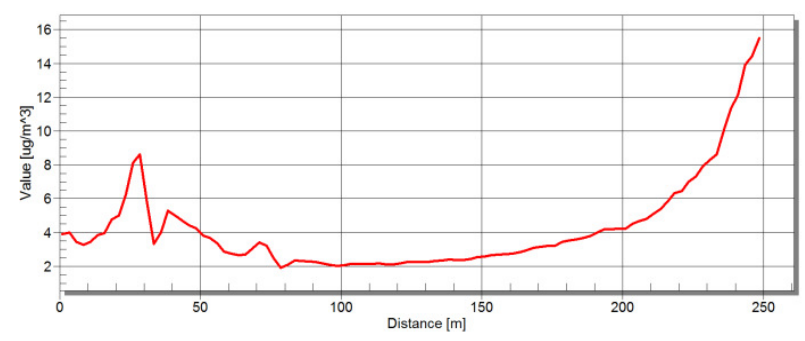

NB Beverley, $\sim$ Sidewalk $\mathrm{NO}_{\mathrm{x}}$

Figure B4 AERMOD View concentration plots 3m Height, CO 7:00 - 8:00 AM, June 13, 2011 (Left) and 8:00 - 9:00 AM, NO July 18, 2011(Right) 


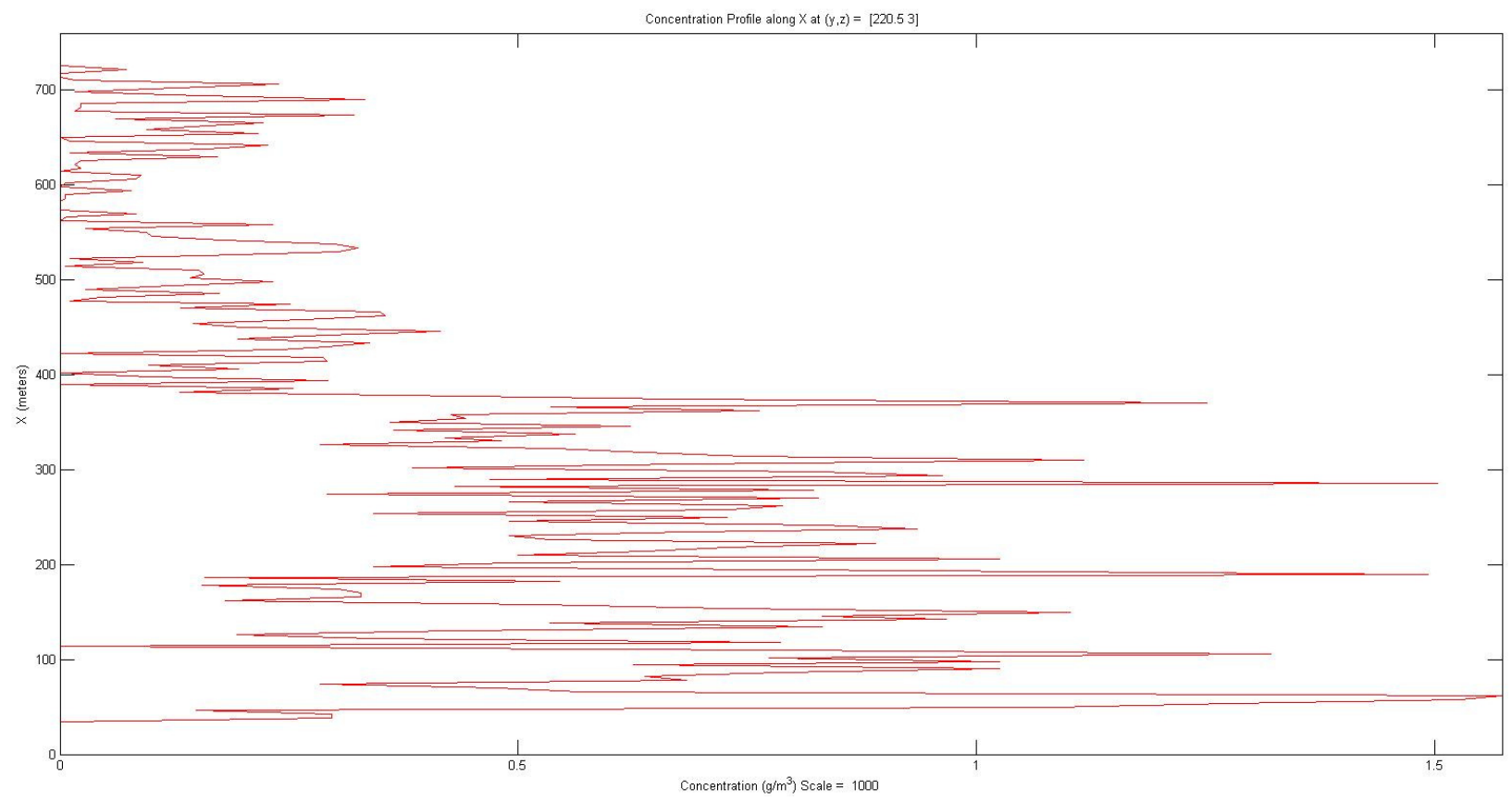

CO June 13, 7:00 - 7:15 AM EB College

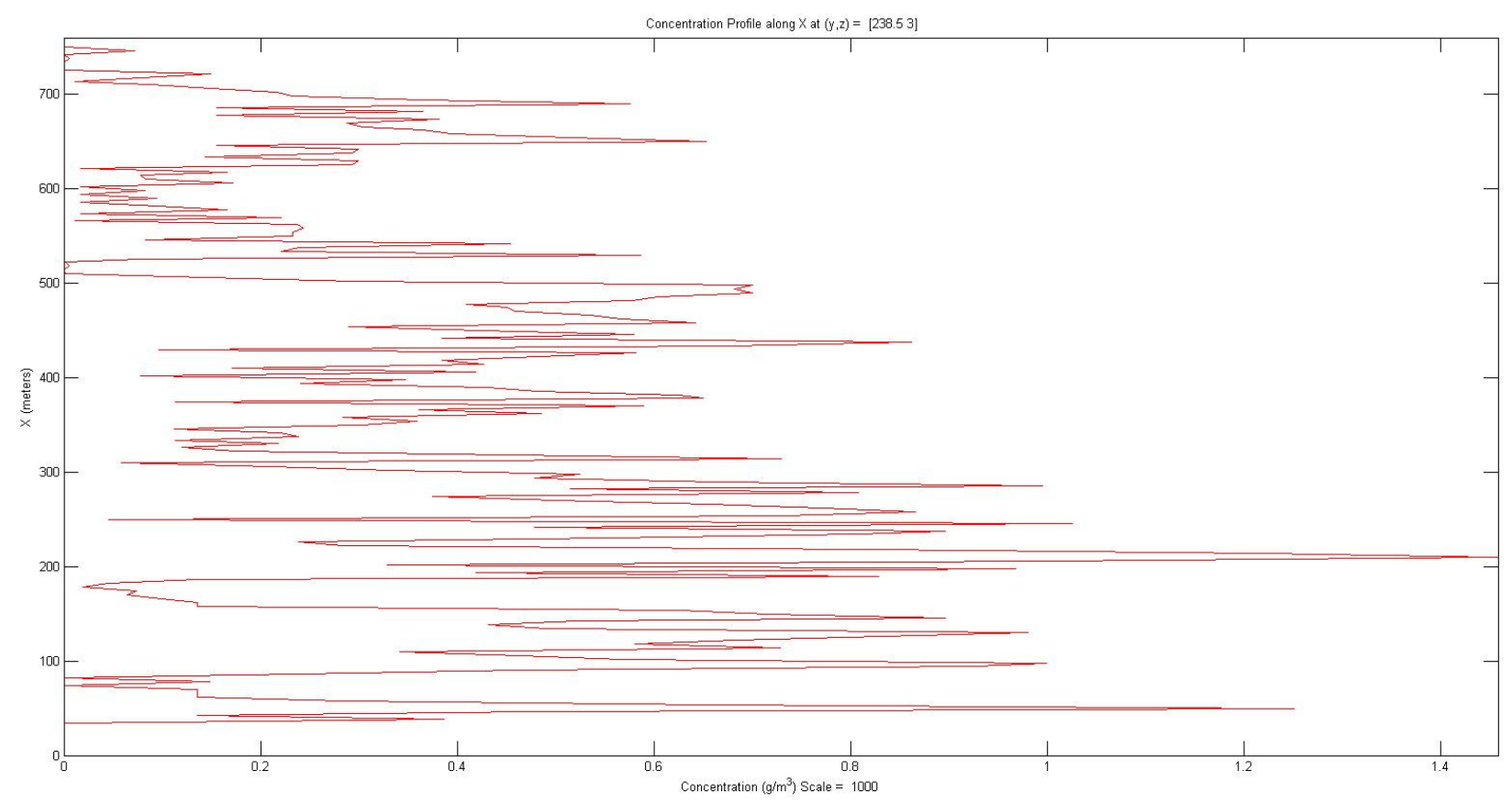

CO June 13, 7:00 - 7:15 AM WB College

Figure B5 QUIC CO Concentration Plots, 3m Height, June 13, 7:00-7:15 AM 


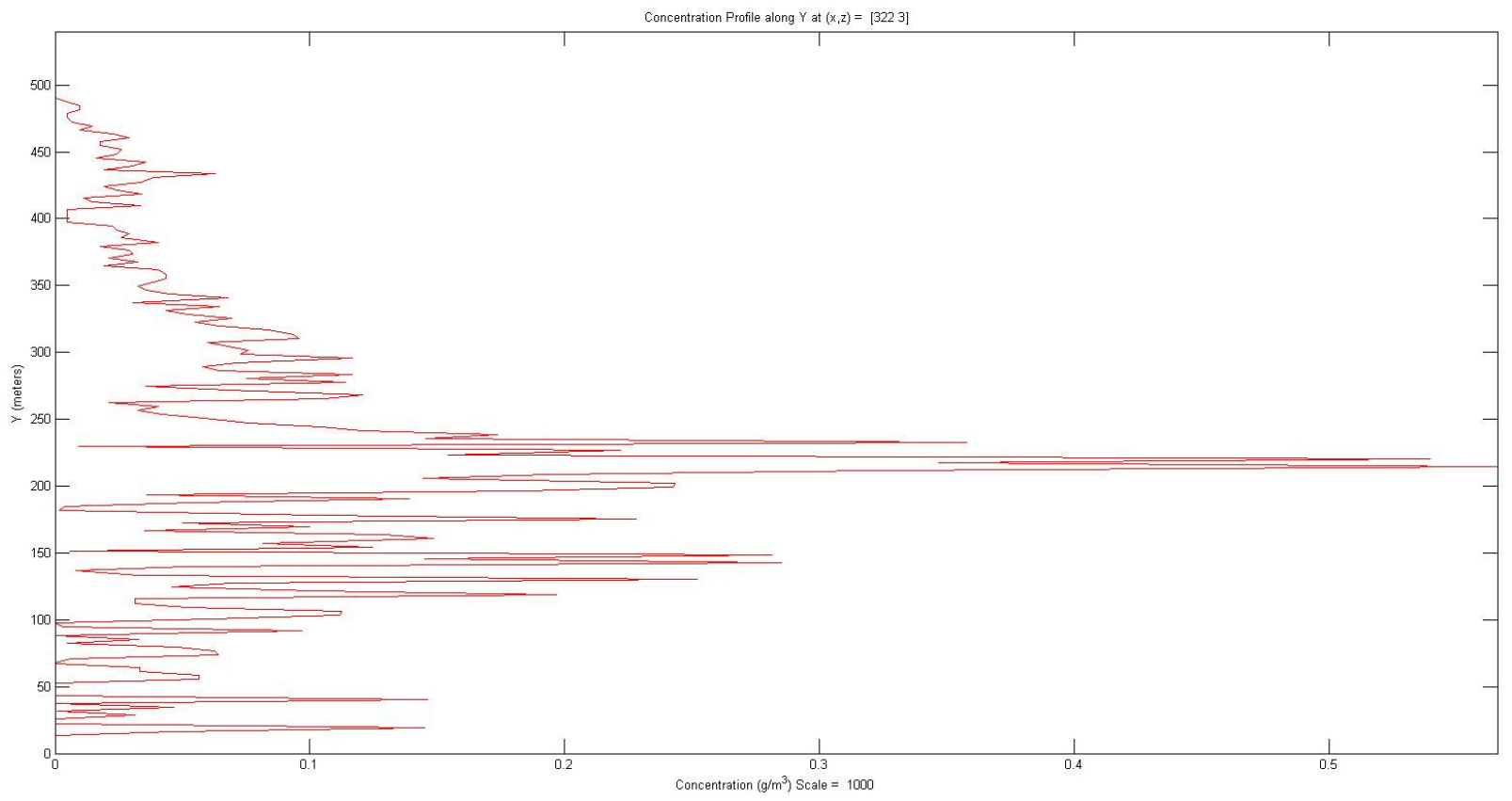

CO June 13, 7:00 - 7:15 AM SB St. George

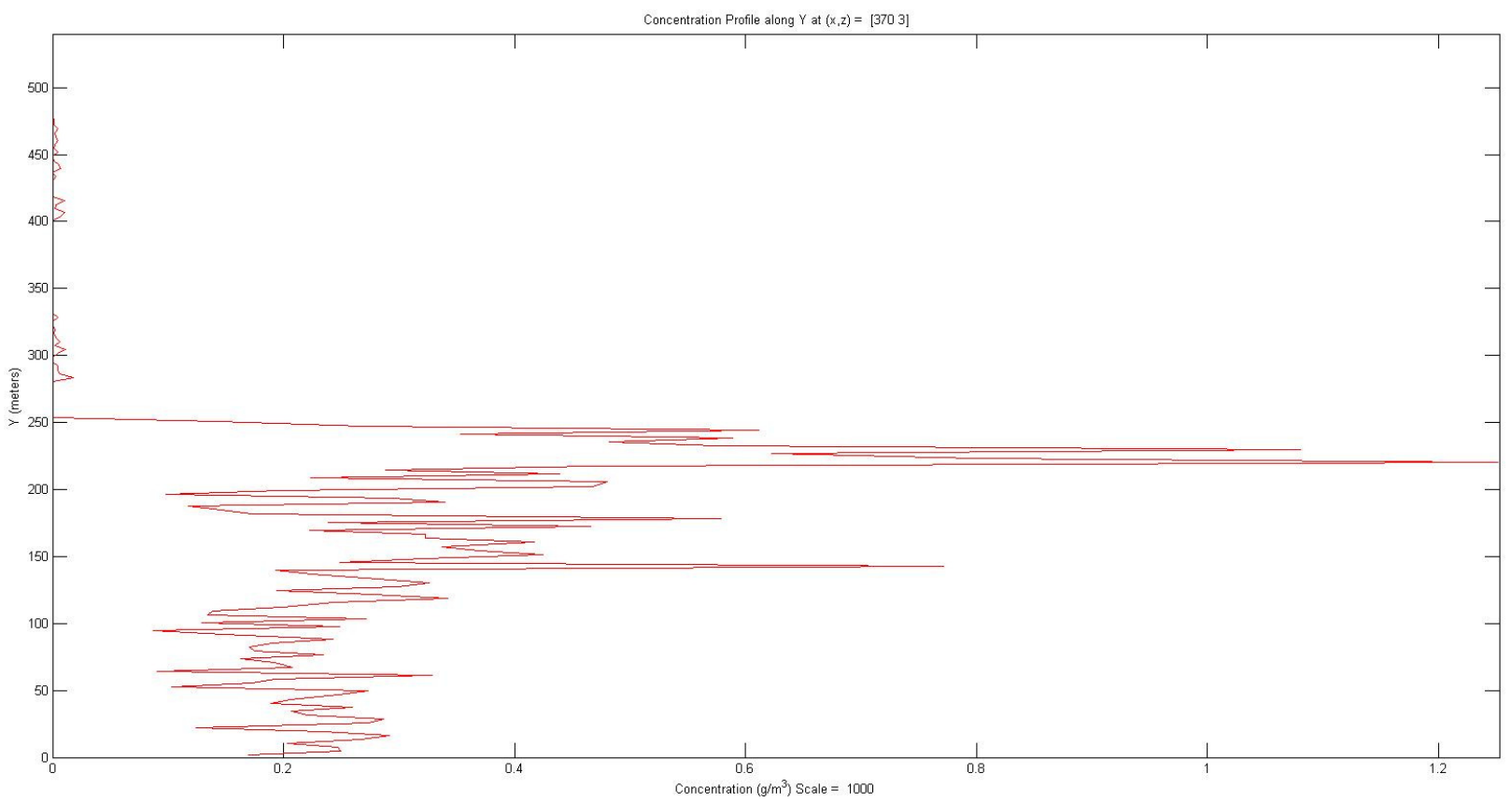

CO June 13, 7:00 - 7:15 AM NB Beverley

Figure B5 QUIC CO Concentration Plots, 3m Height, June 13, 7:00-7:15 AM 


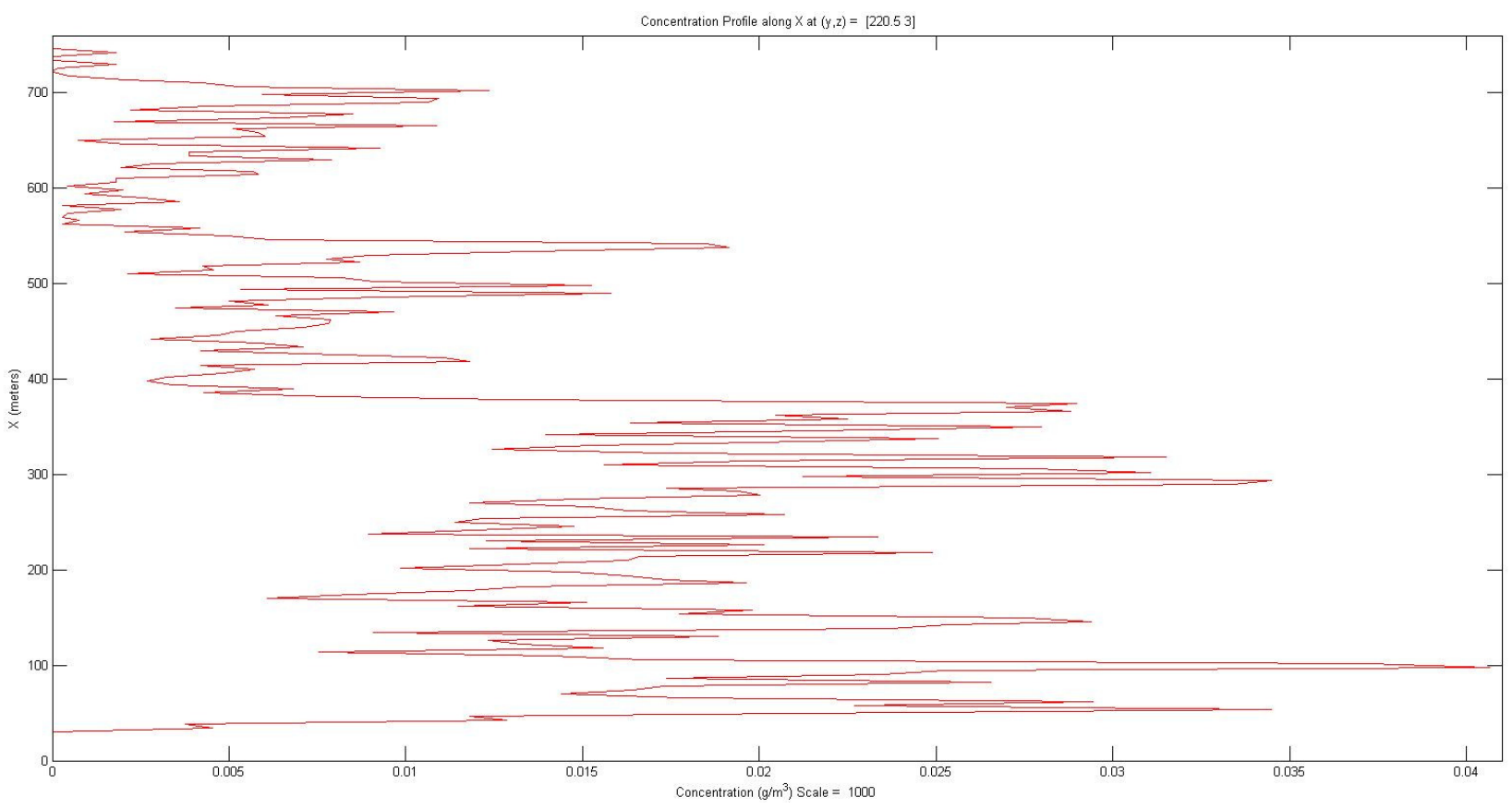

$\mathrm{NO}_{\mathrm{x}}$ July 18, 8:15-8:30 AM EB College

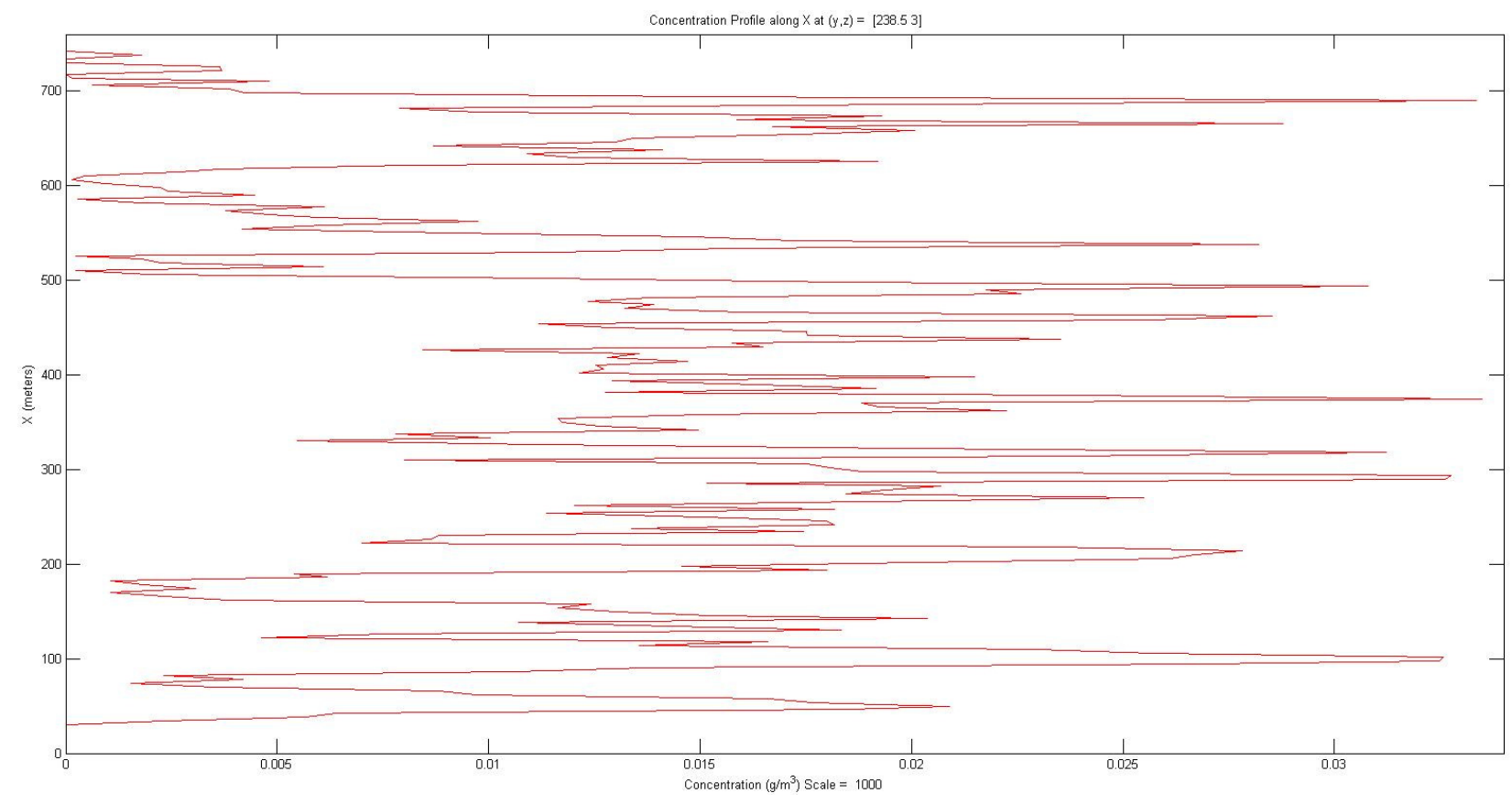

$\mathrm{NO}_{\mathrm{x}}$ July 18, 8:15-8:30 AM WB College

Figure B6 QUIC $\mathrm{NO}_{\mathrm{x}}$ Concentration Plots, 3m Height, July 18, 8:15-8:30 AM 


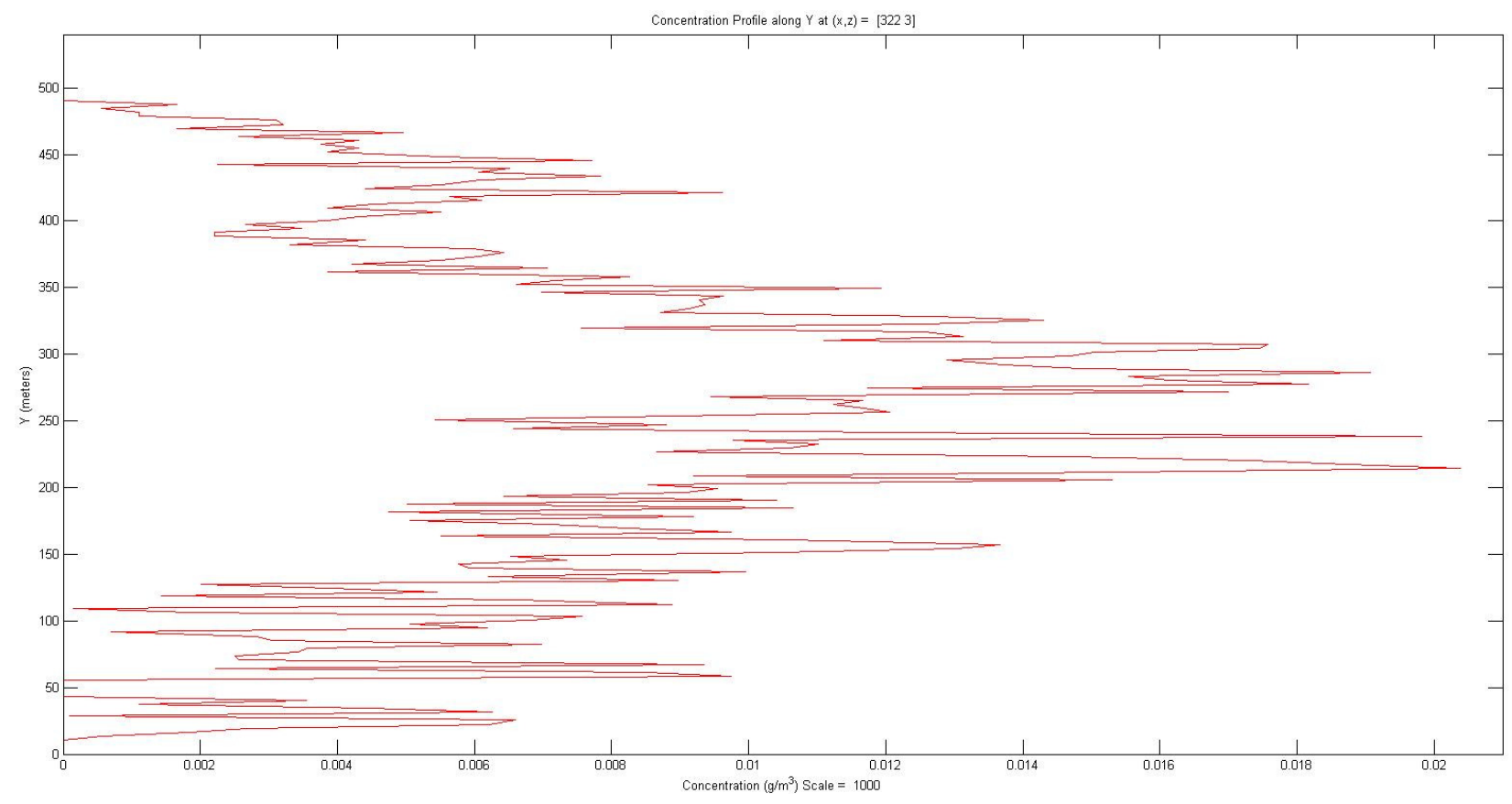

$\mathrm{NO}_{\mathrm{x}}$ July 18, 8:15-8:30 AM SB St. George

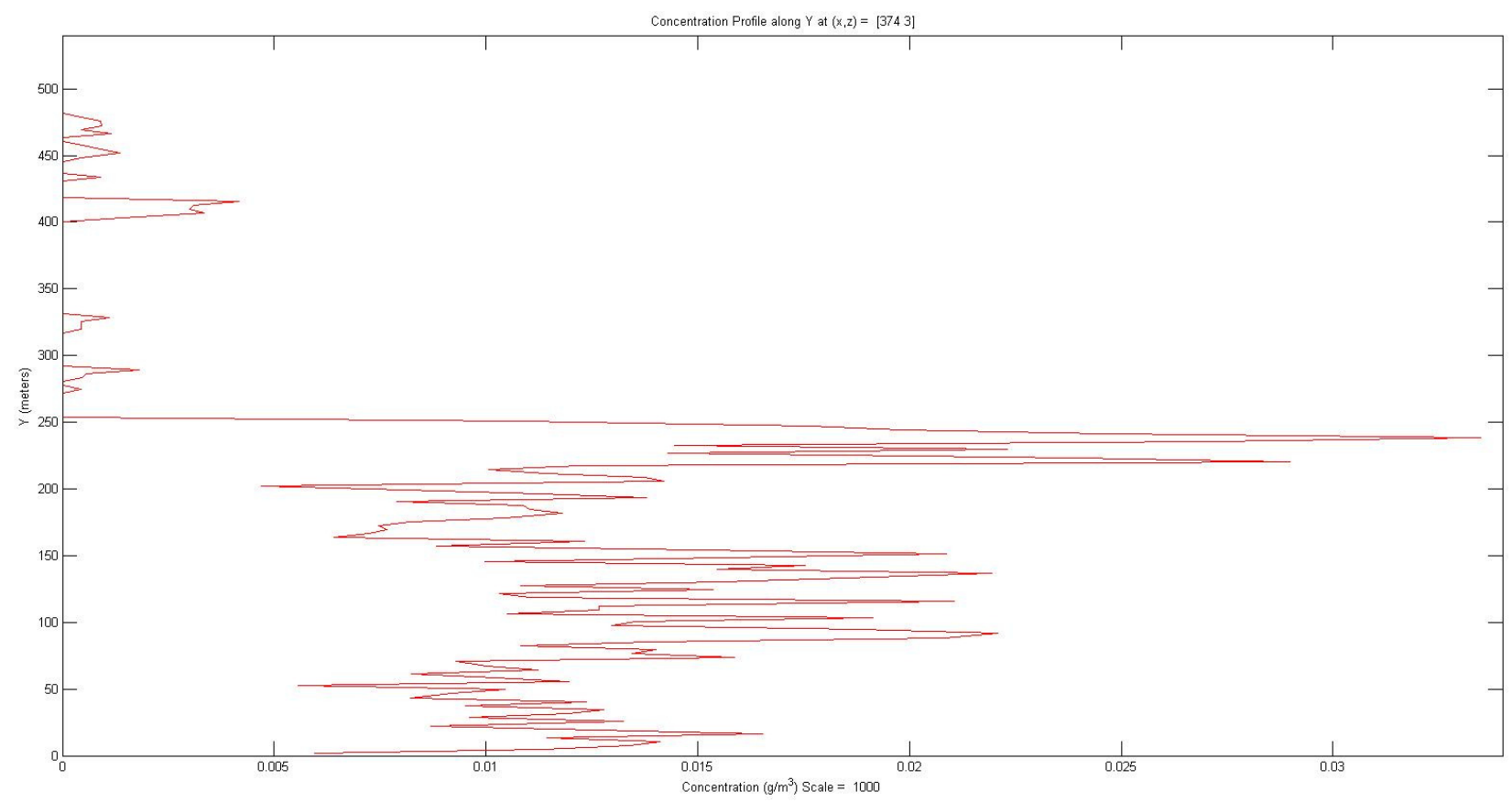

$\mathrm{NO}_{\mathrm{x}}$ July 18, 8:15-8:30 AM NB Beverley

Figure B6 QUIC $\mathrm{NO}_{\mathrm{x}}$ Concentration Plots, 3m Height, July 18, 8:15-8:30 AM 
Table B5 Sample QUIC Input Emission Rate File, July 7, 7:00-715 AM; Highlighted sections $16,17,20$ and 21 are ignored due to negligible emissions

\begin{tabular}{|c|c|c|c|}
\hline Section1 & & \multicolumn{2}{|c|}{ Average Rates from $700-715$ in g per sec } \\
\hline Link & Index & $\mathrm{CO}$ & NOx \\
\hline 3_72 & 10 & 0.016246667 & 0.002071 \\
\hline $8 \_70$ & 16 & 0.423711111 & 0.004009 \\
\hline $9 \_8$ & 17 & 0.050428889 & 0.003738 \\
\hline $70 \_3$ & 128 & 0.018486667 & 0.000689 \\
\hline 72_73 & 132 & 0.365088889 & 0.003311 \\
\hline $73 \_2$ & 134 & 0.004513333 & 0.000327 \\
\hline & & 0.878475556 & 0.014144 \\
\hline Section2 & & \multicolumn{2}{|c|}{ Average Rates from $700-715$ in g per sec } \\
\hline Link & Index & $\mathrm{CO}$ & NOx \\
\hline $1 \_44$ & 4 & 0.022255556 & 0.003058 \\
\hline $2 \_74$ & 6 & 0.008226667 & 0.000511 \\
\hline 44_45 & 80 & 0.076708889 & 0.001664 \\
\hline 45_46 & 82 & 0.418675556 & 0.003513 \\
\hline 46_47 & 84 & 0.000577778 & 0.000162 \\
\hline $47 \_27$ & 86 & 0.000588889 & 0.00014 \\
\hline $74 \_1$ & 136 & 0.00856 & 0.001491 \\
\hline & & 0.535593333 & 0.01054 \\
\hline Section3 & & \multicolumn{2}{|c|}{ Average Rates from $700-715$ in g per sec } \\
\hline Link & Index & $\mathrm{CO}$ & NOx \\
\hline $27 \_48$ & 50 & 0.002546667 & 0.000118 \\
\hline 30_49 & 54 & 0.002342222 & 0.000138 \\
\hline 33_34 & 59 & 0.001715556 & 0.00018 \\
\hline 48_30 & 88 & 0.001013333 & 0.000171 \\
\hline $49 \_50$ & 90 & 0.006177778 & 0.000258 \\
\hline $50 \_33$ & 92 & 0.003326667 & 0.000216 \\
\hline & & 0.017122222 & 0.00108 \\
\hline Section4 & & \multicolumn{2}{|c|}{ Average Rates from 700-715 in g per sec } \\
\hline Link & Index & $\mathrm{CO}$ & NOx \\
\hline 30_48 & 53 & 0.005666667 & 0.000411 \\
\hline 33_50 & 58 & 0.381613333 & 0.004171 \\
\hline 34_33 & 60 & 0.049071111 & 0.003987 \\
\hline $48 \_27$ & 87 & 0.022877778 & 0.00042 \\
\hline 49_30 & 89 & 0.002264444 & 0.000562 \\
\hline 50_49 & 91 & 0.047235556 & 0.001673 \\
\hline & & 0.508728889 & 0.011224 \\
\hline
\end{tabular}




\begin{tabular}{|c|c|c|c|}
\hline Section 5 & & \multicolumn{2}{|c|}{ Average Rates from $700-715$ in g per sec } \\
\hline Link & Index & $\mathrm{CO}$ & NOx \\
\hline 1_74 & 2 & 0.014637778 & 0.002456 \\
\hline $27 \_47$ & 48 & 0.009366667 & 0.000242 \\
\hline $44 \_1$ & 79 & 0.003835556 & 0.000889 \\
\hline 45_44 & 81 & 0.001668889 & 0.000578 \\
\hline 46_45 & 83 & 0.008066667 & 0.000362 \\
\hline 47_46 & 85 & 0.003291111 & 0.000267 \\
\hline \multirow[t]{2}{*}{ 74_2 } & 135 & 0.290404444 & 0.003847 \\
\hline & & 0.331271111 & 0.00864 \\
\hline Section 6 & & \multicolumn{2}{|c|}{ Average Rates from 700-715 in g per sec } \\
\hline Link & Index & $\mathrm{CO}$ & NOx \\
\hline 2_73 & 5 & 0.005604444 & 0.000516 \\
\hline 3_70 & 8 & 0.005444444 & 0.001142 \\
\hline 8_9 & 15 & 0.001306667 & 0.000529 \\
\hline 70_8 & 127 & 0.282946667 & 0.003647 \\
\hline $72 \_3$ & 131 & 0.001368889 & 0.00044 \\
\hline \multirow[t]{2}{*}{ 73_72 } & 133 & 0.007711111 & 0.00036 \\
\hline & & 0.304382222 & 0.006633 \\
\hline Section 7 & & \multicolumn{2}{|c|}{ Average Rates from $700-715$ in g per sec } \\
\hline Link & Index & $\mathrm{CO}$ & NOx \\
\hline $19 \_20$ & 33 & 0.009408889 & 0.00144 \\
\hline 20_23 & 36 & 0.000591111 & 0.00034 \\
\hline $23 \_24$ & 42 & 0.000248889 & 0.000158 \\
\hline 35_43 & 61 & 0.000577778 & 0.000509 \\
\hline 36_35 & 64 & 0.000395556 & 0.000244 \\
\hline 43_58 & 77 & 0.000933333 & 0.000984 \\
\hline \multirow[t]{2}{*}{ 58_19 } & 105 & 0.002231111 & 0.000793 \\
\hline & & 0.014386667 & 0.004469 \\
\hline Section 8 & & \multicolumn{2}{|c|}{ Average Rates from $700-715$ in g per sec } \\
\hline Link & Index & $\mathrm{CO}$ & NOx \\
\hline $1 \_59$ & 1 & 0.003097778 & 0.001224 \\
\hline 42_60 & 75 & 0.001371111 & 0.000227 \\
\hline 59_36 & 107 & 0.000415556 & 0.000253 \\
\hline 60_1 & 109 & 0.006306667 & 0.000853 \\
\hline \multirow[t]{2}{*}{ 61_42 } & 111 & 0.00036 & 0.000296 \\
\hline & & 0.011551111 & 0.002853 \\
\hline
\end{tabular}




\begin{tabular}{|c|c|c|c|}
\hline Section 9 & & \multicolumn{2}{|c|}{ Average Rates from $700-715$ in g per sec } \\
\hline Link & Index & $\mathrm{CO}$ & NOx \\
\hline $10 \_64$ & 18 & 0.000664444 & 0.001011 \\
\hline 13_67 & 25 & 0.016164444 & 0.00202 \\
\hline $14 \_13$ & 27 & 0.002593333 & 0.000747 \\
\hline 37_61 & 73 & 0.000195556 & 0.000153 \\
\hline $62 \_37$ & 113 & 0.000208889 & 0.000149 \\
\hline 63_62 & 115 & 0.000204444 & 0.00016 \\
\hline 64_63 & 117 & 0.00014 & 0.000124 \\
\hline \multirow[t]{2}{*}{ 67_10 } & 123 & 0.053946667 & 0.001071 \\
\hline & & 0.074117778 & 0.005436 \\
\hline Section 10 & & \multicolumn{2}{|c|}{ Average Rates from $700-715$ in $\mathrm{g}$ per sec } \\
\hline Link & Index & $\mathrm{CO}$ & NOx \\
\hline $10 \_67$ & 20 & 0.000111111 & $1.33 \mathrm{E}-05$ \\
\hline 13_14 & 26 & $6.22222 \mathrm{E}-05$ & $6.67 \mathrm{E}-06$ \\
\hline 37_62 & 74 & 0.00012 & $1.11 \mathrm{E}-05$ \\
\hline $61 \_37$ & 112 & 0.000115556 & $1.56 \mathrm{E}-05$ \\
\hline $62 \_63$ & 114 & 0.000162222 & $1.56 \mathrm{E}-05$ \\
\hline 63_64 & 116 & 0.000195556 & $3.56 \mathrm{E}-05$ \\
\hline $64 \_10$ & 118 & 0.000106667 & 0.00002 \\
\hline \multirow[t]{2}{*}{ 67_13 } & 124 & 0.000115556 & $8.89 \mathrm{E}-06$ \\
\hline & & 0.000988889 & 0.000127 \\
\hline Section 11 & & \multicolumn{2}{|c|}{ Average Rates from $700-715$ in $\mathrm{g}$ per sec } \\
\hline Link & Index & $\mathrm{CO}$ & $\mathrm{NOx}$ \\
\hline 1_60 & 3 & 0.004788889 & 0.000609 \\
\hline 36_59 & 65 & 0.05358 & 0.001087 \\
\hline $42 \_61$ & 76 & 0.000188889 & $4.22 \mathrm{E}-05$ \\
\hline 59_1 & 108 & 0.138404444 & 0.001342 \\
\hline \multirow[t]{2}{*}{ 60_42 } & 110 & 0.007282222 & 0.000256 \\
\hline & & 0.204244444 & 0.003336 \\
\hline Section 12 & & \multicolumn{2}{|c|}{ Average Rates from $700-715$ in g per sec } \\
\hline Link & Index & $\mathrm{CO}$ & NOx \\
\hline $19 \_58$ & 34 & 0.000448889 & $6.22 \mathrm{E}-05$ \\
\hline $20 \_19$ & 38 & 0.003544444 & 0.00062 \\
\hline $23 \_20$ & 43 & 0.012002222 & 0.001096 \\
\hline $24 \_23$ & 44 & 0.007035556 & 0.00114 \\
\hline 35_36 & 62 & 0.003128889 & 0.000596 \\
\hline $43 \_35$ & 78 & 0.00266 & 0.000587 \\
\hline $58 \_43$ & 106 & 0.000637778 & 0.000127 \\
\hline
\end{tabular}




\begin{tabular}{|c|c|c|c|}
\hline & & 0.029457778 & 0.004227 \\
\hline Section 13 & & \multicolumn{2}{|c|}{ Average Rates from 700-715 in g per sec } \\
\hline Link & Index & $\mathrm{CO}$ & NOx \\
\hline 3_71 & 7 & 0.000337778 & 4.67E-05 \\
\hline 3_69 & 9 & 0.001173333 & 0.000202 \\
\hline 4_5 & 11 & 3.11111E-05 & 8.89E-06 \\
\hline $6 \_7$ & 12 & $2.66667 \mathrm{E}-05$ & 0 \\
\hline 6_71 & 13 & 0.002 & 0.000247 \\
\hline 7_6 & 14 & 0.000444444 & 0.000122 \\
\hline 69_4 & 126 & 0.000328889 & $9.56 \mathrm{E}-05$ \\
\hline 71_6 & 129 & $3.11111 \mathrm{E}-05$ & $1.78 \mathrm{E}-05$ \\
\hline $71 \_3$ & 130 & 0.000542222 & $9.56 \mathrm{E}-05$ \\
\hline 4_69 & 138 & 0 & 0 \\
\hline $5 \_4$ & 139 & 0 & 0 \\
\hline \multirow[t]{2}{*}{ 69_3 } & 146 & 0 & 0 \\
\hline & & 0.004915556 & 0.000836 \\
\hline Section 14 & & \multicolumn{2}{|c|}{ Average Rates from $700-715$ in g per sec } \\
\hline Link & Index & $\mathrm{CO}$ & NOx \\
\hline $20 \_57$ & 37 & 0.002264444 & 0.000311 \\
\hline $21 \_22$ & 39 & 7.33333E-05 & $1.56 \mathrm{E}-05$ \\
\hline $21 \_57$ & 40 & 0.00252 & 0.000413 \\
\hline $22 \_21$ & 41 & 0.000291111 & 7.33E-05 \\
\hline 57_21 & 103 & 0.001982222 & 0.000131 \\
\hline \multirow[t]{2}{*}{ 57_20 } & 104 & 0.000306667 & $6.44 \mathrm{E}-05$ \\
\hline & & 0.007437778 & 0.001009 \\
\hline Section 15 & & \multicolumn{2}{|c|}{ Average Rates from $700-715$ in $g$ per sec } \\
\hline Link & Index & $\mathrm{CO}$ & NOx \\
\hline $19 \_25$ & 35 & 0.000328889 & 0.00012 \\
\hline 25_19 & 45 & 0.000411111 & $6.67 \mathrm{E}-05$ \\
\hline $25 \_26$ & 46 & 5.11111E-05 & $1.33 \mathrm{E}-05$ \\
\hline \multirow[t]{2}{*}{ 26_25 } & 47 & 0.00076 & 0.000176 \\
\hline & & 0.001551111 & 0.000376 \\
\hline Section 16 & & \multicolumn{2}{|c|}{ Average Rates from $700-715$ in $\mathrm{g}$ per sec } \\
\hline Link & Index & $\mathrm{CO}$ & NOx \\
\hline 35_56 & 63 & 0 & 0 \\
\hline 38_56 & 67 & 4.44444E-06 & $1.33 \mathrm{E}-05$ \\
\hline 38_39 & 68 & 0 & 0 \\
\hline 39_38 & 69 & $1.11111 \mathrm{E}-05$ & $3.56 \mathrm{E}-05$ \\
\hline
\end{tabular}




\begin{tabular}{|c|c|c|c|}
\hline $56 \_35$ & 101 & $1.11111 \mathrm{E}-05$ & $3.56 \mathrm{E}-05$ \\
\hline 56_38 & 102 & 0 & 0 \\
\hline & & 2.66667E-05 & $8.44 \mathrm{E}-05$ \\
\hline Section 17 & & \multicolumn{2}{|c|}{ Average Rates from $700-715$ in g per sec } \\
\hline Link & Index & $\mathrm{CO}$ & NOx \\
\hline 36_55 & 66 & 0 & 0 \\
\hline 40_55 & 70 & 0 & 0 \\
\hline $40 \_41$ & 71 & 0 & 0 \\
\hline 41_40 & 72 & 0 & 0 \\
\hline 55_36 & 99 & 0 & 0 \\
\hline \multirow[t]{2}{*}{ 55_40 } & 100 & 0 & 0 \\
\hline & & 0 & 0 \\
\hline Section 18 & & \multicolumn{2}{|c|}{ Average Rates from 700-715 in g per sec } \\
\hline Link & Index & $\mathrm{CO}$ & NOx \\
\hline $27 \_53$ & 49 & 0.000215556 & 0.000231 \\
\hline $28 \_29$ & 51 & $1.55556 \mathrm{E}-05$ & $2.89 \mathrm{E}-05$ \\
\hline $53 \_54$ & 97 & 0.000377778 & 0.000184 \\
\hline 54_28 & 98 & 2.88889E-05 & $2.89 \mathrm{E}-05$ \\
\hline $28 \_54$ & 141 & 0 & 0 \\
\hline $29 \_28$ & 142 & 0 & 0 \\
\hline 53_27 & 143 & 0 & 0 \\
\hline \multirow[t]{2}{*}{ 54_53 } & 144 & 0 & 0 \\
\hline & & 0.000637778 & 0.000473 \\
\hline Section 19 & & \multicolumn{2}{|c|}{ Average Rates from $700-715$ in $g$ per sec } \\
\hline Link & Index & $\mathrm{CO}$ & NOx \\
\hline 30_51 & 52 & 0.000853333 & $6.67 \mathrm{E}-05$ \\
\hline 31_32 & 55 & 4.88889E-05 & $1.56 \mathrm{E}-05$ \\
\hline $31 \_52$ & 56 & 2.66667E-05 & 0 \\
\hline $32 \_31$ & 57 & 0.000157778 & $3.11 \mathrm{E}-05$ \\
\hline $51 \_52$ & 93 & $3.77778 \mathrm{E}-05$ & $4.44 \mathrm{E}-06$ \\
\hline $51 \_30$ & 94 & 0.00004 & $2.22 \mathrm{E}-06$ \\
\hline $52 \_31$ & 95 & $4.22222 \mathrm{E}-05$ & $6.67 \mathrm{E}-06$ \\
\hline \multirow[t]{2}{*}{$52 \_51$} & 96 & 2.88889E-05 & 0 \\
\hline & & 0.001235556 & 0.000127 \\
\hline Section 20 & & \multicolumn{2}{|c|}{ Average Rates from $700-715$ in $\mathrm{g}$ per sec } \\
\hline Link & Index & $\mathrm{CO}$ & NOx \\
\hline $10 \_66$ & 19 & 8.88889E-06 & $2.22 \mathrm{E}-06$ \\
\hline $10 \_65$ & 21 & $6.66667 \mathrm{E}-06$ & $2.22 \mathrm{E}-06$ \\
\hline
\end{tabular}




\begin{tabular}{|c|c|c|c|}
\hline 11_12 & 22 & 2.22222E-06 & $2.22 \mathrm{E}-06$ \\
\hline 11_66 & 23 & 0 & 0 \\
\hline 12_11 & 24 & 0 & 0 \\
\hline $15 \_65$ & 28 & 0 & 0 \\
\hline $15 \_16$ & 29 & 4.44444E-06 & 0 \\
\hline $16 \_15$ & 30 & 0 & 0 \\
\hline $65 \_10$ & 119 & 0 & 0 \\
\hline $65 \_15$ & 120 & $6.66667 \mathrm{E}-06$ & 4.44E-06 \\
\hline 66_11 & 121 & 2.22222E-06 & 0 \\
\hline \multirow[t]{2}{*}{$66 \_10$} & 122 & 0 & 0 \\
\hline & & $3.11111 \mathrm{E}-05$ & $1.11 \mathrm{E}-05$ \\
\hline Section 21 & & \multicolumn{2}{|c|}{ Average Rates from $700-715$ in $g$ per sec } \\
\hline Link & Index & $\mathrm{CO}$ & NOx \\
\hline 17_68 & 31 & 0 & 0 \\
\hline 18_17 & 32 & 0 & 0 \\
\hline 68_2 & 125 & 0 & 0 \\
\hline $2 \_68$ & 137 & 0 & 0 \\
\hline 17_18 & 140 & 0 & 0 \\
\hline \multirow[t]{2}{*}{ 68_17 } & 145 & 0 & 0 \\
\hline & & 0 & 0 \\
\hline
\end{tabular}


Table B6 Sample AERMOD Input Emission Rate File, July 7, 7:00-9:00 AM; Highlighted line sources are split into two point sources.

\begin{tabular}{|c|c|c|c|c|c|c|}
\hline \multirow{2}{*}{$\frac{\text { Link }}{\text { Index }}$} & \multirow[b]{2}{*}{ \# } & \multicolumn{2}{|c|}{$\begin{array}{l}\text { Average Rates from } \\
7-8 \text { in } \mathrm{g} \text { per sec }\end{array}$} & \multicolumn{2}{|c|}{$\begin{array}{l}\text { Average Rates from } \\
8-9 \text { in } \mathrm{g} \text { per sec }\end{array}$} & \\
\hline & & $\mathrm{CO}$ & NOX & $\mathrm{CO}$ & NOX & \\
\hline $1 \_59$ & 1 & 0.004004 & 0.000986 & 0.004582 & 0.000924 & $\mathrm{Z} 43$ \\
\hline 1_74 & 2 & 0.017016 & 0.002481 & 0.018443 & 0.002558 & $\mathrm{Z} 15$ \\
\hline 1_60 & 3 & 0.007408 & 0.000888 & 0.010441 & 0.001263 & Z39 \\
\hline 1_44 & 4 & 0.022679 & 0.003167 & 0.022565 & 0.003651 & $\mathrm{Z} 17$ \\
\hline $2 \_73$ & 5 & 0.004504 & 0.00048 & 0.008583 & 0.000446 & $\mathrm{Z} 11$ \\
\hline $2 \_74$ & 6 & 0.009053 & 0.000812 & 0.009179 & 0.000987 & $\mathrm{Z} 13$ \\
\hline $3 \_71$ & 7 & 0.000992 & 0.00008 & 0.000768 & 7.94E-05 & \\
\hline 3_70 & 8 & 0.007009 & 0.001471 & 0.008148 & 0.001541 & $\mathrm{Z5}$ \\
\hline 3_69 & 9 & 0.001642 & 0.000202 & 0.002624 & 0.000393 & \\
\hline 3_72 & 10 & 0.018273 & 0.002252 & 0.017664 & 0.002406 & $\mathrm{Z7}$ \\
\hline $4 \_5$ & 11 & 0.000045 & $6.11 \mathrm{E}-06$ & $8.33 \mathrm{E}-05$ & $1.28 \mathrm{E}-05$ & \\
\hline $6 \_7$ & 12 & $3.94 \mathrm{E}-05$ & $3.89 \mathrm{E}-06$ & $2.89 \mathrm{E}-05$ & $3.33 \mathrm{E}-06$ & \\
\hline $6 \_71$ & 13 & 0.002641 & 0.000291 & 0.003137 & 0.000307 & \\
\hline 7_6 & 14 & 0.000798 & 0.000144 & 0.001076 & 0.000162 & \\
\hline 8_9 & 15 & 0.003029 & 0.000434 & 0.001657 & 0.000332 & $\mathrm{Z1}$ \\
\hline 8_70 & 16 & 0.446164 & 0.004386 & 0.462992 & 0.005211 & $\mathrm{Z3}$ \\
\hline $9 \_8$ & 17 & 0.069731 & 0.004373 & 0.075013 & 0.004918 & $\mathrm{Z} 2$ \\
\hline 10_64 & 18 & 0.00098 & 0.000509 & 0.000497 & 0.00044 & \\
\hline $10 \_66$ & 19 & $1.56 \mathrm{E}-05$ & $4.44 \mathrm{E}-06$ & 0.000015 & 4.44E-06 & \\
\hline $10 \_67$ & 20 & 0.000178 & $3.61 \mathrm{E}-05$ & 0.000277 & $5.72 \mathrm{E}-05$ & \\
\hline $10 \_65$ & 21 & 8.89E-06 & $3.33 \mathrm{E}-06$ & 0.00026 & 7.22E-06 & \\
\hline 11_12 & 22 & 2.22E-06 & $1.11 \mathrm{E}-06$ & $3.33 \mathrm{E}-06$ & $1.11 \mathrm{E}-06$ & \\
\hline $11 \_66$ & 23 & 0 & 0 & 0 & 0 & \\
\hline 12_11 & 24 & 0 & 0 & 0 & 0 & \\
\hline $13 \_67$ & 25 & 0.01753 & 0.001519 & 0.020217 & 0.001503 & \\
\hline $13 \_14$ & 26 & 0.000102 & $2.06 \mathrm{E}-05$ & 0.000362 & $4.22 \mathrm{E}-05$ & \\
\hline $14 \_13$ & 27 & 0.002319 & 0.000595 & 0.002397 & 0.0006 & \\
\hline $15 \_65$ & 28 & 0 & 0 & 0 & 0 & \\
\hline $15 \_16$ & 29 & 0.000005 & $1.11 \mathrm{E}-06$ & $3.89 \mathrm{E}-06$ & $5.56 \mathrm{E}-07$ & \\
\hline 16_15 & 30 & 0 & 0 & 0 & 0 & \\
\hline 17_68 & 31 & 0.00008 & $3.33 \mathrm{E}-06$ & 0.000108 & $1.17 \mathrm{E}-05$ & \\
\hline $18 \_17$ & 32 & $3.11 \mathrm{E}-05$ & $5.56 \mathrm{E}-06$ & 0.000116 & $2.78 \mathrm{E}-05$ & \\
\hline 19_20 & 33 & 0.008098 & 0.001129 & 0.007702 & 0.001219 & \\
\hline $19 \_58$ & 34 & 0.000892 & 0.000138 & 0.001086 & 0.000187 & \\
\hline $19 \_25$ & 35 & 0.000373 & 0.000135 & 0.000353 & 0.000148 & \\
\hline $20 \_23$ & 36 & 0.001057 & 0.000227 & 0.001365 & 0.000259 & \\
\hline $20 \_57$ & 37 & 0.00151 & 0.000231 & 0.001192 & 0.00035 & \\
\hline
\end{tabular}




\begin{tabular}{|c|c|c|c|c|c|c|}
\hline 20_19 & 38 & 0.004476 & 0.000753 & 0.005598 & 0.00086 & \\
\hline 21_22 & 39 & $5.44 \mathrm{E}-05$ & $1.28 \mathrm{E}-05$ & $5.17 \mathrm{E}-05$ & 4.94E-05 & \\
\hline $21 \_57$ & 40 & 0.003462 & 0.000471 & 0.004122 & 0.000444 & \\
\hline 22_21 & 41 & 0.000497 & 0.000103 & 0.000607 & 8.72E-05 & \\
\hline $23 \_24$ & 42 & 0.000272 & $8.72 \mathrm{E}-05$ & 0.000283 & $9.44 \mathrm{E}-05$ & \\
\hline $23 \_20$ & 43 & 0.011564 & 0.001192 & 0.012347 & 0.001783 & \\
\hline 24_23 & 44 & 0.006658 & 0.001155 & 0.00722 & 0.001486 & \\
\hline $25 \_19$ & 45 & 0.000326 & $6.89 \mathrm{E}-05$ & 0.000386 & 7.67E-05 & \\
\hline $25 \_26$ & 46 & $5.17 \mathrm{E}-05$ & $2.06 \mathrm{E}-05$ & $5.78 \mathrm{E}-05$ & $3.44 \mathrm{E}-05$ & \\
\hline $26 \_25$ & 47 & 0.001093 & 0.000172 & 0.000945 & 0.000199 & \\
\hline $27 \_47$ & 48 & 0.015174 & 0.00036 & 0.017445 & 0.000383 & $\mathrm{Z} 25$ \\
\hline $27 \_53$ & 49 & 0.000262 & 0.000202 & 0.000447 & 0.000378 & \\
\hline $27 \_48$ & 50 & 0.003588 & 0.000158 & 0.003179 & 0.000275 & $\mathrm{Z} 27$ \\
\hline 28_29 & 51 & $1.22 \mathrm{E}-05$ & $1.94 \mathrm{E}-05$ & $2.67 \mathrm{E}-05$ & $3.72 \mathrm{E}-05$ & \\
\hline $30 \_51$ & 52 & 0.000967 & 0.000075 & 0.001292 & 0.000138 & \\
\hline 30_48 & 53 & 0.003382 & 0.000478 & 0.004523 & 0.000566 & $\mathrm{Z} 29$ \\
\hline 30_49 & 54 & 0.005268 & 0.000192 & 0.011805 & 0.000408 & $\mathrm{Z} 31$ \\
\hline 31_32 & 55 & 5.33E-05 & $1.72 \mathrm{E}-05$ & $8.44 \mathrm{E}-05$ & 0.00002 & \\
\hline 31_52 & 56 & $3.06 \mathrm{E}-05$ & $1.11 \mathrm{E}-06$ & 2.33E-05 & $2.78 \mathrm{E}-06$ & \\
\hline 32_31 & 57 & 0.00031 & $5.17 \mathrm{E}-05$ & 0.000179 & 0.00005 & \\
\hline $33 \_50$ & 58 & 0.437217 & 0.004474 & 0.504466 & 0.005422 & $\mathrm{Z} 35$ \\
\hline 33_34 & 59 & 0.003003 & 0.000262 & 0.002819 & 0.000322 & $\mathrm{Z} 37$ \\
\hline 34_33 & 60 & 0.063581 & 0.004446 & 0.069285 & 0.005518 & $\mathrm{Z} 38$ \\
\hline 35_43 & 61 & 0.000703 & 0.000398 & 0.000723 & 0.000537 & Z49 \\
\hline 35_36 & 62 & 0.004462 & 0.000719 & 0.004787 & 0.000943 & $\mathrm{Z} 47$ \\
\hline $35 \_56$ & 63 & $2.22 \mathrm{E}-06$ & $1.67 \mathrm{E}-06$ & $1.11 \mathrm{E}-06$ & 0 & \\
\hline 36_35 & 64 & 0.000392 & 0.000124 & 0.000403 & 0.000187 & $\mathrm{Z} 48$ \\
\hline 36_59 & 65 & 0.058906 & 0.001171 & 0.059646 & 0.001447 & $\mathrm{Z} 45$ \\
\hline $36 \_55$ & 66 & 0 & 0 & 0 & 0 & \\
\hline 38_56 & 67 & 2.39E-05 & 4.44E-05 & 0.000025 & $6.06 \mathrm{E}-05$ & \\
\hline 38_39 & 68 & 0 & 0 & $5.56 \mathrm{E}-07$ & 0 & \\
\hline 39_38 & 69 & $6.89 \mathrm{E}-05$ & 0.000104 & 8.33E-05 & 0.00017 & \\
\hline $40 \_55$ & 70 & 0 & 0 & 0 & 0 & \\
\hline 40_41 & 71 & 0 & 0 & 0 & 0 & \\
\hline 41_40 & 72 & 0 & 0 & 0 & 0 & \\
\hline 37_61 & 73 & 0.000201 & $8.67 \mathrm{E}-05$ & 0.000279 & $9.22 \mathrm{E}-05$ & Z53 \\
\hline $37 \_62$ & 74 & 0.000185 & 2.22E-05 & 0.000286 & $3.78 \mathrm{E}-05$ & \\
\hline $42 \_60$ & 75 & 0.000917 & 0.000151 & 0.001458 & 0.000218 & $\mathrm{Z} 41$ \\
\hline 42_61 & 76 & 0.00058 & $8.11 \mathrm{E}-05$ & 0.001481 & 0.000132 & $\mathrm{Z} 51$ \\
\hline $43 \_58$ & 77 & 0.001141 & 0.000582 & 0.001158 & 0.000605 & \\
\hline $43 \_35$ & 78 & 0.002836 & 0.000667 & 0.003617 & 0.000843 & $\mathrm{Z} 50$ \\
\hline 44_1 & 79 & 0.006826 & 0.001094 & 0.009067 & 0.001346 & Z18 \\
\hline
\end{tabular}




\begin{tabular}{|c|c|c|c|c|c|c|}
\hline $44 \_45$ & 80 & 0.089063 & 0.001983 & 0.07485 & 0.002264 & Z19 \\
\hline $45 \_44$ & 81 & 0.003402 & 0.000633 & 0.006833 & 0.000789 & $\mathrm{Z} 20$ \\
\hline $45 \_46$ & 82 & 0.484803 & 0.004017 & 0.440084 & 0.004318 & $\mathrm{Z} 21$ \\
\hline $46 \_45$ & 83 & 0.005427 & 0.000411 & 0.006759 & 0.000512 & $\mathrm{Z} 22$ \\
\hline $46 \_47$ & 84 & 0.00083 & 0.000231 & 0.003283 & 0.000484 & $\mathrm{Z} 23$ \\
\hline $47 \_46$ & 85 & 0.002523 & 0.000279 & 0.002699 & 0.000351 & $\mathrm{Z} 24$ \\
\hline 47_27 & 86 & 0.000848 & 0.000181 & 0.002462 & 0.000268 & Z26 \\
\hline $48 \_27$ & 87 & 0.023981 & 0.000548 & 0.027896 & 0.000639 & $\mathrm{Z} 28$ \\
\hline 48_30 & 88 & 0.001413 & 0.000174 & 0.002776 & 0.000379 & $\mathrm{Z} 30$ \\
\hline 49_30 & 89 & 0.002489 & 0.000511 & 0.001542 & 0.000457 & $\mathrm{Z} 32$ \\
\hline 49_50 & 90 & 0.008731 & 0.000309 & 0.020593 & 0.0005 & $\mathrm{Z} 33$ \\
\hline $50 \_49$ & 91 & 0.055977 & 0.001527 & 0.062979 & 0.001958 & Z34 \\
\hline $50 \_33$ & 92 & 0.002886 & 0.000269 & 0.002117 & 0.00034 & $\mathrm{Z} 36$ \\
\hline 51_52 & 93 & 5.89E-05 & $1.89 \mathrm{E}-05$ & 7.22E-05 & $2.44 \mathrm{E}-05$ & \\
\hline 51_30 & 94 & 4.89E-05 & 8.33E-06 & $3.56 \mathrm{E}-05$ & $9.44 \mathrm{E}-06$ & \\
\hline $52 \_31$ & 95 & 5.89E-05 & $1.67 \mathrm{E}-05$ & 7.83E-05 & $1.83 \mathrm{E}-05$ & \\
\hline 52_51 & 96 & $3.44 \mathrm{E}-05$ & $5.56 \mathrm{E}-07$ & $2.56 \mathrm{E}-05$ & $5.56 \mathrm{E}-07$ & \\
\hline $53 \_54$ & 97 & 0.000158 & 0.000114 & 0.00065 & 0.000367 & \\
\hline $54 \_28$ & 98 & $3.44 \mathrm{E}-05$ & $6.44 \mathrm{E}-05$ & 0.000157 & $9.17 \mathrm{E}-05$ & \\
\hline $55 \_36$ & 99 & 0 & 0 & 0 & 0 & \\
\hline 55_40 & 100 & 0 & 0 & 0 & 0 & \\
\hline 56_35 & 101 & $2.17 \mathrm{E}-05$ & 0.000045 & 2.61E-05 & $6.11 \mathrm{E}-05$ & \\
\hline 56_38 & 102 & 0 & 0 & $5.56 \mathrm{E}-07$ & 0 & \\
\hline $57 \_21$ & 103 & 0.001297 & 0.000085 & 0.000863 & 0.000126 & \\
\hline 57_20 & 104 & 0.000443 & $8.11 \mathrm{E}-05$ & 0.000375 & $8.06 \mathrm{E}-05$ & \\
\hline 58_19 & 105 & 0.002691 & 0.000639 & 0.002896 & 0.000976 & \\
\hline $58 \_43$ & 106 & 0.000776 & 0.000152 & 0.000962 & 0.000303 & \\
\hline 59_36 & 107 & 0.000725 & 0.000207 & 0.000798 & 0.000241 & Z46 \\
\hline 59_1 & 108 & 0.137278 & 0.001457 & 0.15829 & 0.001936 & Z44 \\
\hline 60_1 & 109 & 0.004444 & 0.000551 & 0.003431 & 0.000569 & $\mathrm{Z} 40$ \\
\hline $60 \_42$ & 110 & 0.017035 & 0.00051 & 0.021111 & 0.000752 & $\mathrm{Z} 42$ \\
\hline $61 \_42$ & 111 & 0.000503 & 0.000147 & 0.000602 & 0.000151 & $\mathrm{Z} 52$ \\
\hline 61_37 & 112 & 0.000168 & 3.33E-05 & 0.000268 & $5.28 \mathrm{E}-05$ & Z54 \\
\hline 62_37 & 113 & 0.000193 & 7.11E-05 & 0.000211 & 7.44E-05 & \\
\hline $62 \_63$ & 114 & 0.000229 & $3.17 \mathrm{E}-05$ & 0.000352 & $5.56 \mathrm{E}-05$ & \\
\hline $63 \_62$ & 115 & 0.000192 & $7.11 \mathrm{E}-05$ & 0.000213 & 0.000075 & \\
\hline 63_64 & 116 & 0.000237 & 5.33E-05 & 0.000391 & $9.56 \mathrm{E}-05$ & \\
\hline 64_63 & 117 & 0.000126 & $7.06 \mathrm{E}-05$ & 0.000159 & 0.000133 & \\
\hline 64_10 & 118 & 0.000175 & 4.61E-05 & 0.000265 & 7.39E-05 & \\
\hline $65 \_10$ & 119 & 0 & 0 & 0 & 0 & \\
\hline 65_15 & 120 & $6.67 \mathrm{E}-06$ & 3.33E-06 & 0.000005 & 2.22E-06 & \\
\hline 66_11 & 121 & $2.78 \mathrm{E}-06$ & 3.33E-06 & $6.11 \mathrm{E}-06$ & $2.78 \mathrm{E}-06$ & \\
\hline
\end{tabular}




\begin{tabular}{|c|c|c|c|c|c|c|}
\hline 66_10 & 122 & 0 & 0 & 0 & 0 & \\
\hline 67_10 & 123 & 0.067033 & 0.000869 & 0.076059 & 0.000831 & \\
\hline 67_13 & 124 & 0.000166 & $2.83 \mathrm{E}-05$ & 0.000287 & $6.06 \mathrm{E}-05$ & \\
\hline $68 \_2$ & 125 & $5.56 \mathrm{E}-07$ & $1.11 \mathrm{E}-06$ & $6.67 \mathrm{E}-06$ & 3.33E-06 & \\
\hline 69_4 & 126 & 0.000489 & 8.33E-05 & 0.000997 & 0.000166 & \\
\hline $70 \_8$ & 127 & 0.303705 & 0.003693 & 0.359414 & 0.004079 & $\mathrm{Z4}$ \\
\hline 70_3 & 128 & 0.020731 & 0.000949 & 0.026222 & 0.001383 & Z6 \\
\hline 71_6 & 129 & 0.000387 & $3.06 \mathrm{E}-05$ & 0.000226 & $2.78 \mathrm{E}-05$ & \\
\hline 71_3 & 130 & 0.000646 & 0.000108 & 0.001083 & 0.000117 & \\
\hline 72_3 & 131 & 0.003633 & 0.000697 & 0.003647 & 0.00085 & $\mathrm{Z8}$ \\
\hline 72_73 & 132 & 0.387906 & 0.003599 & 0.394935 & 0.004114 & Z9 \\
\hline 73_72 & 133 & 0.004152 & 0.000446 & 0.008819 & 0.000418 & $\mathrm{Z} 10$ \\
\hline $73 \_2$ & 134 & 0.007038 & 0.000463 & 0.00861 & 0.000627 & $\mathrm{Z} 12$ \\
\hline $74 \_2$ & 135 & 0.296633 & 0.00381 & 0.330991 & 0.004092 & $\mathrm{Z} 14$ \\
\hline 74_1 & 136 & 0.012849 & 0.002008 & 0.018346 & 0.002373 & Z16 \\
\hline 2_68 & 137 & 0 & 0 & 0 & 0 & \\
\hline 4_69 & 138 & 0 & 0 & 0 & 0 & \\
\hline 5_4 & 139 & 0 & 0 & 0 & 0 & \\
\hline 17_18 & 140 & 0 & 0 & 0 & 0 & \\
\hline 28_54 & 141 & 0 & 0 & 0 & 0 & \\
\hline 29_28 & 142 & 0 & 0 & 0 & 0 & \\
\hline 53_27 & 143 & 0 & 0 & 0 & 0 & \\
\hline 54_53 & 144 & 0 & 0 & 0 & 0 & \\
\hline 68_17 & 145 & 0 & 0 & 0 & 0 & \\
\hline 69_3 & 146 & 0 & 0 & 0 & 0 & \\
\hline
\end{tabular}

